\author{
UNIVERSITY OF SÃO PAULO \\ SÃO CARLOS SCHOOL OF ENGINEERING
}

LUCAS ALVES DA SILVA SANTOS

Demand-Driven Material Requirements Planning (DDMRP)

Implementation Impacts on Supply Chain Management Strategic Processes: an AHP Approach

São Carlos

2020 



\section{Demand-Driven Material Requirements Planning (DDMRP) Implementation Impacts on Supply Chain Management Strategic Processes: an AHP Approach}

Thesis submitted to the São Carlos School of Engineering of University of São Paulo in partial fulfillment of the requirements for the degree of Master of Science in Production Engineering.

Research area: Process and Operations Management Thesis directed by Prof. Dr. Kleber Francisco Espôsto

\section{CORRECTED VERSION}

The original version is available at the program department

São Carlos 
I AUTHORIZE TOTAL OR PARTIAL REPRODUCTION OF THIS WORK BY ANY CONVENTIONAL OR ELECTRONIC MEANS, FOR RESEARCH PURPOSES, SO LONG AS THE SOURCE IS CITED.

Index card prepared by User Service at "Prof. Dr. Sérgio Rodrigues Fontes Library" at EESC/USP

S237d Demand-Driven Material Requirements Planning (DDMRP) implementation impacts on Supply Chain Management strategic processes: an AHP approach / Lucas Alves da Silva Santos; advisor Kleber Francisco Espôsto. -- São Carlos, 2019.

Master (Thesis) - Graduate Program in Production Engineering and Concentration area in Process and Operations Management. -- São Carlos School of Engineering, at University of São Paulo, 2019.

1. Demand Driven Material Requirements Planning. 2. DDMRP. 3. DDMRP impacts. 4. Supply Chain Management. 5. AHP. I. Título.

Prepared by Eduardo Graziosi Silva- CRB-8/8907 


\section{FOLHA DE JULGAMENTO}

Candidato: Bacharel LUCAS ALVES DA SILVA SANTOS.

Título da dissertação: "Impactos da implementação do Demand-Driven Material Requirements Planning (DDMRP) nos processos estratégicos de gestão da cadeia de suprimentos: uma abordagem AHP"

Data da defesa: 09/03/2020

\section{Comissão Julgadora:}

Prof. Dr. Kleber Francisco Espôsto

\section{(Orientador)}

(Escola de Engenharia de São Carlos/EESC)

Prof. Dr. Moacir Godinho Filho

(Universidade Federal de São Carlos/UFSCar)

Prof. Dr. Luis Antonio de Santa Eulalia

(Université de Sherbrooke)

Coordenador do Programa de Pós-Graduação em Engenharia de Produção:

Prof. Dr. Marcelo Seido Nagano

Presidente da Comissão de Pós-Graduação:

Prof. Titular Murilo Araujo Romero
Resultado:

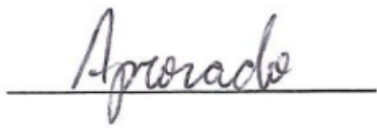

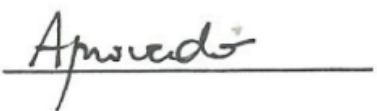

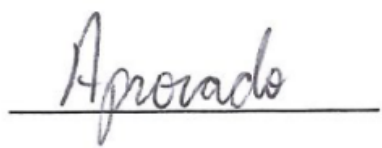



DEDICATION

To my wife Débora, without whom this work would have never been completed. 



\section{ACKNOWLEDGMENTS}

First of all, I would like to express my deep and sincere gratitude to my research supervisor, Prof. Dr. Kleber Francisco Espôsto, for giving me the opportunity to do this research, his trust in my capacity, his tireless support and unparalleled presence of mind during the most turbulent times of this research completion. For all of it, I will be forever grateful.

My wife, for the love, support, patience and incentive. For pushing me forward when I believed I could not make it. Thank you for everything that you always do for me.

My parents, for the whole structure provided that made me who I am today, all the love, care, trust and support. I do not have words to express how thankful I am for having you.

My brother, for being an example and for staying by my side during every tiny conquest. Thank you!

My mother-in-law and father-in-law, for the support, all the help you provide to our family and for making me feel home every single day.

To all my friends, for the laughs, ideas, talks and support in moments of need. Thanks to each one of you.

To the individuals and organizations who generously shared their time and experience for the purpose of this project. Thank you! 



\begin{abstract}
SANTOS, L. A. S. Demand-Driven Material Requirements Planning (DDMRP) Implementation Impacts on Supply Chain Management Strategic Processes: An AHP Approach. 2019. Master Thesis (Master's in Production Engineering) - São Carlos School of Engineering, University of São Paulo, São Carlos, 2020.

Supply Chain Management (SCM) turned out to be one of the main approaches to control costs and enhance companies' performance in competitive markets. However, despite the evolution of theory with several frameworks developed in the past decades, companies still struggle to meet customers' need and implement effective methods to assess demand information. As result, in recent years, new methods were developed aiming to enable companies' processes to highly dynamic environments. Among these adaptations, the Demand Driven Material Requirements Planning (DDMRP) presents itself as an alternative to empower companies to thrive in this new market reality. Although the subject interest has increased in the last five years, academic research is still scarce, and theory is not evolving fast enough. To contribute to the theory development, this study evaluates the impacts that DDMRP implementation has on Lambert's proposed model of Supply Chain Management Processes through an AHP-based analysis. From a literature review 8 SCM processes and 42 SCM strategic sub-processes were identified a structured model using the Analytical Hierarchy Process (AHP) is proposed and applied to rank the perceived impacts in SCM processes that DDMRP implementation inflicts. The inputs for this analysis came from surveys answered by researchers and industry practitioners who are highly experienced in SCM and DDMRP. As one of the research results, a rank was developed detailing which SCM processes and subprocesses are most impacted after DDMRP implementation. Research findings indicate that Manufacturing Flow Management (MFM) and Order Fulfillment (OF) are the two most impacted SCM processes in a DDMRP implementation. It was also possible to conclude that SCM customer related processes, Customer Relationship Management (CRM) and Customer Service Management (CSM) respectively, are highly impacted but their impacts are not fully assessed by current DDMRP literature. The results can help industrial managers/practitioners and researchers to formulate short-term and long-term decision strategies regarding DDMRP implementation to mitigate harmful impacts on SCM processes.
\end{abstract}

Keywords: Demand Driven Material Requirements Planning, DDMRP, DDMRP impacts, Supply Chain Management, AHP. 



\section{RESUMO}

SANTOS, L. A. S. Impactos da Implementação do Demand-Driven Material Requirements Planning (DDMRP) nos Processos Estratégicos de Gestão da Cadeia de Suprimentos: Uma Abordagem AHP. 2019. Dissertação (Mestrado em Engenharia de Produção) - Escola de Engenharia de São Carlos, Universidade de São Paulo, São Carlos, 2020.

A Gestão da Cadeia de Suprimentos (SCM) se tornou uma das principais abordagens para controle de custos e melhoria de performance em mercados competitivos. Entretanto, apesar da evolução da teoria e o desenvolvimento de diversos modelos nas últimas décadas, organizações ainda lutam para atender as necessidades dos clientes e implementar métodos eficientes para avaliar informações de demanda. Como resultado disso, nos últimos anos, novos métodos foram desenvolvidos com objetivo de habilitar os processos de organizações para ambientes altamente dinâmicos. Dentre essas adaptações, o Demand Driven Material Requirements Planning (DDMRP) se mostra como alternativa para permitir que organizações prosperem nessa nova realidade de mercado. Apesar do interesse pelo assunto ter aumentado nos últimos cinco anos, a pesquisa acadêmica ainda é escassa e a teoria não está evoluindo rápido o suficiente. Como forma de abrir caminho para o desenvolvimento da teoria, este estudo avalia os impactos causados pela implementação de DDMRP nos processos de Gestão de Cadeia de Suprimentos propostos por Lambert, através de uma análise baseada em AHP. Partindo da revisão bibliográfica onde 8 processos e 42 sub-processos estratégicos de SCM foram identificados um modelo utilizando o Analytical Hierarchy Process (AHP) foi proposto e aplicado para classificar o nível de impacto nos processos de SCM resultantes da implementação do DDMRP. Os dados para essa análise foram coletados através de pesquisas respondidas por pesquisadores e profissionais da indústria altamente capacitados em Gestão de Cadeias de Suprimentos e DDMRP. Como resultado, uma classificação foi desenvolvida detalhando quais processos e sub-processos estratégicos de SCM são mais impactos após a implementação do DDMRP. Os resultados indicaram que os processos de Gestão do Fluxo de Manufatura (MFM) e Atendimento de Pedidos (OF) são os dois processos de SCM mais impactados. Também foi possível concluir que os processos de SCM relacionados aos clientes finais, Gestão de Relacionamento com Clientes (CRM) e Gestão de Serviços ao Cliente (CSM) respectivamente, são altamente impactados, porém esse impacto não é completamente abordado pela literatura atual de DDMRP. Os resultados obtidos poderão ajudar profissionais e pesquisadores a formular decisões estratégicas relativas à implementação de DDMRP para mitigar impactos danosos aos processos de SCM.

Palavras-chave: Demand Driven Material Requirements Planning, DDMRP, Impactos do DDMRP, Gestão da Cadeia de Suprimentos, AHP. 



\section{LIST OF FIGURES}

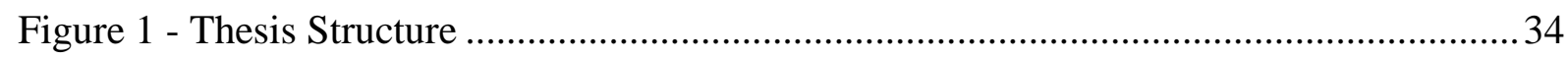

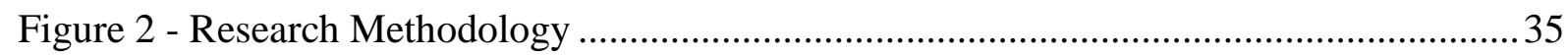

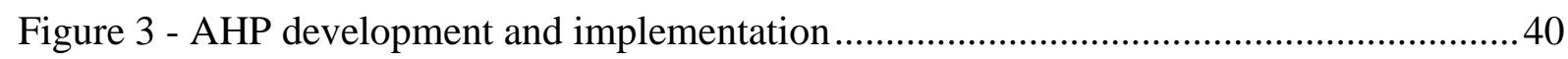

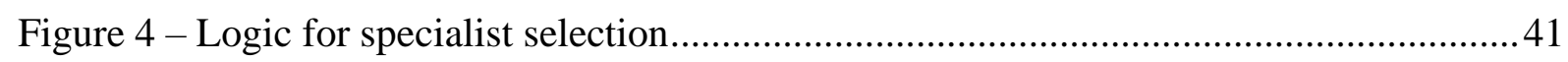

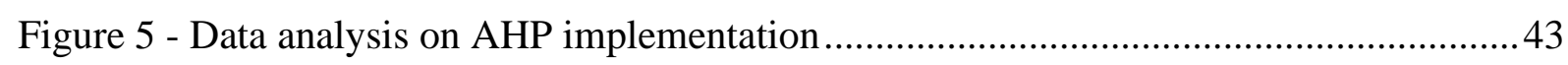

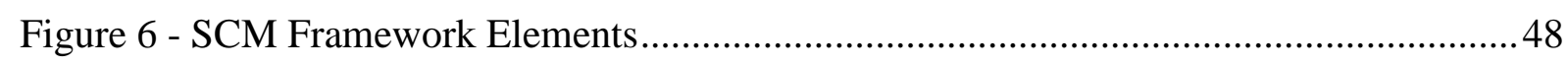

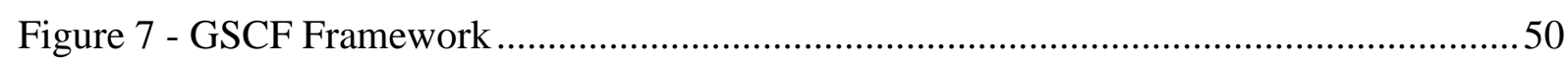

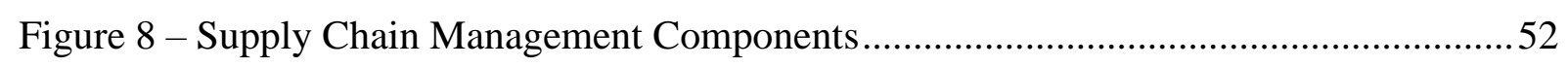

Figure 9 - Updated Supply Chain Management Components ...................................................52

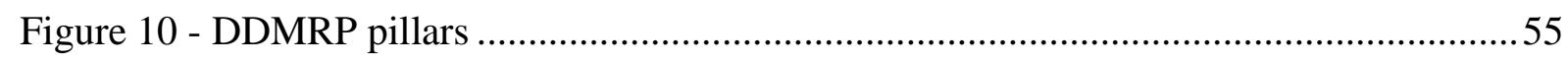

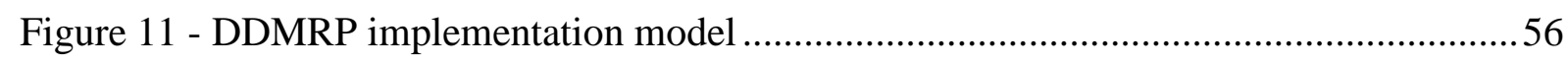

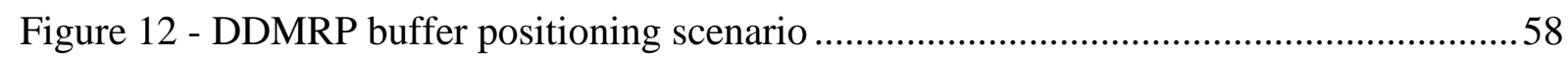

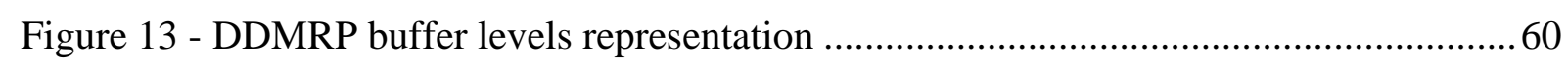

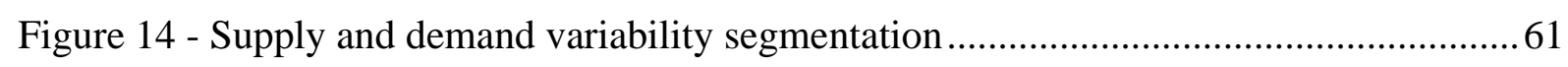

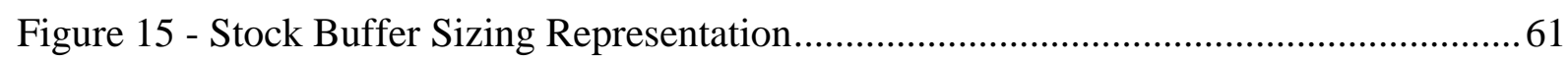

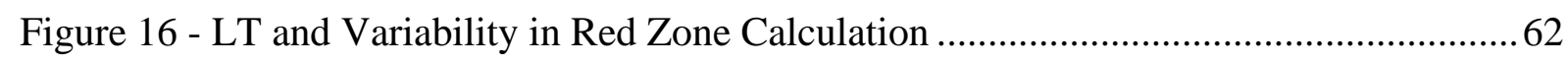

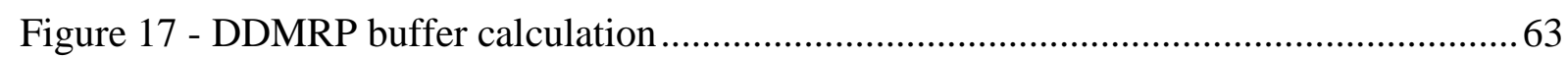

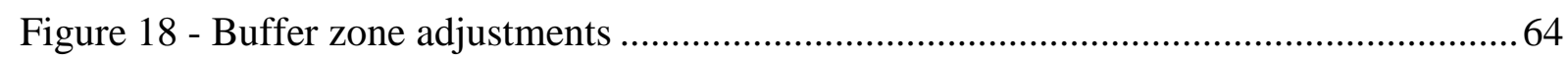

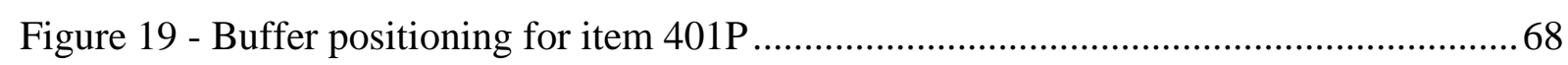

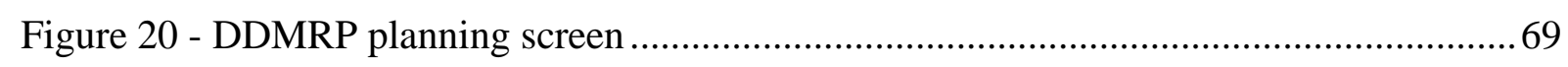

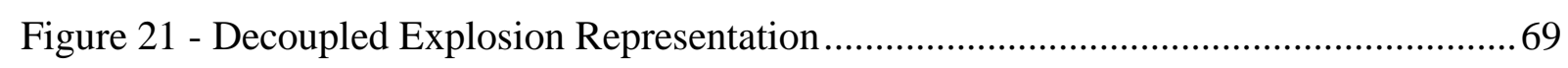

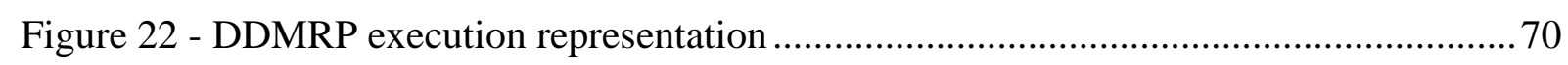

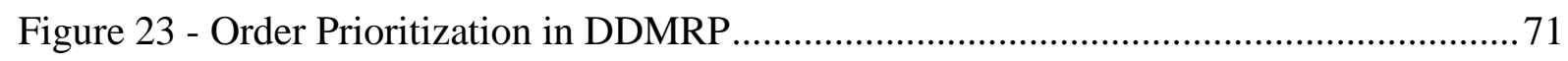

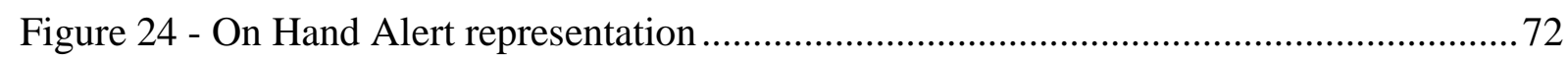

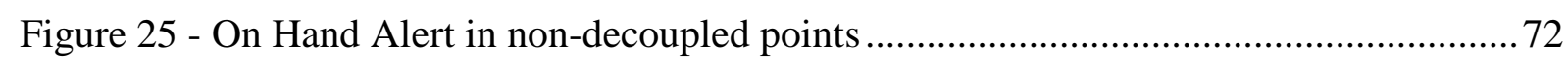

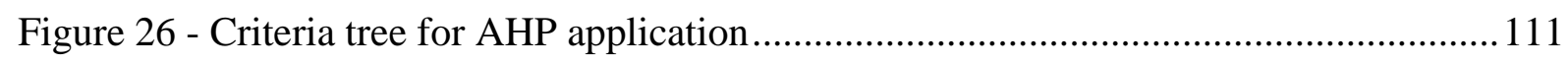

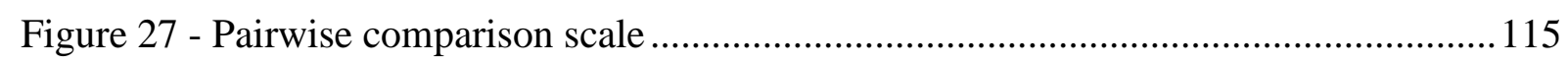

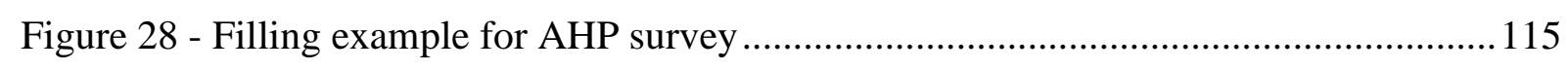

Figure 29 - Relationship between processes in hierarchy design ..................................... 125

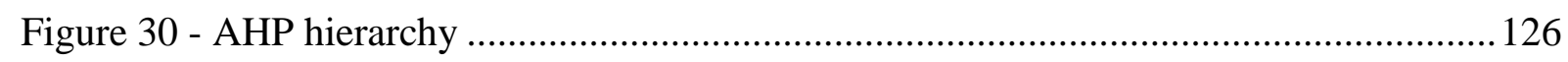

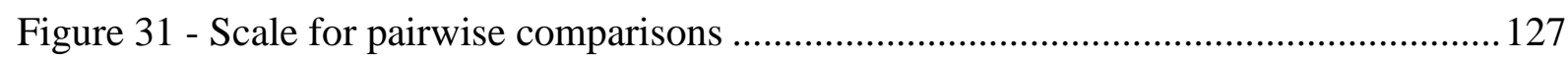





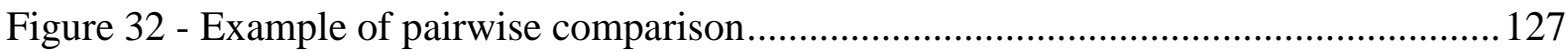

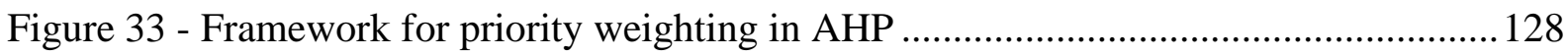

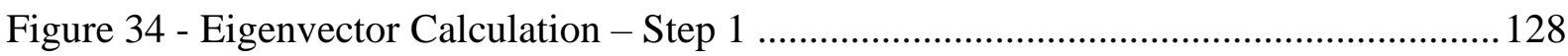

Figure 35 - Eigenvector Calculation - Step 2 ............................................................... 129

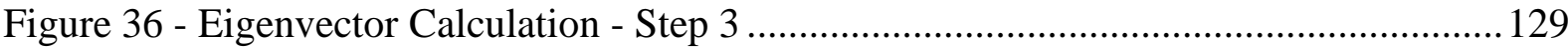

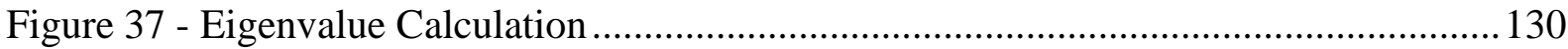

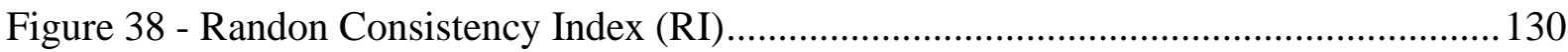

Figure 39 - CRM and SRM critical linkages through the Supply Chain............................... 134

Figure 40 - Sub-processes and interfaces of CRM process ............................................... 135

Figure 41 - Activities and interfaces of CRM strategic sub-processes................................ 137

Figure 42 - Activities and interfaces of CRM operational sub-processes ............................. 139

Figure 43 - Sub-processes and interfaces of SRM process ............................................. 140

Figure 44 - Activities and interfaces of SRM strategic sub-processes ................................ 142

Figure 45 - Activities and interfaces of SRM operational sub-processes ............................ 144

Figure 46 - Sub-processes and interfaces of CSM processes ............................................ 145

Figure 47 - Activities and interfaces of CSM strategic sub-processes ................................. 147

Figure 48 - Activities and interfaces of CSM operational sub-processes ............................ 148

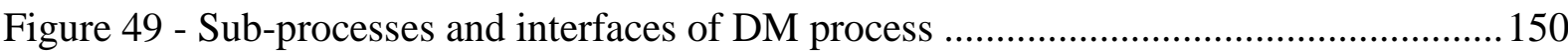

Figure 50 - Activities and interfaces of DM strategic sub-processes ................................... 152

Figure 51 - Activities and interfaces of DM operational sub-processes...............................154

Figure 52 - Sub-processes and interfaces of OF process ................................................. 155

Figure 53 - Activities and interfaces of OF strategic sub-processes .................................... 157

Figure 54 - Activities and interfaces of OF operational sub-processes ................................ 158

Figure 55 - Sub-processes and interfaces of MFM process ............................................... 160

Figure 56 - Five generic manufacturing strategies ....................................................... 161

Figure 57 - Activities and interfaces of MFM strategic sub-processes ................................ 163

Figure 58 - Activities and interfaces of MFM operational sub-processes............................ 165

Figure 59 - Sub-processes and interfaces of PDC process ….............................................. 166

Figure 60 - Activities and interfaces of PDC strategic sub-processes................................... 168

Figure 61 - Activities and interfaces of PDC operational sub-processes ............................... 170

Figure 62 - Sub-processes and interfaces of RM process................................................. 172

Figure 63 - Activities and interfaces of RM strategic sub-processes .................................. 174

Figure 64 - Activities and interfaces of RM operational sub-processes ............................... 175 



\section{LIST OF TABLES}

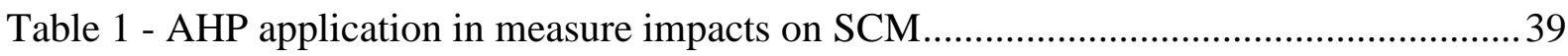

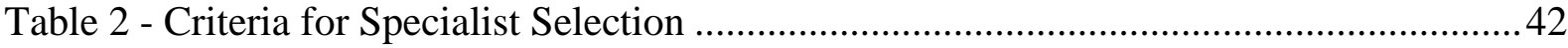

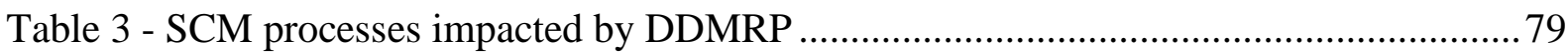

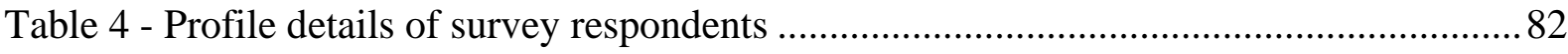

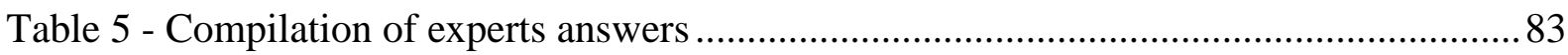

Table 6 - Rank of perceived impact on SCM processes (all respondents) ............................. 84

Table 7 - Rank of perceived impact on SCM processes (researchers) .................................. 85

Table 8 - Rank of perceived impact on SCM processes (industry professionals) ....................86

Table 9 - Rank of perceived impact on SCM strategic sub-processes (all respondents)..........87

Table 10 - 10 most impacted SCM strategic sub-processes ................................................ 89

Table 11 - Search results by keywords and databases........................................................ 106

Table 12 - Detail of analyzed articles of the second literature review ................................. 106 



\section{LIST OF ABBREVIATIONS}

\begin{tabular}{|c|c|c|}
\hline AHP & - & Analytical Hierarchy Process \\
\hline AIJ & - & Aggregation of Individual Judgements \\
\hline ATO & - & Assemble to Order \\
\hline BTO & - & Buy to Order \\
\hline $\mathrm{BOM}$ & - & Bill of Materials \\
\hline $\mathrm{CI}$ & - & Consistency Index \\
\hline CODP & - & Customer Order Decoupling Point \\
\hline CPFR & - & Collaborative Planning Forecasting and Replenishment \\
\hline $\mathrm{CR}$ & - & Consistency Ratio \\
\hline CRM & - & Customer Relationship Management \\
\hline CSM & - & Customer Service Management \\
\hline DDMRP & - & Demand Driven Material Requirement Planning \\
\hline DEMATEL & - & Decision Making Trial and Evaluation Laboratory \\
\hline $\mathrm{DM}$ & - & Demand Management \\
\hline GSCF & - & Global Supply Chain Forum \\
\hline JIT & - & Just in Time \\
\hline MCDA & - & Multi Criteria Decision Analysis \\
\hline MCDM & - & Multi Criteria Decision Method \\
\hline MFM & - & Manufacturing Flow Management \\
\hline MPC & - & Manufacturing Planning and Control \\
\hline MRP & - & Materials Requirement Planning \\
\hline MTO & - & Make to Order \\
\hline MTS & - & Make to Stock \\
\hline $\mathrm{OF}$ & - & Order Fulfillment \\
\hline OTD & - & On Time Delivery \\
\hline OTIF & - & On Time In Full \\
\hline PDC & - & Product Development and Commercialization \\
\hline PSA & - & Product and Service Agreement \\
\hline
\end{tabular}





$\begin{array}{lll}\text { R\&D } & - & \text { Research and Development } \\ \text { RBP } & - & \text { Rate-Based Planning Process } \\ \text { RM } & - & \text { Returns Management } \\ \text { S\&OP } & - & \text { Sales and Operations Planning } \\ \text { SCC } & - & \text { Supply Chain Council } \\ \text { SCM } & - & \text { Supply Chain Management } \\ \text { SCOR } & - & \text { Supply Chain Operations Reference } \\ \text { SKU } & - & \text { Single Key Unit } \\ \text { SRM } & - & \text { Supplier Relationship Management } \\ \text { STS } & - & \text { Ship to Stock } \\ \text { TOC } & - & \text { Theory of Constraints } \\ \text { VMI } & - & \text { Vendor Managed Inventory } \\ \text { WIP } & - & \text { Work In Process }\end{array}$





\section{TABLE OF CONTENTS}

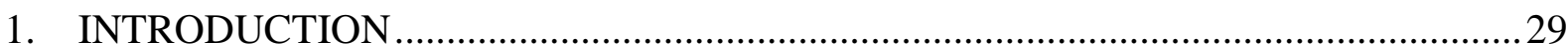

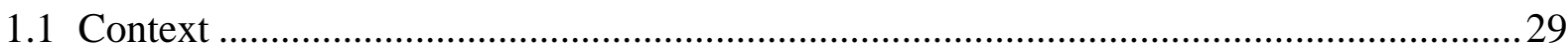

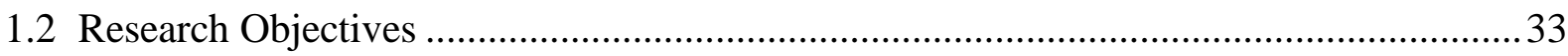

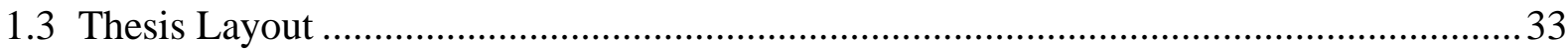

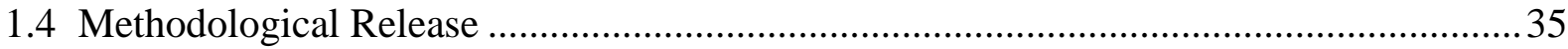

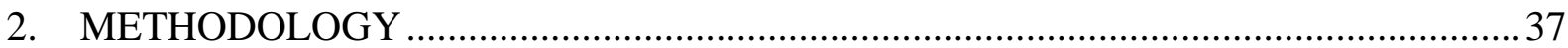

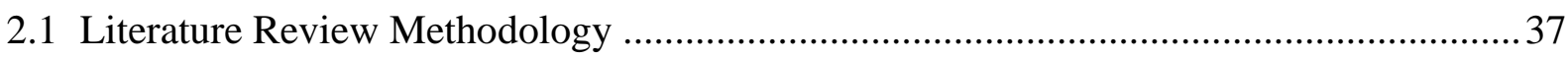

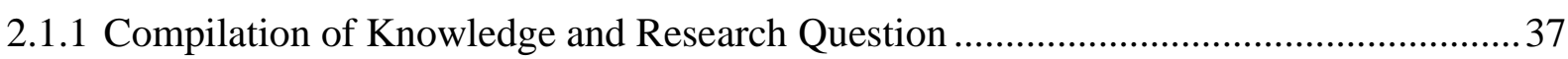

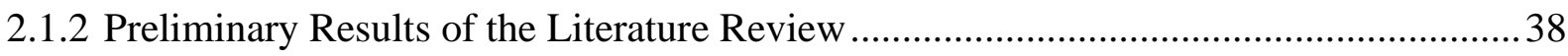

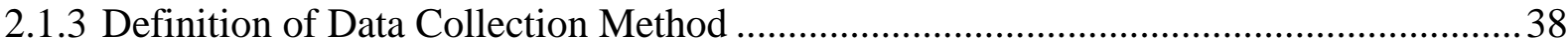

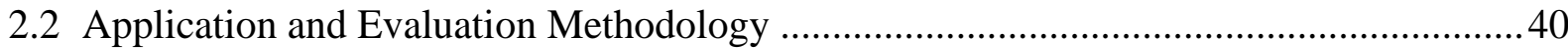

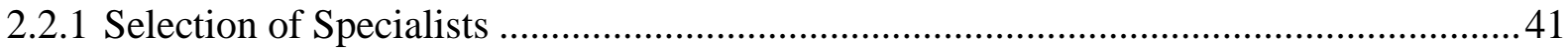

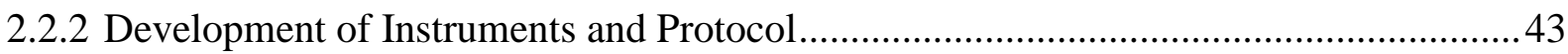

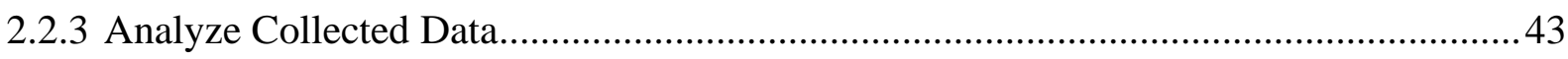

2.3 Conclusions and Recommendations Methodology …................................................. 44

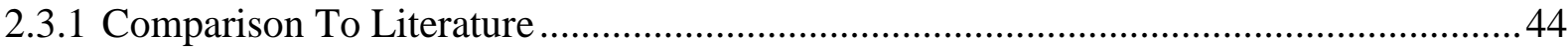

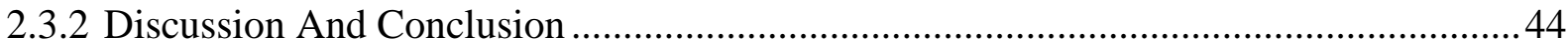

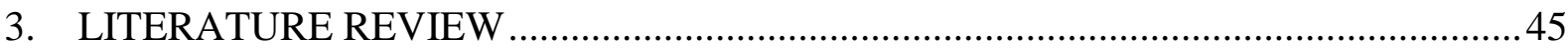

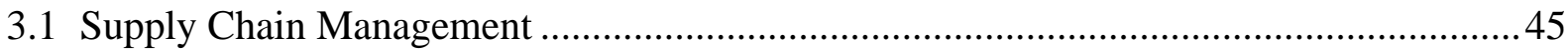

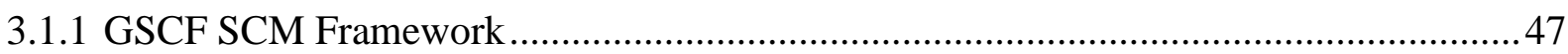

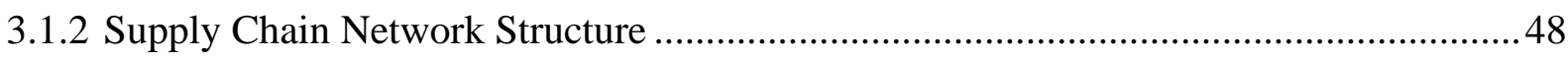

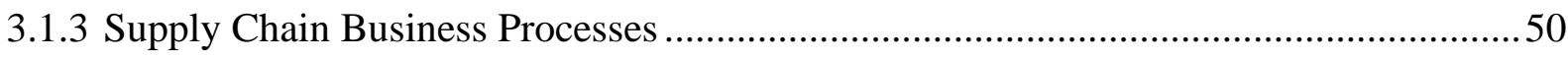

3.1.4 Supply Chain Management Components ....................................................................51

3.1.5 The Agile Paradigm in Supply Chain Management ...................................................53

3.2 The Demand Driven Material Requirements Planning (DDMRP) …..............................55

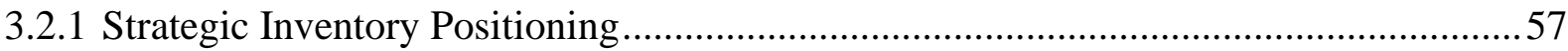

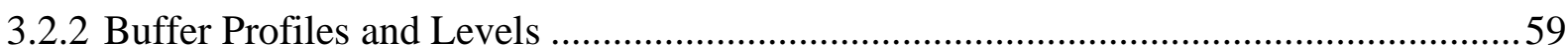

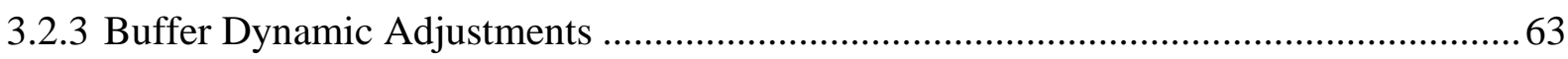

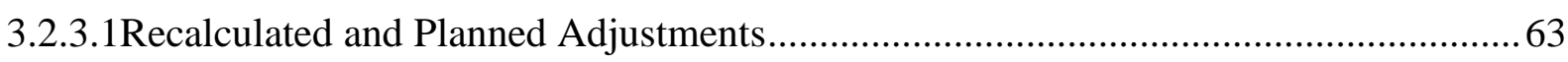

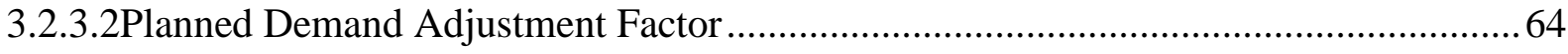

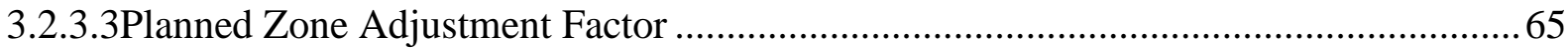





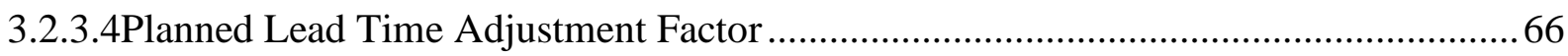

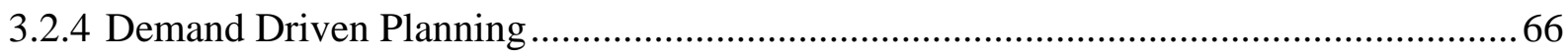

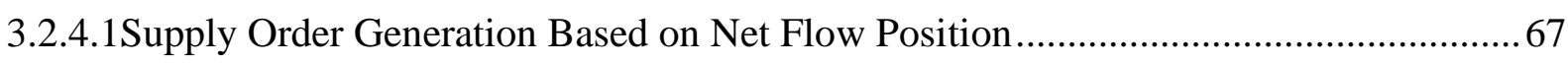

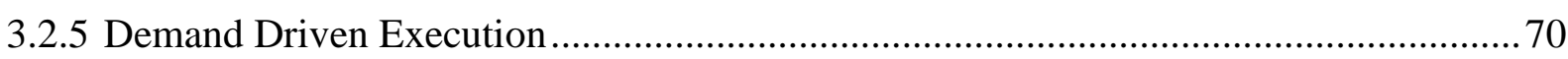

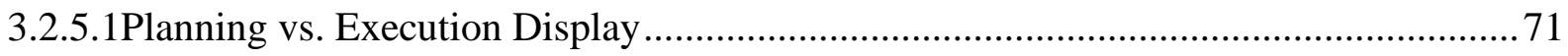

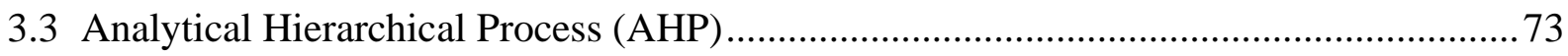

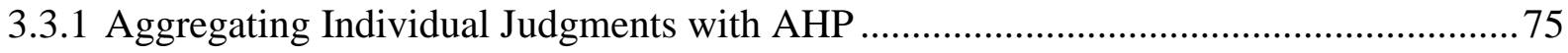

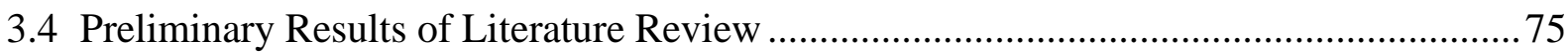

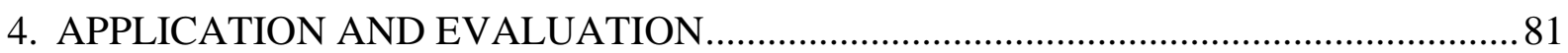

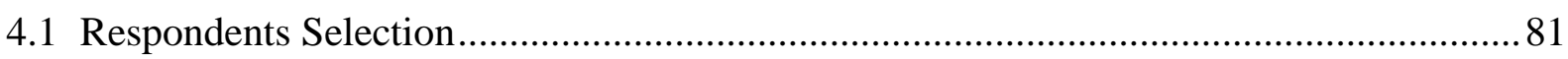

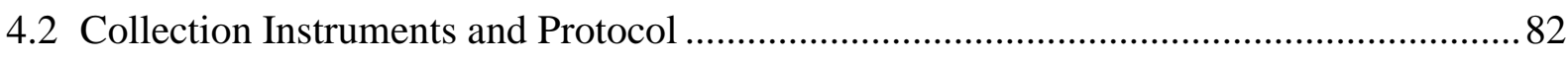

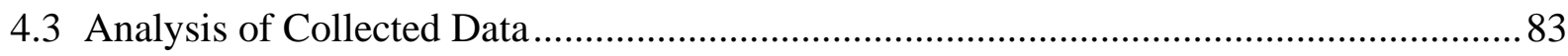

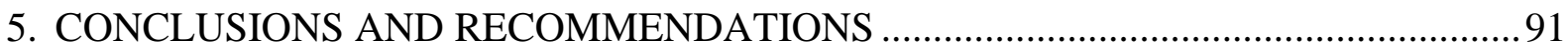

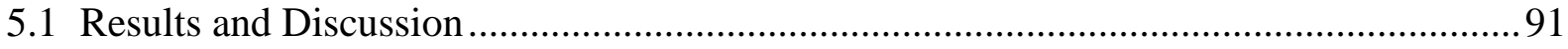

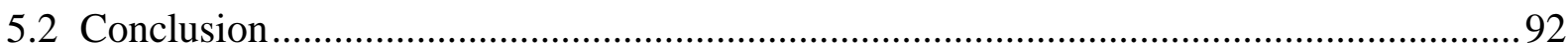

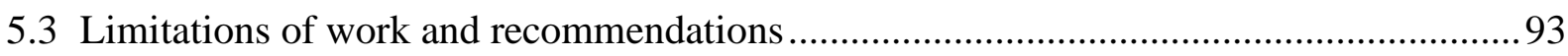

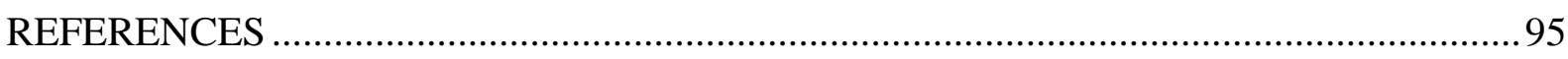

APPENDIX A - RESULTS OF LITERAUTRE REVIEW ON DDMRP ............................ 105

APPENDIX B - COLLECTION INSTRUMENT AND PROTOCOL ................................. 107

APPENDIX C - AHP DEVELOPMENT AND CALCULATION ................................... 125

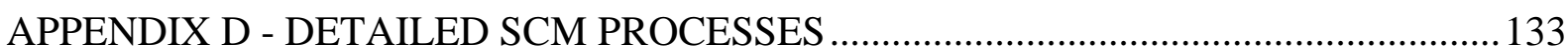





\section{INTRODUCTION}

This chapter has 4 different sections. The first section (1.1) aims to contextualize the thesis theme and its relevance for the development of science. The second section (1.2) breaks the research question into research objectives that must be achieved in order to answer the research question in fill the identified gap. The third section (1.3) details the thesis layout, with its different parts and sections. The last section (1.4) of this chapter is the Methodological Release of the thesis. It shows the research framework used to guide the completion of the thesis and a summary of each of the research activities proposed.

\subsection{Context}

Supply Chain Management (SCM) has turned out to be one of the main means for firms to control costs and enhance economic performance when facing the more and more competitive market these days (HONG et al., 2018). The search for the adjustment between the client's requisites and the products characteristics and the order fulfillment on the market'simposed speed are the main objectives of supply chain managers (AITKEN et al., 2003).

According to the Future of Supply Chain report (O'MARAH; CHEN, 2016), 88\% of 1.441 respondents acknowledged that the alignment of business strategy and supply chain strategy is an equally important part of business success as sales and marketing or $\mathrm{R} \& \mathrm{D} /$ product development.

Since the mid-1990s, academics in the field of logistics, marketing and operationsmanagement attempted to describe supply chain management (LAMBERT; GARCÍADASTUGUE; CROXTON, 2005). Cooper, Lambert and Pagh (1997) used the definition developed by the members of the Global Supply Chain Forum (GSCF). According to Cooper, Lambert and Pagh (1997, p. 2) "Supply Chain Management is the integration of key business processes from end user through original suppliers that provides products, services and information to add value for customers and other stakeholders".

Lambert, García-Dastugue and Croxton (2005) stated that there were five SCM frameworks that recognized the need to implement business processes in the literature, each one with distinctive characteristics and objectives. According to the authors, four of the five SCM frameworks suggest the implementation of standard cross-functional business processes. However, only two of those four, the GSCF and the Supply Chain Operations Reference 
(SCOR) frameworks, included business processes that could be used by management to achieve this integration.

In a comparison between the two frameworks, Lambert, García-Dastugue and Croxton (2005) showed that the GSCF is broad in its scope. According to the authors, this breadth is intentional because it increases the opportunities for supply chain management to provide value. However, it provides some implementation challenges. The SCOR framework, on the other hand, might be easier to implement but the limited functional involvement might result in lower levels of performance and failed initiatives.

Lambert and Enz (2017) state that the definition developed in 1995 and reported in Cooper, Lambert and Pagh (1997) was updated because it did not mention some important elements: relationships, network of organizations or that the processes were cross-functional. Following Lambert (2014) updated definition as it follows: "Supply chain management is the management of relationships in the network of organizations, from end customers through original suppliers, using key cross-functional business processes to create value for customers and other stakeholders". This will be the definition for SCM that will be used in this research and thesis.

Croxton et al. (2001) provided a more detailed view on the sub-processes and activities that comprise the GSCF framework in order to help managers with guidelines to implementation, instructors with material for structuring a SCM course and researchers with a detailed framework for future research on supply chain management. Lambert and Enz (2017) later updated their view.

However, despite the implementation of any SCM framework, since the end of the 90's there is consensus, according to Christopher and Towill (2001), that the success or failure of supply chains is going to be determined on the market by the end customer. Mason-Jones, Naylor and Towill (2000) affirms that to do the right product, on the right price, at the right time arrive to the right customer is not only a competitive success factor, but also a survival one. Smith and Smith (2013a), when presenting the concept of New Normal, where change is not driven by the removal of a limitation but rather the imposition of a set of complex limitations.

Similar to all these authors is the idea that achieve and keep this advantage is a complex task for the companies, especially because of the increased uncertainty generated by the demand variability, since the forecast based planning models are not capable to identify the real needs.

In the context of the above-mentioned factors, the choice of the Manufacturing Planning and Control (MPC) system is crucial for the company (ABUHILAL; RABADI; SOUSA- 
POZA, 2015). According to Kortabarria et al. (2018) in the last century, many MPCs were developed, the most widespread being Material Requirements Planning (MRP), Just in Time (JIT) and Theory of Constraints (TOC).

To cope with this scenario, companies had been increasing investments in infrastructure, technology and management methods (Theory of Constraints, Lean Production, Material Requirement Planning). These investments contributed to increase the cost efficiency in Supply Chains, but other important dimensions did not follow through (SMITH; SMITH, 2013b).

After the introduction of the MRP in 1974 along with its variants (for instance closed loop MRP and MRP II) a period of research focused on various aspects of its operation and impact on firms emerged. For the most part, the major features of MRP have remained the same: linking the planning and scheduling of dependent demand items to the demand of their parent items, time phasing of requirements and the use of static safety stocks (MICLO et al., 2019)

However, despite the improvement in the available tools and methods, a high percentage of clients are still unsatisfied, and the stock levels are still high and misaligned with the real demand (SMITH; SMITH, 2013b). The alignment with real demand can be traced back to the agility and responsivity of a supply chain. According to Christopher et al. (2004), the responsiveness is achieved by becoming demand driven instead of forecast driven.

Recently, from the practitioner world, a fundamental rethinking of the MRP logic emerged - drawing elements of Lean Systems and TOC to improve the overall performance and effectiveness of the MRP logic. This rethinking challenged some of the fundamental assumptions of MRP, such as the replacement of safety stock by dynamic buffers, resulting in a new approach, developed by Ptak and Smith (2016), called Demand Driven MRP (DDMRP) (MICLO et al., 2019).

Ptak and Smith (2016) claim that conventional MRP systems forces organizations and supply chains to operate in a forecast driven manner while the DDMRP would enable companies and supply chains to become demand driven, thus, more agile and responsive.

Evidence from the practitioner world has provided support of the superior performance of DDMRP. According to Miclo et al. (2019) companies that have implemented this approach have claimed significant improvements in increasing on-time delivery, reducing stock outs and in reducing levels of inventory. Alexander (2016) shows, that after implementing DDMRP, the studied company was able to maintain a 100\% On Time in Full delivery (OTIF) despite keeping a high level of Single Key Units (SKUs). Ducrot and Ahmed (2019) confirmed Ptak and Smith 
(2016) claims that companies using DDMRP achieve inventory reduction and increase their service level simultaneously. According to them, companies that applied DDMRP were able to reduce the customer order lead time by half.

Out of the practitioner world, new academic research strongly supports the contention that DDMRP does represent significant improvement in planning and scheduling logic (MICLO et al. 2019; KORTABARRIA et al. 2018; SHOFA; MOEIS; RESTIANA, 2018). On the other hand, research shows that DDMRP has a significant role in reducing Work in Process (WIP) compared to MRP II but with less satisfying On Time Delivery (OTD) under certain scenarios (MICLO et al. 2015).

When a deeper look is taken at similar models developed before Ptak and Smith publish its book in 2016, which can be considered a milestone for the consolidation of the term and application standards, interesting results and similar theories were found.

Burrows III (2012) states on his book how a rate-based planning process (RBP) is the key to becoming market-driven in inventory, replenishment, procurement, and production. According to the author, in RBP, an organization uses expected order rates rather than traditional replenishment signals - true demand rather than forecasting from upstream stock locations. This strategy reduces peaks and valleys of demand variation and results in better utilization, less time wasted and lower raw materials costs.

Farahani, Akkerman and Wilke (2013) developed a hierarchical demand-driven responsive model for production planning and control, using dynamic buffers instead of fixed safety stocks and reorder points. The results show that the authors were able to reduce significantly inventory levels and increase service levels compared to the current practice in the case study.

Regarding the recent increase in number of researches, almost every DDMRP research (LEE; JANG, 2013; IHME, 2015; IHME; STRATTON, 2015; MICLO et al., 2015; 2019; KORTABARRIA et al. 2018; SHOFA; MOEIS; RESTIANA, 2018) are focused on its implementation and the measure of improvements against other MPC systems. Despite current research proving that DDMRP implementation results in a significant improvement over MRP and its variants, there is no study to develop DDMRP theory nor any study on how it relates with other well-established theories in Operations Management.

Because of the importance of SCM to the success of businesses, the lack of studies showing which aspects and processes of SCM are affected by DDMRP implementation reveals itself a great research gap, which may retard the development and evolution of DDMRP theory. 
To fill this gap, this art of DDMRP. In order to research review the theory of Supply Chain Management, its different frameworks, and the state of contribute with the understanding of the DDMRP influence in the SCM processes and sub-processes, the following research question will guide the objectives of this thesis: how DDMRP implementation impacts the processes and strategic sub-processes of SCM and how much they are impacted?

\subsection{Research Objectives}

The main objective of this research is to identify the impact that DDMRP implementation causes in the processes and sub-processes of SCM. To do so, the main objective can be deployed in the following specific ones:

- To identify the most suitable SCM framework to identify changes and impacts caused by DDMRP implementation.

- To evaluate DDMRP literature to identify any aspect that are affected by DDMRP implementation but are not assessed in the current literature.

- To identify which process or processes of the chosen SCM framework will be affected during a DDMRP implementation.

- To measure, through surveys conducted with experts in the field of SCM, at which extent each identified SCM processes are affected because of DDMRP implementation.

\subsection{Thesis Structure}

This thesis comprises four chapters, divided in twelve different parts. Each chapter is divided in three different parts with several different sections. A graphic representation of the thesis structure is presented in Figure 1. 
Figure 1 - Thesis Structure

\begin{tabular}{|c|c|c|c|c|}
\hline $\begin{array}{l}\text { Chapter } 1 \text { - } \\
\text { Introduction }\end{array}$ & $\begin{array}{l}\text { Chapter } 2 \text { - } \\
\text { Methodology }\end{array}$ & $\begin{array}{c}\text { Chapter } 3 \text { - } \\
\text { Literature Review }\end{array}$ & $\begin{array}{c}\text { Chapter } 4 \text { - } \\
\text { Application and } \\
\text { Evaluation }\end{array}$ & $\begin{array}{c}\text { Chapter } 5 \text { - } \\
\text { Conclusions and } \\
\text { Recommendations }\end{array}$ \\
\hline $\begin{array}{c}\text { Part I } \\
\text { Introduction } \\
\text { Section } 1.1 \\
\text { Section } 1.2\end{array}$ & $\begin{array}{c}\text { Part I } \\
\text { Literature Review } \\
\text { Section } 2.1\end{array}$ & $\begin{array}{c}\text { Part I } \\
\text { SCM and DDMRP } \\
\text { Section } 3.1 \\
\text { Section } 3.2\end{array}$ & $\begin{array}{l}\text { Part I } \\
\text { Respondents } \\
\text { Selection } \\
\text { Section } 4.1\end{array}$ & $\begin{array}{l}\text { Part I } \\
\text { Results and } \\
\text { Discussion } \\
\text { Section } 5.1\end{array}$ \\
\hline $\begin{array}{c}\text { Part II } \\
\text { Dissertation } \\
\text { Layout } \\
\text { Section } 1.3\end{array}$ & $\begin{array}{c}\text { Part II } \\
\begin{array}{c}\text { Application and } \\
\text { Evaluation }\end{array} \\
\text { Section } 2.2\end{array}$ & $\begin{array}{c}\text { Part II } \\
\text { Analytical } \\
\text { Hierarchy Process } \\
\text { Section } 3.3\end{array}$ & $\begin{array}{c}\text { Part II } \\
\text { Collection } \\
\text { Instruments } \\
\text { Section } 4.2\end{array}$ & $\begin{array}{c}\text { Part II } \\
\text { Conclusions } \\
\text { Section } 5.2\end{array}$ \\
\hline $\begin{array}{l}\text { Part III } \\
\text { Methodology } \\
\text { Review } \\
\text { Section } 1.4\end{array}$ & $\begin{array}{c}\text { Part III } \\
\text { Conclusions and } \\
\text { Recommendations } \\
\text { Section } 2.3\end{array}$ & $\begin{array}{c}\text { Part III } \\
\text { Preliminary results } \\
\text { of literature review } \\
\text { Section } 3.4\end{array}$ & $\begin{array}{c}\text { Part III } \\
\text { Analysis of } \\
\text { Collected Data } \\
\text { Section } 4.3\end{array}$ & $\begin{array}{c}\text { Part III } \\
\text { Limitations and } \\
\text { recommendations } \\
\text { Section } 5.3\end{array}$ \\
\hline
\end{tabular}

Source: Author (2019)

Chapter 1 - Part I shows the relevance of the researched theme and brings the main research question objectives. Part II is focused on explaining the thesis layout to provide a better understanding to readers. Part III is the Methodological Release, which is a summary of the research design used in the thesis.

Chapter 2 - Part I reviews the methodology used to develop the chapter as well as to explain each one of the research activities comprised in the chapter. Part II is focused on the literature review of relevant theory for the thesis development, such as DDMRP, SCM and Analytic Hierarchy Process (AHP). Part III is a compiled of preliminary results and findings of the literature review performed by the author.

Chapter 3 - Part I is a review of the methodology used in the chapter development, detailing the methodological release presented in Chapter 1. Part II brings the implementation of the AHP approach, showing which subjects were selected to participate in the survey and the development of the collection instruments and protocol. Part III are an initial analysis of the results gathered from the AHP application.

Chapter 4 - Part I is a review of methodology applied in order to interpret the results from the AHP application. Part II shows the conclusion of the thesis based on the data collected in the surveys and the literature review. Part III is comprised of possible limitations of the current work and also gives recommendations for future works. 


\subsection{Methodological Release}

The Figure 2 is a representation of the methodology that guided the construction and the outputs of the research. Each of the steps described in the column Research Activity will be explained in the following sections of this work.

Figure 2 - Research Methodology

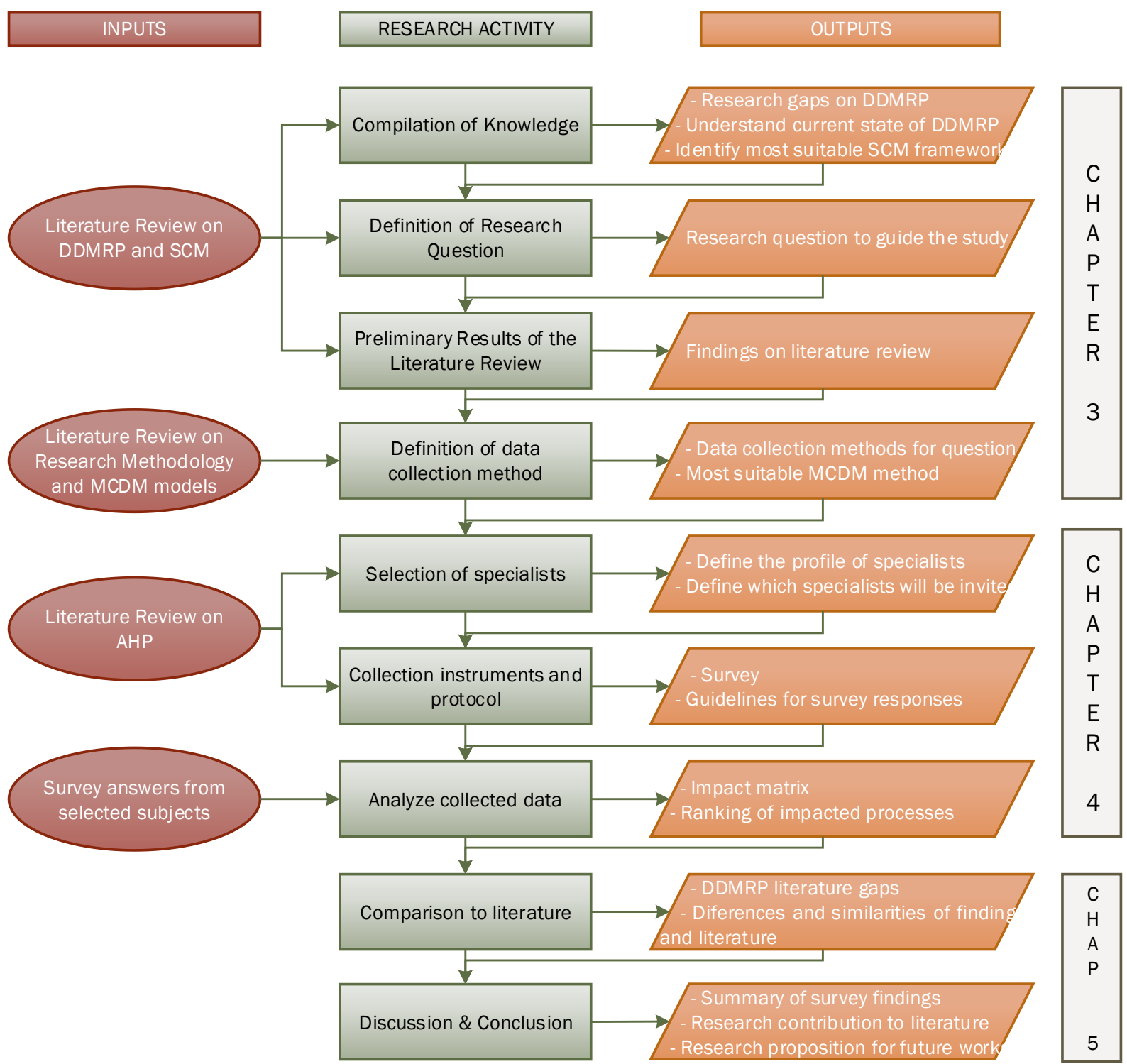

Source: Author (2019)

As shown in the image, there is nine research activities: (1) compilation of knowledge, (2) definition of research question, (3) preliminary results of the Literature Review, (4) definition of data collection method, (5) selection of cases, (6) construction of collect protocol and instruments, (7) analysis of collected data, (8) literature comparison and (9) discussion and conclusion. 
The activities (1) and (2) are explained together in the section 2.1.1 because of its entanglement, where the compilation of knowledge led to questions which triggers the need of more literature review, which contribute to the construction of the research question, almost in a loop of findings and questioning. Based on literature review on DDMRP and SCM, those two steps aim on the understanding of the current state of DDMRP literature in order to find research gaps. This led to the definition of the research question which guided the study.

The activity (3) is explained in section 2.1.2. The main objective of this step is, based on the literature review of SCM and DDMRP to create a preliminary summary of findings in literature of described impacts that DDMRP implementation has on SCM processes and subprocesses.

The activity (4) is explained in section 2.1.3. The main objective of this step is, based on a review on research methodology and multi-criteria decision analysis (MCDA) models to find the right data collection method for the developed research question and afterwards to define the most suitable MCDA method to answer the proposed question.

The step (5) is explained in section 2.2.1. Based on a literature review on Analytic Hierarchical Process (AHP) methodology, the objective of this activity is to identify where and with whom data would be collected to answer the developed research question.

The step (6) is explained in section 2.2.2. From the review of AHP uses to assess impacts on SCM, the survey was developed. Together with the survey, the consent form, set of information need for participants, AHP structure tree, brief review on used terms and the guidelines for answering where developed and sent to the participants that agreed to participate on the survey.

The research activity (7), is explained in section 2.2.3. The main objective of this step is to develop the impact matrix. This matrix shows the level of impact suffered from each SCM strategic process and sub-process after DDMRP implementation. In addition, the processes are ranked from most impacted to least impacted.

The step (8) is explained in section 2.3.1. The objective of this research activity is to identify gaps on DDMRP literature through comparison of the data collection results and proposed theory, looking for similarities and contradictions between data collected and reviewed literature.

The final step (9) is explained in section 2.3.2. This activity seeks to summarize the findings, providing a framework for DDMRP implementers to focus their efforts on the most impacted SCM processes when implementing it. In addition, on this activity, it is important to discuss the results and to generate research propositions for future works based on the findings. 


\section{METHODOLOGY}

This chapter is comprised of 3 different sections, each one with several subsections aimed to describe the methodology applied in the present thesis. The section 2.1 details the methodology which guided the literature review of this thesis. Section 2.2 details the steps and methods used for the application and evaluation of data collected by the author. Lastly, section 2.3 details how the conclusions and recommendations of the work will be developed and presented.

\subsection{Literature Review Methodology}

This section of the work details the parts of the proposed methodology that assisted in the construction of the literature review for the present thesis. Following the steps proposed by the methodology, the author gathered the needed literature needed for the completion of the thesis.

\subsubsection{Compilation of Knowledge and Research Question}

As stated by Yin (2014) the (a) type of research question, (b) the extent of control a researcher has over actual behavioral events and (c) the degree of focus on contemporary events defines the research method. Questions of "how, why?" with no control of events and focused on contemporary events are suitable for case study research. Questions of "who, what, where, how many, how much?" with no control of events and focused on contemporary events are suitable for surveys.

The development of this work began with an extensive literature review on the subjects in order to develop and refine the research questions. The initial review revealed the lack of research on this field. From the access of Web of Science, Emerald Insight, Science Direct, Scopus and Google Scholar, most of the relevant papers researched were theory testing research, focused on application or comparison of the theory. The results and keywords used are provided in Appendix A.

The research question that is focus of this work is: How DDMRP implementation impacts the processes and strategic sub-processes of SCM and how much they are impacted? This question emerged from the identified gap resulting from literature review and was 
presented in Chapter 1. Until now, there are no studies or definitions on how DDMRP relates to SCM and how impacted the SCM processes are after its implementation.

This research questions, which can be separated in two different questions, leads to the combination of research methodologies that are used in this work. Specialists' opinions that were collected through survey to identify the linkages between DDMRP implementation and impacts in SCM processes and how strong or weak are those impacts.

\subsubsection{Preliminary Results of the Literature Review}

This step of the research aims to gather all the researched knowledge in order to partially answer the research question. After the literature review, the author searched for links between two different theories, in this case DDMRP and SCM, in order to identify which processes and strategic sub-processes of SCM were impacted in a DDMRP implementation according to current theory development of both subjects.

With this categorization in hand, after the completion of the survey, the author is made a comparison of the survey findings in the impacted processes and sub-processes with the reviewed literature. According to Eisenhardt (1989) the comparison with the literature involves asking what it is similar to, what does it contradict and why, in order to increase both the quality and the validity of the findings.

The preliminary results of the literature review is presented in the Table 3 of this work, in section 2.4 .

\subsubsection{Definition of Data Collection Method}

Yin (2001) lists six main types of data collection methods: documentation, archival records, interviews, direct observations, participant-observation, and physical artifacts. The present work relies in structured surveys as the major source of data to answer to the formulated research question.

To gather data, identify and measure the impacts of DDMRP in SCM processes, the AHP methodology is used to structure the survey. AHP, as a decision-making tool, is used to organize a complex problem into a hierarchical structure. It uses a system of pair wise comparisons to recognize the importance of the decision factors in the system (SAATY, 1980).

According to Tramarico et al. (2015), since 1993, AHP has been the most applied Multi Criteria Decision Making (MCDM) method in the field of Supply Chain Management. 
Regarding the assessment of impacts in Supply Chain Management, Table 1 brings the results of the literature review of several studies that successfully applied AHP to measure impacts in Supply Chain Management and other related areas as well.

Table 1 - AHP application in measure impacts on SCM

\begin{tabular}{|c|c|c|c|}
\hline No. & Authors & Method & Contribution \\
\hline 1 & $\begin{array}{l}\text { Nouri, Nikabadi } \\
\text { and Olfat (2019) }\end{array}$ & $\begin{array}{l}\text { Fuzzy } \\
\text { AHP }\end{array}$ & $\begin{array}{l}\text { Identify the impact of supply chain features in a } \\
\text { hospital supply chain. }\end{array}$ \\
\hline 2 & $\begin{array}{l}\text { Abdel-Basset, } \\
\text { Manogaran and } \\
\text { Mohamed (2018) }\end{array}$ & $\begin{array}{c}\text { AHP \& } \\
\text { DEMATEL }\end{array}$ & $\begin{array}{l}\text { Measure the impacts of security criteria in the security } \\
\text { of a Smart Supply Chain }\end{array}$ \\
\hline 3 & $\begin{array}{l}\text { Govindan, Lutra } \\
\text { an Mangla (2017) }\end{array}$ & $\begin{array}{l}\text { Fuzzy } \\
\text { AHP }\end{array}$ & $\begin{array}{l}\text { Identify which indications has the biggest impact in } \\
\text { supply chain effectiveness }\end{array}$ \\
\hline 4 & $\begin{array}{l}\text { Gandhi et al. } \\
\text { (2016) }\end{array}$ & AHP & $\begin{array}{l}\text { Evaluate the success factor that most impact the } \\
\text { implementation of Green Supply Chain Management }\end{array}$ \\
\hline 5 & $\begin{array}{l}\text { Drake, Lee and } \\
\text { Hussain (2013) }\end{array}$ & AHP & $\begin{array}{l}\text { Measure the impact of component's competitive } \\
\text { criteria in the strategic priorities of businesses }\end{array}$ \\
\hline 6 & $\begin{array}{l}\text { Mathiayazhagan, } \\
\text { Govindan and } \\
\text { Haq (2013) }\end{array}$ & AHP & $\begin{array}{l}\text { Identified and prioritize the existing pressures for } \\
\text { implementation of Green Supply Chain Management }\end{array}$ \\
\hline 7 & $\begin{array}{l}\text { Zhang and Yue } \\
\text { (2006) }\end{array}$ & AHP & $\begin{array}{l}\text { Identify the main factor impacting the harmony } \\
\text { degree of community }\end{array}$ \\
\hline
\end{tabular}

Source: Author (2019)

Tramarico et al (2015) found on its bibliometric study on AHP that it can be combined with different methods, such as: Goal Programming, Fuzzy Logic, Genetic Algorithm and Neural Network. Some of the articles which used AHP to measure impacts in SCM combined AHP with Fuzzy logic. Saaty and Tran (2007) criticizes the use of Fuzzy AHP (FAHP) mainly regarding the outcome of the consistency ratio (CR), which measures the consistency of the pairwise comparison matrix and is used to improve the validity of the outcome. In FAHP this inconsistency cannot be showed, and the inconsistency of judgment remains. The uncertainty in AHP is successfully remedied by using the intermediate values in the 1-9 scale combined with the verbal scale and that seems to work better to obtain accurate results than using fuzziness to change the number for convenience and rather arbitrarily (SAATY; TRAN, 2007). 
In one of the works evaluated, DEMATEL is also used to assess the impacts in SCM. According to Wu (2008), DEMATEL is an approach that helps the decision-maker to identify the interdependence between the factors, resulting in the categorization of factors by dividing them into cause and effect groups. In this work, since the objective is to identify how and how much different factors are impacted by DDMRP implementation, the use of DEMATEL will not contribute to achieve this objective.

A representation of the framework used in the AHP development and implementation based on Saaty (2008) proposition is shown in Figure 3. The first step is to define the problem e determine which knowledge is sought, this resulted in the goal, or level 1 of AHP criteria tree. The second step is to structure the decision hierarchy in goal, main factors and sub-factors. This structure is represented in a criteria tree. The third step is to construct the set of pairwise comparison matrices to compare the elements in the same levels. Through the collection instrument, the responses are analyzed to create the matrices. The consistency ratio is also checked in this step. The last step is to obtain the global priority for each sub-factor, this will be used to create the impact matrix. Each step of this framework is explained in detail in the literature review of this work.

A more detailed explanation on AHP is presented in section 2.5 and also in the Appendix $\mathrm{C}$ of this present thesis.

Figure 3 - AHP development and implementation

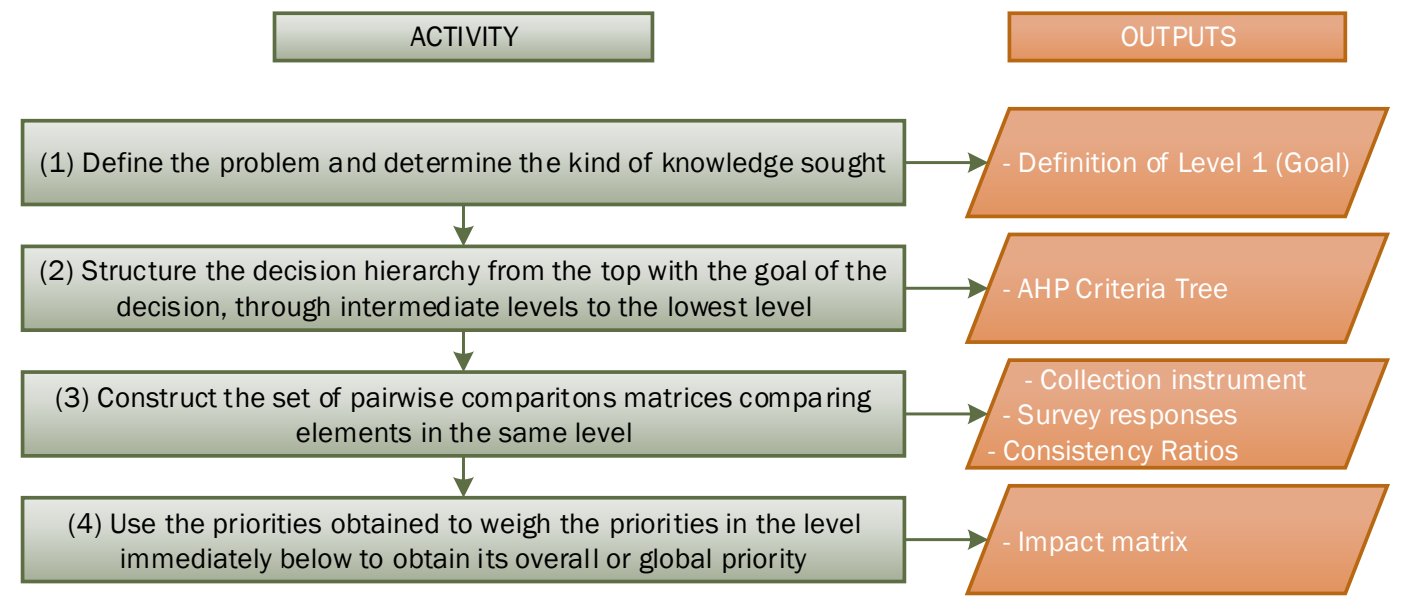

Source: Adapted from Saaty (2008)

\subsection{Application and Evaluation Methodology}

This section of the work details the parts of the proposed methodology that assisted the development of the application and the evaluation method for the present thesis. Following the 
steps proposed by the methodology, the author constructed the instruments necessary for data collection and the necessary methodology to analyze all the gathered data.

\subsubsection{Selection of Specialists}

A group of expert evaluation is widely used in the various spheres of activity with the aim of receipt of decisions in relation to overcoming of certain problem on the basis of opinion of skilled experts that have the special skills of knowledge in the concrete sphere of activity (VELYCHKO et al., 2015). According to Hughes (1996) there is a widespread feeling that the expert estimations approach must be particularly intuitive and therefore liable to be personally biased and sensitive to political pressures.

A strict criterion was developed in order to identify and invite specialists to participate in the study. Since following a criterion that merges all the three themes in this present thesis would reduce or even making it impossible to find an acceptable number of specialists, the areas of Supply Chain Management, Material Management or DDMRP were targeted.

Ivlev et al. (2015) proposed a method for selecting expert groups. Based on its questionnaire for evaluation of expert's competence, the possible experts were submitted to this analysis in order to evaluate if the criteria were met. The specialist selection method used in order to evaluate the specialists, both in academia and in industry is represented in Figure 4.

Figure 4 - Logic for specialist selection

$$
\left(\sum_{c=1}^{n} \mathrm{~A}_{i c}>4.0 \rightarrow A_{i} \in j\right) \vee\left(A_{i} \notin j\right)
$$

Source: Author (2019)

Figure 4 exemplifies the logic used to verify the specialist adherence to the proposed survey. Consider $\mathrm{A}_{i}$ a possible subject for answering the questionnaire, $n$ the number of criteria, $\mathrm{c}$ is the criteria itself and $j$ the group of respondents. If the sum of the criteria $\mathrm{A}_{i 1}$ to $\mathrm{A}_{i n}$ is greater than 4.0, then subject $A_{i}$ is considered for responding the questionnaire, otherwise, the participant is not invited to the survey. The data to evaluate each specialist score was gathered either from the $\mathrm{CV}$ of the respondents, which were all available online (University Website, LinkedIn or Lattes Platform), or through direct contact.

For this evaluation, five criteria were used. Each one of them (C1 to $\mathrm{C} 5)$ was evaluated in a score according to a previously established rate. Criteria $\mathrm{C} 1$ to $\mathrm{C} 4$ were evaluated from values 0 to 1 , and criteria $\mathrm{C} 5$ was evaluated from 0 to 2. Table 2 summarizes the criteria and 
the scores that were evaluated. The criteria were slightly changed when evaluating specialists in academia and specialists in industry.

Table 2 - Criteria for Specialist Selection

\begin{tabular}{|c|c|c|c|c|c|}
\hline Criteria for Academia & $\mathrm{W}$ & Cat & Criteria for Industry & $\mathrm{W}$ & Cat \\
\hline \multicolumn{3}{|l|}{ Position } & \multicolumn{3}{|l|}{ Position } \\
\hline Professor & 1,0 & $\mathrm{C} 1$ & Head of related area & 1,0 & $\mathrm{C} 1$ \\
\hline PhD candidate & 0,8 & $\mathrm{C} 1$ & Work in related area & 0,5 & $\mathrm{C} 1$ \\
\hline Masters candidate & 0,4 & $\mathrm{C} 1$ & Head of any area & 0,2 & $\mathrm{C} 1$ \\
\hline Undergraduate & 0,0 & $\mathrm{C} 1$ & Work in any area & 0,0 & $\mathrm{C} 1$ \\
\hline \multicolumn{3}{|l|}{ Education in area } & \multicolumn{3}{|l|}{ Education in area } \\
\hline $\mathrm{PhD}$ & 1,0 & $\mathrm{C} 2$ & $\mathrm{PhD}$ & 1,0 & $\mathrm{C} 2$ \\
\hline Master & 0,6 & $\mathrm{C} 2$ & Master & 0,6 & $\mathrm{C} 2$ \\
\hline Bachelor & 0,2 & $\mathrm{C} 2$ & Bachelor & 0,2 & $\mathrm{C} 2$ \\
\hline None & 0,0 & $\mathrm{C} 2$ & None & 0,0 & $\mathrm{C} 2$ \\
\hline \multicolumn{3}{|l|}{ Published papers in area } & \multicolumn{3}{|l|}{ DDMRP use in Company } \\
\hline $4+$ papers & 1,0 & $\mathrm{C} 3$ & DDMRP head of implementation & 1,0 & $\mathrm{C} 3$ \\
\hline 3 papers & 0,6 & $\mathrm{C} 3$ & DDMRP operationalization & 0,6 & $\mathrm{C} 3$ \\
\hline 1-2 papers & 0,4 & $\mathrm{C} 3$ & Worked with DDMRP & 0,4 & $\mathrm{C} 3$ \\
\hline 0 papers & 0,0 & $\mathrm{C} 3$ & Don’t work with DDMRP & 0,0 & $\mathrm{C} 3$ \\
\hline \multicolumn{3}{|l|}{ Experience in area } & \multicolumn{3}{|l|}{ Experience in area } \\
\hline $10+$ years & 1,0 & $\mathrm{C} 4$ & $10+$ years & 1,0 & $\mathrm{C} 4$ \\
\hline $10-5$ years & 0,6 & $\mathrm{C} 4$ & $10-5$ years & 0,6 & $\mathrm{C} 4$ \\
\hline $3-5$ years & 0,3 & $\mathrm{C} 4$ & $3-5$ years & 0,3 & $\mathrm{C} 4$ \\
\hline$<3$ years & 0,0 & $\mathrm{C} 4$ & $<3$ years & 0,0 & $\mathrm{C} 4$ \\
\hline \multicolumn{3}{|l|}{ Specialization } & \multicolumn{3}{|l|}{ Specialization } \\
\hline DDMRP & 2,0 & $\mathrm{C} 5$ & DDMRP & 2,0 & $\mathrm{C} 5$ \\
\hline SCM & 1,0 & $\mathrm{C} 5$ & SCM & 1,0 & $\mathrm{C} 5$ \\
\hline Material Management & 0,5 & $\mathrm{C} 5$ & Material Management & 0,5 & $\mathrm{C} 5$ \\
\hline None of the above & 0,0 & $\mathrm{C} 5$ & None of the above & 0,0 & $\mathrm{C} 5$ \\
\hline
\end{tabular}

Source: Author (2019)

In order to be characterized as an expert, every invited specialist should met the criteria specified in Figure 4. The selected subjects were involved in academia, practitioner environment and software development, in such way that the views and answers are going to reflect the view of theorists and practitioners on the field that the study is being carried.

For this research, 22 subjects identified met the criteria and were invited to participate on the survey for data collection. The invitation was made after the definition of data collection method and the construction of the collect instruments and protocols. 


\subsubsection{Development of Instruments and Protocol}

Yin (2005) highlights the importance of the protocol as one of the main tactics to increase the reliability of research. According to the author it should contain a general overview, with objectives, research questions and literature on the subject.

According to Saaty (2008), to make a decision in an organized way to generate priorities, there is a need to decompose the decision into the following steps.

1. Define the problem and determine the kind of knowledge sought.

2. Structure the decision hierarchy from the top with the goal of the decision, then the objectives from a broad perspective, through the intermediate levels to the lowest levels

3. Construct a set of pairwise comparison matrices. Each element in an upper level is used to compare the elements in the level immediately below with respect to it.

The collection instrument used in the research is available on the Appendix B of this work and follows Saaty's (2008) recommendations on how to develop an AHP decision matrix.

\subsubsection{Analyze Collected Data}

According to Yin (2005) data analysis can be conceptualized as the execution of the activities of examination, categorization, and classification in tables, testing or recombination of quantitative and qualitative evidences.

For the present research, the main objective of data analysis is to generate an impact matrix which will demonstrate the level of impact suffered for each process and sub-process of SCM after DDMRP implementation. According to Saaty (1980), to analyze data collected from answers, 5 steps must be taken. The Figure 5 is a representation of the steps needed, each of the steps are discussed in detail in Appendix $\mathrm{C}$ of this work.

Figure 5 - Data analysis on AHP implementation

\begin{tabular}{|c|c|c|c|c|}
\hline $\begin{array}{l}\text { (1) Calculate the } \\
\text { eigenvector }\end{array}$ & $\begin{array}{l}\text { (2) Calculate the } \\
\text { eigenvalue }\end{array}$ & $\begin{array}{l}\text { (3) Calculate the } \\
\text { consistency } \\
\text { index }(\mathrm{Cl})\end{array}$ & $\begin{array}{l}\text { (4) Calculate the } \\
\text { Random Index } \\
\text { (RI) }\end{array}$ & $\begin{array}{l}\text { (5) Calculate the } \\
\text { Consistency } \\
\text { Ratio (CR) }\end{array}$ \\
\hline
\end{tabular}

Source: Adapted from Saaty (1980) 


\subsection{Conclusions and Recommendations Methodology}

This section of the work details the parts of the proposed methodology that assisted the conclusion and proposed recommendations of this thesis. Following the steps proposed by the methodology, the author drawn the conclusions and built the recommendations for future works together with a critical analysis of the limitations of this thesis.

\subsubsection{Comparison To Literature}

It is particularly important to address literature that conflicts with the findings. Not to do so reduces confidence in the findings and doing it may force into more creative thinking and deeper insights. Overall effective comparison to literature increases both the quality and the validity of the findings (VOSS et al., 2002).

For the current work, comparison to literature will be conducted following Eisenhardt's (1989) which involves asking what is similar, what is different and why. This step aims to raise perceived gaps in literature that may be revealed after the analysis of results.

\subsubsection{Discussion And Conclusion}

The final step of the proposed work is a ranking that will help to drive DDMRP implementation through the Supply Chain processes, identifying which processes are most impacted and therefore which process should be prioritized during DDMRP efforts in order to gather better results. This framework will answer the questions of "which processes are impacted?" and "how much they are impacted?"

In addition, the discussion of the research contributions to literature that emerged from the research development, possible limitations found during the completion of the present thesis and propositions for future works regarding DDMRP and Supply Chain Management will be made. 


\section{LITERATURE REVIEW}

The present chapter is comprised of 5 different sections, each with several sub-sections. The first section (2.1) brings a methodological review of the chapter, showing which parts of the methodology presented in the section 1.4 were developed in this chapter. The second section (2.2) is a literature review on Supply Chain Management (SCM). The third section (2.3) is a literature review on Demand Driven Material Requirements Planning (DDMRP). The fourth section (2.4) brings the preliminary results of the literature review. The final section of this chapter (2.5) is a literature review on AHP, the data collection method chosen by the author.

\subsection{Supply Chain Management}

According to Lambert, Cooper and Pagh (1998) the term SCM was introduced firstly by consultants in the early 1980's and has subsequently gained tremendous attention. As stated by the authors, since the 90's academics have been attempting to give structure to it.

To provide a formal definition for SCM, Lambert, Cooper and Pagh (1998) used the version developed in 1994 and modified in 1998 by the Global Supply Chain Forum (GSCF). To them Supply Chain Management is the integration of key business processes from end user through original suppliers that provides products, services, and information that add value for customers and other stakeholders.

Mentzer et al. (2001) in a literature review to define the term, including the definition provided by Lambert, Cooper and Pagh (1998), defined SCM as it follows: "SCM is the systemic, strategic coordination of the traditional business functions and the tactics across these business functions within a particular company and across businesses within the supply chain, for the purposes of improving the long-term performance of the individual companies and the supply chain as a whole."

Nowadays terms are being added to nominate new theories and practices, such as Demand Driven Supply Chain (Cecere et al., 2004) and Green Supply Chain (Srivastava, 2007). According to Emmet and Crocker (2006) network is replacing the term chain in an attempt to find new ways to show how thinking and practice are evolving, but the definition still has the fundamental aspects.

According to Lambert and Enz (2017) a new definition was provided by Lambert (2014) this time including relationships, network of organizations and the cross-functionality of processes. Lambert (2014) defined SCM as: "the management of relationships in the network 
of organizations, from end customers through original suppliers, using key cross-functional business processes to create value for customer and other stakeholders".

Through analysis of the definitions, Brandão (2018) stated three fundamental aspects: (1) movement - flow - of materials, resources, information which goes through the interrelations; (2) coordination of the flow, activities, processes and chain links synchronism; (3) optimization in the use of resources and customer satisfaction.

Different authors worked to structure SCM conceptually, proposing models to elaborate, guide and evaluate the relations in the supply chain in order to develop better management practices.

According to Lambert, García-Dastugue and Croxton (2005) there were five SCM frameworks that recognize the need to implement business processes in the literature, each one with distinctive characteristics and objectives. According to the authors, four of the five SCM frameworks suggest the implementation of standard cross-functional business processes. However, only two of those four, the GSCF and the SCOR frameworks, include business processes that could be used by management to achieve this integration.

Lambert and Enz (2017) when giving an overview on the The Supply Chain Operations Reference (SCOR), state that the framework started being developed in 1996 by the SupplyChain Council (SCC) with four business processes: plan, source, make and deliver, to be implemented within the firm and eventually connected across firms in the supply chain. Two more processes were added until 2012, returns and enable, giving the SCOR model its most recent structure.

SCOR and GSCF framework are similar in that they both advocate cross-functional involvement and recognize that business processes will not replace corporate functions. However, the number of corporate functions included in each framework is different and the type of cross-functional involvement differs as well. In case of SCOR, the cross-functional involvement is pursued primarily within three functions: logistics, production and purchasing (LAMBERT; ENZ, 2017).

According to Lambert, Garcia-Dastugue and Croxton (2005) focusing on three functions might make SCOR easier to implement but management is attempting to manage the supply chain without critical input from marketing, finance, and research and development. Those functions left out have the potential to maliciously or inadvertently undermine the initiatives.

Several of the companies that helped to develop the GSCF framework are using SCOR. According to interviewed managers, SCOR is a useful tool for identifying areas of improvement to achieve quick payback opportunities and achieve cost reductions and asset efficiency. The 
GSCF framework is more strategic and focuses on increasing long-term shareholder value through closer cross-functional relationships with key members of the supply chain (LAMBERT; GARCIA-DASTUGUE; CROXTON. 2005).

Because of its breadth, the GSCF framework was chosen to be the foundation of this research. The higher number of corporate functions provide more room for analysis and identification of possible impacts due to DDMRP implementation. The following topics of this literature review describe in detail the GSCF SCM framework, with its main processes, strategic and operational sub-processes.

\subsubsection{GSCF SCM Framework}

The GSCF defines supply chain management as "the integration of key business processes from end user through original suppliers that provides products, services, and information that add value for customer and other stakeholders" (Lambert, Cooper and Pagh, 1998).

In order to create a framework to guide and orient the implementation and management of the supply chains, Cooper, Lambert and Pagh (1997) presented a conceptual model that later would be called the GSCF Framework. Their model considers the companies and their relations across the supply chain as well as three fundamental elements.

Lambert and Enz (2017) highlights several aspects that made the research, which started at 1992, unique at the time, but the two most significant were that the members of the research center would be executives from non-competing companies and the executives would determine the research agenda. The mission was to provide the opportunity for leading practitioners and academics to pursue the critical issues related to achieving excellence in SCM.

The executives were unanimous in their belief that the long-term success of their organizations would depend on the ability to collaborate with key customers and suppliers. The executives identified 18 relationships that were considered good partnerships and studied them believing that, if they studied these good relationships, the team would learn what made them successful so they could build more relationships like these and have fewer relationships that failed to meet expectations. A multiple case study approach was used to increase the robustness and the managerial meaningfulness of the findings (LAMBERT; ENZ, 2017). 
According to Cooper, Lambert and Pagh (1997), on the proposed model, the three fundamental elements are: the supply chain network structure, the supply chain business processes, and the management components as shown in Figure 6.

Figure 6 - SCM Framework Elements

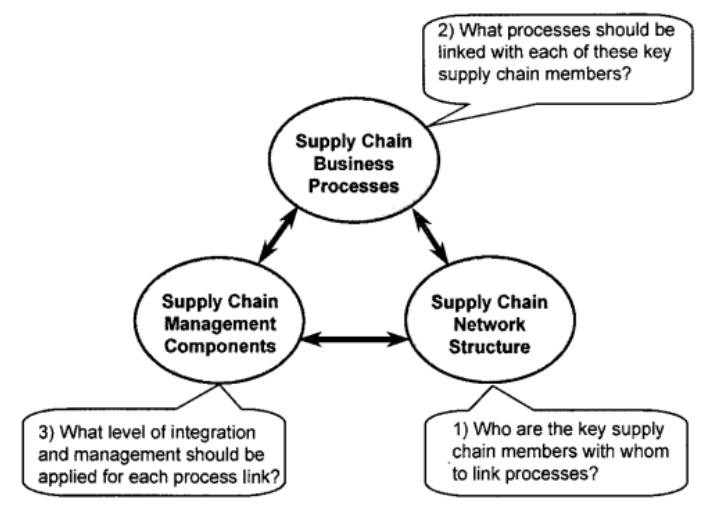

Source: Cooper, Lambert and Pagh (1997)

\subsubsection{Supply Chain Network Structure}

Lambert and Cooper (2000) describe the supply chain network structure as the links between the member firms of a supply chain. According to them, all firms participate in a supply chain, from the raw materials to the ultimate consumer. How much of this supply chain needs to be managed depends on several factors including the complexity of the product, the number of available suppliers and the availability of raw materials.

For most manufacturers, the supply chain looks less like a pipeline or chain than an uprooted tree, where the branches and roots are the extensive network of customers and suppliers (COOPER et al., 1997). The question is how many of these branches and roots need to be managed. The closeness of the relationship at different points in the supply chain will differ (LAMBERT; COOPER, 2000).

According to Cooper and Gardner (1993) not all links throughout the supply chain should be closely coordinated and integrated. The most appropriate relationship is the one that best fits the specific sets of circumstances. Other authors support the idea of different relationships for different sets of circumstances.

Ayers and Malmberg (2002) states that consumer base are not monolithic, and some cases demand different supply chains and different systems for each type of customer. Supporting the same idea, Gattorna (2009) wrote on his book that companies that have a 
superior performance recognizes the differences across its supply chains and aligns the value delivery strategy according to those differences.

It is important to have an explicit knowledge and understanding of how the supply chain network structure is configured. To this, it is important to know (1) the members of the supply chain, (2) the structural dimension of the network, and (3) the different types of process links across the supply chain (LAMBERT; COOPER, 2000).

Regarding the identification of Supply Chain members, Lambert and Cooper (2000) affirms that when determining the network structure, it is necessary to identify who the members are and which one of them are critical to the success of the company and the supply chain and, thus, should be allocated managerial attention and resources. The members include all companies/organizations with whom the focal company interacts directly or indirectly through its suppliers or customers, from point of origin to point of consumption.

To make the networks more manageable, it is necessary to distinguish between primary and supporting members. Primary members of a supply chain are all those autonomous companies or strategic business units who carry out value-adding activities (managerial and/or operational) in the business processes designed to produce a specific output for a particular customer or market (LAMBERT; COOPER, 2000).

The differentiation between primary and supporting members is important because, according to Lambert and Cooper (2000), after the definition, it is possible to define the point of origin and the point of consumption of the supply chain. The origin occurs where no previous primary suppliers exist. The consumption is where no further value is added, and the product and/or service is consumed.

Regarding the structural dimension of the network, Lambert and Cooper (2000) raises three structural dimensions of the network that are essential to describe, analyze and manage the supply chain. These dimensions are the horizontal structure, the vertical structure, and the horizontal position of the focal company within the end points of the supply chain.

The first dimension, horizontal structure, refers to the numbers of tiers across the supply chain. It may be long, with numerous tiers, or short, with few tiers. The second dimension, the vertical structure, refers to the number of suppliers/customers represented within each tier. A company can have a narrow vertical structure, with few companies at each tier level, or a wide vertical structure with many suppliers and/or customers at each tier level. The third structural dimension is the company's horizontal position within the supply chain. A company can be 
positioned at or near the initial source of supply, be at or near to the ultimate customer, or somewhere between these end points of the supply chain. (LAMBERT; COOPER, 2000)

Lambert and Cooper (2000) also highlights how the supply chains looks different from each company's perspective, since management of each company sees its firm as the focal company and views membership and network structure differently. However, the fact that each firm is a member of the other's supply chain, it is important for management of each firm to understand their interrelated roles and perspectives.

\subsubsection{Supply Chain Business Processes}

The integration up and downstream in a supply chain cannot be achieved if there is no common understanding among the processes in different firms part of the same supply chain. Croxton et al. (2001), in supporting to this statement, says that to build links between the supply chain members it is necessary for companies to implement a standard set of supply chains processes. Practitioners and educators need a common definition of SCM and a shared understanding of the processes.

In the GSCF framework, eight key business processes identified run the length of the supply chain and cut across firms and functional silos within each firm (see Figure 7).

Figure 7 - GSCF Framework

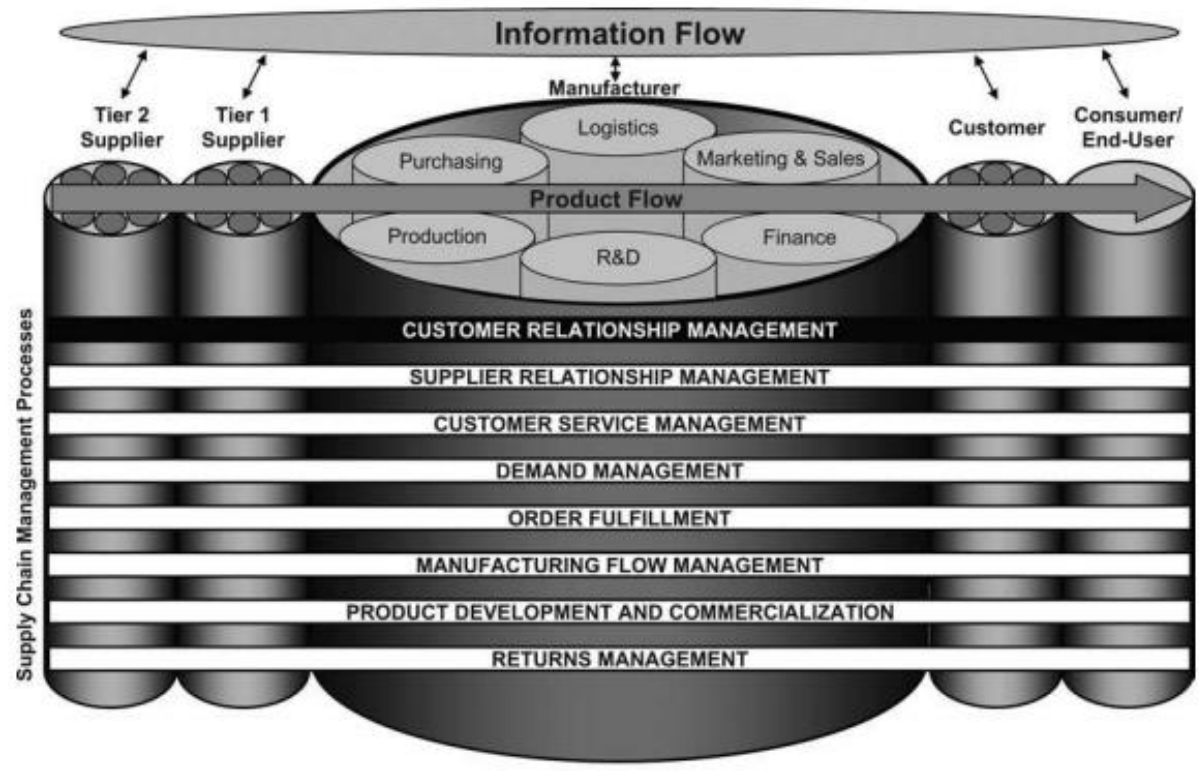

Source: Lambert (2009)

The first thing you see on the image, above all the flows, being shared by all its nodes, is the information flow. According to Power (2005) one of the main elements which allows 
supply chain integration. Fiala (2005) exposes how an information asymmetry is a source of inefficiency in supply and the precise exchange of information across supply chain is a very important issue for coordinating actions of units.

Below it, the functional silos are shown, from the perspective of the manufacturer, in the center of the Supply Chain. The functional silos include Marketing, Research and Development, Finance, Production, Purchasing and Logistics and is replicated to the others nodes of the supply chain. Activities in these processes reside inside a functional silo, but an entire process will not be contained within one function (CROXTON et. al, 2001).

The silos are interconnected by material, financial, information and decisional flow, since the supplier to the end customer, adding value through the network until its end. Those flows go through each of the eight key processes identified by the GSCF from the first supplier to the end-customer, except return management, which flows on the opposite way.

Lambert and Cooper (2000) were the first to describe each of the eight processes in detail. Croxton et al. (2001) expanded its work to also describe the activities that make them, the interfaces between each of the processes and the interactions between function and key members of the supply chain.

All the processes, sub-processes and its relationships are explained in a detailed manner in the Appendix D of the current thesis.

\subsubsection{Supply Chain Management Components}

The SCM management components are the third element of the SCM framework (see Figure 6) according to Lambert and Cooper (2001). Nine management components for successful SCM were identified by the authors: planning and control; work structure; organization structure; product flow facility structure; information flow facility structure; management methods; power and leadership structure; risk and reward structure; and culture and attitude.

One of the essential underlying premises of the SCM framework is that these management components are common across all business processes and members of the supply chain. It is the management of these common components that is important, since they determine how the business processes, and thus the supply chain, are managed and structured (COOPER; LAMBERT; PAGH, 1997). 
Lambert and Cooper (2001) divided the management components in two groups (see Figure 8). The first group is the physical and technical group, which includes the most visible, tangible, measurable and easy-to-change components. The second group is comprised of the managerial and behavioral components. These components are less tangible and visible and are often difficult to assess and alter.

Figure 8 - Supply Chain Management Components

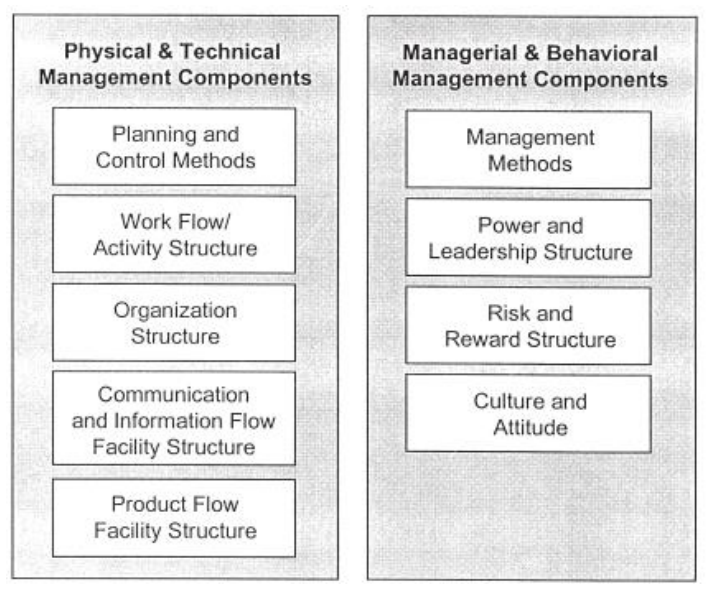

Source: Lambert and Cooper (2001)

Lambert and Cooper (2001) found through a review on change management literature that if one focus only in the first group, the results will be disappointing at best. According to the authors, both groups must be aligned to improve competitiveness and profitability of the supply chain.

Later, these groups were renamed and amplified as the research team continued the study on factors that determine the successful integration of the supply chain processes as shown in Figure 9 (LAMBERT; ENZ, 2017).

Figure 9 - Updated Supply Chain Management Components
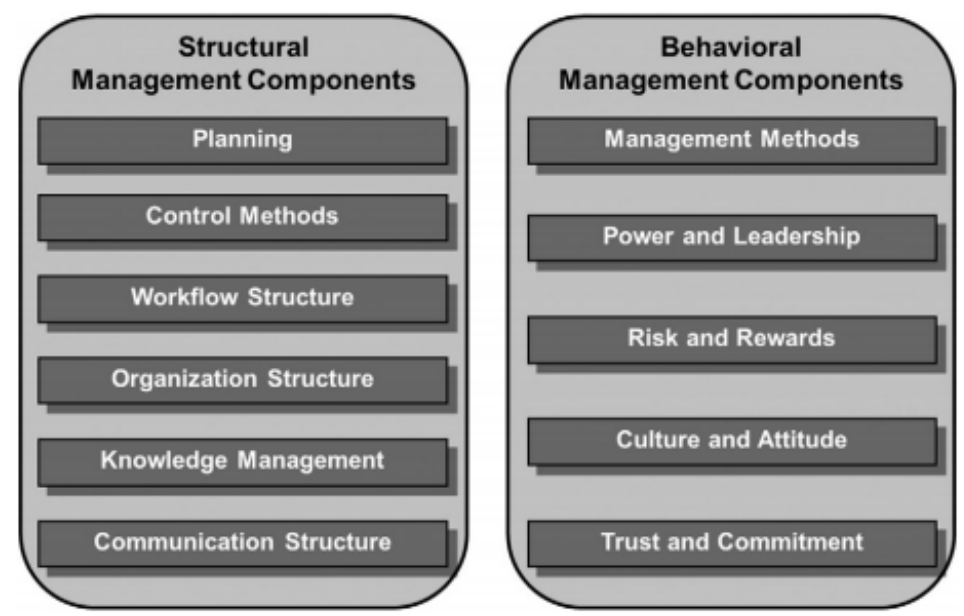

Source: Lambert and Enz (2017) 
The "physical and technical management components" were renamed "structural management components" and the "managerial and behavioral management components" were renamed "behavioral management components". The planning and control methods were separated into a planning component and a control methods component. Communication and information flow facility structure were broken into two categories: knowledge management and communication structure. Product flow facility was removed from the managerial components and trust and commitment was added as a behavioral management component (LAMBERT; ENZ, 2017).

\subsubsection{The Agile Paradigm in Supply Chain Management}

Agility is a business-wide capability that embraces organizational structures, information systems, logistics processes, and, in particular, mindsets. A key characteristic of an agile organization is flexibility. The origins of agility as a business concept lies in flexible manufacturing systems (FMS) (CHRISTOPHER, 2000).

According to Blome et al. (2013) the concept of agility has experienced increasing attention in production and Supply Chain Management research due to its importance for managerial practice, in which agility was seen as an emerging competitive weapon, a requirement for world class manufacturing performance and as a new paradigm in manufacturing.

Dove (1994) and later Fisher (1997) were the first researchers to consider agility together with the concept of Supply Chain Management. However, the description of Agile Supply Chains came a little bit latter, with Towill (1997) and Mason-Jones and Towill (1999).

Enhancing the term, focusing on supply chains, Naylor et al. (1999) defines and agility as the use of market knowledge and virtual corporations to exploit opportunities to profit in an unstable environment. In a broader context, Christopher (2000), relates supply chain agility to both business processes and the interfaces between these processes and the market. As stated by Christopher (2000), companies which focus on agility have market sensitivity and will profit on using its supply chains to rapidly answer to unexpected changes at low costs.

An agile supply chain empathizes the market sensitivity and a rapid answer to customer needs. To provide its elements, the supply chain must improve its processes and its functional integration using advanced manufacturing and information technologies (GUNASEKARAN; YUSUF, 2002). 
As stated by Roh et al. (2014), agile supply chains can rapidly transmit the customer real time demand to all manufacturing processes to ease the connectivity between the IT systems and processes coordination among different functions. According to Qi et al. (2017), the agile supply chain encourages the integration with external partners to generate opportunities and to enable companies to create value and detect rapidly demand variations.

According to Swafford et al. (2008) organizations with agile supply chain respond better to unpredicted events. Besides, agile supply chains are inherently more focused on the market because they are better in synchronize supply and demand.

In its description of agile supply chains, Christopher et al. (2004) discuss four distinct characteristics that they have:

1) Market Sensitivity: Being close to customer and capture trends as they emerge using a variety of means. Data is analyzed daily and is used to determine replenishment requirements where the intention is to continue to make the product available

2) Virtual Integration: The agile supply chain is virtual in the sense that it is connect and integrated through shared information on real demand so that all the players in the chain are all working in the same set of numbers.

3) Network Based: A distinguishing feature of agile companies is their use of flexible arrangements with a wide supply base. In an agile network there is a tendency for the focal firm to act as the 'orchestrator' of the network, the membership of which will change according to requirements.

4) Process alignment: Responsive supply chains require a high level of process alignment both within the company and externally with upstream and downstream partners. By process alignment is meant the ability to create 'boundaryless' connections, where there are no delays caused by hand-offs or buffers between the different stages in the chain.

Agarwal et al. (2007) on its work on modeling the agility of supply chain, found 15 variables that are present in agile supply chains: (1) Market Sensitiveness; (2) Delivery Speed; (3) Data accuracy; (4) New Product Introduction; (5) Centralized and collaborative planning; (6) Process Integration; (7) Use of IT tools; (8) Lead Time Reduction; (9) Service Level Improvement; (10) Cost Minimization; (11) Customer Satisfaction; (12) Quality Improvement; (13) Minimizing Uncertainty; (14) Trust Development; (15) Minimizing Resistance to Change. Some of the identified variables are characteristics of Demand Driven Supply Chains (DDSC). As stated by Cecere et al. (2004), a demand-driven supply chain is defined as a supply 
chain in which every part involved are sensitive and responsive to the demand information from the end customer and answers to its demand variability rapidly and with low cost.

To cope with the emerging demand driven environment and enable companies to become more responsive to changing markets, new approaches were developed, among them, the rethinking of MRP logic, called Demand Driven MRP (DDMRP).

\subsection{The Demand Driven Material Requirements Planning (DDMRP)}

The term "demand driven" was originally defined as the ability to "sense changing customer demand and adapt planning and production while pulling from suppliers all in real time". The term was pioneered in 2002, but the original definition still works in today's more mature and larger demand driven body of knowledge (PTAK; SMITH, 2016).

Created by Carol Ptak and Chad Smith, DDMRP was first presented in the third edition of Orlicky's Material Requirements Planning in 2011 (PTAK; SMITH, 2011) and in the Demand Driven Material Requirements Planning (DDMRP) book (PTAK; SMITH, 2016).

DDMRP is a fundamental rethinking of the MRP logic - drawing elements of Lean Systems and TOC to improve the overall performance and effectiveness of the MRP logic. This rethinking challenged some of the fundamental assumptions of MRP, such as the replacement of safety stock by dynamic buffers (MICLO et al. 2019).

As stated by Miclo (2016), in order to cope with current market issues, DDMRP uses well-known concepts taken from MRP (Material Requirements Planning), DRP (Distribution Requirements Planning), Lean, Six Sigma, and TOC (Theory Of Constraints) along with specific innovations (see Figure 10).

Figure 10 - DDMRP pillars

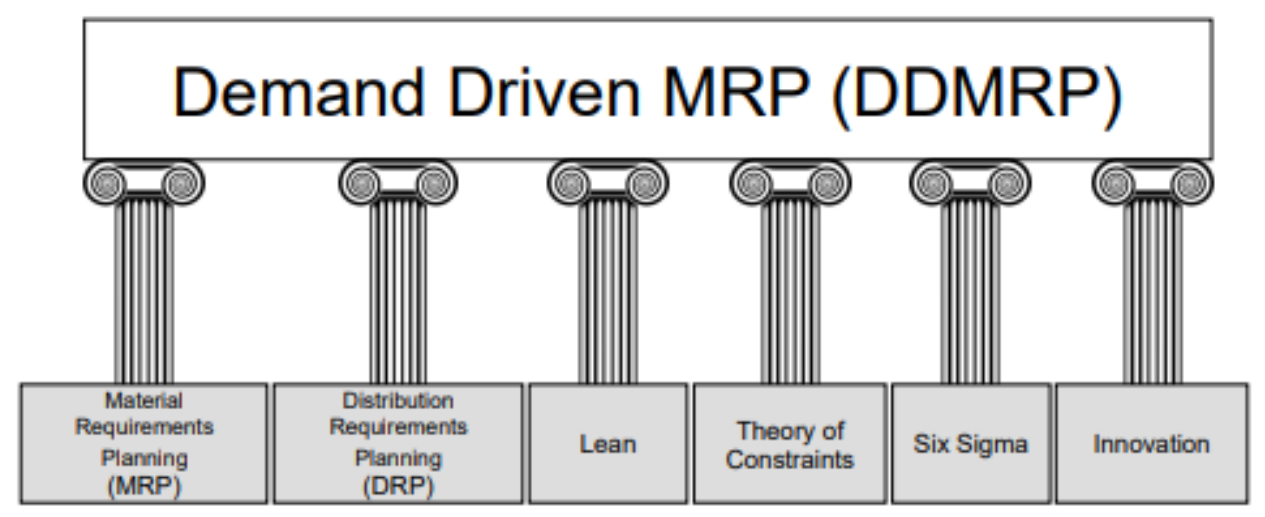

Source: Ptak and Smith (2016) 
DDMRP is divided into 3 steps and 5 components (see Figure 11). The first step, position, consists in determining where to position the decoupling points (or push/pull boundaries, as discussed above). Then the flow is protected with buffers that are sized and dynamically adjusted according to the demand level. Finally, the flow is pulled firstly with demand driven planning which enables the supply orders to be generated. It is then possible to move to execution phase which is a daily visual and collaborative management step (MICLO, 2016).

Figure 11 - DDMRP implementation model

\begin{tabular}{|c|c|c|c|c|}
\hline \multicolumn{5}{|c|}{ Demand Driven Material Requirements Planning } \\
\hline $\begin{array}{c}\text { Strategic } \\
\text { Inventory } \\
\text { Positioning }\end{array}$ & $\begin{array}{c}\text { Buffer Profiles } \\
\text { and Levels }\end{array}$ & $\begin{array}{c}\text { Dynamic } \\
\text { Adjustments }\end{array}$ & $\begin{array}{c}\text { Demand Driven } \\
\text { Planning }\end{array}$ & $\begin{array}{c}\text { Visible and } \\
\text { Collaborative } \\
\text { Execution }\end{array}$ \\
\hline Position & \multicolumn{3}{|c|}{ Protect } & \multicolumn{3}{|c|}{ Pull } \\
\hline
\end{tabular}

Source: Ptak and Smith (2016)

The first three components essentially define the initial and evolving configuration of a DDMRP model. Strategic inventory positioning will determine where the decoupling points are placed. Buffer profiles and levels will determine the amount of protection at those decoupling point. Dynamic adjustments define how that level of protection flexes up or down based on operating parameters, market changes, and planned or known future events (PTAK; SMITH, 2016).

The fourth and fifth elements define the actual operational aspects of a DDMRP system: planning and execution. In DDMRP, demand driven planning is the process by which supply orders (purchase orders, manufacturing orders, and stock transfer orders) are generated. Visible and collaborative execution is the process by which a DDMRP system manages open supply orders (PTAK; SMITH, 2016).

According to Ptak and Smith (2016) the purpose of DDMRP is to create integrated and robust supply chain design and control solution where companies can improve Return-OverInvestiment (ROI) by having less bullwhip effect in the whole chain through better responsiveness and visibility in the chain. The beauty of DDMRP is its comprehensive approach on connecting different theories into simplified, practical and easy to follow solutions. Each of the previous steps are explained in detail in the following sections of this thesis. 


\subsubsection{Strategic Inventory Positioning}

The key to protecting and promoting the flow of relevant information requires the use of decoupling points. Decoupling enables a bidirectional benefit - it mitigates the demand signal distortion (relevant information) and supply continuity variability (relevant materials) inherent in the bullwhip effect (PTAK; SMITH, 2016).

As stated by Ptak and Smith (2016) the first component of DDMRP is determining where the decoupling points and their respective buffers should be placed. This component becomes the cornerstone of the Demand Driven Operating Model. The selection of these points is a strategic decision that influences the performance of the supply-demand network in many regards.

How to answer properly where the decoupling points should be placed, we must consider six key factors as described by Ptak and Smith (2016):

(1) Customer tolerance time: the amount of time potential customers are willing to wait for delivery of a good or a service;

(2) Market potential lead time: this lead time will allow an increase of price or the capture of additional business through either existing or new customer channels. For example, a one-week reduction in lead time may only result in an increase in orders, whereas a two-week reduction could result in both an increase in orders and a potential price increase in some of those orders;

(3) Sales order visibility horizon: the time frame in which we typically become aware of sales orders or actual dependent demand;

(4) External variability: "Demand variability: the potential for swings and spikes in demand that could overwhelm resources. Supply variability: The potential for and severity of disruptions in sources of supply and/or specific suppliers";

(5) Inventory leverage and flexibility: places in the integrated bill of material (BOM) structure or the distribution network that provide a company with the most available options as well as the best lead time compression to meet the business needs;

(6) Critical operation protection: The same way that variability can impact a BOM, the longer and more complex the routing structure and dependent chain of events, the more important it can be to protect identified key areas.

According to Ptak and Smith (2016) the six factors must be applied systematically across the entire BOM, routing structure, manufacturing facilities, and supply-demand network 
to determine the best decoupling positions for purchased, manufactured and finished items in order to protect and promote the flow of relevant information and drive ROI performance.

The addition of decoupling points disrupts the traditional concepts of lead-times in manufacturing. Its use for manufactured parts brings a new form of lead-time that only assumes availability of the component on parent order release at decoupling points. This new form of lead-time is called decoupled lead-time (DLT). It can be defined as: the longest cumulative coupled lead time chain in a manufactured item's product structure It is a form of cumulative lead time but is limited and defined by the placement of decoupling points within a product structure (PTAK; SMITH, 2016).

To explain the DLT, Miclo (2016) summarizes Ptak and Smith (2016) explanation. Using an article BOM named FPD for Final Product D, the FPD end item is composed of several subassembly parts manufactured from 3 purchased components (401P, 410P and 412P) with respectively 10, 45 and 45 lead time days. The manufacturing lead times for each reference is the value in the circle (in days). A DDMRP buffer positioning scenario is also defined for this $\mathrm{BOM}$ in the right side of the Figure 12.

Figure 12 - DDMRP buffer positioning scenario
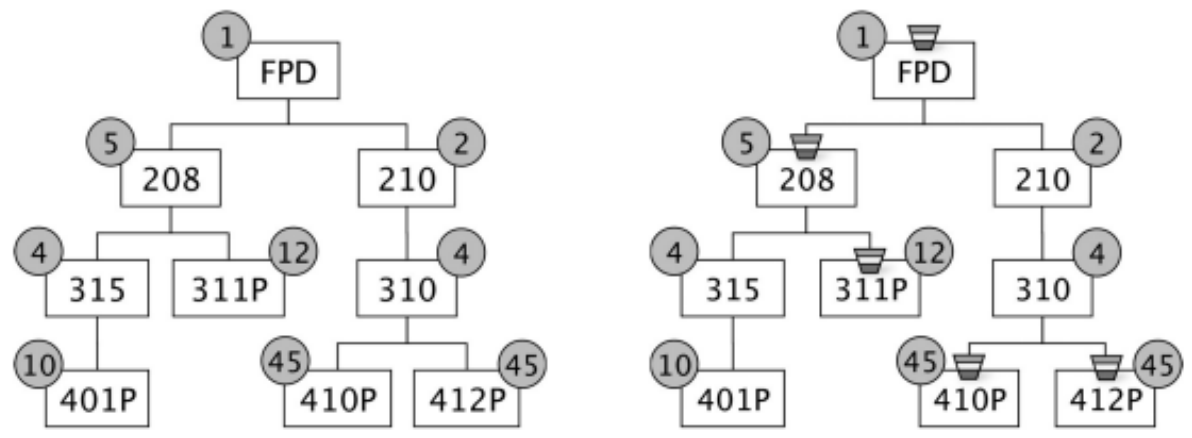

Source: Ptak and Smith (2016)

In this buffer positioning scenario, DLT for FPD item would be the longest between "1" (because 208 is buffered) and "7" (1 for FPD, 2 for 210 and 4 for 310), so FPD DLT is 7.

In addition, Ptak and Smith (2016) states that since conventional material planning systems were not designed to use decoupling points, this form of lead time has remained hidden or at best obscured for decades. By using the DLT information, planners can now determine more realistic dates for the replenishment of parts and the inventory levels required for the decoupling points buffers. 


\subsubsection{Buffer Profiles and Levels}

Following the steps developed by Ptak and Smith (2016), after placing the decoupling points, the next step is to develop the mechanism that allows a decoupling point to stay decoupled - a buffer. In this case, the buffer will be a level of stock that is carefully sized and maintained in order to protect a decoupling point. Buffers are the heart of a DDMRP system and serve three primary purposes:

(1) Shock absorption. Dampening both supply and demand variability significantly reduces or eliminates the transfer of variability that creates nervousness and the bullwhip effect.

(2) Lead time compression. By decoupling supplier lead times from the consumption side of the buffer, lead times are instantly compressed.

(3) Supply order generation. All relevant demand information, supply information, and on-hand information are combined at the buffer to produce a "net flow" equation that determines supply order generation.

The buffers, as suggested by Ptak and Smith (2016) are divided in parts, which levers are determined by summing the zones that comprise them. Mainly, the buffers are comprised of three zones.

Green Zone: The green zone is the heart of the supply order generation process. It determines average order frequency and typical order size. The green zone is determined by one of three factors. Whichever factor yields the greatest number determines the size of the green zone.

Yellow Zone: The yellow zone is the hearth of the inventory coverage in the buffer. The yellow zone is always calculated as 100 percent average daily usage (ADU) x decoupled lead time (DLT).

Red Zone: The red zone is the embedded safety in the buffer. The higher the variability associated with the part or SKU, the larger the red zone will be. Calculating the red zone is accomplished with three sequential equations.

The Figure 13 represents a summary of the purposes and calculations for a DDMRP buffer. Performing the calculation for each of these zones is accomplished through a combination of a grouping assignment (called buffer profiles) and individual part attributes. 
Figure 13 - DDMRP buffer levels representation

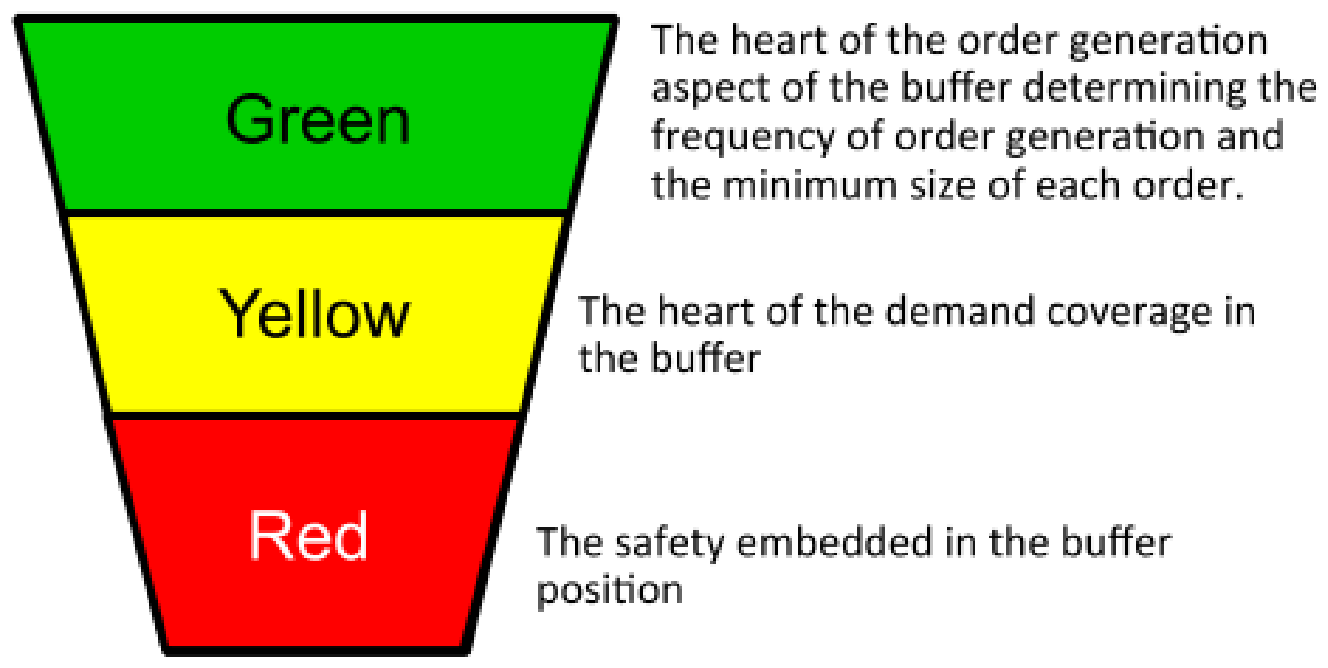

Source: Ptak and Smith (2016)

Three factors define the buffer profiles and zones (PTAK; SMITH, 2016). Miclo (2016) provides an excellent summary of those factors based on the work of Ptak and Smith (2011, 2016).

Four individual part parameters are required as well as three buffer profile parameters in order to size the three zones. The four individual part parameters are:

- Location: for distributed parts, this will have an impact on the buffer sizing

- Decoupling Lead Time (DLT): according to the part's lead time, the zone profiles will be differently sized. Indeed, dependind on wheter a part has a short or long lead time, its behavior and management will be adapted.

- Minimum Order Quantity (MOQ): if there is a significant MOQ, the means of generating supply orders must also be adapted.

- Average Daily Usage (ADU): all the stock buffer zones will be proportional to daily consumption.

Then, the parts will be assigned to buffer profiles. These profiles will be organized depending on the three buffer profile parameters listed below:

Factor 1: Item type indicate whether the decoupled item is manufactured $(\mathrm{M})$, purchased $(\mathrm{P})$, and distributed (D). Reason for grouping items in these three groups is due to the different lead time horizons between the groups where "short" one-week lead time of purchase part would not necessarily be "short" lead time for manufactured part.

Factor 2: Lead time is categorized into three groups: short, medium, and long. Again, it is important to cluster lead times separately per each item type - P, M and D - since the 
comparison between them can be misleading. The lead time category will ne used to supply a "lead time factor" to parts within a profile.

Factor 3: Variability is segmented into three groups: high, medium and low and is analyzed from supply and demand perspectives. In Figure 14 below is presented how the segmentation for both supply and demand variability can be done when defining heuristically the variability factor for each part or SKU from different item type categories.

Figure 14 - Supply and demand variability segmentation

\begin{tabular}{|l|l|l|l|}
\cline { 2 - 4 } \multicolumn{1}{c|}{} & High & Medium & Low \\
\hline $\begin{array}{l}\text { Supply } \\
\text { variability }\end{array}$ & $\begin{array}{l}\text { "Frequent supply } \\
\text { disruptions" }\end{array}$ & $\begin{array}{l}\text { "Occasional supply } \\
\text { disruptions" }\end{array}$ & $\begin{array}{l}\text { "Reliable supply (either a highly } \\
\text { reliable single source or multiple } \\
\text { alternate sources that can react } \\
\text { within the purchasing lead time" }\end{array}$ \\
\hline $\begin{array}{l}\text { Demand } \\
\text { variability }\end{array}$ & $\begin{array}{l}\text { "Subject to frequent } \\
\text { spikes" }\end{array}$ & $\begin{array}{l}\text { "Subject to } \\
\text { occasional spikes" }\end{array}$ & $\begin{array}{l}\text { "Little to no spike activity - its } \\
\text { demand is relatively stable" }\end{array}$ \\
\hline
\end{tabular}

Source: Adapted from Hietikko (2014)

Miclo (2016) noted that the last two parameters have no mathematical definition. They must be defined from experience (or common sense) with some rules. After all the factors are defined, the calculation for each zone of the buffer can be performed. The Figure 15 shows the parameters required to size the stock buffers.

Figure 15 - Stock Buffer Sizing Representation

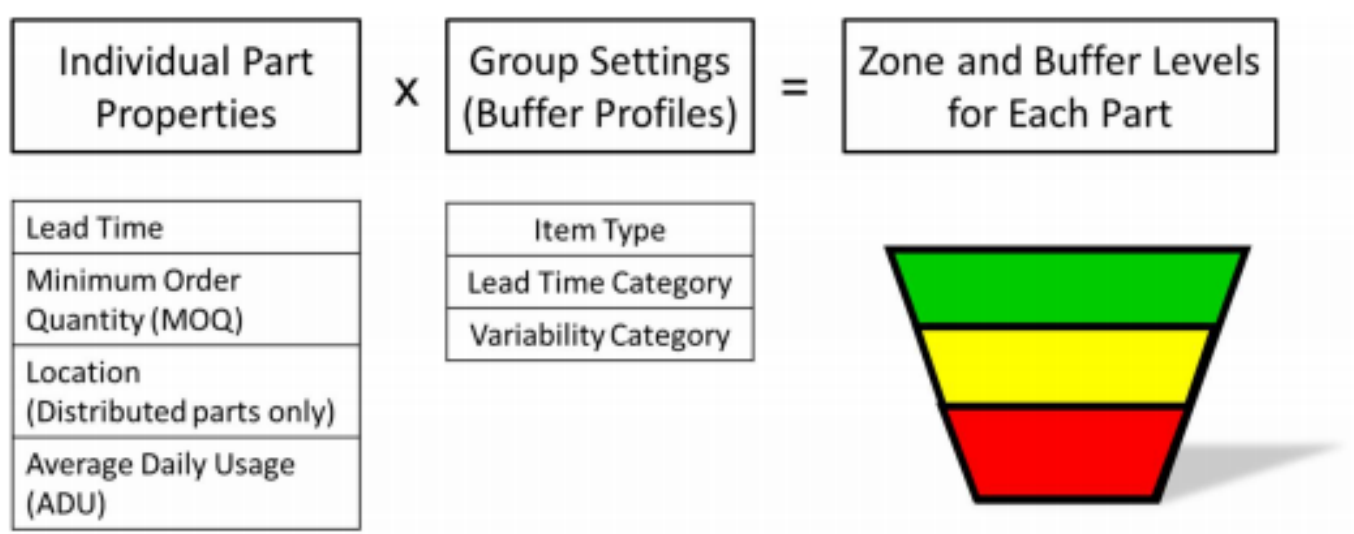

Source: Ptak and Smith (2016)

With all this data, stock buffers can be sized according to in Inventory position point of view. First step is the Yellow zone. It is calculated as follows:

Yellow zone $=$ ADU $x$ DLW 
Then, the Red zone can be calculated. It is composed of a Red zone base and a Red zone safety. The first zone is based on lead time and the safety zone is sized to absorb variability (demand and supply).

$$
\begin{aligned}
& \text { Red zone base }=\text { Yellow zone } \mathrm{x} \text { Lead Time factor }(\mathrm{LTF}) \\
& \text { Red zone safety = Red zone base x Variability factor (VF) } \\
& \text { Red zone = Red zone base }+ \text { Red zone safety }
\end{aligned}
$$

According to Miclo (2016) the current hypothesis made in DDMRP is that the lead time and variability factors must be adapted to the company context. However, Ptak and Smith (2016) provides some categories for both lead time and variability factors (Figure 16).

Figure 16 - LT and Variability in Red Zone Calculation

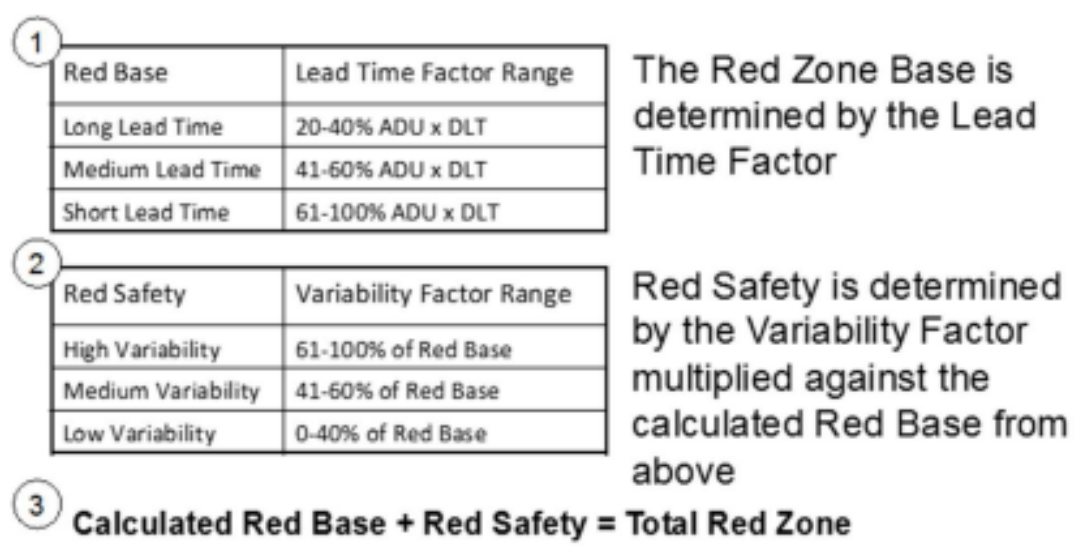

Source: Ptak and Smith (2016)

Notice that the longer the lead time of the part, the smaller the lead time factor should be. A smaller lead time factor produces a smaller green zone calculation. Since the green zone determines average order size and frequency, a smaller lead time factor will lead to smaller and more frequent orders. This may seem counterintuitive for many planners and buyers, but the DDMRP approach forces as frequent ordering as possible for long lead time parts (until MOQ or imposed order cycle becomes a constraining factor) (PTAK; SMITH, 2016).

Finally, the green zone is "the heart of the order generation aspect of the buffer determining the frequency of order generation and the minimum size of each order. There are three ways to size the green zone:

Green zone $=$ Yellow Zone $\mathrm{x}$ Lead Time Factor

Green zone $=$ MOQ

Green zone $=$ ADU $x$ imposed or desired order cycle in days 
The lead time factor for the green zone does not necessarily be the same as the red zone lead time factor. The most convenient way to size the green zone is to choose the maximum value between (1), (2) and (3).

After the three zones are sized, "Top Of" equations are calculated. The Figure 17 represents a complete calculation of a buffer in DDMRP.

Figure 17 - DDMRP buffer calculation

(1) Top Of Red $(\mathrm{TOR})=$ Red zone

(2) Top Of Yellow (TOY) $=$ TOR + Yellow Zone

(3) Top Of Green (TOG) $=$ TOY + Green Zone

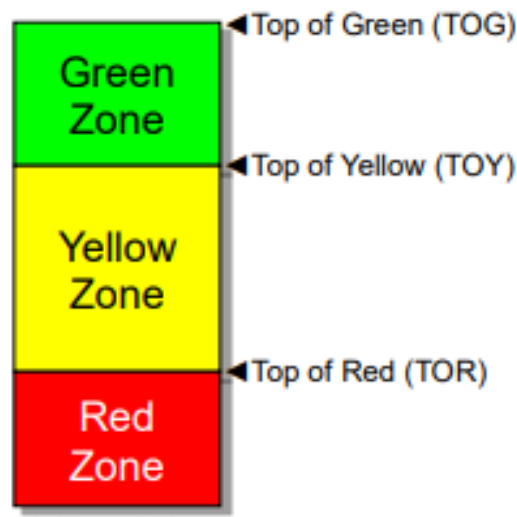

Source: Ptak and Smith (2016)

\subsubsection{Buffer Dynamic Adjustments}

Considering today's supply chains are incredibly dynamic, the buffers calculated must adjust and adapt to changing conditions. By understanding the equations to set the buffer zones, then the factors that can change a part's buffer over the course of time are also understood. These changes can come from part attribute changes or buffer profile changes (PTAK; SMITH, 2016).

\subsubsection{Recalculated and Planned Adjustments}

Recalculated adjustments are automated adjustments to buffer levels based on changes to individual part attributes or buffer profile adjustments. There are three critical factors for all buffered parts that directly impact the buffer equations: ADU, lead time and minimum order quantity (MOQ). ADU and lead-time tend to have the most dramatic impact because they are 
involved in all three zone determinations. The most dynamic part attribute is the ADU, as it is consistently being recalculated and updated (PTAK; SMITH, 2016).

In a DDMRP system, ADU will always be changing since it is frequently recalculated. Within some time periods the level of change could be relatively small, but it is changing nonetheless. Figure 18 shows the buffer zones adjusting over the course of a six-month period. As ADU quintuples over that period, the buffer adjusts up accordingly.

Figure 18 - Buffer zone adjustments

\begin{tabular}{|c|c|c|c|c|c|c|c|c|c|}
\hline Date & Red & Yellow & Green & ADU & $\begin{array}{l}\text { Red } \\
\text { Base }\end{array}$ & $\begin{array}{c}\text { Red } \\
\text { Safety }\end{array}$ & DLT & LTF & VF \\
\hline $01 /$ jan & 70 & 100 & 50 & 10 & 50 & 20 & 10 & 0,5 & 0,4 \\
\hline 15/jan & 105 & 150 & 75 & 15 & 75 & 30 & 10 & 0,5 & $\overline{0,4}$ \\
\hline $01 / \mathrm{fev}$ & 161 & 230 & 115 & 23 & 115 & 46 & 10 & 0,5 & 0,4 \\
\hline $15 / \mathrm{fev}$ & 266 & 380 & 190 & 38 & 190 & 76 & 10 & 0,5 & 0,4 \\
\hline $01 / \mathrm{mar}$ & 315 & 450 & 225 & 45 & 225 & 90 & 10 & 0,5 & 0,4 \\
\hline $15 / \mathrm{mar}$ & 364 & 520 & 260 & 52 & 260 & 104 & 10 & 0,5 & 0,4 \\
\hline $01 / a b r$ & 385 & 550 & 275 & 55 & 275 & 110 & 10 & 0,5 & 0,4 \\
\hline $15 / a b r$ & 406 & 580 & 290 & 58 & 290 & 116 & 10 & 0,5 & 0,4 \\
\hline 01/mai & 378 & 540 & 270 & 54 & 270 & 108 & 10 & 0,5 & 0,4 \\
\hline $15 / \mathrm{mai}$ & 392 & 560 & 280 & 56 & 280 & 112 & 10 & 0,5 & 0,4 \\
\hline 01/jun & 406 & 580 & 290 & 58 & 290 & 116 & 10 & 0,5 & 0,4 \\
\hline 15/jun & 371 & 530 & 265 & 53 & 265 & 106 & 10 & 0,5 & 0,4 \\
\hline
\end{tabular}

Source: Adapted from Ptak and Smith (2016)

Ptak and Smith (2016) also states that the other factors can change as well, so it is important to always track the decoupled lead time (DLT), lead time factor (LTF) and variability factor (VF), as a change in each of these factors will impact the buffer sizing.

In numerous sectors there are seasonality periods. DDMRP recommends the use of Planned Adjustment Factors (PAF) to manage this phenomenon. According to Ptak and Smith (2016) planned adjustments are based on certain strategic, historical, and business intelligence factors. These planned adjustments are manipulations of the buffer equation that affect inventory positions by raising or lowering buffer levels and their corresponding zones at certain points in time. These manipulations tend to be confined to demand manipulations, zonal manipulations or lead time manipulations.

\subsubsection{Planned Demand Adjustment Factor}

Demand manipulations are made through the demand adjustment factor (DAF). DAF is a manipulation of the ADU input within a specific time period. This manipulation occurs by 
adjusting the ADU to a historically proven or planned position base on an approved business case or as a reaction to rapid changes in demand within short periods.

As stated by Ptak and Smith (2016) buffers are only designed to absord variability to a certain extent. It can often be the case that variability up or down can threaten the effectiveness of the buffer to protect that decoupling point. DAF should be employed when variability threatens to overwhelm the buffers. In this case, the adjustment should be up. When variability will cause large amounts of prolonged excess inventory, the adjustment should be down.

DAF are used for common situations such as rapid changes in demand, product transition and seasonality. These planned adjustments separate what is known, the pattern of the demand, from what is unknown, the level of actual demand that will be experienced (PTAK; SMITH, 2016).

Another application of DAF occurs regarding seasonality. Many companies have products with seasonal uplifts and troughs that may pose challenges to DDMRP buffers if no properly addressed.

\subsubsection{Planned Zone Adjustment Factor}

Another way to adjust part buffers is through zonal manipulations. This could apply to the individual part or a group of parts affected in the same way by the adjustment. A zone adjustment factor can be applied to any of the three zones of a buffer. The zones serve different purposes, so the zone adjustment factor should apply to the appropriate zone based on the rationale for the adjustment (PTAK; SMITH, 2016).

Ptak and Smith (2016) summarizes the different types of zone adjustments and its effects in each different zone.

Green zone determines order size and frequency. Thus, when order size and frequency need to be adjusted, the green zone can be manipulated up or down. The green zone of certain items can be raised to create less frequent and larger orders to save the capacity lost in additional setups. Downward adjustments might occur when there is sufficient excess capacity, and market responsiveness is the key.

Yellow zone is the heart of demand coverage in the buffer. Typically, a yellow zone adjustment occurs as a response to a planned short-term promotional event or a planned or known supply disruption. A short-term promotional does not last long enough to justify a DAF schema. A factor can be applied to size the yellow zone to the expected demand within that 
time frame. A week promotion expected to triple sales for the week can justify a factor of 3 being applied to the yellow zone for that product/components.

Red zone is the embedded safety in the buffer. It should be adjusted when there is a known or planned but temporary change in volatility that does not warrant moving the parts to another buffer profile.

\subsubsection{Planned Lead Time Adjustment Factor}

As stated by Ptak and Smith (2016) a lead time adjustment factor could apply to an individual part or a group of parts affected in the same way by what is prompting the adjustment. The use of a lead time adjustment factor coincides with a planned or known expansion of the lead times of a group of items. For example, if a major transportation route to a warehouse will be temporarily disrupted due to construction, a lead time factor may need to be applied to products at the warehouse that come through that route.

\subsubsection{Demand Driven Planning}

The first three steps of the five components framework proposed by Ptak and Smith (2016) has only been related to model the DDMRP environment. The system now must be monitored. The last two components concern the planning and the execution steps.

The most relevant demand signal is a sales order. It is known and stated desire from a known customer to buy. Yet using this most accurate piece of demand information has eluded planning professionals for decades. Decoupling opens the door for its effective use. This highly accurate form of demand will provide the demand input into a daily planning equation for each buffered position. This equation is called the net flow equation (PTAK; SMITH, 2016).

The net flow equation provides the supply order generation recommendation signal (timing and quantity) for buffer replenishment. It is a key and unique aspect of DDMRP and should be performed daily on all decoupled positions. The net flow equation is simple:

On-hand + on-order - qualified sales order demand $=$ net flow position

On-hand is the quantity of stock that is physically available. On-order is the quantity of stock that has been ordered but not received, irrespective of time. This could be a single 
incoming order or several incoming orders. Qualified sales order demand is the sum of sales orders past due, sales orders due today and qualified spikes.

The net flow equation answers all the questions for any robust planning equation: (1) what do I have? The on-hand value; (2) that is coming to me? The on-order value; (3) what demand do I need to fulfill immediately? Sales order past due and due today; (4) what future demand is relevant? Qualified future spikes.

Two conditions must be met to qualify as an order spike. In DDMRP, an order spike is a qualifying quantity of known cumulative daily demand within a qualifying time window that threatens the integrity of the buffer. That means the qualifying level (order spike threshold OST) and the qualifying time window (order spike horizon - OSH) must be defined.

The setting of the threshold level involves determining a level of daily demand that jeopardizes the integrity of the buffer. Ptak and Smith (2016) explore three alternatives. The first two set the threshold in relation to the red zone of the buffer. In early DDMRP implementations a default heuristic spike threshold of 50 percent of the red zone. The second method relates to the border of the red base and red safety portion of the buffer for finished items, where spike threshold could be set for the amount equivalent to the red zone base value. The third method is related to the ADU of a specific part, where an order spike threshold (OST) is determined in multiples of the ADU.

No matter what method is used of OST determination, the OST should always be within the total red zone value. The red zone is the safety embedded in the buffer. Having an OST value greater than that total safety opens the door for insufficient coverage from the buffer.

The setting of the horizon involves setting a qualifying future time window within which cumulative daily demand can qualify as a spike if that cumulative daily value is above the OST. The OSH should be set to be at least one decoupled lead time in the future for the buffered part. This allows enough time for the part's buffer to properly compensate for the spike. If the order spike horizon is beyond the sales order visibility horizon, it means that qualified spikes will routinely appear within the order spike horizon. In this case the part's buffer profile should be set to a higher variability category to compensate for this late qualification.

\subsubsection{Supply Order Generation Based on Net Flow Position}

Each time net flow equation is computed for each buffer, it yields a number that is called the net flow position within each buffer. The net flow position will dictate whether a supply 
order will be recommended against the buffered position. If the position is below the top of yellow (TOY), then a supply order is recommended for a quantity that is the difference between the net flow position and the top of green (TOG) (PTAK; SMITH, 2016).

To help visualize, Ptak and Smith (2016) provide an example using the buffer positioning for the product 401P (see Figure 19). TOG is the sum of all the zones of a buffer. In the 401P example this is 10.888 . TOY is the sum of the yellow and red zones, which is 8.938 . TOR is the full quantity of the red zone, which is 2.438 . When the net flow position is at or below 8.938 , a supply order will be generated to restore the net flow position to TOG. This means that the typical order will be at least the full amount of the green zone (1.950) or greater.

Consider the following information for 401P:

$$
\begin{aligned}
& \text { On-hand }=2.652 \\
& \text { On-order }=6.233 \\
& \text { Qualified sales order demand }=712
\end{aligned}
$$

Figure 19 - Buffer positioning for item 401P

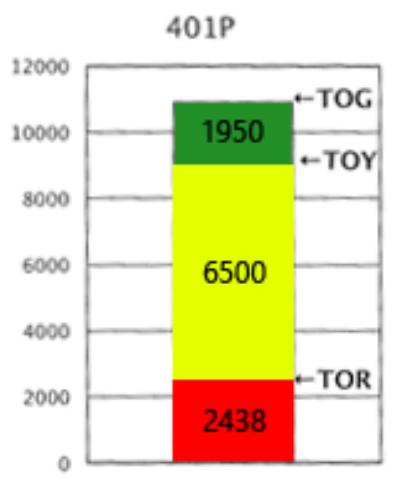

Source: Adapted from Ptak and Smith (2016)

Based on the information provided, the net flow position for 401P for this specific day is 8.173. This means the net flow position is below TOY. This creates a supply order recommendation of 2.715 . Once this supply order is approved, the net flow position changes to 10.888. The order recommendation has now become an on-order quantity. This increases the total on-order quantity to 8.948 ( 2.715 new on-order quantity +6.233 old on-order quantity). The net flow equation after order acceptance is 2.652 (on-hand) +8.948 (on-order) -712 (qualified sales order demand).

The net flow position is typically displayed as a percentage of TOG and with the zone color that the position falls within. In the 401P example, the net flow position would be displayed as 75.1 percent and be coded yellow. The Figure 20 shows a basic DDMRP planning screen. 
Figure 20 - DDMRP planning screen

\begin{tabular}{|c|c|c|c|c|c|c|c|c|c|c|c|}
\hline \multicolumn{12}{|c|}{ Taday's Date: 15 -July } \\
\hline Part\# & Planning Priority & On-Hand & On-Order & $\begin{array}{l}\text { Qualified } \\
\text { Demand }\end{array}$ & $\begin{array}{l}\text { Net Flow } \\
\text { Position }\end{array}$ & $\begin{array}{l}\text { Order } \\
\text { Recommendation }\end{array}$ & $\begin{array}{l}\text { Request } \\
\text { Date }\end{array}$ & Top RED & $\begin{array}{l}\text { Top } \\
\text { reLLow }\end{array}$ & $\begin{array}{l}\text { Top } \\
\text { GREEN }\end{array}$ & $\begin{array}{l}\text { Lead } \\
\text { Time }\end{array}$ \\
\hline 406P & RED $19.8 \mathrm{y}$ & 401 & 506 & 263 & 644 & 260 争 & 4.Aug & 750 & 2750 & 3250 & 20 \\
\hline $403 \mathrm{P}$ & YELOW 43.48 & 1412 & 981] & 412 & 1981 & 2579 & $23-\mathrm{Ju}$ & 1200 & 3600 & 4560 & 8 \\
\hline $402 \mathrm{P}$ & YELOWW $69.0 \%$ & 601 & 753 & 112 & 1242 & 558 & $24-\mathrm{Ju}$ & 540 & 1440 & 1800 & 9 \\
\hline $405 \mathrm{P}$ & YELLOW 74.0\% & 3400 & 4251 & 581 & 7070 & 2480 & 24-Ju! & 1756 & 7606 & 9556 & 9 \\
\hline $401 \mathrm{P}$ & YELLOW 75.19 & 2652 & 6233 & 712 & 8173 & 2715 & 25-Juा & 2438 & 8938 & 10888 & 10 \\
\hline $404 \mathrm{P}$ & GREEN 97.6\% & 1951 & 1560 & 291 & 3220 & d & & 1050 & 2550 & 3300 & 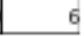 \\
\hline
\end{tabular}

Source: Ptak and Smith (2016)

The next part that is important to talk about is how the supply orders flow through the shop floor. Ptak and Smith (2016) explains the concept of decoupled explosion. When a supply order is generated at a higher level, decoupling stops the explosion of the bill of material at decoupling points placed at lower levels. The explosion can and will be stopped because that decoupling point is buffered. The net flow equation is then independently calculated at that point. Supply order generation only continues if that position's net flow equation calls for resupply. Under that condition, the explosion then begins again relative to that part's respective components (see Figure 21).

Figure 21 - Decoupled Explosion Representation

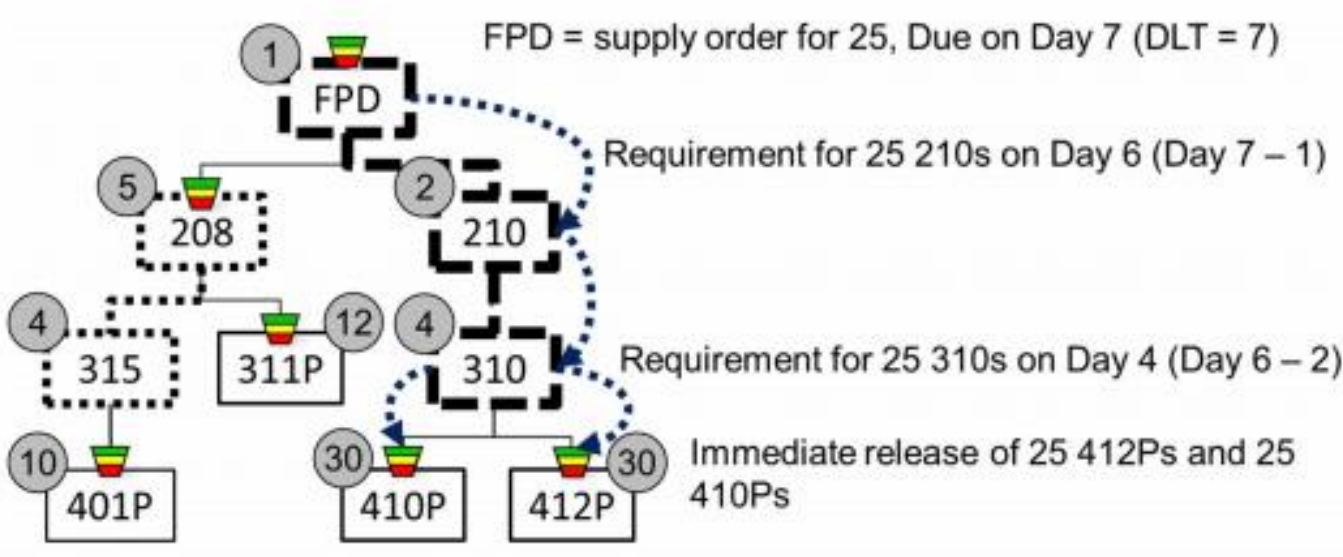

Source: Ptak and Smith (2016)

It is important to note on the example in Figure 21 that there are no safety stocks for the non-buffered parts (210 and 310), therefore the requirements are equal to the supply order. In addition, the decoupled explosion stops on the next strategic DDMRP buffer and it will only continue if the new net flow equation calculated for those buffers end up being below the TOY (MICLO, 2016). 


\subsubsection{Demand Driven Execution}

The last component to DDMRP implementation is the execution part of the process. According to Ptak and Smith (2016) there is a careful distinction between planning and execution. "Planning" is the process of generating supply order requirements using the net flow equation and the elements of decoupled explosion. Planning ends once the recommendation has been approved and becomes an open supply order. In DDMRP, "execution" is the management of open supply orders against relevant criteria. These criteria are defined in two basic categories necessary to protect and promote flow: buffer status and synchronization as shown in Figure 22.

Figure 22 - DDMRP execution representation

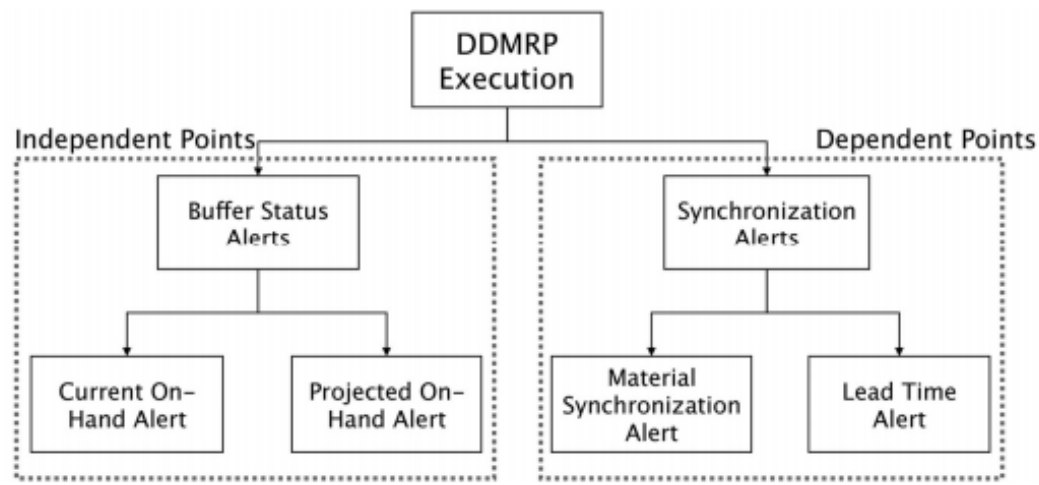

Source: Ptak and Smith (2016)

Buffer status alerts show the current and projected status of the decoupling point position (independent points) across the Demand Driven Operating Model. These alerts use the current and projected on-hang position rather than the net flow. If there is no on-hand, then the decoupling point is not decoupled and will most likely pass on variability. This can occur despite a green net flow position. On-hand tell if the position is capable of performing its purpose.

Synchronization alerts are designed to highlight problems regarding dependencies. These dependencies are about known demand requirements versus projected supply availability.

Contrary to the classical prioritization by due date, execution order prioritization is easier with DDMRP buffer status. According to Ptak and Smith (2016) the buffer that is in jeopardy should set the priority (see Figure 23). Ultimate, priority by buffer status is about aligning efforts to best protect the DDMRP model. The model was built under careful and 
strategic consideration, aligning efforts to the strategic operating model of a business in real time is the pinnacle of effective execution.

Figure 23 - Order Prioritization in DDMRP

\begin{tabular}{|l|l|l|l|l|}
\hline Order \# & Due Date & Buffer Status & Order Type & Customer \\
\hline MO 645181 & $05 / 14$ & BED - 13.2\% & MTS & Internal \\
\hline MO 845172 & $05 / 13$ & BFD - 36.2\% & MTS & Internal \\
\hline MO 831162 & $05 / 12$ & YELLOW - 62.1\% & MTS & Internal \\
\hline MO 831145 & $05 / 12$ & YELLOW - 72.1\% & MTS & Internal \\
\hline MO 821158 & $05 / 12$ & YELLOW - 87.2\% & MTS & Internal \\
\hline
\end{tabular}

Source: Ptak and Smith (2016)

\subsubsection{Planning vs. Execution Display}

The buffer status can provide a quick and intuitive way to align efforts to best protect the DDMRP model. Buffer status alerts do not use the net flow equation; they utilize on-hand values only. This separates the activities dedicated to supply order generation from the activities dedicated to open supply order management.

The on-hand target is calculated as top of red (TOR) to TOR + the green zone value. The on-hand position should fluctuate between those values. If the on-hand is consistently above TOR, there is no real concerns. Thus, when considering the buffer status alerts for the management of open supply orders against buffered positions when on-hand is above TOR, the buffer status alert will display green as "OK".

When the on-hand goes below that hand, an alert is made. Yellow and red are determined by the severity of the on-hand situation in relation to the total red zone value. The red zone is the safety in the buffer, when on-hand dips into that safety zone, a flag should go up, colored yellow. If on-hand continues to go down on safety zone, the flag becomes more urgent; should change from yellow to red.

The point where the yellow turn red is called the on-hand alert level. The most common way to determine the on-hand alert level is to set it to 50 percent of the red zone. The percentage value is calculated based upon the on-hand level as a percentage of the red zone. The lower the percentage, the less safety remains (see Figure 24). 
Figure 24 - On Hand Alert representation

\begin{tabular}{|r|r|r|r|c|}
\hline Part \# Example & \multicolumn{1}{|c|}{} \\
\hline Day & On-Hand & TOR & $\begin{array}{c}\text { On-Hand } \\
\text { Alert }\end{array}$ & Status \\
\hline 1 & 72 & 50 & 25 & GREEN - 144.0\% \\
\hline 2 & 26 & 50 & 25 & YELLOW - 52.0\% \\
\hline 3 & 20 & 50 & 25 & RED - 40.0\% \\
\hline
\end{tabular}

Source: Ptak and Smith (2016)

There are two types of buffer status alerts. Ptak and Smith (2016) summarize both alerts. According to them, the current on-hand alert, and the projected on-hand alert. The current onhand alert is designed to show what replenished positions are currently in trouble from and onhand perspective only. For planning and purchasing team, these alerts are meant to identify parts where open supply may need to be immediately expedited. For manufacturing team, it provides relevant information about which manufacturing orders should take precedence.

The other buffer status alert is the projected on-hand alert. It calculates the red zone penetration in the near future in order to warn supply chain personnel about impending buffer integrity problems. To do this, it requires information from demand and supply perspective. Unlike net-flow equation, it is not designed to recommend new supply orders but to point out positions that may need existing supply orders expedited in order to maintain the buffer's purpose.

Ptak and Smith (2016) also explain the synchronization alerts for points that are not decoupled in DDMRP. Material synchronization alert display supply shortfalls against known demand allocations. For example, an on-hand alert in a decoupling point may generate a material synchronization alert in the point below (see Figure 25).

Figure 25 - On Hand Alert in non-decoupled points

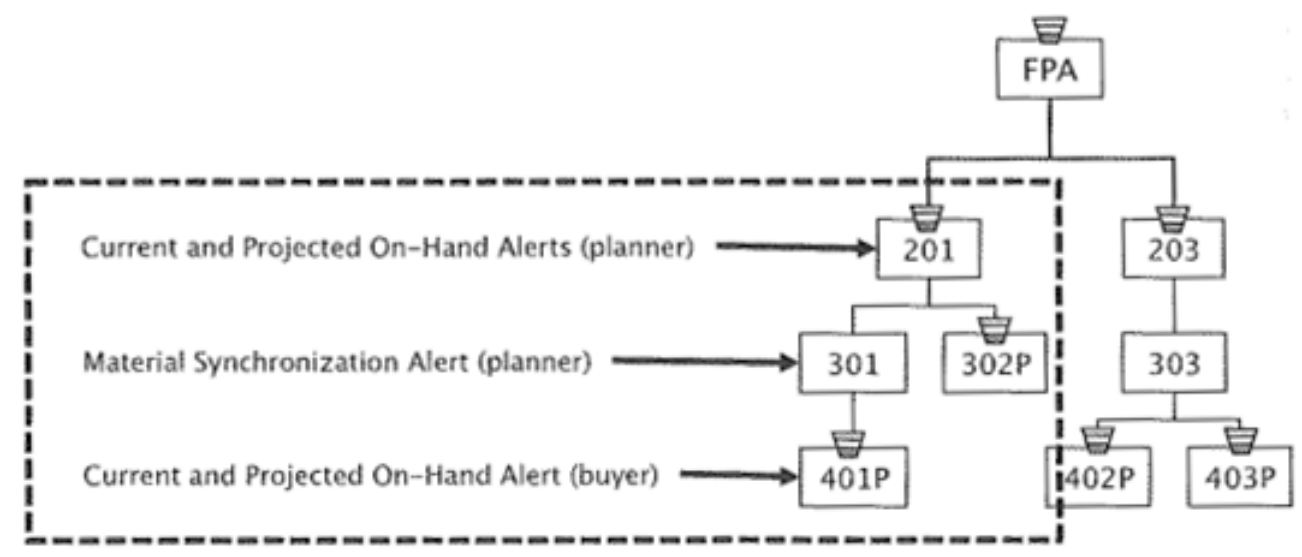

Source: Ptak and Smith (2016) 
Lead time alert is the second synchronization alert. According to Ptak and Smith (2016) it is an execution alert for strategic non-buffered items and are used to prompt personnel to check up the status of critical stocked parts before those parts become a synchronization issue. The lead time alert horizon is the last three days of the order's lead time. When the order is three days away from being due, the order enter the green zone, on the next day it enters the yellow zone of the lead time alert horizon. On due date it is in the red zone of the alert horizon. If the order is past its due date, probably it will create a material synchronization alert for the demand allocation that generate the order in the first place.

\subsection{Analytical Hierarchical Process (AHP)}

More than one criterion is usually needed to reach a decision, therefore making it more complex. Hence, it is important to structure the problem and to explicitly assess relevant criteria before reaching a decision. Several methods have been developed to solve multi-criteria problems, and common to many of them is the idea that most decision-making can be improved by breaking down the general evaluation of alternatives into evaluations on a number of relevant criteria (TRAMARICO et al., 2015).

According to Sipahi and Timor (2010) multi-criteria decision-making (MCDM) is essential in decision-making process. Analytic Hierarchy Process (AHP) is one of the most used MCDM methods as a management tool in several industrial sectors, as supply chain, logistics and training among others, with the aim of assessing strategy and performance.

The AHP approach was developed in early 1970s in response to military contingency planning, scarce resources allocation, and the need for political participation in disarmament agreements (SAATY, 1980). According to Yang and Lee (1997) the AHP is a structured method to elicit preference opinion from decision makers. One of its features is to quantify decision makers' subjective judgments by assigning corresponding numerical values based on the relative importance of factors under consideration.

According to Saaty (1980) AHP's methodological procedure can easily be incorporated into multiple objective programming formulations with interactive solution process. The AHP approach involves decomposing a complex and unstructured problem into a set of components organized in a multilevel hierarchic form.

Saaty (1986) affirms that there are two kinds of comparisons, absolute and relative. In the former, an alternative is compared with a standard in memory developed through 
experience; in the latter, alternatives are compared in pairs according to a common attribute. AHP has been used to carry out both types of comparisons resulting in ratio scales of measurement. The scales derived from absolute and relative comparisons are called respectively absolute and relative measurement scales.

Vargas (1990) introduces four AHP theory axioms. (1) Reciprocal Comparison: The decision maker must be able to make comparisons and state the strength of his preferences. The intensity of these preferences must satisfy the reciprocal condition: If $\mathrm{A}$ is $\mathrm{x}$ times more preferred than $B$, then $B$ is $1 / x$ times more preferred than alternative A. (2) Homogeneity: The preference of one option over another are represented by means of a bounded scale. (3) Independence: When expressing preferences, criteria are assumed independent of the properties of the alternatives. (4) Expectations: for the purpose of making a decision, the hierarchic structure is assumed to be complete.

In addition, Vargas (1990) structured the AHP in two phases: hierarchy design and hierarchy evaluation. According to the author, two decision makers would normally structure two different hierarchies of the same problem. Thus, a hierarchy is not unique. In addition, the evaluation phase is based on the concept of paired comparisons. The elements in a level of the hierarchy are compared in relative terms as to their importance or contribution to a given criterion that occupies the level immediately above the elements being compared.

According to Xia and Wu (2007) AHP consists of three parts: the hierarchy structure, the matrix of pairwise comparison ratios and the method for calculation the weights. In AHP, the decision maker is asked to estimate pairwise comparison rations with respect to strength of preference between subjects of comparison. Thus, the AHP is deeply related to human judgement.

Saaty (2008) structured AHP in a four-step approach. The first step is to define the problem and determine the kind of knowledge sought. The second is to structure the decision hierarchy from the top with the goal of the decision, then the objectives from a broad perspective, through the intermediate levels to the lowest level. The third proposed step is to construct a set of pairwise comparison matrices, comparing each element in an upper level to the level immediately below. The last step if to use the priorities obtained from the comparisons to weigh the priorities in the level immediately below.

A full guide with the steps needed for construction and calculation of results using the AHP method is provided in the Appendix $\mathrm{C}$ of this present work. 


\subsubsection{Aggregating Individual Judgments with AHP}

According to Forman and Peniwati (1998) there are several possible ways to aggregate information when more than one (perhaps many) individuals participate in a decision process, including: (1) aggregating the individual judgments for each set of pairwise comparisons into an 'aggregate hierarchy'; (2) synthesizing each of the individual's hierarchies and aggregating the resulting priorities; and (3) aggregating the individual's derived priorities in each node in the hierarchy.

The two basic ways to aggregate individual preferences into a group preference, depending on whether the group wants to act together as a unit or as separate individuals. In case the group structure is homogeneous and decision makers are willing to act like one single individual, a synergistic aggregation of individual judgments (AIJ) is possible. Each decision maker conducts the pairwise comparisons by himself. Afterwards the geometric mean method could be used to obtain the group judgment for each entry of the comparison matrices (SAATY, 1989; FORMAN; PENIWATI, 1998).

According to Aczél and Saaty (1983), when using the AIJ, arithmetic mean should not be used due to the non-reciprocity of the collective pairwise comparison matrices, in order to keep the cardinal feature of the judgments, geometric mean must be used to aggregate the individual judgements. Saaty (2008) also noted that the geometric mean method is among the most used method in the AHP to aggregate individual ratings of experts.

\subsection{Preliminary Results of Literature Review}

Based on the past sections, it is possible to suppose the impacts that implementation of DDMRP as stated in theory has on the Supply Chain Management processes described by Lambert et al. (2000). To do that, we should recap each SCM process and search for links between them and current DDMRP theory.

The first process, as described by Croxton et al. (2001) is Customer Relationship Management. Through the literature review, the implementation of DDMRP should impact in providing guidelines for the degree of differentiation of the PSA sub-process. The improvement of capabilities of the firm after DDMRP implementation (LEE; JANG, 2013; IHME, 2015; IHME; STRATTON, 2015; KORTABARRIA et al., 2018; GEORGE, 2018; MICLO et al., 2015; 2019) should be considered when tailoring PSAs with customers. 
The second process, Supplier Relationship Management should be impacted by DDMRP in two of its sub-processes. Both are related with the flow protection, as stated by Ptak and Smith (2016), all rules and tools of the business should be built around the protection and promotion of flow. Considering this, it is important when identifying the criteria to categorize suppliers to consider the service level to protect the flow. In addition, when providing guidelines to tailor PSAs with suppliers, it is needed to be clearly stated the importance of keeping the supply without any major disruption.

In the third sub-process, Customer Service Management, considering the framework provided by Bolumole et al. (2003), there were no major impacts found in DDMRP implementation literature that would affect CSM process.

The fourth process is Demand Management. According to Croxton et al. (2002) the process is concerned with balancing the customers' requirements with the capabilities of the firm. After review of DDMRP literature, this process figures possibly as one of the most impacted SCM processes. The first sub-process which is determine management goals and strategy is heavily impacted, because, after DDMRP implementation, the main demand management goal should be protect and promote flow, as already stated by Ptak and Smith (2016).

The second sub-process is to determine forecasting procedures. Becoming demand driven requires a fundamental shift from the centrality of supply and cost-based operation methods to a centrality of actual demand and flow-based methods. The term "actual demand" is extremely important in distinguishing it from a rebranded and somehow superior forecasting approach (PTAK; SMITH, 2016). The typical forecast methods are replaced with a method of planning with the actual demand.

The third sub-process is to plan the information flow. As Ptak and Smith (2016) stated, DDMRP is a formal multi-echelon planning and execution method to protect and promote the flow of relevant information and materials through the establishment. Therefore, the planning on how information and materials flow changes after DDMRP implementation.

The fourth demand management sub-process is to determine synchronization procedures. It is also impacted with DDMRP implementation. Croxton et al. (2002) states that this sub-process is frequently referred to as Sales and Operation planning (S\&OP). Ptak and Smith (2016) proposes a new model where actual demand runs the system, as opposed to traditional Sales and Operations Planning (S\&OP), where the outcome is a master production schedule - a statement of what can and will be built - Demand Driven S\&OP defines a capability so the company can profitably build what can and will be sold. 
The fifth demand management sub-process is to develop contingency management system. According to Croxton et al. (2002) those plans are necessary to respond to significant internal or external event that disrupt the balance of supply and demand. Ptak and Smith (2016) state that DDMRP has its own rules for buffer adjustments to adapt to changing conditions. Therefore, the way which contingency are managed should be substantially affected after DDMRP implementation.

The fifth process of Supply Chain Management is the order fulfillment process. As discussed in previous sections of this work, order fulfillment involves generating, filling, delivering, and servicing customer orders (CROXTON, 2003). The first sub-process of order fulfillment is to review marketing strategy, supply chain structure and customer service goals. According to Croxton (2003) the process needs to be designed around the customer, but within the limits of the firm's business capabilities. Considering this, once DDMRP improves firms and supply chain capabilities, it should be taken in consideration when reviewing the goals of the process.

The second sub-process of order fulfillment is to define requirements for order fulfillment. According to Croxton (2003) one of its activities is to define lead-time and customer service requirements for each customer segment. Since DDMRP uses a different lead-time concept than traditional MRP, as stated by Ptak and Smith (2016) "it only assumes availability of the component on parent order at decoupling points", the lead-time requirements should be reviewed after DDMRP implementation.

The other sub-process of order fulfillment that should be impacted by DDMRP implementation is to define a plan for order fulfillment. Especially when determining allocation rules and, according to Croxton (2003), operational requirements of the order fulfillment environment, including how many orders need to be filled per day and how many dock-doors will be needed. DDMRP has a different view regarding prioritization of orders. Contrary to due date, the buffer that is in jeopardy always set the priority (PTAK; SMITH, 2016).

The manufacturing flow management process should also be heavily impacted by DDMRP implementation. The first sub-process is to develop the manufacturing strategy. When creating buffers and decoupling points, changes in the manufacturing strategy may be needed to better accommodate the new system. As an example, a process, which worked as MTS, may change to ATO because of DDMRP implementation.

The second sub-process, determine degree of manufacturing flexibility requirement, is also impacted because of DDMRP implementation. According to Golsby and Garcia-Dastugue 
(2003), manufacturing flexibility ensures the company's ability to manage resources and uncertainty to meet various customer requests. As stated by George (2018), the use of DLT paves the way to better see the inventory and leverage flexibility.

The third sub-process of manufacturing flow management is to determine push pull boundaries. As mentioned earlier, the push-pull boundary is the same concept as the customer order decoupling point (CODP). The first component of DDMRP is determining where the decoupling points and their respective buffers should be placed (PTAK; SMITH, 2016). Therefore, the whole sub-process must be reviewed to implement DDMRP.

The fourth sub-process is to identify manufacturing constraints and requirements. As stated by Goldsby and Garcia-Dastugue (2003) it comprises several activities, such as document capabilities, determine stock quantities and location, develop disposal requirements, develop contingency plans, and others. When implementing DDMRP, the stock positioning and sizing is crucial to the correct operation of buffers, in additions, stocks are dynamic, changing according to the actual demand.

The last sub-process of manufacturing flow management is to develop the framework of metrics "to be used to measure and monitor the performance of the process and sets the goals for performance improvement" (CROXTON et al., 2002). According to Ptak and Smith (2016) DDMRP metrics should consider if buffer levels at decoupling points are protecting and promoting flow by measuring signal integrity and decoupling point integrity.

The product development and commercialization are also impacted by DDMRP implementation. One sub-process was identified during the review, which is to identify product rollout issues and constraints. When DDMRP is implemented there is a need to use Demand Adjustment Factors (DAF) with product introduction, deletion and transition between products (PTAK; SMITH, 2016). Therefore, to keep the stability of DDMRP, new products should always provide important information, such as a projected average daily usage.

In the last process, returns management as described by Rogers et al. (2002), there were no issues in the sub-processes that were identified as having a significant impact in DDMRP implementation. The Table 3 summarizes the DDMRP impacts in the different processes and sub-processes of supply chain management as identified by the author. 
Table 3 - SCM processes impacted by DDMRP

\begin{tabular}{|c|c|c|}
\hline $\begin{array}{c}\text { SCM } \\
\text { PROCESS }\end{array}$ & $\begin{array}{c}\text { SCM } \\
\text { STRATEGIC } \\
\text { SUB-PROCESS }\end{array}$ & DDMRP CURRENT THEORY \\
\hline CRM & $\begin{array}{l}\text { Provide guidelines } \\
\text { for PSA }\end{array}$ & $\begin{array}{l}\text { When tailoring PSAs with customers it is important to remind } \\
\text { that DDMRP improves the capabilities of the firm (LEE; JANG, } \\
\text { 2013; IHME, 2015; IHME; STRATTON, 2015; MICLO et al. } \\
\text { 2015, 2018). }\end{array}$ \\
\hline SRM & $\begin{array}{l}\text { Identify criteria for } \\
\text { categorizing } \\
\text { suppliers }\end{array}$ & $\begin{array}{l}\text { When categorizing suppliers, the service level should be } \\
\text { considered as one of the most important criteria, since protecting } \\
\text { and promoting flow is the fundamental principle of DDMRP. }\end{array}$ \\
\hline SRM & $\begin{array}{l}\text { Provide guidelines } \\
\text { for PSA }\end{array}$ & $\begin{array}{l}\text { When tailoring PSAs with suppliers the protection of flow } \\
\text { needed for DDMRP should be taken in consideration, higher } \\
\text { levels of service should be expected from suppliers to not } \\
\text { compromise flow. }\end{array}$ \\
\hline $\mathrm{DM}$ & $\begin{array}{l}\text { Demand } \\
\text { Management Goals } \\
\text { and Strategy }\end{array}$ & $\begin{array}{l}\text { The fundamental principle to business generate value is flow. } \\
\text { All rules and tools of a business should be built around the } \\
\text { protection and promotion of flow (PTAK; SMITH, 2016) }\end{array}$ \\
\hline $\mathrm{DM}$ & $\begin{array}{l}\text { Forecasting } \\
\text { Procedures }\end{array}$ & $\begin{array}{l}\text { DDMRP uses actual demand instead of forecast demand. The } \\
\text { term "actual demand" is important in distinguishing it from a } \\
\text { rebranded and superior forecasting approach (PTAK; SMITH, } \\
\text { 2016) }\end{array}$ \\
\hline $\mathrm{DM}$ & $\begin{array}{l}\text { Plan Information } \\
\text { Flow }\end{array}$ & $\begin{array}{l}\text { DDMRP is a formal planning and execution method to protect } \\
\text { and promote flow of relevant information and materials through } \\
\text { the establishment (PTAK; SMITH, 2016) }\end{array}$ \\
\hline $\mathrm{DM}$ & $\begin{array}{l}\text { Synchronization } \\
\text { Procedures }\end{array}$ & $\begin{array}{l}\text { This process involves the procedures required to match the } \\
\text { demand forecast to the SC. When implementing DDMRP this } \\
\text { process changes from a traditional S\&OP to a Demand Driven } \\
\text { S\&OP. }\end{array}$ \\
\hline $\mathrm{DM}$ & $\begin{array}{l}\text { Contingency } \\
\text { Management } \\
\text { System }\end{array}$ & $\begin{array}{l}\text { DDMRP has rules for buffer adjustments to adapt to changing } \\
\text { conditions (PTAK; SMITH, 2016). This changes how to } \\
\text { manage contingencies but does not eliminate the need to manage } \\
\text { it. }\end{array}$ \\
\hline $\mathrm{OF}$ & Review strategy & $\begin{array}{l}\text { DDMRP improves the capabilities of supply chain (LEE; } \\
\text { JANG, 2013; IHME, 2015; IHME; STRATTON, 2015; MICLO } \\
\text { et al. 2015, 2018) and should be considering when reviewing } \\
\text { strategy for order fulfillment. }\end{array}$ \\
\hline OF & $\begin{array}{l}\text { Define requirements } \\
\text { for order fulfillment }\end{array}$ & $\begin{array}{l}\text { DDMRP uses different lead-time concept than traditional MRP. } \\
\text { It only assumes availability of the component on parent order at } \\
\text { decoupling points (PTAK; SMITH, 2016). }\end{array}$ \\
\hline $\mathrm{OF}$ & $\begin{array}{l}\text { Define plan for } \\
\text { order fulfillment }\end{array}$ & $\begin{array}{l}\text { DDMRP has a different view regarding prioritization. Contrary } \\
\text { to due date, the buffer that is in jeopardy always set the priority } \\
\text { (PTAK; SMITH, 2016) }\end{array}$ \\
\hline MFM & $\begin{array}{l}\text { Develop manufact. } \\
\text { strategy }\end{array}$ & $\begin{array}{l}\text { When considering the creation of buffers and decoupling points } \\
\text { in DDMRP, changes may be needed in the manufacturing } \\
\text { strategy in order to better accommodate the new system. }\end{array}$ \\
\hline MFM & $\begin{array}{l}\text { Determine degree of } \\
\text { flexibility required }\end{array}$ & $\begin{array}{l}\text { The use of DLT paves the way to better see the inventory } \\
\text { leverage and flexibility (GEORGE, 2018) and should be } \\
\text { considered in this step after DDMRP implementation }\end{array}$ \\
\hline MFM & $\begin{array}{l}\text { Determine push pull } \\
\text { boundaries }\end{array}$ & $\begin{array}{l}\text { The first component of DDMRP is determining where the } \\
\text { decoupling points and their respective buffers should be placed } \\
\text { (PTAK; SMITH,, 2016). }\end{array}$ \\
\hline
\end{tabular}




\begin{tabular}{cll}
\hline MFM & $\begin{array}{l}\text { Identify Constraints } \\
\text { and Requirements }\end{array}$ & $\begin{array}{l}\text { Regarding determination of stock quantities and locations that } \\
\text { is a step of this sub-process, DDMRP stocks are always located } \\
\text { in buffers and should be set causally linked to real demand }\end{array}$ \\
\hline MFM & $\begin{array}{l}\text { Develop framework } \\
\text { of metrics }\end{array}$ & $\begin{array}{l}\text { DDMRP metrics should consider if buffer levels at decoupling } \\
\text { points are protecting and promoting flow by measuring signal } \\
\text { integrity and decoupling point integrity (PTAK; SMITH, 2016) }\end{array}$ \\
\hline PD\&C & $\begin{array}{l}\text { Product rollout } \\
\text { issues and } \\
\text { constraints }\end{array}$ & $\begin{array}{l}\text { When DDMRP is implemented there is a need to use Demand } \\
\text { Adjustment Factors (DAF) with product introductions, deletion } \\
\text { and transition between products (PTAK; SMITH, 2016) }\end{array}$ \\
\hline
\end{tabular}

Source: Author (2019) 


\section{APPLICATION AND EVALUATION}

The present chapter has 4 sections. The first section (4.1) explains the process of cases selection for survey application. The second section (4.2) brings the steps taken to create the collection instruments and collection protocol for the survey. The third section (4.3) analyzes the collected data from the survey using the proposed methodology.

\subsection{Respondents Selection}

The main source of data needed for this study were specialists, both in academia and industry who studied and/or have implemented DDMRP in their respective fields. The subjects were contacted and several follow-ups where conducted through emails and telephone calls. Totally, 22 researchers and practitioners in DDMRP field were targeted for participating in the research, the targeted group was divided between academic researchers, industry practitioners and software developers. Regarding industries that implemented DDMRP, middle and seniorlevel managers were selected to answers the questionnaire. From the targeted group, 18 subjects agreed to participate.

After sorting out the received responses from the experts, a total of 9 responses (which were completed in all aspects and received within the proposed time frame) were used for the research purpose. As Saaty (2008) proposed, AHP may be applied to responses of large as well as small groups, however the number of respondents may depend upon the nature of problem and availability of experts. As long as the sample is representative of the totality of specialists on the subject and their answers shows some degree of stability (CR falls within the proposed range), the sample size should be enough to realize the analysis.

Another important point to consider is the response rate of respondents. According to Malhotra and Grover (1998) the higher the response rate the better, response rates of under $20 \%$ are extremely undesirable. In the present study, the response rate was 50\%, from the 18 specialists who agreed to participate, 9 send their answers complete and within the time frame. Following Malhotra and Grover (1998) proposition, that is an acceptable response rate.

The Table 4 represents the profile details of the participants. The following table was designed in order to not be possible to identify any of the survey respondents. 
Table 4 - Profile details of survey respondents

\begin{tabular}{lllc}
\hline S. No. & \multicolumn{1}{c}{ Casic data of respondents } & \multicolumn{1}{c}{$\mathbf{N}^{\mathbf{0}}$ of respondents } \\
\hline $\mathbf{1}$ & Type of professional & Academic Researcher & 06 \\
& Industry Practitioner & 03 \\
& Software Developer & 00 \\
& Total & 09 \\
\hline $\mathbf{2}$ & Location of professional & Europe & 02 \\
& North America & 02 \\
& South America & 05 \\
& Total & 09 \\
\hline
\end{tabular}

Source: Author (2019)

\subsection{Collection Instruments and Protocol}

The creation of the collection instruments and protocol was carried out in two stages. The full collection instrument and protocol for this research is available in the Appendix B of this work

In the first stage, the processes and sub-processes of Lambert's framework for Supply Chain Management were identified. In total, 8 main processes and 42 sub-processes were identified. Following this identification, the processes and sub-processes were used to develop the AHP tree (see Appendix B - Figure 26) in order to provide the data needed to create the questionnaire.

The AHP tree or decision hierarchy structure consists of three levels, that are, the goal of research (measure the impact of DDMRP implementation on the processes and strategic subprocesses of SCM), shown in Level 1, the main processes (main factors being impacted) shown at Level 2 and the strategic sub-processes (strategic sub-processes being impacted) shown at Level 3. The AHP tree, processes and sub-processes identified are shown in the Section B of the Appendix B of this present work.

The second stage is the development of the collection protocol, which includes the form that must be filled to complete the survey, the guidelines for survey completion and the information about the research to the participants. The survey form and the guidelines for completion were developed following Saaty's (1980) work on AHP (see Appendix C) and is presented in the Section C of the Appendix B. 
The information about the research for participants included several information needed for the participants to complete the research and can be seen in the Section A of the Appendix B. Among the information provided, there were an (1) invitation letter for participation in the study, (2) a consent formulary and (3) basic information for participants, such as participants profile, right to decline, methodology of survey conduction, confidentiality of data, use of information, availability of results and contact information of the researchers responsible for the survey.

\subsection{Analysis of Collected Data}

Based on the listed processes and strategic sub-processes, the AHP methodology is used to prioritise them in accordance with their relative impact suffered from DDMRP implementation. The experts were consulted using the collection instrument developed in the previous section of this work and a hierarchy was formed.

With the experts' responses compiled, the consistency index (CI) and the consistency ratio (CR) were calculated following Saaty (1980), as described in the Appendix C of this work. For every pairwise comparison, the CR was calculated. The results are shown in the Table 5. The highlighted numbers show the SCM process/processes that, in the expert point of view, was/were the most impacted by DDMRP implementation. The red numbers indicate the answers that were not used in the final analysis.

Table 5 - Compilation of experts' answers

\begin{tabular}{lccccccccc}
\hline & CRM & SRM & CSM & DM & OF & MFM & PDC & RM & CR \\
\hline R1 & 0,86 & 0,31 & 0,86 & 1,02 & $\mathbf{3 , 3 0}$ & $\mathbf{3 , 3 0}$ & 0,20 & 0,17 & 0,20 \\
\hline R2 & 0,68 & 1,14 & 1,09 & 1,27 & 1,81 & $\mathbf{2 , 6 5}$ & 0,23 & 0,35 & 0,12 \\
\hline R3 & 2,64 & 0,85 & $\mathbf{2 , 6 8}$ & 1,43 & 0,52 & 1,45 & 0,18 & 0,15 & 0,19 \\
\hline R4 & 1,03 & 1,09 & 0,20 & 1,09 & 1,13 & $\mathbf{3 , 8 3}$ & 0,25 & 0,21 & 0,08 \\
\hline R5 & 0,41 & 0,48 & 0,66 & 2,79 & 1,70 & $\mathbf{3 , 0 0}$ & 0,71 & 0,35 & 0,21 \\
\hline R6 & 0,54 & 0,44 & 0,62 & 1,44 & 2,63 & $\mathbf{3 , 7 3}$ & 1,06 & 0,18 & 0,27 \\
\hline R7 & 1,02 & 1,99 & 1,51 & 2,40 & 4,08 & 3,01 & 0,32 & 0,29 & $\mathbf{0 , 6 7}$ \\
\hline R8 & 1,50 & 1,32 & 0,38 & $\mathbf{1 , 5 9}$ & $\mathbf{1 , 5 9}$ & $\mathbf{1 , 5 9}$ & 0,23 & 0,23 & 0,04 \\
\hline R9 & 1,48 & 0,78 & 2,22 & 0,37 & 0,77 & $\mathbf{4 , 4 6}$ & 0,18 & 0,15 & 0,24 \\
\hline
\end{tabular}

Source: Author (2019) 
Following Wedley's (1993) proposition, where the higher the order of the matrix, higher values of CR should be accepted (in opposition to Saaty's proposed parameters) the author rejected any $\mathrm{CR}>0,30$ to compose the aggregated judgment. In this work, because of this rule, the answers of the R7 subject were not used in the calculation of the final comparison matrix.

It is important to add that, according to Forman and Peniwati (1998), after agreeing to the general structure of the hierarchy, the group 'merges' further by agreeing on the relative importance of the criteria. Once this process is done, the previous individual judgements with respect to the relative importance of the criteria become irrelevant, consequently there is no synthesis for everyone. Based on this, the acceptance of individual CRs higher than the Saaty (2008) proposed maximum of 0,20 will not affect the result, as long as the CR of the aggregated judgments are inside the proposed parameters.

As shown in Table 5, 7 out of 9 experts perceived Manufacturing Flow Management (MFM) as the most impacted SCM process after DDMRP implementation. It is important to notice that these answers are not aggregated and were shown to elicit the experts' judgements regarding the most impacted SCM processes.

After applying the geometric mean to aggregate the individual judgments, as proposed in the Appendix $\mathrm{C}$ of this work, the level of impact suffered by each SCM process is given in Table 6. The impact weight is provided both in absolute and relative numbers, in order to provide a better scenario for analysis. The absolute weight is the number found in the matrix operations, which represents their impact compared to other processes in order of magnitude, the relative weight is the same number transformed to a $0-1$ scale. The CR of this analysis is $\mathrm{CR}=0,03$, between the parameters proposed by Saaty (2008).

Table 6 - Rank of perceived impact on SCM processes (all respondents)

\begin{tabular}{lccc}
\hline \multicolumn{1}{c}{ SCM Process } & $\begin{array}{c}\text { Absolute Impact } \\
\text { Weight }\end{array}$ & $\begin{array}{c}\text { Relative Impact } \\
\text { Weight }\end{array}$ & Rank \\
\hline Manufacturing Flow Management & 2,85 & 0,344 & 1 \\
\hline Order Fulfillment & 1,42 & 0,172 & 2 \\
\hline Demand Management & 1,17 & 0,141 & 3 \\
\hline Customer Relationship Management & 0,93 & 0,112 & 4 \\
\hline Customer Service Management & 0,73 & 0,089 & 5 \\
\hline Supplier Relationship Management & 0,69 & 0,084 & 6 \\
\hline Product Development and Creation & 0,28 & 0,034 & 7 \\
\hline Returns Management & 0,21 & 0,025 & 8 \\
\hline
\end{tabular}


Source: Author (2019)

According to the findings, as explained before, Manufacturing Flow Management is the most impacted SCM process in DDMRP implementation. The perceived impact weight of 2,85, shows that it is twice more impacted than the second SCM process in the ranking (Order Fulfillment), which has an perceived impact weight of 1,42. The third process more impacted is the Demand Management process, with an absolute perceived impact weight of 1,17. The least impacted processes in the aggregated analysis are Product Development and Creation and Returns Management.

These results are aligned with the preliminary results of the literature review. DDMRP is extremely focused on changes in how companies organize its flow of products, the processes needed to attend orders and how the company understand and treat the demand signals. The perception of specialists on the subject reinforces that the focus that DDMRP theory has on the operational side of companies is carried to its implementation, generating high impacts on the processes more involved with flow of materials and information through the company.

One important tendency to be analyzed is the difference of perception between researchers and industry practitioners. Table 7 and Table 8 shows the results of the analysis when separating the two group of respondents.

Table 7 - Rank of perceived impact on SCM processes (researchers)

\begin{tabular}{lccc}
\hline \multicolumn{1}{c}{ SCM Process } & $\begin{array}{c}\text { Absolute Impact } \\
\text { Weight }\end{array}$ & $\begin{array}{c}\text { Relative Impact } \\
\text { Weight }\end{array}$ & Rank \\
\hline Manufacturing Flow Management & 2,75 & 0,312 & 1 \\
\hline Order Fulfillment & 1,37 & 0,167 & 3 \\
\hline Demand Management & 1,48 & 0,180 & 2 \\
\hline Customer Relationship Management & 0,88 & 0,107 & 4 \\
\hline Customer Service Management & 0,61 & 0,074 & 6 \\
\hline Supplier Relationship Management & 0,79 & 0,095 & 5 \\
\hline Product Development and Creation & 0,31 & 0,038 & 7 \\
\hline Returns Management & 0,22 & 0,027 & 8 \\
\hline Soure: Aut & & & \\
\hline
\end{tabular}

Source: Author (2019)

Table 7 brings the results of the aggregated individual judgments of respondents classified as researchers. The $\mathrm{CR}$ for this aggregation is $\mathrm{CR}=0,02$, which shows a high consistency between answers and is inside Saaty's (2008) proposed parameters. 
Analyzing the results, we notice almost the same outcome as in the aggregated results. The notable changes are Demand Management, which, according to researchers' opinions is the second most impacted SCM process in a DDMRP implementation. It is important to highlight that the three most impacted processes are still the same, such as the two least impacted process. One of the reasons of this repetition is the sample size, there is double respondents from academia than industry. However, it reinforces the existence of great focus on materials and information flow present in DDMRP theory, aligned with the results gathered from the literature review.

Table 8 shows the results of the aggregated individual judgments of respondents classified as industry professionals. The $\mathrm{CR}$ for this aggregation is $\mathrm{CR}=0,14$, which shows some level of inconsistency between answers, but are inside Saaty's (2008) proposed parameters. The comparisons between the two different analyses must be made using only the rank.

As stated in AHP theory, the results are a comparison between them, so it only represents the judgments among the same group, not between different groups. Following AHP propositions, it is correct to state that, to researchers and industry professionals, Manufacturing Flow Management is twice more impacted that Order Fulfillment $(2,75 / 1,37=2 ; 3,93 / 1,55=$ 2,5), but it is not correct to state that for industry professionals MFM is 1,5 times more impacted than MFM to researchers $(3,93 / 2,75=1,5)$.

Table 8 - Rank of perceived impact on SCM processes (industry professionals)

\begin{tabular}{lccc}
\hline \multicolumn{1}{c}{ SCM Process } & $\begin{array}{c}\text { Absolute Impact } \\
\text { Weight }\end{array}$ & $\begin{array}{c}\text { Relative Impact } \\
\text { Weight }\end{array}$ & Rank \\
\hline Manufacturing Flow Management & 3,93 & 0,419 & 1 \\
\hline Order Fulfillment & 1,55 & 0,166 & 2 \\
\hline Demand Management & 0,59 & 0,063 & 5 \\
\hline Customer Relationship Management & 1,10 & 0,118 & 4 \\
\hline Customer Service Management & 1,36 & 0,145 & 3 \\
\hline Supplier Relationship Management & 0,48 & 0,051 & 6 \\
\hline Product Development and Creation & 0,02 & 0,021 & 7 \\
\hline Returns Management & 0,02 & 0,018 & 8 \\
\hline Soure: Aur & & & \\
\hline
\end{tabular}

Source: Author (2019)

When we analyze the results of the industry professionals, there is a noticeable shift in the trend of the most impacted processes. Manufacturing Flow Management (MFM) and Order 
Fulfillment (OF) continues to be the most impacted SCM processes in industry professional views, however, Customer Service Management (CSM) and Customer Relationship Management (CRM) appear as the third and fourth most impacted SCM processes, respectively. This shift in the trend may occur because, when implementing DDMRP in industries, there is an interface of dealing with customers that do not have great focus on DDMRP theory, aligned with the preliminary findings of the literature review.

The difference of analysis between researches and industry professionals reinforces two main points, primarily is the focus on materials flow and information flow that DDMRP implementation has and second is an important final customer facet that is very present and important when implementing DDMRP in organizations.

The strategic sub-processes of SCM were also analyzed by the experts. The focus of the analysis was to identify, among the strategic sub-processes, which were more affected during a DDMRP implementation, regarding the other strategic sub-processes in the same analyzed SCM process. Table 9 represents a ranking of the strategic sub-processes, showing which of the strategic sub-processes were the most impacted, relative to their specific process and relative to all of studied strategic SCM sub-processes.

Regarding Table 9, the absolute weight is the number found in the matrix operations, which represents their perceived impact regarding to other sub-processes in the same process. The process rank is a ranking of the most impacted to the least impacted sub-process regarding the specific process that it belongs. The relative impact weight is the absolute impact transformed into a $0-1$ scale, the global impact weight is the result of the multiplication of the relative impact weight of the sub-process and the relative impact weight of the process that it belongs to. The Global Rank is the result of the ranking of the global impact weight, showing which strategic sub-process is most impacted in DDMRP implementation to the one that is the least impacted. The acronyms are the same used in the survey and their meaning can be found in the Appendix B of this work.

Table 9 - Rank of perceived impact on SCM strategic sub-processes (all respondents)

\begin{tabular}{llccccc}
\hline $\begin{array}{c}\text { Main } \\
\text { Process }\end{array}$ & $\begin{array}{c}\text { Sub- } \\
\text { Process }\end{array}$ & $\begin{array}{c}\text { Absolute } \\
\text { Impact Weight }\end{array}$ & $\begin{array}{c}\text { Process } \\
\text { Rank }\end{array}$ & $\begin{array}{c}\text { Relative Impact } \\
\text { Weight }\end{array}$ & $\begin{array}{c}\text { Global Impact } \\
\text { Weight }\end{array}$ & $\begin{array}{c}\text { Global } \\
\text { Rank }\end{array}$ \\
\hline CRM & CRM1 & 0,709 & 4 & 0,1403 & 0,01574 & 24 \\
\cline { 2 - 7 } & CRM2 & 0,451 & 5 & 0,0893 & 0,01002 & 30 \\
\cline { 2 - 7 } & CRM3 & 0,778 & 3 & 0,1541 & 0,01728 & 21 \\
\cline { 2 - 7 } & CRM4 & 1,709 & 1 & 0,3386 & 0,03798 & 8 \\
\hline CRM5 & 1,402 & 2 & 0,2777 & 0,03115 & 12 \\
\hline SRM & SRM1 & 0,902 & 3 & 0,1779 & 0,01492 & 25 \\
\hline
\end{tabular}


Table 9 - Rank of perceived impact on SCM strategic sub-processes (all respondents)

\begin{tabular}{|c|c|c|c|c|c|c|}
\hline & SRM2 & 0,707 & 4 & 0,1396 & 0,01170 & 28 \\
\hline & SRM3 & 0,637 & 5 & 0,1257 & 0,01054 & 29 \\
\hline & SRM4 & 1,548 & 1 & 0,3055 & 0,02561 & 16 \\
\hline & SRM5 & 1,273 & 2 & 0,2513 & 0,02107 & 18 \\
\hline \multirow[t]{4}{*}{ CSM } & CSM1 & 0,574 & 4 & 0,1414 & 0,01254 & 27 \\
\hline & CSM2 & 0,722 & 3 & 0,1779 & 0,01577 & 23 \\
\hline & CSM3 & 0,963 & 2 & 0,2371 & 0,02102 & 19 \\
\hline & CSM4 & 1,801 & 1 & 0,4437 & 0,03933 & 6 \\
\hline \multirow[t]{6}{*}{ DM } & DM1 & 0,927 & 3 & 0,1537 & 0,02166 & 17 \\
\hline & DM2 & 0,557 & 6 & 0,0924 & 0,01301 & 26 \\
\hline & DM3 & 0,709 & 5 & 0,1177 & 0,01658 & 22 \\
\hline & DM4 & 1,331 & 2 & 0,2208 & 0,03111 & 13 \\
\hline & DM5 & 0,879 & 4 & 0,1458 & 0,02054 & 20 \\
\hline & DM6 & 1,625 & 1 & 0,2696 & 0,03798 & 7 \\
\hline \multirow[t]{5}{*}{ OF } & OF1 & 1,019 & 3 & 0,1990 & 0,03413 & 11 \\
\hline & $\mathrm{OF} 2$ & 1,029 & 2 & 0,2009 & 0,03447 & 10 \\
\hline & OF3 & 0,912 & 4 & 0,1781 & 0,03054 & 14 \\
\hline & OF4 & 0,811 & 5 & 0,1583 & 0,02716 & 15 \\
\hline & OF5 & 1,351 & 1 & 0,2637 & 0,04524 & 4 \\
\hline \multirow[t]{5}{*}{ MFM } & MFM1 & 0,521 & 5 & 0,1013 & 0,03488 & 9 \\
\hline & MFM2 & 0,652 & 4 & 0,1268 & 0,04366 & 5 \\
\hline & MFM3 & 1,781 & 1 & 0,3467 & 0,11933 & 1 \\
\hline & MFM4 & 1,069 & 3 & 0,2080 & 0,07162 & 3 \\
\hline & MFM5 & 1,116 & 2 & 0,2171 & 0,07475 & 2 \\
\hline \multirow[t]{6}{*}{ PDC } & PDC1 & 1,717 & 1 & 0,2855 & 0,00959 & 31 \\
\hline & PDC2 & 0,648 & 6 & 0,1078 & 0,00362 & 41 \\
\hline & PDC3 & 0,725 & 5 & 0,1206 & 0,00405 & 38 \\
\hline & PDC4 & 1,154 & 2 & 0,1920 & 0,00645 & 32 \\
\hline & PDC5 & 0,757 & 4 & 0,1259 & 0,00423 & 37 \\
\hline & PDC6 & 1,011 & 3 & 0,1682 & 0,00565 & 33 \\
\hline \multirow[t]{6}{*}{$\mathbf{R M}$} & RM1 & 1,218 & 1 & 0,2022 & 0,00507 & 34 \\
\hline & RM2 & 0,892 & 5 & 0,1481 & 0,00372 & 40 \\
\hline & RM3 & 1,080 & 2 & 0,1792 & 0,00450 & 35 \\
\hline & RM4 & 0,812 & 6 & 0,1348 & 0,00338 & 42 \\
\hline & RM5 & 0,965 & 4 & 0,1603 & 0,00402 & 39 \\
\hline & RM6 & 1,056 & 3 & 0,1754 & 0,00440 & 36 \\
\hline
\end{tabular}

Source: Author (2019)

Table 9 shows how the different strategic sub-process are impacted regarding its main process. For example, strategic sub-process CRM4, which is "Develop framework of metrics for customer's impact on firm's profitability" is the most impacted strategic sub-process of Customer Relationship Management in a DDMRP implementation, but globally it is the eighth more impacted strategic sub-process. 
Four out of five of the most impacted strategic sub-processes are from Manufacturing Flow Management (MFM), reinforcing the focus of DDMRP in material flow. The same trend does not repeat with Order Fulfillment (OF) and Demand Management (DM) the second and the third most impacted processes according to the experts' judgements.

In order to provide a better view of the results, Table 10 was created showing the 10 most impacted SCM strategic sub-processes ranked from the most impacted strategic subprocess to the least impacted strategic sub-process. The table must be read following the same guidelines provided to Table 9.

According to the findings, the most impacted strategic sub-process is MFM3, which is to determine of push-pull boundaries or customer order decoupling points. This result was partially expected, since, as stated by Ptak and Smith (2016) the first component of DDMRP is determining where the decoupling points and their respective buffers should be placed.

Table 10 - 10 most impacted SCM strategic sub-processes

\begin{tabular}{llccccc}
\hline $\begin{array}{c}\text { Main } \\
\text { Process }\end{array}$ & $\begin{array}{c}\text { Sub- } \\
\text { Process }\end{array}$ & $\begin{array}{c}\text { Absolute } \\
\text { Impact Weight }\end{array}$ & $\begin{array}{c}\text { Process } \\
\text { Rank }\end{array}$ & $\begin{array}{c}\text { Relative Impact } \\
\text { Weight }\end{array}$ & $\begin{array}{c}\text { Global Impact } \\
\text { Weight }\end{array}$ & $\begin{array}{c}\text { Global } \\
\text { Rank }\end{array}$ \\
\hline MFM & MFM3 & 1,781 & 1 & 0,347 & 0,119 & 1 \\
\hline MFM & MFM5 & 1,116 & 2 & 0,217 & 0,075 & 2 \\
\hline MFM & MFM4 & 1,069 & 3 & 0,208 & 0,072 & 3 \\
\hline OF & OF5 & 1,351 & 1 & 0,264 & 0,045 & 4 \\
\hline MFM & MFM2 & 0,652 & 4 & 0,127 & 0,044 & 5 \\
\hline CSM & CSM4 & 1,801 & 1 & 0,444 & 0,039 & 6 \\
\hline DM & DM6 & 1,625 & 1 & 0,270 & 0,038 & 7 \\
\hline CRM & CRM4 & 1,709 & 1 & 0,339 & 0,038 & 8 \\
\hline MFM & MFM1 & 0,521 & 5 & 0,101 & 0,035 & 9 \\
\hline OF & OF2 & 1,029 & 2 & 0,201 & 0,034 & 10 \\
\hline SOHי: A & & & & & & \\
\hline
\end{tabular}

Source: Author (2019)

The second most impacted strategic sub-process is MFM5, which is to develop framework of metrics to measure the effectiveness of the MFM process. Since DDMRP has a whole new view on measuring effectiveness of the production processes, it should be expected that this sub-process would be affected by DDMRP implementation.

The third most impacted strategic sub-process is MFM4, which is to identify manufacturing constraints and requirements. As shown in the preliminary results, when implementing DDMRP, the stock positioning and sizing is crucial to the correct operation of buffers, in additions, stocks are dynamic, changing according to the actual demand.

Analyzing the fourth most impacted strategic sub-process, OF5, which is responsible to develop framework of metrics to measure the effectiveness of the OF process. It is made clear 
by the respondents that DDMRP implementation has a great impact on the creation and representation of the organizations' metrics. Amongst the 10 most impacted sub-processes, 5 of them (MFM5, OF5, CSM4, DM6 and CRM4) were related with development of metrics framework for that specific process.

According to Smith and Smith (2013a) the required changes to sustain competitiveness in the New Normal require new rules and measures. To embrace and deploy those metrics will require the removal of some very ingrained, even hard-coded assumptions, metrics, and rote behavior. Unless people can think systemically and design operating models, these metrics will elude us; the metrics are a function of understanding the fundamental principles of flow and systemic thinking.

Initiatives in develop Demand Driven Supply Chain Management (DDSCM) specific metrics are still in development. According to Khul (2018), only metrics that consistently support the flow of relevant information and materials should be used when implementing Demand Driven initiatives. This transition does not necessarily dictate that all previous metrics need to be replaced, however, potential conflicts must be eliminated, and information must be made available to all stages. 


\section{CONCLUSIONS AND RECOMMENDATIONS}

The present chapter has 3 sections. The first section (5.1) discuss the results and findings of this thesis comparing it with the researched literature. The second section (5.2) concludes the work, exposing its contributions to development of science. The third section (5.3) is a review of the limitations found during the work development and recommendations for future works in the same field of study.

\subsection{Results Discussion}

This study represents an effort to improve DDMRP theory and to provide some guidelines for implementation in the context of SCM. In this connection, the SCM processes and strategic sub-processes were evaluated regarding their perceived received impact from a DDMRP implementation in specialists' point of view. Further, the findings of this analysis may assist Supply Chain professionals in planning decision strategies useful in the effective implementation of DDMRP initiatives.

This study performed an AHP analysis as a mean to understand at which extent SCM processes are impacted during DDMRP implementation. Through the data collection from surveys with specialists it was possible to measure the relative impacts and answer the research question of "how DDMRP implementation impacts the processes and strategic sub-processes of SCM and how much they are impacted?"

Using the framework proposed by the Global Supply Chain Forum, which is the one of the most comprehensive model according to the literature review, it was possible to develop a survey to build a hierarchy of the most impact suffered among the SCM processes and strategic sub-processes of this framework in a DDMRP implementation.

According to the findings of the present study, Manufacturing Flow Management and Order Fulfillment are the most impacted SCM processes in a DDMRP implementation. These results reinforce the previous findings that DDMRP theory is extremely focused in promoting the flow of materials (manufacturing flow management) and flow of information (order fulfillment).

A lot of similarities were found when comparing the results gathered with the preliminary results of the literature review. We found the most evidence of impacts suffered regarding the processes of Manufacturing Flow Management, Demand Management and Order 
Fulfillment, which, according to the experts' judgements, are the three most impacted processes in a DDMRP implementation.

One trend identified was the difference of judgment regarding the impacts of DDMRP in SCM process when we analyze the separated answers of industry professional and researchers. The industry professionals reported a greater impact suffered by processes responsible for dealing with end customers, respectively Customer Relationship Management and Customer Service Management. When performing the literature review, we did not find in DDMRP theory evidences that these sub-processes would be among the most impacted ones after its implementation.

The perceived impact on CRM and CSM processes reported by industry professionals were identified in current researches that assess the improvements of DDMRP over other MPC systems. Results such as increase in OTIF, increase in service level and lead-time reduction directly impacts customer's relationship with the company. The main concern raised by the difference in judgments is that DDMRP theory needs to be more comprehensive in order to assess these impacts.

Another relevant outcome was the revelation of metric-related strategic sub-processes being amongst the most impacted sub-processes of SCM. This outcome indicates that DDMRP has a great impact on how companies measure their performance and therefore managers should pay a great attention on its indicators while implementing DDMRP.

The Demand Driven theory is evolving to involve more than material and information flow. Although new propositions, such as Demand Driven Adaptive Enterprise (DDAE), being developed in order to create a more sensitive organization were the impacts are assessed in a more comprehensive way, these initiatives are under development and still do not have strong academic evidence of its benefits in organizations in order to fill this perceived gap in DDMRP theory.

\subsection{Conclusion}

According to the results shown in previous section, this work was effective in measure the level of impact that DDMRP implementation has on SCM processes. Understand these impacts and its magnitude provides DDMRP practitioners required knowledge to assess relevant trade-offs that occur during its implementation.

Two main results of this thesis can be highlighted. First, the ranking and categorization of the impacts on SCM processes and sub-processes after DDMRP implementation (Table 6 
and Table 9) and the identification of perceived impacts on processes and sub-processes that were not fully assessed by the current DDMRP literature.

The AHP methodology helps in ranking the impact inflicted on SCM processes and subprocesses according to their relative importance. The research outcome reveals that the SCM main process impacted is the Manufacturing Flow Management. Consequently, huge focus on this process must be given to increase the chances of a successful DDMRP initiative in an organization. The results gathered can help managers and researchers not only to prioritize the processes during DDMRP implementation but also to guide it and raise points of attention during research and practice.

Besides ranking the level of impact in the SCM processes, one of the purposes of the present work is the enrichment of DDMRP theory aside from the comparison of performance and results of its implementation. The results gathered are important in establish some groundwork for theory evolution, by measuring its impacts and discovering lacks in theory to permit the development of new studies to assess these gaps in the most effective way.

\subsection{Limitations of work and recommendations}

The major limitation of this work is the lack of academic literature regarding DDMRP. The small number of published articles in DDMRP is a reflex of little number of academics researching this field and industries implementing it. That way, it was difficult to gather many survey respondents to have a broader coverage of the results.

Another limitation is that, despite having respondents from South America, North America and Europe, the industry professional profile was composed only of Brazilian cases, which can possibly add a regional bias into the analysis of the industry respondents.

It is important to add that AHP, as every other decision method, is not perfect to represent what really happens and has a subjective nature that is intrinsic to the method. To reduce this subjectivity, the respondents could be accompanied during the answering of the survey, in order that every term and concepts were understood the same way by them.

This thesis represents a small step into evolution of DDMRP theory and it is focused on expanding the coverage of the subject and to facilitate implementation of the method for current and future practitioners. To understand implementation impacts is an important asset in order to evolve theory for missing aspects that are evidenced in the field. The future work that evolve 
from this one will be able to focus on specific aspects of these impacts, resulting in more assertive outcomes.

Future works should focus on improving limitations of this one. The first suggestion is in expanding the number of analyzed subjects. Since new research in DDMRP are being published, the number of researchers and professionals are growing as well, resulting in a greater number of possible subjects for surveys and interviews.

Another recommendation is to gather different profiles to participate in the researches, such as practitioners, researchers, software developers and consultants, located in different countries to remove the possibility of regional bias. The plurality of participants combined with use of other methods to collect data, in a more open structure way, would possibly result in outcomes that were not assessed because of the strict characteristic of the AHP methodology.

Since the research pointed the determination of push-pull boundaries as the most impacted strategic sub-process in a DDMRP implementation, it raises the importance of expand the research regarding the positioning of DDMRP buffers. Current theory suggests that experience should be used to decide where to position strategic buffers (MICLO, 2016). Future work on DDMRP could explore new ways of positioning buffers, without need to rely only on experts' opinions.

Another outcome on the analysis of the sub-processes was that 5 out of the 10 most impacted sub-processes are related with metrics, revealing a substantial impact that DDMRP implementation inflicts on SCM metrics. Until now there are no studies on how SCM metrics relates with DDMRP metrics. Developments on this subject would help practitioners and researchers to mitigate possible harmful outcomes that may happen resulting from DDMRP endeavors in organizations.

Lastly, the use of a more exploratory approach towards novel theories in the Demand Driven field would be interesting. More comprehensive theories, such as DDAE, which could fill the literature gaps perceived in this thesis, are still in an embryonic state in academic research. New research in this area would benefit every Demand Driven practitioner in providing better tools to deal with impacts that are not assessed by the current DDMRP academic research. 


\section{REFERENCES}

ABDEL-BASSET, M.; MANOGARAM, G.; MOHAMED, M. Internet of Things (IoT) and its impact on supply chain: A framework for building smart, secure and efficient systems. Future Generation Computer Systems, n. 86, pp. 614-628, 2018

ABUHILAL, L.; RABADI, G.; SOUSA-POZA, A. Supply Chain inventory control: A comparison among JIT, MRP and MRP with information sharing using simulation. Engineering Management Journal, v. 18, n. 2, pp. 51-57, 2015

ACZEL, J.; SAATY, T. Procedures for synthesizing ratio judgements. Journal of Mathematical Psychology, v. 27, n. 1, pp. 93-102, 1983

AGARWAL, A.; SHANKAR, R.; TIVARI, M. Modeling agility of supply chain. Industrial Marketing Management, v.36 n.4, pp. 443-457, 2007

AITKEN, J.; CHILDERHOUSE, P.; TOWILL, D. The impact of product life cycle on supply chain strategy. International Journal of Production Economics, v. 85, n. 2, pp.127-140, 2003

ALEXANDER, M. Manufacturing Excellence without forecast-driven MRP. Logistics \& Transport Focus, v. 18, n. 11, pp. 44-45, 2016.

ALONSO, J.; LAMATA, M. Consistency in the Analytic Hierarchy Process: A new approach. International Journal of Uncertainty, Fuzziness and Knowledge-Based Systems, v. 14, n. 4, pp. 445-459, 2006

AYERS, J.; MALMBERG, D. Supply Chain Systems: Are you Ready? Information Strategy: The Executives Journal, v. 19, p. 18-27, 2002

BLOME, C. et al. Antecedents and Enablers of Supply Chain Agility and its Effect on Performance. International Journal of Production Research, v. 51, n. 4, pp. 1295-1318, 2013.

BOLUMOLE, Y.; KNEMEYER, A.; LAMBERT, D. The Customer Service Management Process. The International Journal of Logistics Management, v. 14, n. 2, pp. 15-31, 2003. 
BRANDÃO, M. Avaliação do valor do Lead Time na Cadeia de Suprimentos de Produtos de Luxo. 2018, Thesis (Masters in Production Engineering), Universidade Federal de São Carlos.

BRIOZO, R.; Localização de uma Unidade de Pronto Atendimento - UPA 24h: uma aplicação de método multicritério de tomada de decisão. 2013. Thesis (Master Program in Production Engineering), University of São Paulo.

BURROWS III, R. The Market Driven Supply Chain: A revolutionary model for sales and operations planning in the new on-demand economy. AMACOM, 2012.

CECERE, L.; O'MARAH, K.; PRESLAN, L. Driven by demand. Supply Chain Management Review, v. 8; pp. 15-16, 2004

CHRISTOPHER, M. The Agile Supply Chain: Competing in Volatile Markets, Industrial Marketing Management, v. 29, pp. 37-44, 2000

CHRISTOPHER, M.; LOWSON, R.; PECK, E. Creating Agile Supply Chains in the Fashion Industry, International Journal of Retail \& Distribution Management, v. 32, n. 8, p. 367 376,2004

CHRISTOPHER, M.; TOWILL, D. An integrated model for the design of agile supply chain. International Journal of Physical Distribution and Logistics Management, v. 31, n. 4, pp. 235-246, 2001.

COOPER, M. et al. Meshing Multiple Alliances. Journal of Business Logistics, v. 18, n. 1, pp 67-89, 1997

COOPER, M.; GARDNER, J. Good Business Relationship: More than just partnerships or strategic alliances, International Journal of Physical Distribution and Logistics Management, v. 23, n. 6, pp.14-20, 1993

COOPER, M.; LAMBERT, D.; PAGH, J. Supply Chain Management: More than a new name for logistics, The International Journal of Logistics Management, v. 8, n. 1, pp. 1-14, 1997

CROXTON, et al. The Supply Chain Management Processes, International Journal of Logistics Management, v. 12, n. 2, pp. 13-36, 2001 
CROXTON, K. The Order Fulfillment Process. The International Journal of Logistics Management, v. 14, n. 1, pp. 19-32, 2003

CROXTON, K.; LAMBERT, D.; GARCIA-DASTUGUE, S.; ROGERS, D. The Demand Management Process. The International Journal of Logistics Management, v. 13, n. 2, pp. 51-66, 2002

DEMETER, K. Manufacturing Strategy and Competitiveness. International Journal of Production Economics, v. 81-82, pp. 205-213, 2003

DOVE, R. Tools for Analyzing and Constructing Agile Capabilities. Perspectives on Agility Series, Agility Forum: Bethlehem, PA. 1994

DRAKE, P.; LEE, D.; HUSSAIN, M. The lean and agile purchasing portfolio model. Supply Chain Management: An International Journal, v. 18, n. 1, pp. 3-20, 2013

DUCROT, L.; AHMED, E. Investigation of Potential Added Value of DDMRP in Planning Under Uncertainty and Finite Capacity. 2019. Thesis (Master of Applied Science in Supply Chain Management), Massachusetts Institute of Technology (MIT).

EISENHARDT, M. Building theory from case study research. Academy of Management Review, v. 14, n.4, pp. 532-550, 1989

EMMET, S.; CROCKER, B. The Relationship-Driven Supply Chain: Creating a Culture of Collaboration throughout the Supply Chain, 2nd ed. New York, NY: Gower Publishing Company, 2006

FARAHANI, P.; AKKERMAN, R.; WILKE, J. A hierarchical demand-driven production planning and control framework for the FMCG industry: An SAP-based approach, IEEE International Conference, December 2013, Bangkok, Thailand, 2013

FIALA, P. Information Sharing in Supply Chains. OMEGA, v. 33, n. 5, pp. 419-123, 2005.

FISHER, M. What Is the Right Supply Chain for Your Product? A Simple Framework Can Help You Figure out the Answer. Harvard Business Review, v. 75, pp. 105-116, 1997

FORMAN, E.; PENIWATI, K. Aggregating individual judgments and priorities with the Analytic Hierarchy Process. European Journal of Operational Research, v. 108, pp. 165169,1998 
GANDHI, S. et al. A combined approach using AHP and DEMATEL for evaluating success factors in implementation of green supply chain management in Indian manufacturing industries. International Journal of Logistics Research and Applications, v. 19, n. 6, pp. 537-561, 2016

GATTORNA, J. Living Supply Chains: Alinhamento dinâmico da Cadeia de Valor. São Paulo, SP: Prentice Hall, 2009

GENOVESE, A.; ACQUAYE, A.; FIGUEROA, A.; KOH, L. Sustainable supply chain management and the transition towards a circular economy: Evidence and some applications.

OMEGA, v. 66, pp. 344-357, 2017.

GEORGE, A. Demand Driven Material Requirement Planning (DDMRP) - A new method for production and planning management. 2018. Thesis (Master Program in Industrial Engineering), Politecnico di Milano.

GOLDSBY, T.; GARCIA-DASTUGUE, S. The Manufacturing Flow Management Process. The International Journal of Logistics Management, v. 14, n. 2, pp. 33-52, 2003

GOVINDAN, K.; MANGLA, S.; LUTHRA, S. Prioritizing indications in improving supply chain performance using fuzzy AHP: insights from the case example of four Indian manufacturing companies. Production Planning \& Control, v. 28, n.6-8, pp. 552-573, 2017

GUNASEKARAN, A.; YUSUF, Y. Agile manufacturing: a taxonomy of strategic and technological imperatives. International Journal of Production Research, v. 40, n. 6, pp. $1357-1385,2002$

HIETIKKO, J. Supply Chain Integration with Demand Driven Material Requirements Planning System, 2014, Thesis (Master Program in Industrial Management), University of Vaasa

HILL, T. Manufacturing Strategy - Text and Cases. 2 ed. New York, NY: PALGRAVE, 2000.

HO, D.; NEWELL, G.; WALKER, A. The importance of property-specific attributes in assessing CBD office building quality. Journal of Property Investment \& Finance, v. 23, n. 5, pp. 424-444, 2005. 
HONG, J.; ZHANG, Y.; DING, M. Sustainable supply chain management practices, supply chain dynamic capabilities, and enterprise performance. Journal of Cleaner Production, v. 172 , pp. 3508-3519, 2018

HUGHES, R. Expert judgement as an estimating method. Information and Software Technology, v.38, pp. 67-75, 1996

IHME, M. Interpreting and applying demand driven MRP: a case study. 2015, Thesis (Doctorate in Industrial Engineering), Nottingham Trent University.

IHME, M.; STRATTON, R. Evaluating demand driven MRP: a case based simulated study. International Conference of the European Operations Management Association. Neuchatel, Switzerland. 2015

IVLEV, I.; KNEPPO, P.; BARTAK, M. Method for selecting expert groups and determining the importance of experts' judgements for the purpose of managerial decision-making tasks in health system. Business Administration and Management, v.18, n.2, pp.57-72, 2015

KHUL, M. Flow Metrics: An important piece to the puzzle. E-3 Magazine. v. 4, pp. 12, 2018.

KORTABARRIA, A. et al. Material Management without Forecasting: From MRP to Demand Driven MRP, Journal of Industrial Engineering and Management, v. 11, n. 4, pp. 632-650, 2018.

KUMAR, A.; SHARMAN, G. We love your product, but Where Is It? Sloan Management Review, v. 33, n. 2, pp. 93-99, 1992

LAMBERT, D. Customer Relationship Management as a business process. Journal of Business \& Industrial Marketing, v. 25, n. 1, pp. 4-17, 2009.

LAMBERT, D. Supply Chain Management: Processes, partnerships, performance (4 ed.). Ponte Vedra Beach, FL: Supply Chain Management Institute, 2014

LAMBERT, D.; COOPER, M. Issues in Supply Chain Management, Industrial Marketing Management, v. 29, pp. 65-83, 2000

LAMBERT, D.; COOPER, M.; PAGH, J. Supply Chain Management: Implementation Issues and Research Opportunities, The International Journal of Logistics Management, v. 9, n. 2, pp. 1-19, 1998 
LAMBERT, D.; ENZ, M. Issues in Supply Chain Management: Progress and potential. Industrial Marketing Management, v. 62, pp. 1-16, 2017

LAMBERT, D.; GARCÍA-DASTUGUE, S.; CROXTON, K. An Evaluation of ProcessOriented Supply Chain Management Frameworks, Journal of Business Logistics, v. 26, n. 1, 2005

LAMBERT, D.; SCHWIETERMAN, M. Supplier Relationship management as a macro business process. Supply Chain Management: An International Journal, v. 17, n.3, pp. 337 352,2012

LEE, J.; JANG; S. A case study to decide the proper inventory on-hand level based on Demand Driven MRP replenishment buffer. Journal of the Korean Society of Supply Chain Management, v. 13, pp. 29-42, 2013

MALHOTRA, M.; GROVER, V. An assessment of survey research in POM: from constructs to theory. Journal of Operations Management, v. 16, pp. 407-425, 1998.

MASON-JONES, R.; TOWILL, D. R. Total cycle time compression and the agile supply chain. International Journal of Production Economics, v. 62, p. 61-73, 1999

MASON-JONES, R.; NAYLOR, B.; TOWILL, D. Lean, agile or leagile? Matching your supply chain to the marketplace. International Journal of Production Research, v. 38, n. 17, pp. 4061-4070, 2000

MATHIYAZHAGAN, K.; GOVINDAN, K.; HAQ, A. Pressure analysis for green supply chain management implementation in Indian industries using Analytic Hierarchy Process. International Journal of Production Research, v. 52, n. 1, pp. 188-202, 2014

MENTZER, J. et al. Defining Supply Chain Management. Journal of Business Logistics, v. 22 , n. 2, pp. 1-25, 2001

MICLO, R. Challenging the "Demand Driven MRP" Promises: A Discrete Event Simulation Approach. 2016, Thesis (Doctorate in Industrial Engineering), Ecole Des Mines D'Albi-Carmaux.

MICLO, R. et al. Demand Driven MRP: assessment of a new approach to materials management, International Journal of Production Research, v. 57, n. 1, pp. 166-181, 2019 MICLO, R. et al. MRP vs. Demand-Driven MRP: Towards and Objective Comparison, 6th IESM Conference, October 2015, Seville, Spain, 2015 
MOLLENKOPF, D.; RUSSO, I.; FRANKEL, R. The returns management process in supply chain strategy. International Journal of Physical Distribution \& Logistics Management, v. 37, n. 9, pp. 568-592, 2007

NAYLOR, B.; NAIM, M. M.; BERRY, D. Leagility: Integrating the lean and agile manufacturing paradigms in the total supply chain, International Journal of Production Economics, v. 62, n. 1-2, p. 107-118, 1999

NOURI, F.; NIKABADI, M; OLFAT, L. The Role of Supply Chain Features in the Effectiveness of Sustainability Practices in the Service Supply Chain: Application of Fuzzy Rule-Based System. International Journal of Information, Technology \& Decision Making, v. 18, n. 3, pp. 867-899, 2019

O'MARAH, K.; CHEN, X. Future of supply chain. SCM World. 2016 available in: http://www.scmworld.com/wpcontent/uploads/2017/07/Future_of_Supply_Chain_2016_.pdf

OSTENDORF, J.; MOUZAS, S.; CHAKRABARTI, R. Innovation in business networks: The role of leveraging resources. Industrial marketing Management, v. 43, n. 3, pp. 504-511, 2014.

POWER, D. Supply Chain management integration and implementation: a literature review. Supply Chain management: and International Journal, v. 10, n. 4, pp. 252-263, 2005

PTAK, C.; SMITH, C. Demand Driven Material Requirement Planning (DDMRP). Norwalk, CT: Industrial Press, 2016

PTAK, C.; SMITH, C. Orlicky's Material Requirements Planning, 3 ed. McGraw Hill Professional, 2011

QI, Y. et al. The impact of operations and supply chain strategies on integration and performance. International Journal of Production Economics, v. 185, pp. 162-174, 2017

ROGERS, D.; LAMBERT, D.; CROXTON, K.; GARCÍA-DASTUGUE, S. The Returns Management Process. The International Journal of Logistics Management, v. 13, n. 2, pp. $1-18,2002$

ROGERS, D.; LAMBERT, D.; KNEMEYER, M. The Product Development and Commercialization Process. The International Journal of Logistics Management, v. 15, n. 1, pp. 43-56, 2004 
$\mathrm{ROH}$, et al. Implementation of a responsive supply chain strategy in global complexity: The case of manufacturing firms. International Journal of Production Economics, v. 147, pp. 198-210, 2014

SAATY, T. Absolute and Relative measurement with the AHP. The most livable cities in the United States. Socio-Economic Planning Sciences, v. 26, n. 6, pp. 327-331, 1986

SAATY, T. Decision Making, Scaling, and Number Crunching. Decision Sciences, v. 20, n. 2, pp. 404-409, 1989

SAATY, T. Decision making with the analytic hierarchy process. International Journal of Services Sciences, v. 1, n. 1, pp.83-98, 2008

SAATY, T. The Analytic Hierarchy Process. 1 ed, New York: McGraw-Hill, 1980

SAATY, T.; TRAN, L. On the invalidity of fuzzifying numerical judgments in the Analytic Hierarchy Process. Mathematical and Computer Modelling, v. 49, n. 9, pp. 62-75, 2007

SAATY, T.; VARGAS, L. Models, Methods, Concepts \& Applications of the Analytical Hierarchy Process. New York, NY: Springer Science \& Business Media, 2012.

SCHILLING, M.; HILL, C. Managing the New Product Development Process: Strategic Imperatives, The Academy of Management Executive, v. 12, n. 3, pp. 67-81, 1998

SHOFA, M. J.; MOEIS, A. O.; RESTIANA, N. Effective production planning for purchased part under long lead time and uncertain demand: MRP Vs demand-driven MRP, IOP Conf. Series: Materials Science and Engineering, v. 337, 2018

SIMCHI-LEVI, D.; SIMCHI-LEVI, E.; WATSON, M: Tactical Planning For Reinventing The Supply Chain IN: HARRISON, T. P.; LEE, H. L.; NEALE J. J. The Practice Of Supply Chain Management: Where Theory And Application Converge, 2nd ed. New York, NY: Springer, Cap. 2, p 13-30, 2005

SIPAHI, S.; TIMOR, M. The analytic hierarchy process and analytic network process: an overview of applications. Management Decision, v. 18, n. 5, pp. 775-808, 2010.

SMITH, D.; SMITH, C. Demand Driven Performance: Using Smart Metrics. 1 ed. New York, NY: McGraw-Hill, 2013a 
SMITH, D.; SMITH, C. What's wrong with Supply Chain Metrics? Strategic Finance, October, pp. 27-33, 2013b

SRIVASTAVA, S. Green supply-chain management: A state-of-the-art literature review. International Journal of Management Reviews, v. 9, n. 1, pp. 53-80, 2007

SWAFFORD, P. et al. Achieving supply chain agility through IT integration and flexibility. International Journal of Production Economics, v. 116, pp. 288-297, 2008

TOWILL, D. R. The seamless supply chain: the predators' strategic advantage. International Journal of the Techniques of Manufacturing, v. 13, n. 1, p. 37-56, 1997

TRAMARICO, C.; SALOMON, V.; MARINS, F. Analytic Hierarchy Process and Supply Chain Management: A bibliometric study. Procedia Computer Science, v. 55, pp. 441-450, 2015

TURNBULL, P.; FORD, D.; CUNNINGHAM, M. Interaction, relationships and networks in business markets: an evolving perspective. Journal of Business and Industrial Marketing, v. 11, n. 3/4, pp. 44-62, 1996.

VARGAS, L. An overview of the Analytic Hierarchy Process and its applications. European Journal of Operational Research, v. 48, pp. 2-8, 1990

VELYCHKO, O.; GORDIYENKO, T.; KOLOMIETS, L. Methodologies of expert's competence evaluation and group expert evaluation. Metallurgical and Mining Industry, v.7, n.2, pp.262-271, 2015

VOSS, C.; TSIKRIKTSIS, N.; FROHLICH, M. Case research in operations management. International Journal of Operation \& Production Management, v.22, n.2, pp. 195-219, 2002

WEDLEY, W. Consistency prediction for incomplete AHP matrices. Mathematical and Computer Modelling, v. 17, n. 4-5, pp. 151-161, 1993

WORTMANN, J. C. Production Management systems for one-of-a-kind products. Computers in Industry, v. 19, n. 1, 1992

WU, W. Choosing knowledge management strategies by using a combined AHP and DEMATEL approach. Expert Systems with Applications, v. 35, pp. 828-835, 2008 
XIA, W.; WU, Z. Supplier selection with multiple criteria in volume discount environments. OMEGA, v. 35, pp. 494-504, 2007

YANG, J.; LEE, H. An AHP decision model for facility location selection. Facilities, v. 15, n.9-10, pp. 241-254, 1997.

YIN, R. Case study research: design and methods. 5 ed. Thousand Oaks: Sage Publications, 2014

YIN, R. Estudo de Caso: Planejamento e Métodos. 2 ed. São Paulo, SP: Bookman, 2001.

ZHANG, M.; YUE, H. Analysis of the Impact Factors on the Harmony Degree of Community Based on AHP. Proceedings of the 15th International Conference on Industrial Engineering and Engineering Management, v. A-C; pp. 2293-2297, 2008 


\section{APPENDIX A - RESULTS OF LITERAUTRE REVIEW ON DDMRP}

Represented in this appendix are the results of the literature reviews on DDMRP performed during the realization of the research. The last update of the review was in June 2019. Two searches were performed during the realization of the work in the following databases: Emerald Insight, Science Direct, Web of Knowledge, Scopus and Google Scholar.

The first search was realized only in Web of Knowledge database and considered all the available fields for the selected keywords. The keywords used in the first search was a combination of the terms MRP, material planning, production planning, demand management and material management in one side with demand driven, customer driven, market driven, demand oriented, customer oriented, market oriented, demand-driven, customer-driven, market-driven, demand-oriented, customer-oriented and market-oriented on the other side. The first search was only made in the Web of Knowledge database because it was the only that supported the input of the full string. The full search string was defined as it follows:

MRP AND "demand driven" or MRP AND "customer driven" or MRP AND "market driven" or MRP AND "demand oriented" or MRP AND "customer oriented" or MRP AND "market oriented" or MRP AND "demand-driven" or MRP AND "customer-driven" or MRP AND "market-driven" or MRP AND "demandoriented" or MRP AND "customer-oriented" or MRP AND "market-oriented" or "material planning" AND "demand driven" or "material planning" AND "customer driven" or "material planning" AND "market driven" or "material planning" AND "demand oriented" or "material planning" AND "customer oriented" or "material planning" AND "market oriented" or "material planning" AND "demand-driven" or "material planning" AND "customer-driven" or "material planning" AND "market-driven" or "material planning" AND "demand-oriented" or "material planning" AND "customer-oriented" or "material planning" AND "market-oriented" or "production planning" AND "demand driven" or "production planning" AND "customer driven" or "production planning" AND "market driven" or "production planning" AND "demand oriented" or "production planning" AND "customer oriented" or "production planning" AND "market oriented" or "production planning" AND "demand-driven" or "production planning" AND "customer-driven" or "production planning" AND "market-driven" or "production planning" AND "demand-oriented" or "production planning" AND "customer-oriented" or "production planning" AND "market-oriented" or "demand management" AND "demand driven" or "demand management" AND "customer driven" or "demand management" AND "market driven" or "demand management" AND "demand oriented" or "demand management" AND "customer oriented" or "demand management" AND "market oriented" or "demand management" AND "demand-driven" or "demand management" AND "customer-driven" or "demand management" AND "market-driven" or "demand management" AND "demand-oriented" or "demand management" AND "customeroriented" or "demand management" AND "market-oriented" or "material management" AND "demand driven"

This first search returned 40 different articles that were used for an initial categorization of DDMRP. After this first characterization, a more focused review as performed, this time in different databases with narrow search strings. 
Table 11 - Search results by keywords and databases

\begin{tabular}{|c|c|c|c|c|c|}
\hline \multirow[b]{2}{*}{ Search } & \multicolumn{5}{|c|}{ Results } \\
\hline & $\begin{array}{c}\text { Emerald } \\
\text { Insight }\end{array}$ & $\begin{array}{c}\text { Science } \\
\text { Direct }\end{array}$ & $\begin{array}{l}\text { Web of } \\
\text { Science }\end{array}$ & Scopus & $\begin{array}{l}\text { Google } \\
\text { Scholar }\end{array}$ \\
\hline 1 DDMRP & 0 & 1 & 7 & 11 & 31 \\
\hline 2 MRP AND "demand driven" & 1 & 3 & 10 & 17 & 16 \\
\hline 3 MRP AND "customer driven" & 0 & 1 & 1 & 2 & 0 \\
\hline 4 MRP AND "market driven" & 0 & 0 & 0 & 1 & 0 \\
\hline 5 MRP AND "demand oriented" & 0 & 0 & 0 & 0 & 0 \\
\hline 6 MRP AND "customer oriented" & 1 & 1 & 3 & 5 & 0 \\
\hline 7 MRP AND "market oriented" & 0 & 0 & 1 & 1 & 0 \\
\hline 8 "material requirements planning" AND "demand driven" & 0 & 2 & 4 & 5 & 2 \\
\hline 9 "material requirements planning" AND "customer driven" & 1 & 2 & 1 & 1 & 1 \\
\hline 10 "material requirements planning" AND "market driven" & 0 & 0 & 0 & 0 & 0 \\
\hline 11 "material requirements planning" AND "demand oriented" & 0 & 0 & 0 & 0 & 0 \\
\hline 12 "material requirements planning" AND "customer oriented" & 0 & 1 & 1 & 0 & 0 \\
\hline 13 "material requirements planning" AND "market oriented" & 0 & 0 & 0 & 0 & 0 \\
\hline TOTAL OF ARTICLES FOUND & 3 & 11 & 28 & 43 & 50 \\
\hline TOTAL OF ARTICLES WITHOUT REPETITION & 3 & 2 & 14 & 2 & 3 \\
\hline TOTAL OF RELEVANT ARTICLES & 3 & 2 & 13 & 2 & 3 \\
\hline
\end{tabular}

Source: Author (2019)

This second search returned 23 articles in total, with 3 more articles being found in magazines in CAPES database. The articles were categorized in its relevance for the theme, type of result and used methodology. The characterization of the article are represented in the table below.

Table 12 - Detail of analyzed articles of the second literature review

\begin{tabular}{|l|l|l|l|l|}
\hline Author & Year & Type & Method & Work Relevance \\
\hline Pekarcikova et al. & 2019 Article & Application & High \\
\hline Kortabarria et al. & 2019 Article & Comparison & High \\
\hline Kortabarria et al. & 2018 Article & Comparison & High \\
\hline Miclo et al. & 2019 Article & Comparison & High \\
\hline Shofa, Moeis and Restiana & 2017 Article & Comparison & High \\
\hline Miclo, Fontanilli and Lauras & 2015 Article & Comparison & High \\
\hline Smith and Smith & 2013 Article & Theory Build & High \\
\hline Favaretto and Marin & 2018 Working Paper & Comparison & High \\
\hline Smith and Smith & 2013 Article & Theory Build & High \\
\hline Erraoui et al. & 2019 Article & Theory Build & Medium \\
\hline Mula et al. & 2014 Article & Theory Build & Medium \\
\hline Miclo et al. & 2016 Article & Comparison & Medium \\
\hline Mohebbi et al. & 2007 Article & Comparison & Medium \\
\hline Abith & 2018 Dissertation & Application & Medium \\
\hline Baptiste & 2018 Conference & Application & Medium \\
\hline Castiglione et al. & 2018 Article & Theory Build & Medium \\
\hline Hincapie & 2018 Dissertation & Application & Medium \\
\hline Luscombe & 1994 Article & Theory Build & Medium \\
\hline Cheikhrouhou et al. & 2009 Article & NA & Low \\
\hline Langella & 2007 Article & NA & Low \\
\hline Martin et al. & 2018 Conference & NA & Low \\
\hline Yeh & 2000 Article & NA & Low \\
\hline Hao et al. & 1998 Article & NA & None \\
\hline Heim et al. & 2014 Article & NA & None \\
\hline Tamura and Fujita & 1995 Article & NA & None \\
\hline Wikner and Tang & 2008 Article & NA & None \\
\hline
\end{tabular}

Source: Author (2019) 


\section{APPENDIX B - COLLECTION INSTRUMENT AND PROTOCOL}

Dear Participant,

We are currently undertaking a research project into the impacts of DDMRP in the processes and strategic sub-processes of Supply Chain Management, based on Lambert and Cooper (2000) framework developed together with the Global Supply Chain Forum.

As part of this research, we are conducting a multi criteria analysis in order to cluster experts' opinions for evaluate the impact that DDMRP implementation has on Supply Chain Management Processes.

DDMRP is a new research area of study in academy. It involves a rethinking of Materials Management and use concepts taken from MRP (Material Requirements Planning), DRP (Distribution Requirements Planning), Lean, Six Sigma, and TOC (Theory of Constraints) along with specific innovations (MICLO, 2016).

Until now, academic research upon DDMRP has been mostly focused on applying it in different environments and measuring its results. Mindful of this, the purpose of this study is to identify the extents of the impacts that DDMRP implementation has on Supply Chain Management and evaluate if DDMRP theory has room for potential improvements, focused on specific areas and processes of SCM.

In the following pages, we would like to obtain your opinion as an expert in material management / supply chain management / production planning and control / DDMRP through a survey questionnaire, in which you will be requested to prioritize eight SCM processes and its strategic sub-processes regarding of how much impact it suffers from DDMRP implementation.

The information you will provide will be of great value for this research, and accordingly, your participation is anticipated and very much appreciated. We sincerely hope you can assist on this research project.

Lucas Santos

Master's Candidate

São Carlos School of Engineering

University of São Paulo

Prof. Dr. Kleber Esposto

Supervisor of the Master Research

São Carlos School of Engineering

University of São Paulo 
Researcher: Lucas Santos, Masters Candidate

Supervisor: Prof. Dr. Kleber Francisco Esposto, Professor at EESC - USP

\section{INFORMED CONSENT FORM}

You are being asked to participate in a research study regarding the impacts of DDMRP on SCM strategic processes and sub-processes as described by Lambert and Cooper (2000). Researcher Lucas Santos is conducting this research under the supervision of Prof. Dr. Kleber Francisco Esposto.

Please, read the information provided in Sections A and B carefully. You should ask the researcher Lucas Santos to explain any sections that are unclear to you and to answer any questions that you may have. If, after deciding to participate in this study, you find you have more questions, you should contact the researcher at the number or email given at the end of this form.

If you decide to participate in this research, please complete the survey and return it directly to the researcher through email (lucasalves02@gmail.com or lucassantos@usp.br) which are also available at the end of this form. Please, keep a copy of this consent form for your records as it contains important information, including names and telephone numbers that you may wish to have in the future.

By completing and returning the attached survey, you are consenting to participate in this research. All the information provided by the respondents will not be disclosed and will only be known by the researcher and his supervisor. The individual answers, if published on the study, will not disclose the name of the respondent. Care will be taken with the reported information to make impossible to any reader to identify the identity of the information source. 


\section{SECTION A - INFORMATION FOR PARTICIPANTS}

\section{Participants}

Experts include those identified as having an extensive knowledge of, or ability in Demand Driven Material Requirements Planning (DDMRP), Supply Chain Management, Materials Planning, Production Planning and Control and correlated areas. Experts are expected to include university academics, professional engineers, planners, practitioners, etc.

\section{Participants' Right to Decline}

Your participation is voluntary and you can withdraw from the survey after having agreed to participate. You are free to refuse to answer any question that is being asked in the questionnaire. The researcher may contact you in case of any missing answer in order to elicit any errors in the survey responses. If after returning the questionnaire you decide that you no longer want to participate in this research, you should inform the researcher Lucas Santos by email or telephone. Your answers will be removed from the research and the questionnaire will be deleted if the study is not finished by the time you warn the researcher.

\section{Time to Complete Survey}

The survey will take approximately 45 minutes to complete.

\section{Conducting Survey}

The survey will be conducted by mailing the questionnaire directly to the participant in the provided email and asking the respondent to mail the survey back when completed.

Each interested participant will be provided with a cover letter, informed consent form, processes description, questionnaire and a summary of the used terms to facilitate the weighting of the questions.

\section{Confidentiality}

The information provided by participants will not be disclosed. Only participant's name will be asked and it will not be known to any other person than the researcher and his supervisor. The individual answers, if published on the study, will not disclose the name of the respondent. The answers given by respondents will be only used for research purposed and for writing a report. Care will be taken in report information so as to make impossible to any reader to identify the role and hence the identity of the information source. 


\section{Use of Information}

The information and findings obtained will be used for writing a thesis as one of the requirements to obtain the Master's title in Production Engineering. In addition, they may be used in seminars, conference presentations and research publications always respecting the data confidentiality

\section{Availability of Results}

A summary of the results is expected to be available by January 2020. Participants wanting a copy of the full study should inform the researcher by email.

\section{Contact Information}

If you have any questions or if you have a problem you think may be related to your participation in this research study, or if you would like to withdraw, you may communicate with the researcher responsible for this research study or with someone on the research team at the following numbers and/or emails:

Lucas Alves da Silva Santos: REDACTED - lucassantos@ usp.br

Kleber Francisco Esposto: REDACTED - kleberesposto@usp.br

\section{Participant Statement}

I have read this consent form. I have been given the opportunity to ask questions and my questions were answered to my satisfaction.

I understand that I may refuse to participate in this study and that if I refuse to participate this will not result in the loss of any benefits or services to which I am otherwise entitled. I agree to participate in this study. I also understand that if, for any reason, I wish to stop participating, I will be free to do so, and this will have no effect on me. I have been given a copy of this consent form for my records.

Name:

Date: 


\section{SECTION B - MULTI-CRITERIA ANALYSIS FOR EVALUATING DDMRP IMPACTS ON SUPPLY CHAIN MANAGEMENT PROCESSES}

Figure 26 - Criteria tree for AHP application

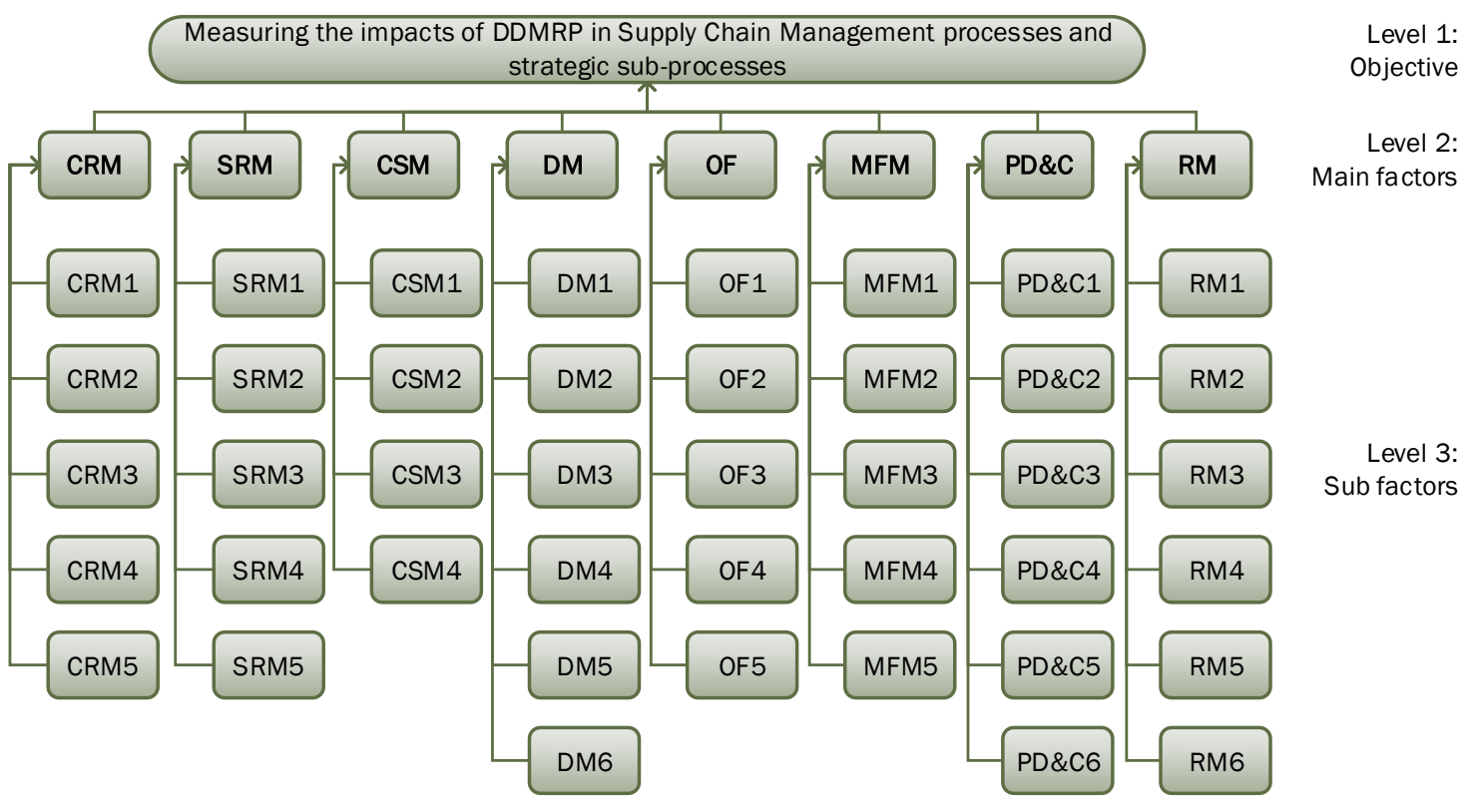

Source: Author (2019)

Goal: To measure the impacts of DDMRP in Supply Chain Management processes

Main Processes: Eight main processes were identified as proposed by Lambert and Cooper (2000) framework for Supply Chain Management. A brief summary of each process is provided below based on Lambert and Enz (2017):

1. Customer Relationship Management (CRM): The CRM process provides the structure for how relationships with customers will be developed and maintained. Involves identifying groups of customers and determine strategies for each group.

2. Supplier Relationship Management (SRM): The SRM process provides the structure for how relationships with suppliers will be developed and maintained. Involves identifying groups of suppliers and determining strategies for each group.

3. Customer Service Management (CSM): The CSM is the processes that deals with the administration of the Product and Service Agreement (PSA) by proactively intervening on the customer's behalf if there is any risk that can interfere with keeping the promises that have been made.

4. Demand Management (DM): The DM is the process that balances the customer's demand with the capabilities of the supply chain. With the right process in place, 
management can match supply with demand proactively and execute the plan with minimal disruptions. The process is not limited to forecasting. It includes synchronizing supply and demand, reducing variability and increasing flexibility.

5. Order Fulfillment (OF): The OF includes all activities necessary to design a network and enable a firm to meet customer requests while maximizing its profitability. Evaluating service requirements; labor, materials, transportations and utilities cost; tax rates and where profits should be earned to legally minimize tax liability.

6. Manufacturing Flow Management (MFM): The MFM is the process that includes all activities necessary to obtain, implement and manage flexibility in the supply chain and to move products into, through and out of the plants. It involves evaluate the current and desired flexibility of strategic resources, the positioning of decoupling points and configurations of multiples supply chains to attend different customer segments.

7. Product Development and Commercialization (PDC): The PDC is the process that provides the structure for developing and bringing to market products jointly with customers and suppliers. It not only enables management to coordinate the efficient flow of new products across the supply chain, but also assists other members of the supply chain with the ramp-up of manufacturing, logistics, marketing and other activities necessary to support the commercialization of the product.

8. Returns Management (RM): The RM is the process by which activities associated with returns, reverse logistics, gatekeeping, and avoidance are managed within the firm and across key members of the supply chain. It enables not only to make the reverse product flow efficient, but also to identify opportunities to reduce unwanted returns.

Sub Processes: 42 strategic sub-processes were identified following Croxton et al. (2001) work. A description of each sub-process is provided below:

\section{CRM strategic sub-processes}

CRM1 - Review corporate and marketing strategy regarding customers segments; CRM2 - Identify criteria for categorizing customers within markets and segments; CRM3 - Provide guidelines for the degree of differentiation in the PSA;

CRM4 - Develop framework of metrics for customer's impact on firm's profitability; CRM5 - Develop guidelines for sharing process improvement benefits with customers. 


\section{SRM strategic sub-processes}

SRM1 - Review corporate, marketing, manufacturing and sourcing strategies;

SRM2 - Identify criteria to further segment suppliers;

SRM3 - Provide guidelines for the degree of differentiation in the PSA;

SRM4 - Develop framework of metrics for supplier's impact on firm's profitability;

SRM5 - Develop guidelines for sharing process improvement benefits with suppliers.

\section{CSM strategic sub-processes}

CSM1 - Develop customer service strategy for the set of PSA features from CRM;

CSM2 - Develop response procedures for events that require responses to customers;

CSM3 - Identify and develop the structure the implement response procedures;

CSM4 - Develop framework of metrics to monitor the performance of the process.

\section{DM strategic sub-processes}

DM1 - Determine demand management goals and strategy (eg increase flexibility vs. improve forecast accuracy);

DM2 - Determine the forecasting procedures such as timeframes and data sources;

DM3 - Plan the information flow on how data will be communicate and shared across flow and outside supply chain;

DM4 - Determine synchronization procedures to match the forecast to firm's capabilities;

DM5 - Develop contingency management system for events that disrupt the balance of supply and demand;

DM6 - Develop framework of metrics to monitor the performance of the process.

\section{OF strategic sub-processes}

OF1 - Review of marketing strategy, supply chain structure and customer service goals; OF2 - Define requirements for order fulfillment, such as what value-added services will be provided as well as the impact on the profitability of the firm and supply chain; OF3 - Evaluate logistics network to have a clear view of supply chain capabilities; OF4 - Define plan for order fulfillment to determine how orders will be taken and filled; OF5 - Develop framework of metrics to measure the performance of the process. 


\section{MFM strategic sub-processes}

MFM1 - Develop the manufacturing strategy that best accommodates customer demand;

MFM2 - Determine degree of flexibility requirement the firm and SC requires;

MFM3 - Determine push-pull boundaries/customer order decoupling points;

MFM4 - Identify manufacturing constraints and requirements;

MFM5 - Develop framework of metrics to measure the effectiveness of the process.

\section{PD\&C strategic sub-processes}

PD\&C1 - Review corporate, marketing, manufacturing and sourcing strategies;

PD\&C2 - Develop idea generation and screening procedures;

PD\&C3 - Establish guidelines for cross-functional product development team;

PD\&C4 - Identification of product rollout issues and constraints;

PD\&C5 - Establishment of new product project guidelines;

PD\&C6 - Develop framework of metrics.

\section{RM strategic sub-processes}

RM1 - Determine RM goals and strategy (improve customer loyalty, increase profits, etc)

RM2 - Develop return avoidance, gatekeeping and disposition guidelines;

RM3 - Develop returns network and flow options;

RM4 - Develop credit rules to determine how returned merchandise will be valued;

RM5 - Determine secondary markets where returns may be sold or used;

RM6 - Develop framework of metrics. 


\section{SECTION C: SURVEY APPLICATION TO EVALUATE DDMRP IMPACTS}

In the following sheets, we would like to elicit your opinion in order to select amongst the alternatives. The pair wise comparison scale (Figure 27) is used to express the importance of one element over another. You will be judging the impact that DDMRP has on the processes.

Figure 27 - Pairwise comparison scale

\section{Explanation}

Numeric Values

\begin{tabular}{|l|c|}
\hline If Option A and Option B are equally impacted impact: Mark/Insert >> & 1 \\
\hline If Option A is moderately more impacted than Option B: Mark/Insert >> & 3 \\
\hline If Option A is strongly more impacted than Option B: Mark/Insert >> & 5 \\
\hline If Option A very strongly more impacted than Option B: Mark/Insert >> & 7 \\
\hline If Option A is extremely more impacted than Option B: Mark/Insert >> & 9 \\
\hline Use even numbers for intermediate judgments & $2,4,6,8$ \\
\hline
\end{tabular}

Source: Adapted from Saaty (2008)

\section{Filling Example:}

Given Options A \& B, you can judge relative impact as shown in the Figure 28:

If you believe the option 'Customer Relationship Management - CRM' in column A is strongly more impacted by DDMRP implementation than the option 'Supplier Relationship Management - SRM' in column B, then you mark the space relative for number 5 with $(\mathrm{X})$ on the left hand side.

If you believe the option 'Demand Management - DM' in column B is extremely more impacted by DDMRP implementation than the option 'Supplier Relationship Management - SRM' in column A, then you mark the space relative for number 9 with (X) on the right hand side.

Figure 28 - Filling example for AHP survey

\begin{tabular}{|c|c|c|c|c|c|c|c|c|c|c|c|c|c|c|c|c|c|c|}
\hline \multirow[t]{2}{*}{$\begin{array}{c}\text { A } \\
\text { Options }\end{array}$} & 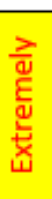 & & 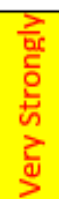 & & 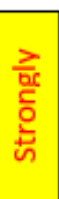 & & 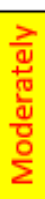 & & 》 & & 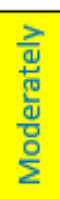 & & $\begin{array}{l}\text { 하 } \\
\text { के } \\
\text { के }\end{array}$ & & 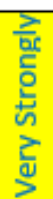 & & 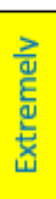 & \multirow[t]{2}{*}{$\begin{array}{c}\text { B } \\
\text { Options }\end{array}$} \\
\hline & 9 & 8 & 7 & 6 & 5 & 4 & 3 & 2 & 1 & 2 & 3 & 4 & 5 & 6 & 7 & 8 & 9 & \\
\hline$\overline{\mathrm{CRM}}$ & 9 & 8 & 7 & 6 & $x$ & 4 & 3 & 2 & 1 & 2 & 3 & 4 & 5 & 6 & 7 & 8 & 9 & SRM \\
\hline SRM & 9 & 8 & 7 & 6 & 5 & 4 & 3 & 2 & 1 & 2 & 3 & 4 & 5 & 6 & 7 & 8 & 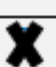 & $\overline{D M}$ \\
\hline
\end{tabular}

Source: Author (2019) 


\section{Regarding the main processes of SCM}

Using the scale from 1 to 9 (where 9 is extremely more impacted and 1 is equally impacted) please indicate in which extent each process (refer section B) is more impacted than the other in a DDMRP implementation from options A (left) to options B (right).

\begin{tabular}{|c|c|c|c|c|c|c|c|c|c|c|c|c|c|c|c|c|c|c|}
\hline \multirow[t]{2}{*}{$\begin{array}{c}\text { A } \\
\text { Options }\end{array}$} & 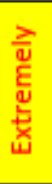 & & 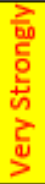 & & 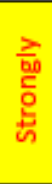 & & $\begin{array}{l}\frac{7}{y} \\
\frac{\pi}{20} \\
\frac{4}{2} \\
\frac{0}{2}\end{array}$ & & 츰 & & $\begin{array}{l}\frac{2}{20} \\
\frac{\pi}{02} \\
\frac{0}{2} \\
\frac{0}{2}\end{array}$ & & 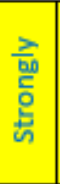 & & 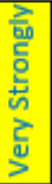 & & 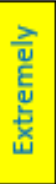 & \multirow[t]{2}{*}{$\begin{array}{c}\text { B } \\
\text { Options }\end{array}$} \\
\hline & 9 & 8 & 7 & 6 & 5 & 4 & 3 & 2 & 1 & 2 & 3 & 4 & 5 & 6 & 7 & 8 & 9 & \\
\hline CRM & 9 & 8 & 7 & 6 & 5 & 4 & 3 & 2 & 1 & 2 & 3 & 4 & 5 & 6 & 7 & 8 & 9 & SRM \\
\hline CRM & 9 & 8 & 7 & 6 & 5 & 4 & 3 & 2 & 1 & 2 & 3 & 4 & 5 & 6 & 7 & 8 & 9 & CSM \\
\hline CRM & 9 & 8 & 7 & 6 & 5 & 4 & 3 & 2 & 1 & 2 & 3 & 4 & 5 & 6 & 7 & 8 & 9 & $\mathrm{DM}$ \\
\hline CRM & 9 & 8 & 7 & 6 & 5 & 4 & 3 & 2 & 1 & 2 & 3 & 4 & 5 & 6 & 7 & 8 & 9 & $\mathrm{OF}$ \\
\hline CRM & 9 & 8 & 7 & 6 & 5 & 4 & 3 & 2 & 1 & 2 & 3 & 4 & 5 & 6 & 7 & 8 & 9 & MFM \\
\hline CRM & 9 & 8 & 7 & 6 & 5 & 4 & 3 & 2 & 1 & 2 & 3 & 4 & 5 & 6 & 7 & 8 & 9 & PD\&C \\
\hline CRM & 9 & 8 & 7 & 6 & 5 & 4 & 3 & 2 & 1 & 2 & 3 & 4 & 5 & 6 & 7 & 8 & 9 & $\mathrm{RM}$ \\
\hline SRM & 9 & 8 & 7 & 6 & 5 & 4 & 3 & 2 & 1 & 2 & 3 & 4 & 5 & 6 & 7 & 8 & 9 & $\mathrm{CSM}$ \\
\hline SRM & 9 & 8 & 7 & 6 & 5 & 4 & 3 & 2 & 1 & 2 & 3 & 4 & 5 & 6 & 7 & 8 & 9 & $\mathrm{DM}$ \\
\hline SRM & 9 & 8 & 7 & 6 & 5 & 4 & 3 & 2 & 1 & 2 & 3 & 4 & 5 & 6 & 7 & 8 & 9 & $\mathrm{OF}$ \\
\hline SRM & 9 & 8 & 7 & 6 & 5 & 4 & 3 & 2 & 1 & 2 & 3 & 4 & 5 & 6 & 7 & 8 & 9 & MFM \\
\hline SRM & 9 & 8 & 7 & 6 & 5 & 4 & 3 & 2 & 1 & 2 & 3 & 4 & 5 & 6 & 7 & 8 & 9 & PD\&C \\
\hline SRM & 9 & 8 & 7 & 6 & 5 & 4 & 3 & 2 & 1 & 2 & 3 & 4 & 5 & 6 & 7 & 8 & 9 & $\mathrm{RM}$ \\
\hline CSM & 9 & 8 & 7 & 6 & 5 & 4 & 3 & 2 & 1 & 2 & 3 & 4 & 5 & 6 & 7 & 8 & 9 & DM \\
\hline $\mathrm{CSM}$ & 9 & 8 & 7 & 6 & 5 & 4 & 3 & 2 & 1 & 2 & 3 & 4 & 5 & 6 & 7 & 8 & 9 & $\mathrm{OF}$ \\
\hline CSM & 9 & 8 & 7 & 6 & 5 & 4 & 3 & 2 & 1 & 2 & 3 & 4 & 5 & 6 & 7 & 8 & 9 & MFM \\
\hline CSM & 9 & 8 & 7 & 6 & 5 & 4 & 3 & 2 & 1 & 2 & 3 & 4 & 5 & 6 & 7 & 8 & 9 & PD\&C \\
\hline $\mathrm{CSM}$ & 9 & 8 & 7 & 6 & 5 & 4 & 3 & 2 & 1 & 2 & 3 & 4 & 5 & 6 & 7 & 8 & 9 & $\mathrm{RM}$ \\
\hline $\mathrm{DM}$ & 9 & 8 & 7 & 6 & 5 & 4 & 3 & 2 & 1 & 2 & 3 & 4 & 5 & 6 & 7 & 8 & 9 & $\mathrm{OF}$ \\
\hline $\mathrm{DM}$ & 9 & 8 & 7 & 6 & 5 & 4 & 3 & 2 & 1 & 2 & 3 & 4 & 5 & 6 & 7 & 8 & 9 & MFM \\
\hline $\mathrm{DM}$ & 9 & 8 & 7 & 6 & 5 & 4 & 3 & 2 & 1 & 2 & 3 & 4 & 5 & 6 & 7 & 8 & 9 & PD\&C \\
\hline $\mathrm{DM}$ & 9 & 8 & 7 & 6 & 5 & 4 & 3 & 2 & 1 & 2 & 3 & 4 & 5 & 6 & 7 & 8 & 9 & $\mathrm{RM}$ \\
\hline $\mathrm{OF}$ & 9 & 8 & 7 & 6 & 5 & 4 & 3 & 2 & 1 & 2 & 3 & 4 & 5 & 6 & 7 & 8 & 9 & MFM \\
\hline $\mathrm{OF}$ & 9 & 8 & 7 & 6 & 5 & 4 & 3 & 2 & 1 & 2 & 3 & 4 & 5 & 6 & 7 & 8 & 9 & PD\&C \\
\hline $\mathrm{OF}$ & 9 & 8 & 7 & 6 & 5 & 4 & 3 & 2 & 1 & 2 & 3 & 4 & 5 & 6 & 7 & 8 & 9 & $\mathrm{RM}$ \\
\hline MFM & 9 & 8 & 7 & 6 & 5 & 4 & 3 & 2 & 1 & 2 & 3 & 4 & 5 & 6 & 7 & 8 & 9 & PD\&C \\
\hline MFM & 9 & 8 & 7 & 6 & 5 & 4 & 3 & 2 & 1 & 2 & 3 & 4 & 5 & 6 & 7 & 8 & 9 & $\mathrm{RM}$ \\
\hline PD\&C & 9 & 8 & 7 & 6 & 5 & 4 & 3 & 2 & 1 & 2 & 3 & 4 & 5 & 6 & 7 & 8 & 9 & $\mathrm{RM}$ \\
\hline $\mathbf{A}$ & 9 & 8 & 7 & 6 & 5 & 4 & 3 & 2 & 1 & 2 & 3 & 4 & 5 & 6 & 7 & 8 & 9 & \\
\hline Options & 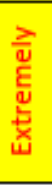 & & 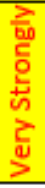 & & $\begin{array}{l}\text { 하으 } \\
\text { 한 }\end{array}$ & & 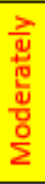 & & 竞 & & 苞 & & 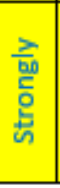 & & 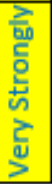 & & 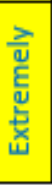 & $\begin{array}{c}\text { B } \\
\text { Options }\end{array}$ \\
\hline
\end{tabular}




\section{Regarding the strategic sub-processes of Customer Relationship Management}

Using the scale from 1 to 9 (where 9 is extremely more impacted and 1 is equally impacted) please indicate in which extent each sub-process (refer to section B) is more impacted than the other in a DDMRP implementation from A (left) to options B (right).

\begin{tabular}{|c|c|c|c|c|c|c|c|c|c|c|c|c|c|c|c|c|c|c|}
\hline \multirow[t]{2}{*}{$\begin{array}{c}\text { A } \\
\text { Options }\end{array}$} & 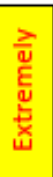 & & 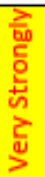 & & 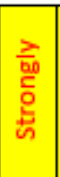 & & $\begin{array}{l}\frac{7}{y} \\
\frac{\pi}{0} \\
\frac{\mathrm{u}}{0} \\
\frac{0}{2}\end{array}$ & & 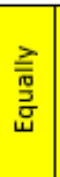 & & 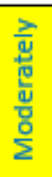 & & 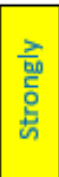 & & 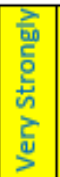 & & 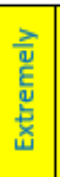 & \multirow[t]{2}{*}{$\begin{array}{c}\text { B } \\
\text { Options }\end{array}$} \\
\hline & 9 & 8 & 7 & 6 & 5 & 4 & 3 & 2 & 1 & 2 & 3 & 4 & 5 & 6 & 7 & 8 & 9 & \\
\hline CRM1 & 9 & 8 & 7 & 6 & 5 & 4 & 3 & 2 & 1 & 2 & 3 & 4 & 5 & 6 & 7 & 8 & 9 & CRM2 \\
\hline CRM1 & 9 & 8 & 7 & 6 & 5 & 4 & 3 & 2 & 1 & 2 & 3 & 4 & 5 & 6 & 7 & 8 & 9 & CRM3 \\
\hline CRM1 & 9 & 8 & 7 & 6 & 5 & 4 & 3 & 2 & 1 & 2 & 3 & 4 & 5 & 6 & 7 & 8 & 9 & CRM4 \\
\hline CRM1 & 9 & 8 & 7 & 6 & 5 & 4 & 3 & 2 & 1 & 2 & 3 & 4 & 5 & 6 & 7 & 8 & 9 & CRM5 \\
\hline CRM2 & 9 & 8 & 7 & 6 & 5 & 4 & 3 & 2 & 1 & 2 & 3 & 4 & 5 & 6 & 7 & 8 & 9 & CRM3 \\
\hline CRM2 & 9 & 8 & 7 & 6 & 5 & 4 & 3 & 2 & 1 & 2 & 3 & 4 & 5 & 6 & 7 & 8 & 9 & CRM4 \\
\hline CRM2 & 9 & 8 & 7 & 6 & 5 & 4 & 3 & 2 & 1 & 2 & 3 & 4 & 5 & 6 & 7 & 8 & 9 & CRM5 \\
\hline CRM3 & 9 & 8 & 7 & 6 & 5 & 4 & 3 & 2 & 1 & 2 & 3 & 4 & 5 & 6 & 7 & 8 & 9 & CRM4 \\
\hline CRM3 & 9 & 8 & 7 & 6 & 5 & 4 & 3 & 2 & 1 & 2 & 3 & 4 & 5 & 6 & 7 & 8 & 9 & CRM5 \\
\hline CRM4 & 9 & 8 & 7 & 6 & 5 & 4 & 3 & 2 & 1 & 2 & 3 & 4 & 5 & 6 & 7 & 8 & 9 & CRM5 \\
\hline \multirow{2}{*}{$\begin{array}{c}\text { A } \\
\text { Options }\end{array}$} & 9 & 8 & 7 & 6 & 5 & 4 & 3 & 2 & 1 & 2 & 3 & 4 & 5 & 6 & 7 & 8 & 9 & \multirow[b]{2}{*}{$\begin{array}{c}\text { B } \\
\text { Options }\end{array}$} \\
\hline & 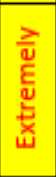 & & 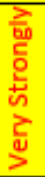 & & 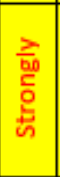 & & 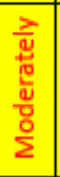 & & 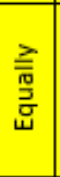 & & 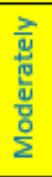 & & 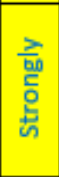 & & 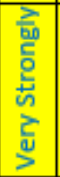 & & 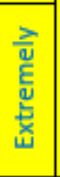 & \\
\hline
\end{tabular}

CRM1 - Review corporate and marketing strategy regarding customers segments;

CRM2 - Identify criteria for categorizing customers within markets and segments;

CRM3 - Provide guidelines for the degree of differentiation in the PSA;

CRM4 - Develop framework of metrics for customer's impact on firm's profitability;

CRM5 - Develop guidelines for sharing process improvement benefits with customers. 
Regarding the strategic sub-processes of Supplier Relationship Management

Using the scale from 1 to 9 (where 9 is extremely more impacted and 1 is equally impacted) please indicate in which extent each sub-process (refer to section B) is more impacted than the other in a DDMRP implementation from A (left) to options B (right).

\begin{tabular}{|c|c|c|c|c|c|c|c|c|c|c|c|c|c|c|c|c|c|c|}
\hline \multirow[t]{2}{*}{$\begin{array}{c}\text { A } \\
\text { Options }\end{array}$} & 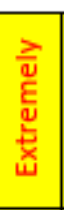 & & 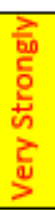 & & 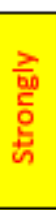 & & 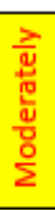 & & $\begin{array}{l}\frac{2}{\overline{\underline{w}}} \\
\frac{\bar{z}}{\mathrm{w}}\end{array}$ & & 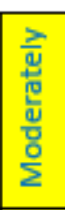 & & 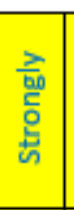 & & 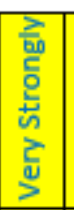 & & 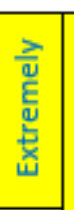 & \multirow[t]{2}{*}{$\begin{array}{c}\text { B } \\
\text { Options }\end{array}$} \\
\hline & 9 & 8 & 7 & 6 & 5 & 4 & 3 & 2 & 1 & \begin{tabular}{|l|}
2 \\
\end{tabular} & 3 & 4 & 5 & 6 & 7 & 8 & 9 & \\
\hline SRM1 & 9 & 8 & 7 & 6 & 5 & 4 & 3 & 2 & 1 & 2 & 3 & 4 & 5 & 6 & 7 & 8 & 9 & SRM2 \\
\hline SRM1 & 9 & 8 & 7 & 6 & 5 & 4 & 3 & 2 & 1 & 2 & 3 & 4 & 5 & 6 & 7 & 8 & 9 & SRM3 \\
\hline SRM1 & 9 & 8 & 7 & 6 & 5 & 4 & 3 & 2 & 1 & 2 & 3 & 4 & 5 & 6 & 7 & 8 & 9 & SRM4 \\
\hline SRM1 & 9 & 8 & 7 & 6 & 5 & 4 & 3 & 2 & 1 & 2 & 3 & 4 & 5 & 6 & 7 & 8 & 9 & SRM5 \\
\hline SRM2 & 9 & 8 & 7 & 6 & 5 & 4 & 3 & 2 & 1 & 2 & 3 & 4 & 5 & 6 & 7 & 8 & 9 & SRM3 \\
\hline SRM2 & 9 & 8 & 7 & 6 & 5 & 4 & 3 & 2 & 1 & 2 & 3 & 4 & 5 & 6 & 7 & 8 & 9 & SRM4 \\
\hline SRM2 & 9 & 8 & 7 & 6 & 5 & 4 & 3 & 2 & 1 & 2 & 3 & 4 & 5 & 6 & 7 & 8 & 9 & SRM5 \\
\hline SRM3 & 9 & 8 & 7 & 6 & 5 & 4 & 3 & 2 & 1 & 2 & 3 & 4 & 5 & 6 & 7 & 8 & 9 & SRM4 \\
\hline SRM3 & 9 & 8 & 7 & 6 & 5 & 4 & 3 & 2 & 1 & 2 & 3 & 4 & 5 & 6 & 7 & 8 & 9 & SRM5 \\
\hline SRM4 & 9 & 8 & 7 & 6 & 5 & 4 & 3 & 2 & 1 & 2 & 3 & 4 & 5 & 6 & 7 & 8 & 9 & SRM5 \\
\hline $\mathbf{A}$ & 9 & 8 & 7 & 6 & 5 & 4 & 3 & 2 & 1 & 2 & 3 & 4 & 5 & 6 & 7 & 8 & 9 & \\
\hline Options & 군 & & 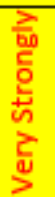 & & 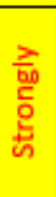 & & 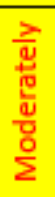 & & 要 & & 空 & & 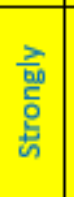 & & 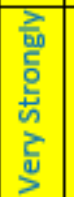 & & 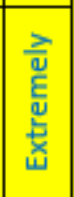 & $\begin{array}{c}\text { B } \\
\text { Options }\end{array}$ \\
\hline
\end{tabular}

SRM1 - Review corporate, marketing, manufacturing and sourcing strategies;

SRM2 - Identify criteria to further segment suppliers;

SRM3 - Provide guidelines for the degree of differentiation in the PSA;

SRM4 - Develop framework of metrics for supplier's impact on firm's profitability;

SRM5 - Develop guidelines for sharing process improvement benefits with suppliers. 


\section{Regarding the strategic sub-processess of Customer Service Management}

Using the scale from 1 to 9 (where 9 is extremely more impacted and 1 is equally impacted) please indicate in which extent each sub-process (refer to section B) is more impacted than the other in a DDMRP implementation from A (left) to options B (right).

\begin{tabular}{|c|c|c|c|c|c|c|c|c|c|c|c|c|c|c|c|c|c|c|}
\hline \multirow[t]{2}{*}{$\begin{array}{c}\text { A } \\
\text { Options }\end{array}$} & 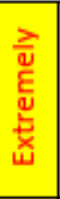 & & 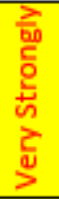 & & 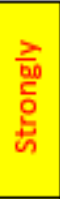 & & 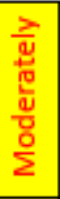 & & 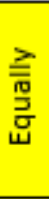 & & 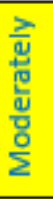 & & $\begin{array}{l}\text { 금 } \\
\text { w0 } \\
\text { 离 } \\
\text { 心 }\end{array}$ & & 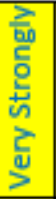 & & 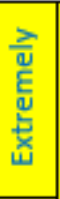 & \multirow[t]{2}{*}{$\begin{array}{c}\text { B } \\
\text { Options }\end{array}$} \\
\hline & 9 & 8 & 7 & 6 & 5 & 4 & 3 & 2 & 1 & 2 & 3 & 4 & 5 & 6 & 7 & 8 & 9 & \\
\hline & 9 & 8 & 7 & 6 & 5 & & 3 & & 1 & 7 & 3 & & 5 & 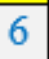 & 7 & 8 & 9 & \\
\hline CSM1 & 9 & 8 & 7 & 6 & 5 & & 3 & & & 2 & 3 & 4 & 5 & 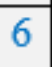 & 7 & 8 & 9 & CSM3 \\
\hline CSM1 & 9 & 8 & 7 & 4 & 5 & 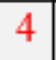 & 3 & & 1 & 2 & 3 & 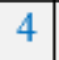 & 5 & 0 & 7 & 8 & 9 & CSM4 \\
\hline CSM2 & 9 & 8 & 7 & 0 & 5 & 7 & 3 & 2 & 1 & 2 & 3 & 7 & 5 & 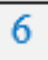 & 7 & 8 & 9 & CSM3 \\
\hline CSM2 & 9 & 8 & 7 & 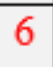 & 5 & 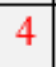 & 3 & 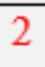 & 1 & 2 & 3 & 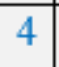 & 5 & 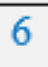 & 7 & 8 & 9 & CSM4 \\
\hline CSM3 & 9 & 8 & 7 & 6 & 5 & 4 & 3 & 2 & 1 & 2 & 3 & 4 & 5 & 6 & 7 & 8 & 9 & CSM4 \\
\hline
\end{tabular}

CSM1 - Develop customer service strategy for the set of PSA features from CRM;

CSM2 - Develop response procedures for events that require responses to customers;

CSM3 - Identify and develop the structure the implement response procedures;

CSM4 - Develop framework of metrics to monitor the performance of the process. 


\section{Regarding the strategic sub-processess of Demand Management}

Using the scale from 1 to 9 (where 9 is extremely more impacted and 1 is equally impacted) please indicate in which extent each sub-process (refer to section B) is more impacted than the other in a DDMRP implementation from A (left) to options B (right).

\begin{tabular}{|c|c|c|c|c|c|c|c|c|c|c|c|c|c|c|c|c|c|c|}
\hline \multirow[t]{2}{*}{$\begin{array}{c}\text { A } \\
\text { Options }\end{array}$} & 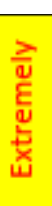 & & 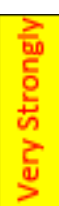 & & 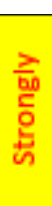 & & 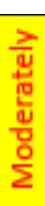 & & 竞 & & 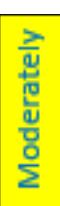 & & 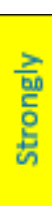 & & 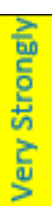 & & $\begin{array}{l}\text { 금 } \\
\text { हूँ } \\
\text { है }\end{array}$ & \multirow[t]{2}{*}{$\begin{array}{c}\text { B } \\
\text { Options }\end{array}$} \\
\hline & 9 & 8 & 7 & 6 & 5 & 4 & 3 & 2 & 1 & 2 & 3 & 4 & 5 & 6 & 7 & 8 & 9 & \\
\hline DM1 & 9 & 8 & 7 & 6 & 5 & 4 & 3 & 7 & 1 & 2 & 3 & 4 & 5 & 6 & 7 & 8 & 9 & $\mathrm{DM} 2$ \\
\hline DM1 & 9 & 8 & 7 & 6 & 5 & 4 & 3 & 2 & 1 & 2 & 3 & 4 & 5 & 6 & 7 & 8 & & $\mathrm{DM} 3$ \\
\hline DM1 & 9 & 8 & 7 & 6 & 5 & 4 & 3 & 2 & 1 & 2 & 3 & 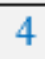 & 5 & 6 & 7 & 8 & 9 & DM4 \\
\hline DM1 & 9 & 8 & 7 & 6 & 5 & 4 & 3 & 7 & 1 & 7 & 3 & 4 & 5 & 6 & 7 & 8 & 9 & DM5 \\
\hline DM1 & 9 & 8 & 7 & 6 & 5 & 4 & 3 & 7 & 1 & 2 & 3 & 4 & 5 & 6 & 7 & 8 & 9 & DM6 \\
\hline DM2 & 9 & 8 & 7 & 6 & 5 & 4 & 3 & 2 & 1 & 2 & 3 & 4 & 5 & 6 & 7 & 8 & 9 & $\mathrm{DM} 3$ \\
\hline $\mathrm{DM} 2$ & 9 & 8 & 7 & 6 & 5 & 4 & 0 & 2 & 1 & 2 & 3 & 4 & 5 & 6 & 7 & 8 & 9 & DM4 \\
\hline $\mathrm{DM} 2$ & 9 & 8 & 7 & 6 & 5 & 4 & 2 & 7 & 1 & 2 & 3 & 4 & 5 & 6 & 7 & 8 & 9 & DM5 \\
\hline $\mathrm{DM} 2$ & 9 & 8 & 7 & 6 & 5 & 4 & 3 & 2 & 1 & 2 & 3 & 4 & 5 & 6 & 7 & 8 & 9 & DM6 \\
\hline DM3 & 9 & 8 & 7 & 6 & 5 & 4 & 3 & 2 & 1 & 2 & 3 & 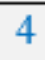 & 5 & 6 & 7 & 8 & 9 & DM4 \\
\hline DM3 & 9 & 8 & 7 & 6 & 5 & 4 & 2 & 2 & 1 & . & 3 & 4 & 5 & 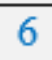 & 7 & 8 & 9 & DM5 \\
\hline $\mathrm{DM} 3$ & 9 & 8 & 7 & 6 & 5 & 4 & 3 & 2 & 1 & 2 & 3 & 4 & 5 & 6 & 7 & 8 & 9 & DM6 \\
\hline DM4 & 9 & 8 & 7 & 6 & 5 & 4 & 3 & 2 & 1 & 2 & 3 & 4 & 5 & 0 & 7 & 8 & 9 & DM5 \\
\hline DM4 & 9 & 8 & 7 & 6 & 5 & 4 & 3 & 2 & 1 & 2 & 3 & 4 & 5 & 6 & 7 & 8 & 9 & DM6 \\
\hline DM5 & 9 & 8 & 7 & 6 & 5 & 4 & 3 & 2 & 1 & 2 & 3 & 4 & 5 & 6 & 7 & 8 & 9 & DM6 \\
\hline \multirow{2}{*}{$\begin{array}{c}\text { A } \\
\text { Options }\end{array}$} & 9 & 8 & 7 & 6 & 5 & 4 & 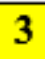 & 2 & T & 2 & 3 & 4 & 5 & 6 & 7 & 8 & 9 & \multirow[b]{2}{*}{$\begin{array}{c}\text { B } \\
\text { Options }\end{array}$} \\
\hline & 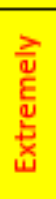 & & 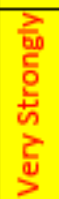 & & 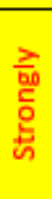 & & $\begin{array}{l}\frac{7}{4} \\
\frac{0}{2} \\
\frac{0}{0}\end{array}$ & & $\underline{\underline{\pi}}$ & & 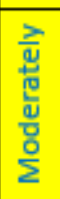 & & 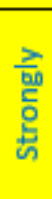 & & 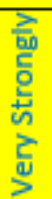 & & 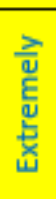 & \\
\hline
\end{tabular}

DM1 - Determine demand management goals and strategy (eg increase flexibility vs. improve forecast accuracy);

DM2 - Determine the forecasting procedures such as timeframes and data sources;

DM3 - Plan the information flow on how data will be communicate and shared across flow and outside SC

DM4 - Determine synchronization procedures to match the forecast to firm's capabilities;

DM5 - Develop contingency management system for events that disrupt the balance of supply and demand;

DM6 - Develop framework of metrics to monitor the performance of the process. 


\section{Regarding the strategic sub-processess of Order Fulfillment}

Using the scale from 1 to 9 (where 9 is extremely more impacted and 1 is equally impacted) please indicate in which extent each sub-process (refer to section B) is more impacted than the other in a DDMRP implementation from A (left) to options B (right).

\begin{tabular}{|c|c|c|c|c|c|c|c|c|c|c|c|c|c|c|c|c|c|c|}
\hline \multirow[t]{2}{*}{$\begin{array}{c}\text { A } \\
\text { Options }\end{array}$} & 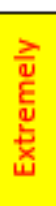 & & 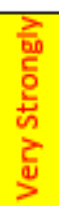 & & $\begin{array}{l}\text { 学 } \\
\text { o. } \\
\text { 志 }\end{array}$ & & 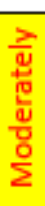 & & 竞 & & 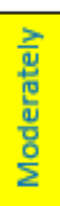 & & 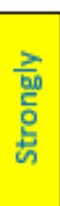 & & 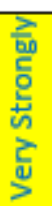 & & 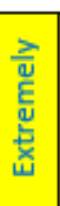 & \multirow[t]{2}{*}{$\begin{array}{c}\text { B } \\
\text { Options }\end{array}$} \\
\hline & 9 & 8 & 7 & 6 & 5 & 4 & 3 & 2 & 1 & 2 & 3 & 4 & 5 & 6 & 7 & 8 & 9 & \\
\hline OF1 & 9 & 8 & 7 & 6 & 5 & 4 & 3 & 2 & 1 & 2 & 3 & 4 & 5 & 6 & 7 & 8 & 9 & $\mathrm{OF} 2$ \\
\hline OF1 & 9 & 8 & 7 & 6 & 5 & 4 & 3 & 2 & 1 & 2 & 3 & 4 & 5 & 6 & 7 & 8 & 9 & OF3 \\
\hline OF1 & 9 & 8 & 7 & 6 & 5 & 4 & 3 & 2 & 1 & 2 & 3 & 4 & 5 & 6 & 7 & 8 & 9 & $\mathrm{OF} 4$ \\
\hline OF1 & 9 & 8 & 7 & 6 & 5 & 4 & 3 & 2 & 1 & 2 & 3 & 4 & 5 & 6 & 7 & 8 & 9 & OF5 \\
\hline OF2 & 9 & 8 & 7 & 6 & 5 & 4 & 3 & 2 & 1 & 2 & 3 & 4 & 5 & 6 & 7 & 8 & 9 & OF3 \\
\hline OF2 & 9 & 8 & 7 & 6 & 5 & 4 & 3 & 2 & 1 & 2 & 3 & 4 & 5 & 6 & 7 & 8 & 9 & $\mathrm{OF} 4$ \\
\hline $\mathrm{OF} 2$ & 9 & 8 & 7 & 6 & 5 & 4 & 3 & 2 & 1 & 2 & 3 & 4 & 5 & 6 & 7 & 8 & 9 & OF5 \\
\hline OF3 & 9 & 8 & 7 & 6 & 5 & 4 & 3 & 2 & 1 & 2 & 3 & 4 & 5 & 6 & 7 & 8 & 9 & OF4 \\
\hline OF3 & 9 & 8 & 7 & 6 & 5 & 4 & 3 & 2 & 1 & 2 & 3 & 4 & 5 & 6 & 7 & 8 & 9 & OF5 \\
\hline OF4 & 9 & 8 & 7 & 6 & 5 & 4 & 3 & 2 & 1 & 2 & 3 & 4 & 5 & 6 & 7 & 8 & 9 & OF5 \\
\hline $\mathbf{A}$ & 9 & 8 & 7 & 6 & 5 & 4 & 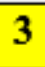 & 2 & 1 & 2 & 3 & 4 & 5 & 6 & 7 & 8 & 9 & \\
\hline Options & 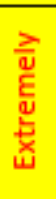 & & 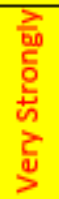 & & 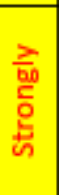 & & 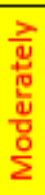 & & $\underset{\underline{\underline{N}}}{\underline{\underline{N}}}$ & & $\begin{array}{l}\frac{\lambda}{\mathrm{v}} \\
\frac{\mathrm{v}}{\mathrm{v}} \\
\frac{\mathrm{d}}{\mathrm{c}} \\
\frac{\mathrm{c}}{2}\end{array}$ & & 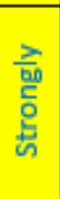 & & 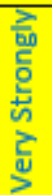 & & 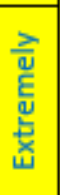 & $\begin{array}{c}\text { B } \\
\text { Options }\end{array}$ \\
\hline
\end{tabular}

OF1 - Review of marketing strategy, supply chain structure and customer service goals;

OF2 - Define requirements for order fulfillment, such as what value-added services will be provided as well as the impact on the profitability of the firm and supply chain;

OF3 - Evaluate logistics network to have a clear view of supply chain capabilities;

OF4 - Define plan for order fulfillment to determine how orders will be taken and filled;

OF5 - Develop framework of metrics to measure the performance of the process. 
Regarding the strategic sub-processess of Manufacturing Flow Management

Using the scale from 1 to 9 (where 9 is extremely more impacted and 1 is equally impacted) please indicate in which extent each sub-process (refer to section B) is more impacted than the other in a DDMRP implementation from A (left) to options B (right).

\begin{tabular}{|c|c|c|c|c|c|c|c|c|c|c|c|c|c|c|c|c|c|c|}
\hline \multirow[t]{2}{*}{$\begin{array}{c}\text { A } \\
\text { Options }\end{array}$} & 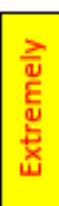 & & 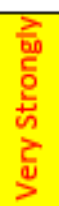 & & 京 & & 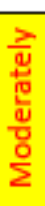 & & 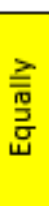 & & 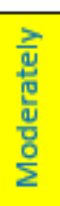 & & 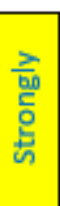 & & 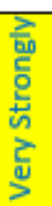 & & 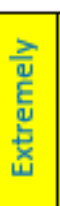 & \multirow[t]{2}{*}{$\begin{array}{c}\text { B } \\
\text { Options }\end{array}$} \\
\hline & 9 & 8 & 7 & 6 & $=$ & 4 & 3 & 2 & 1 & 2 & 3 & 4 & 5 & 6 & 7 & 8 & 9 & \\
\hline MFM1 & 9 & & 7 & 6 & 5 & 4 & 2 & T & 1 & 2 & 3 & 4 & 5 & 6 & 7 & 8 & 9 & MFM2 \\
\hline MFM1 & 9 & 8 & 7 & 6 & & 4 & & 8 & 1 & 2 & 3 & 4 & 5 & 6 & 7 & 8 & 9 & MFM3 \\
\hline MFM1 & 9 & & 7 & 6 & & 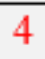 & & & 1 & 2 & 3 & 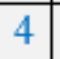 & 5 & 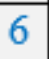 & 7 & 8 & 9 & \\
\hline MFM1 & 9 & 0 & 7 & 6 & & 4 & & & 1 & 8 & 3 & 4 & 5 & 6 & 7 & 8 & 9 & MFM5 \\
\hline MFM2 & 9 & 8 & 7 & 6 & & 4 & 2 & 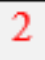 & 1 & 2 & 3 & 4 & 5 & 6 & 7 & 8 & 9 & MFM3 \\
\hline MFM2 & 9 & 8 & 7 & 6 & & 4 & & & 2 & 2 & 3 & 4 & 5 & 6 & 7 & 8 & 9 & MFM4 \\
\hline MFM2 & 9 & 8 & 7 & c & & 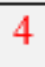 & & & & 2 & 3 & T & 5 & 6 & 7 & $\gamma$ & 9 & MFM5 \\
\hline MFM3 & 9 & 0 & 7 & 0 & & 4 & J & 2 & 1 & 2 & 3 & $T$ & 5 & 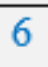 & 7 & 8 & 9 & MFM4 \\
\hline MFM3 & 9 & 8 & 7 & 6 & & 4 & 3 & $?$ & 1 & 2 & 3 & 4 & 5 & 6 & 7 & 8 & 9 & MFM5 \\
\hline MFM4 & 9 & 8 & 7 & 6 & & 4 & & 2 & & 2 & 3 & 4 & 5 & 6 & 7 & 8 & 9 & MFM5 \\
\hline $\mathbf{A}$ & 9 & 0 & 7 & 0 & & & & & & 2 & 3 & 4 & 5 & 0 & 7 & 8 & 9 & \\
\hline Options & 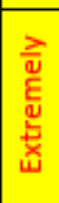 & & 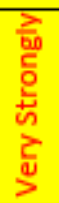 & & 함 & & "艹 & & 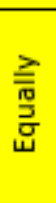 & & 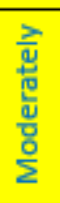 & & 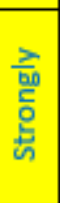 & & 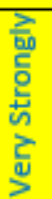 & & $\begin{array}{l}\text { 츰 } \\
\text { है } \\
\text { 毫 }\end{array}$ & $\begin{array}{c}\text { B } \\
\text { Options }\end{array}$ \\
\hline
\end{tabular}

MFM1 - Develop the manufacturing strategy that best accommodates customer demand;

MFM2 - Determine degree of flexibility requirement that the firm and the SC requires;

MFM3 - Determine push-pull boundaries/customer order decoupling points;

MFM4 - Identify manufacturing constraints and requirements;

MFM5 - Develop framework of metrics to measure the effectiveness of the process. 
Regarding strategic sub-processes of Product Development and Commercialization

Using the scale from 1 to 9 (where 9 is extremely more impacted and 1 is equally impacted) please indicate in which extent each sub-process (refer to section B) is more impacted than the other in a DDMRP implementation from A (left) to options B (right).

\begin{tabular}{|c|c|c|c|c|c|c|c|c|c|c|c|c|c|c|c|c|c|c|}
\hline \multirow[t]{2}{*}{$\begin{array}{c}\text { A } \\
\text { Options }\end{array}$} & 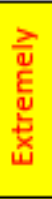 & & 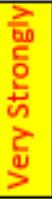 & & 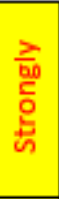 & & 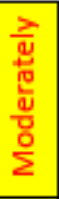 & & 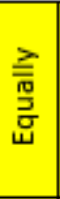 & & एँ & & 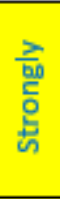 & & 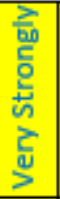 & & 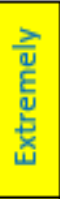 & \multirow[t]{2}{*}{$\begin{array}{c}\text { B } \\
\text { Options }\end{array}$} \\
\hline & 9 & 8 & 7 & 6 & 5 & 4 & 3 & 2 & 1 & 2 & 3 & 4 & 5 & 6 & 7 & 8 & 9 & \\
\hline PD\&C1 & 0 & 8 & 7 & & 5 & 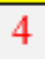 & 3 & & 1 & 2 & 3 & 4 & 5 & 6 & 7 & 8 & 9 & \\
\hline $\mathrm{PD} \& \mathrm{C} 1$ & s & & 7 & & 5 & & 3 & 2 & 1 & 2 & J & 4 & 5 & 6 & 7 & 8 & 9 & \\
\hline $\mathrm{PD} \& \mathrm{C} 1$ & 9 & & 7 & & 5 & & 3 & & 1 & 2 & 3 & 4 & 5 & 6 & 7 & 8 & 9 & \\
\hline $\mathrm{PD} \& \mathrm{C} 1$ & 0 & & 7 & & 5 & & 3 & 2 & 1 & 2 & J & 4 & 5 & 6 & 7 & 0 & 9 & FDoC \\
\hline PD\&C1 & 9 & & 7 & & 5 & 4 & 2 & 2 & 1 & 2 & J & 4 & 5 & 6 & 7 & 0 & 9 & 1000 \\
\hline PD\&C2 & 9 & & 7 & & 5 & & 3 & & 1 & 2 & J & 4 & 5 & 6 & 7 & 8 & 9 & \\
\hline $\mathrm{PD} \& \mathrm{C} 2$ & $y$ & 8 & $77+3$ & 5 & 5 & & 3 & & 1 & 2 & 3 & 4 & 5 & 6 & 7 & 0 & 9 & $\mathrm{PD} \& \mathrm{C}$ \\
\hline $\mathrm{PD} \& \mathrm{C} 2$ & 9 & & 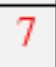 & 6 & 5 & +2 & 3 & 2 & 1 & 2 & J & 4 & 5 & 6 & 7 & 0 & 9 & FDed \\
\hline $\mathrm{PD} \& \mathrm{C} 2$ & 9 & & 7 & & 5 & & & & 1 & 2 & & 4 & 5 & 6 & 7 & 8 & 9 & $2 \Gamma C_{6}+2$ \\
\hline $\mathrm{PD} \& \mathrm{C} 3$ & 9 & 8 & 7 & 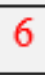 & 5 & & 3 & & 1 & 2 & J & 4 & 5 & 6 & 7 & 0 & 9 & PD\&C4 \\
\hline PD\&C3 & 9 & 8 & $t$ & 0 & 5 & & 3 & 2 & 1 & 2 & 3 & 4 & 5 & 6 & 7 & 0 & 9 & FDOC \\
\hline PD\&C3 & 9 & 8 & 7 & 6 & 5 & & 3 & 2 & 1 & 2 & J & 4 & 5 & 6 & 7 & 8 & 9 & $\mathrm{PD} \& \mathrm{C6}$ \\
\hline $\mathrm{PD} \& \mathrm{C} 4$ & 9 & 8 & 7 & $c$ & 5 & & 3 & 2 & 1 & 2 & 3 & 4 & 5 & 6 & 7 & 8 & 9 & PDACS \\
\hline PD\&C4 & 9 & 8 & $f$ & 0 & 5 & 4 & 3 & 2 & 1 & 2 & J & 4 & 5 & 6 & 7 & 0 & 9 & FDCU \\
\hline PD\&C5 & 9 & 8 & 7 & 6 & 5 & ( & 3 & & 1 & 2 & 3 & 4 & 5 & 6 & 7 & 8 & 9 & D\&C6 \\
\hline \multirow{2}{*}{$\begin{array}{c}\text { A } \\
\text { Options }\end{array}$} & 9 & 8 & 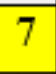 & & 5 & & 3 & & 1 & 2 & & 4 & 5 & 6 & 7 & 3 & 9 & \multirow[b]{2}{*}{$\begin{array}{c}\text { B } \\
\text { Options }\end{array}$} \\
\hline & 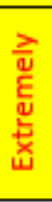 & & 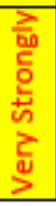 & & 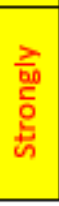 & & 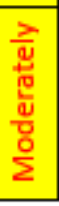 & & 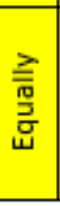 & & 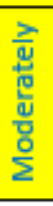 & & 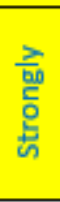 & & 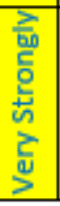 & & 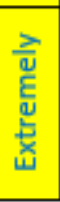 & \\
\hline
\end{tabular}

PD\&C1 - Review corporate, marketing, manufacturing and sourcing strategies;

PD\&C2 - Develop idea generation and screening procedures;

PD\&C3 - Establish guidelines for cross-functional product development team;

PD\&C4 - Identification of product rollout issues and constraints;

PD\&C5 - Establishment of new product project guidelines;

PD\&C6 - Develop framework of metrics. 
Regarding the strategic sub-processes of Returns Management

Using the scale from 1 to 9 (where 9 is extremely more impacted and 1 is equally impacted) please indicate in which extent each sub-process (refer to section B) is more impacted than the other in a DDMRP implementation from A (left) to options B (right).

\begin{tabular}{|c|c|c|c|c|c|c|c|c|c|c|c|c|c|c|c|c|c|c|}
\hline \multirow[t]{2}{*}{$\begin{array}{c}\text { A } \\
\text { Options }\end{array}$} & 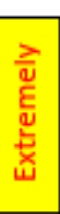 & & 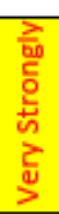 & & 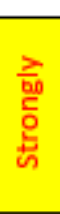 & & 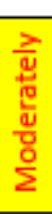 & & 竞 & & 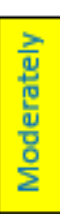 & & 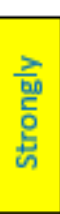 & & 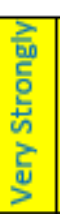 & & 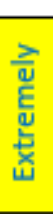 & \multirow[t]{2}{*}{$\begin{array}{c}\text { B } \\
\text { Options }\end{array}$} \\
\hline & 9 & 8 & 7 & 6 & 5 & 4 & 3 & 2 & 1 & 2 & 3 & 4 & 5 & 6 & 7 & 8 & 9 & \\
\hline RM1 & 9 & 0 & 7 & 6 & 5 & 4 & 2 & 4 & 1 & 2 & 3 & 4 & 5 & 6 & 7 & 8 & 9 & $\mathrm{RM} 2$ \\
\hline RM1 & 9 & 8 & 7 & 6 & 5 & 4 & 3 & 7 & 1 & 7 & 3 & 4 & 5 & 6 & 7 & 8 & 9 & RM3 \\
\hline RM1 & 9 & 8 & 7 & 6 & 5 & 4 & 3 & 2 & 1 & 2 & 3 & 4 & 5 & 6 & 7 & 8 & 9 & RM4 \\
\hline RM1 & 9 & 0 & 7 & 6 & 5 & 4 & 3 & 2 & 1 & 2 & 3 & 4 & 5 & 6 & 7 & 8 & 9 & RM5 \\
\hline RM1 & 9 & 8 & 7 & 6 & 5 & 4 & 3 & 7 & 1 & 7 & 3 & 4 & 5 & 6 & 7 & 8 & 9 & RM6 \\
\hline RM2 & 9 & 8 & 7 & 6 & 5 & 4 & 3 & & 1 & 2 & 3 & 4 & 5 & 6 & 7 & 8 & 9 & RM3 \\
\hline RM2 & 9 & 8 & 7 & 6 & 5 & 4 & 5 & 2 & 1 & 2 & 3 & 4 & 5 & 6 & 7 & 8 & 9 & RM4 \\
\hline RM2 & 9 & 8 & 7 & 6 & 5 & 4 & J & 2 & 1 & 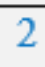 & 3 & 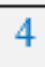 & 5 & 6 & 7 & 8 & 9 & RM5 \\
\hline RM2 & 9 & 8 & 7 & 6 & 5 & 4 & 3 & - & 1 & 2 & 3 & 4 & 5 & 6 & 7 & 8 & 9 & RM6 \\
\hline RM3 & 9 & 8 & 7 & 6 & 5 & 4 & 3 & 2 & 1 & 2 & 3 & 4 & 5 & 0 & 7 & 8 & 9 & RM4 \\
\hline RM3 & 9 & 8 & 7 & 6 & 5 & 4 & 3 & 2 & 1 & 2 & 3 & 4 & 5 & 6 & 7 & 8 & 9 & RM5 \\
\hline RM3 & 9 & 8 & 7 & 6 & 5 & 4 & 3 & 2 & 1 & 2 & 3 & 4 & 5 & 6 & 7 & 8 & 9 & RM6 \\
\hline RM4 & 9 & 8 & 7 & 6 & 5 & 4 & 3 & 2 & 1 & 2 & 3 & 4 & 5 & 6 & 7 & 8 & 9 & RM5 \\
\hline RM4 & 9 & 8 & 7 & 6 & 5 & 4 & 3 & 2 & 1 & 2 & 3 & 4 & 5 & 6 & 7 & 8 & 9 & RM6 \\
\hline RM5 & 9 & 8 & 7 & 6 & 5 & 4 & 3 & 2 & 1 & 2 & 3 & 4 & 5 & 6 & 7 & 8 & 9 & RM6 \\
\hline $\mathbf{A}$ & 9 & 8 & 7 & 6 & 5 & 4 & 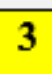 & & 1 & 2 & 3 & 4 & 5 & 6 & 7 & 8 & 9 & \\
\hline Options & 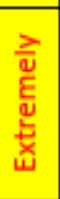 & & 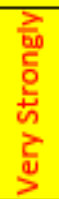 & & 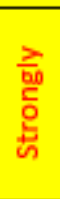 & & $\begin{array}{l}\frac{8}{8} \\
\text { o }\end{array}$ & & $\stackrel{2}{\underline{\pi}}$ & & 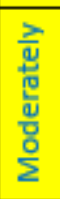 & & 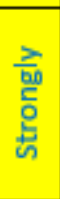 & & 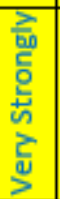 & & 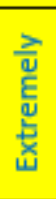 & $\begin{array}{c}\text { B } \\
\text { Options }\end{array}$ \\
\hline
\end{tabular}

RM1 - Determine RM goals and strategy (improve customer loyalty, increase profits, etc) RM2 - Develop return avoidance, gatekeeping and disposition guidelines;

RM3 - Develop returns network and flow options;

RM4 - Develop credit rules to determine how returned merchandise will be valued;

RM5 - Determine secondary markets where returns may be sold or used;

RM6 - Develop framework of metrics. 


\section{APPENDIX C - AHP DEVELOPMENT AND CALCULATION}

\section{THE HIERARCHY STRUCTURE}

The hierarchy structure, as proposed by Vargas (1990), Xia and Wu (2007) and Saaty (2008) consists in breaking down the complex problem into more manageable sub-problems through the multi-level decision hierarchy. Saaty (2008) divides the hierarchy structure in two different steps, first when the kind of knowledge sought is defined and second when the hierarchy structure is built.

According to Vargas (1990) the hierarchy design involves three nonsequential interrelated processes: level and element identification, concept definition, and question formulation. Figure 29 shows the relationship between these components.

Figure 29 - Relationship between processes in hierarchy design

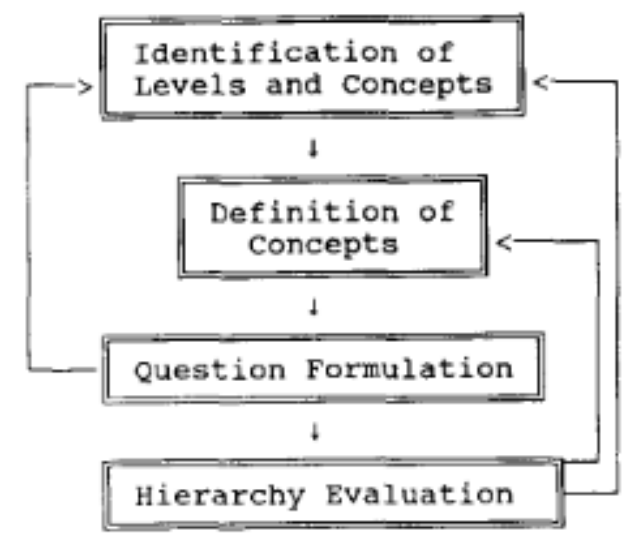

Source: Vargas (1990)

Hierarchic design is an iterative process where the concepts, the questions to be answered and the answers associated with the questions, determine the elements and the levels of the hierarchy. Because ambiguities in the questioning process may lead the decision maker to select wrong criteria or alternative, all questions should be answerable and consistent with existing information (VARGAS, 1990).

Xia and Wu (2007) highlights how decision makers cannot simultaneously handle many factors when making a decision, thus, it is necessary to break down the complex problem into more manageable sub-problems through the multi-level decision hierarchy.

Saaty (1980) emphasizes some of advantages of problem hierarchy. According to the author, the hierarchy representation of a system may be used to describe how changes in priority in higher levels affect the priority in lower levels. The hierarchy details the structure and functions of a system in the lowest levels, allowing a general view of actors and its purposes in 
the highest levels. Also, the hierarchy designed systems develop more efficiently than other developed in a general way. Lastly, the hierarchy systems are stable and flexibles, stable because small changes have small effects and flexible because additions in a well-structured hierarchy does not interfere in performance.

Usually, the hierarchy follows a four-level structure in which the top level represents the goal of the problem. The second level of the hierarchy contains the general criteria which are usually considered in evaluating the goal in level one. The third level, the criteria are decomposed into various sub-criteria that may affect the criteria in level two (XIA; WU, 2007; SAATY, 1980).

According to Briozo (2013) the level one, or problem goal, may be from any nature, such as supply selection, best investment choice or location of an enterprise. Several authors (Vargas, 1990; Saaty, 2008; Tramarico et al., 2015) researched AHP application and found applications in a variety of areas, from economic/management problems, to architecture, social, law, health, medicine, population dynamics, etc. showing the versatility of AHP.

Figure 30 represents a hierarchy structure as proposed by AHP methodology to construct the set of pairwise comparisons needed to AHP to achieve its goals. As stated before, the level 1 contain the objective or main goal of the hierarchy analysis, level 2 is a set of criteria directly linked to the goal, level 3 is sub-criteria directly linked to level 2 criteria, and alternatively, level 4 is the set of different alternatives to be evaluated, which may or may not be used, depending on the type of AHP implementation.

Figure 30 - AHP hierarchy
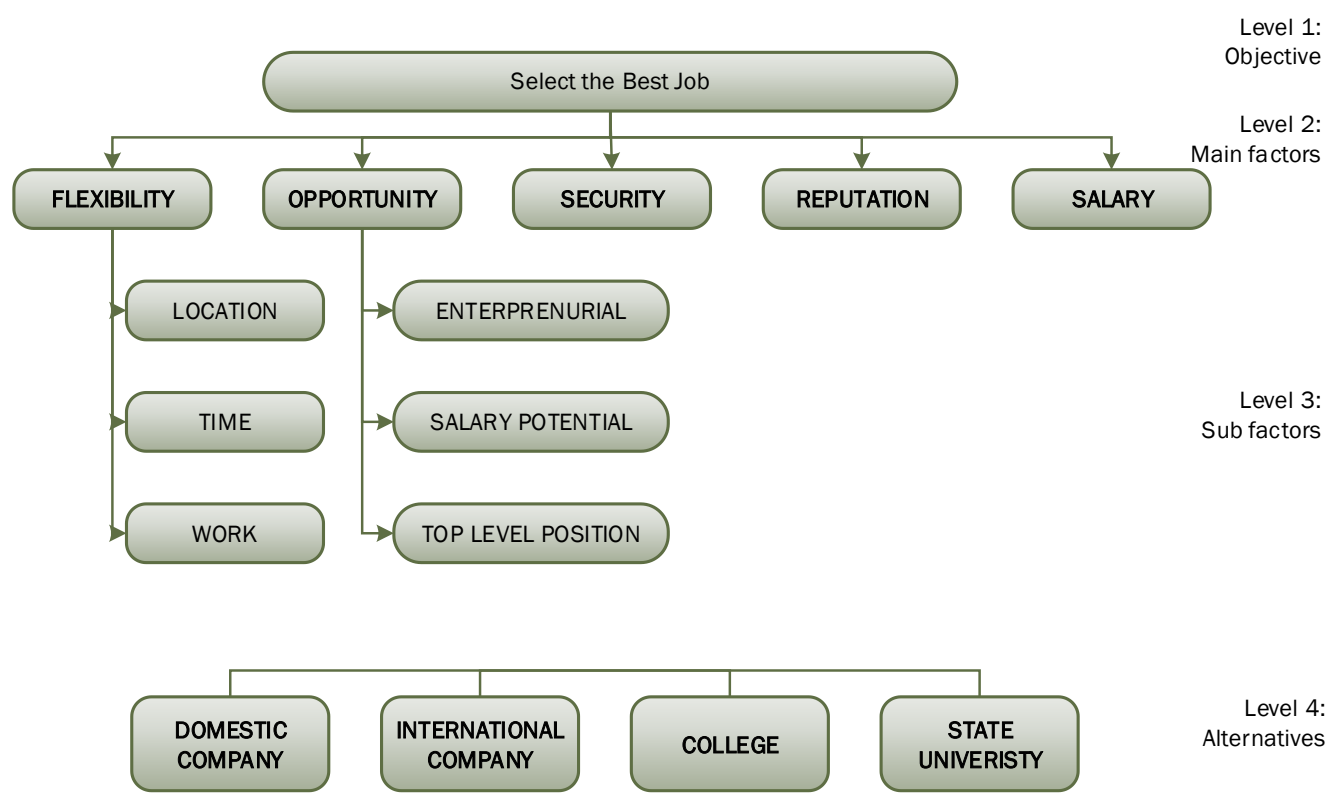

Source: Adapted from Saaty (2008) 


\section{CREATION OF PAIRWISE COMPARISON MATRICES}

To make comparisons, there is a need of a scale of numbers that indicates how many times more important or dominant one element is over another element with respect to the criterion or property to which they are compared (SAATY, 2008). Figure 31 shows the scale proposed by Saaty $(1980 ; 2008)$. The scale is a representation of the intensity of importance of one alternative over another.

Figure 31 - Scale for pairwise comparisons

\begin{tabular}{lll}
\hline $\begin{array}{l}\text { Intensity of } \\
\text { Importance }\end{array}$ & \multicolumn{1}{c}{ Definition } & \multicolumn{1}{c}{ Explanation } \\
\hline 1 & $\begin{array}{l}\text { Equal Importance } \\
\text { Weak or slight } \\
\text { Moderate importance }\end{array}$ & $\begin{array}{l}\text { Two activities contribute equally to the objective } \\
\text { Experience and judgement slightly favour } \\
\text { one activity over another }\end{array}$ \\
4 & $\begin{array}{l}\text { Moderate plus } \\
\text { Strong importance }\end{array}$ & $\begin{array}{l}\text { Experience and judgement strongly favour } \\
\text { one activity over another }\end{array}$ \\
5 & $\begin{array}{l}\text { Strong plus } \\
\text { Very strong or } \\
\text { demonstrated importance }\end{array}$ & $\begin{array}{l}\text { An activity is favoured very strongly over } \\
\text { another; its dominance demonstrated in practice }\end{array}$ \\
8 & $\begin{array}{l}\text { Very, very strong } \\
\text { Extreme importance }\end{array}$ & $\begin{array}{l}\text { The evidence favouring one activity over another } \\
\text { is of the highest possible order of affirmation }\end{array}$
\end{tabular}

Source: Saaty (2008)

To apply the method, a comparison matrix is filled based on the scale proposed by Saaty (1980; 2008) represented in Figure 31 in order to calculate the eigenvector and eigenvalue of the matrix. The judgments are made comparing two elements together, a pairwise comparison. Saaty (2008) provides an example (Figure 32) in which the scale is used to compare the relative consumption of drinks in the USA.

Figure 32 - Example of pairwise comparison

\begin{tabular}{lcccccccc}
\hline \multicolumn{7}{c}{ Which drink is consumed more in the USA? } \\
\hline \multicolumn{7}{c}{ An example of examination using judgements } \\
\hline Drink consumption in US & Coffee & Wine & Tea & Beer & Sodas & Milk & Water \\
Coffee & 1 & 9 & 5 & 2 & 1 & 1 & $1 / 2$ \\
Wine & $1 / 9$ & 1 & $1 / 3$ & $1 / 9$ & $1 / 9$ & $1 / 9$ & $1 / 9$ \\
Tea & $1 / 5$ & 2 & 1 & $1 / 3$ & $1 / 4$ & $1 / 3$ & $1 / 9$ \\
Beer & $1 / 2$ & 9 & 3 & 1 & $1 / 2$ & 1 & $1 / 3$ \\
Soda & 1 & 9 & 4 & 2 & 1 & 2 & $1 / 2$ \\
Milk & 1 & 9 & 3 & 1 & $1 / 2$ & 1 & $1 / 3$ \\
Water & 2 & 9 & 9 & 3 & 2 & 3 & 1 \\
\hline
\end{tabular}

Source: Saaty (2008)

The subject compares the drink indicated on the left with another indicated at the top and answers the question: How many times more, or how strongly more is that drink consumed in the US than the one at the top? The subject then enters the number from the scale that is 
appropriate for the judgement: for example enter 9 in the (coffee, wine) position meaning that coffee consumption is 9 times more than wine consumption. Automatically, 1/9 is assigning to the (wine, coffee) position. Note that water is consumed more than coffee, so the subject enters 2 in the (water, coffee) position, and $1 / 2$ in the (coffee, water) position.

The quantity of judgements (q) necessary to determine the performance of each alternative related to each criteria is defined by the equation 1 , where $n$ is the number of comprised alternatives.

$$
\mathrm{q}=[\mathrm{n} *(\mathrm{n}-1)] / 2
$$

In the example represented in Figure 32, 21 comparisons must be made in order to complete the comparisons needed to evaluate the ranking or preference of one of the seven drinks over the others.

\section{PRIORITY WEIGHTING IN AHP}

According to Xia and Wu (2007) once the hierarchy has been structured, the weights of criteria should be calculated. Saaty's work (1980) provided a 5 step framework to weight the priorities in AHP as it follows in Figure 33. Based on example provided in Figure 32 each of the steps will be followed in order to construct the priority based on the comparison made.

Figure 33 - Framework for priority weighting in AHP

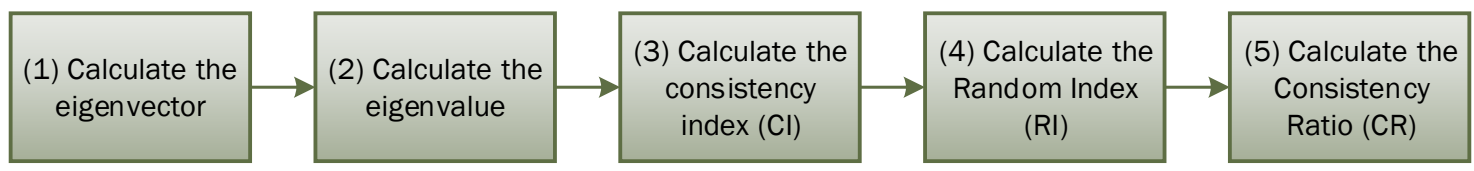

Source: Adapted from Saaty (1980)

The first step is to calculate the eigenvector. In order to calculate it, the first step is sum the weights of the evaluation, as shown in Figure 34

Figure 34 - Eigenvector Calculation - Step 1

\begin{tabular}{|c|c|c|c|c|c|c|c|}
\hline $0^{p+5}$ & Coffee & Wine & Tea & Beer & Soda & Milk & Water \\
\hline Coffee & 1 & 9 & 5 & 2 & 1 & 1 & $1 / 2$ \\
\hline Wine & $1 / 9$ & 1 & $1 / 3$ & $1 / 9$ & $1 / 9$ & $1 / 9$ & $1 / 9$ \\
\hline Tea & $1 / 5$ & 2 & 1 & $1 / 3$ & $1 / 4$ & $1 / 3$ & $1 / 9$ \\
\hline Beer & $1 / 2$ & 9 & 3 & 1 & $1 / 2$ & 1 & $1 / 3$ \\
\hline Soda & 1 & 9 & 4 & 2 & 1 & 2 & $1 / 2$ \\
\hline Milk & 1 & 9 & 3 & 1 & $1 / 2$ & 1 & $1 / 3$ \\
\hline Water & 1 & 9 & 9 & 3 & 2 & 3 & 1 \\
\hline
\end{tabular}


Source: Adapted from Saaty (2008)

The second step in calculating the eigenvector is, after summing the evaluation weights, is to calculate the normalized pairwise comparison matrix, by dividing each element in original matrix by the evaluation sum.

After obtaining the new matrix (Figure 35), the sum of each line must be calculated, as well as the sum of the sums.

Figure 35 - Eigenvector Calculation - Step 2

\begin{tabular}{|c|c|c|c|c|c|c|c|}
\hline $0^{2} 5^{v^{5}}$ & Coffee & Wine & Tea & Beer & Soda & Milk & Water \\
\hline Coffee & 0,208 & 0,188 & 0,197 & 0,212 & 0,187 & 0,118 & 0,173 \\
\hline Wine & 0,023 & 0,021 & 0,013 & 0,012 & 0,021 & 0,013 & 0,038 \\
\hline Tea & 0,042 & 0,042 & 0,039 & 0,035 & 0,047 & 0,039 & 0,038 \\
\hline Beer & 0,104 & 0,188 & 0,118 & 0,106 & 0,093 & 0,118 & 0,115 \\
\hline Soda & 0,208 & 0,188 & 0,158 & 0,212 & 0,187 & 0,237 & 0,173 \\
\hline Milk & 0,208 & 0,188 & 0,118 & 0,106 & 0,093 & 0,118 & 0,115 \\
\hline Water & 0,208 & 0,188 & 0,355 & 0,318 & 0,373 & 0,355 & 0,346 \\
\hline
\end{tabular}

$\Sigma$

1,283

0,141

0,283

0,843

1,361

0,947

2,143

$\Sigma$

7,000

Source: Adapted from Saaty (2008)

In the last step to calculate the eigenvector, the sum of the lines of the new normalized matrix must be divided by the sum of the sums (which will be the matrix order $n$ ). This way, the eigenvector is obtained. The calculation is shown in Figure 36.

Figure 36 - Eigenvector Calculation - Step 3

\begin{tabular}{lc}
\hline & EIGENVECTOR \\
\hline $1,283 / 7,000$ & $\mathbf{0 , 1 8 3}$ \\
$0,141 / 7,000$ & $\mathbf{0 , 0 2 0}$ \\
$0,283 / 7,000$ & $\mathbf{0 , 0 4 0}$ \\
$0,843 / 7,000$ & $\mathbf{0 , 1 2 0}$ \\
$1,361 / 7,000$ & $\mathbf{0 , 1 9 4}$ \\
$0,947 / 7,000$ & $\mathbf{0 , 1 3 5}$ \\
$2,143 / 7,000$ & $\mathbf{0 , 3 0 6}$ \\
\hline
\end{tabular}

Source: Adapted from Saaty (2008)

Some conclusions may be drawn from the eigenvector. If the Consistency Ratio (CR), which will be discussed forward, is within the correct range, the eigenvector shows that alternative "water" is the most preferred one $(0,306)$ in relation to the other alternatives. 
Following Saaty's (1980) proposal, the next step of calculations to weight the comparisons is to calculate the eigenvalue. In order to calculate the eigenvalue, the original matrix must be multiplied by the eigenvector as shown in the Figure 37.

Figure 37 - Eigenvalue Calculation

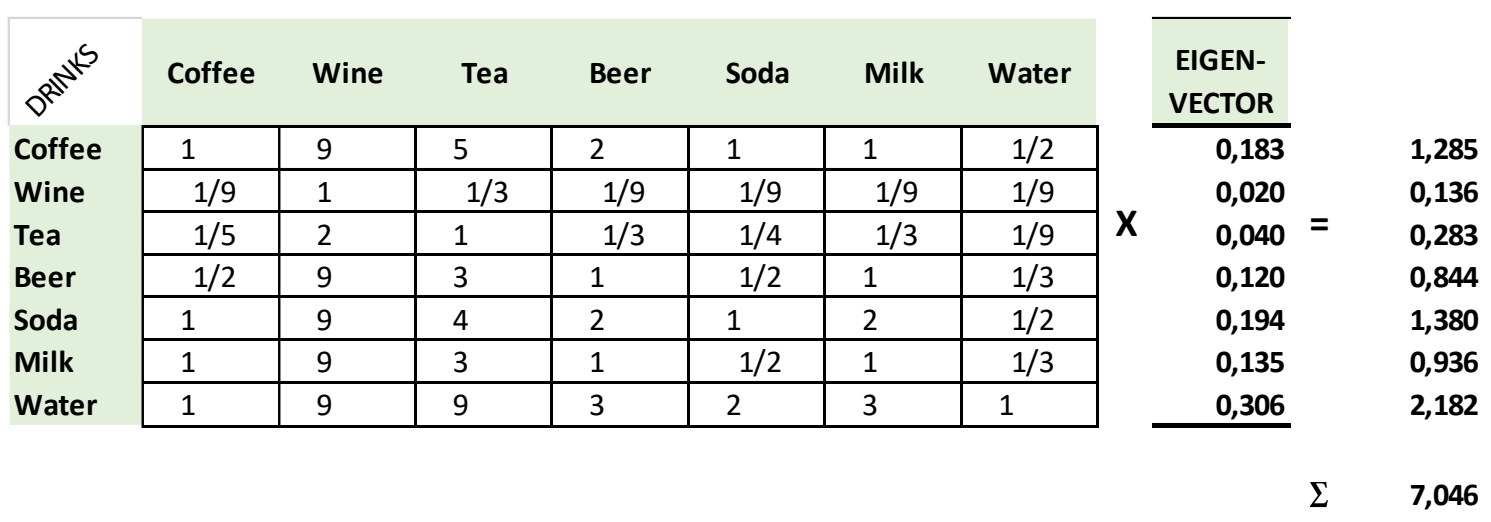

Source: Adapted from Saaty (2008)

The eigenvalue $\left(\lambda_{\max }\right)$ is the sum of the result of the matrix multiplication. After its calculation, the Consistency Index (CI) must be calculated using the equation 2 . The $\mathrm{CI}$ is used to measure the consistency of the comparisons, and will later be used to calculate the Consistency Ratio (CR).

$$
C I=\frac{\lambda_{\max }-n}{(n-1)}
$$

For the following example, the $\mathrm{CI}$ is 0,008 . The last step if to calculate the Consistency Ratio (CR), but before that, there is a need to identify the Random Consistency Index (RI), which considers a random error, related to the matrix order. Saaty (1980) calculated different RI for each matrix varying from orders 1 to 10 . The RI are represented in the Figure 38 .

Figure 38 - Randon Consistency Index (RI)

\begin{tabular}{lrrrrrrrrrr}
\hline matrix order & 1 & 2 & 3 & 4 & 5 & 6 & 7 & 8 & 9 & 10 \\
RI & 0.00 & 0.00 & 0.58 & 0.90 & 1.12 & 1.24 & 1.32 & 1.41 & 1.45 & 1.49 \\
\hline
\end{tabular}

Source: Adapted from Saaty (2008)

With these information in hand, the CR can be calculated following the equation 3 . According to Saaty and Tran (2007) the CR of the pairwise comparison matrix is a measure used in AHP to improve the validity of the outcome, i.e., when a matrix of comparison has inconsistency, the decision maker must change his/her opinion about some comparison to improve the consistency of the outcome.

$$
C R=\frac{\mathrm{CI}}{R I}
$$


For the following example, the CR is 0.006. According to Saaty (1980), AHP applications with consistency ratios greater than 0.10 should be revised, although a ratio of less than 0.20 is considered tolerable. In cases where $C R>0.20$, the evaluator judgment must be reviewed in order to elicit any possible mistakes or even discarded.

Some authors (WEDLEY, 1993; HO, NEWELL; WALKER, 2005; ALONSO; LAMATA, 2006) criticize the CR value proposed by Saaty (1980) and create different approaches for CR acceptance to the pairwise matrices. Wedley (1993) highlights the evaluation of matrix size in order to determine the consistency ratio and its range of acceptance, according to the author, the highest the order, higher should be the CR tolerance outside Saaty's proposed limits.

Alonso and Lamata (2006) propose a new method for calculate the CR by recalculating the Random Consistency Index (RI) using as sample 500.000 generated matrices instead of 500 as calculated by Saaty's (1980) RI table. Ho, Newell and Walker (2005) highlights the importance of accepting CRs greater than 0.20 in order to accommodate non experts' analysis in its AHP application. 


\section{APPENDIX D - DETAILED SCM PROCESSES}

\section{THE CUSTOMER RELATIONSHIP MANAGEMENT (CRM) PROCESS}

Increasingly, Customer Relationship Management (CRM) is being viewed as strategic, process-oriented, cross-functional, value-creating for buyer and seller, and means of achieving financial performance (LAMBERT; ENZ, 2017).

The customer relationship management process, according to Croxton et al. (2001), provides the structure for how the relationship with the customer is developed and maintained in order to achieve some goals:

- Identify key customers and customer groups to be targeted as parts of the firm's business mission;

- Customer teams tailor Product and Service Agreements (PSA) to meet the needs of key accounts and segments of other customers;

- Teams work with key accounts to improve processes, and eliminate demand variability and non-value-add activities;

- Performance reports are designed to measure the profitability of individual customers as well as the firm's financial impact on those costumers.

According to Bolumole et al. (2003) PSAs are documents that match specific customer or customer segment needs with a firm's products and/or services. They represent a firm's commitment to a customer based on a realistic understanding of customer expectations and the firm's own capabilities and profitability requirements.

As a result of (1) competitive pressures; (2) the need to achieve cost efficiency in order to be a low-cost, high-quality supplier; (3) a recognition of the fact that the customers are not equal in terms of their profitability; and, (4) knowledge that customer retention can significantly affect profitability, CRM has become a critical business process (LAMBERT, 2009).

According to Lambert (2009) CRM and Supplier Relationship Management, provide the critical linkages throughout the supply chain (see Figure 39). For each supplier in the supply chain, the ultimate measure of success for the CRM process is the growth in profitability of an individual customer or segment of customers over time. For each customer, the most comprehensive measure of success for the Supplier Relationship Management Process is the impact that a supplier has on the firm's profitability. The overall performance of the supply 
chain is determined by the combined improvement in profitability of all of its members from one year to the next.

Figure 39 - CRM and SRM critical linkages through the Supply Chain

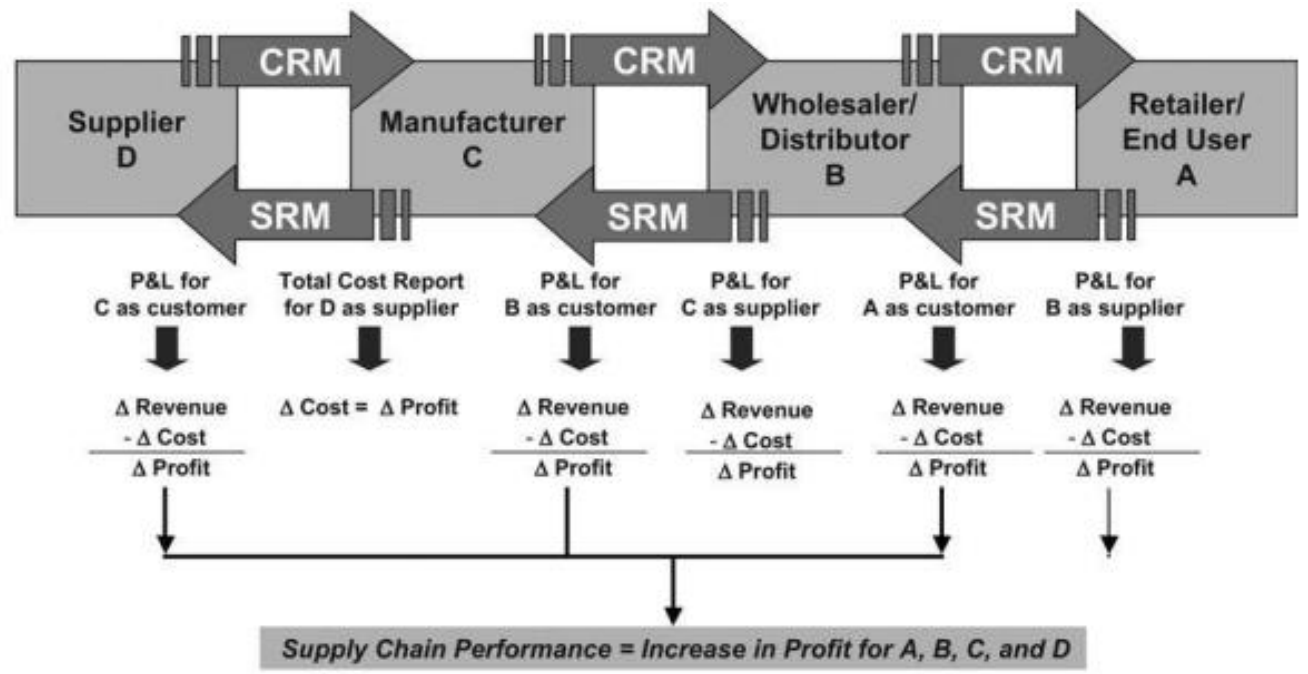

Source: Lambert (2008)

Authors who wrote about CRM process (Croxton et al., 2001; Lambert 2009) divided it in two parts, the strategic process, in which management stablishes and strategically manages the process, and the operational process in which implementation takes place.

At the strategic level, the CRM process provides the framework for managing relationship with customers, and it is comprised of five sub processes. At the operational level, there are seven sub-processes. The sub-processes and its interface with other SCM processes are shown in Figure 40. 
Figure 40 - Sub-processes and interfaces of CRM process

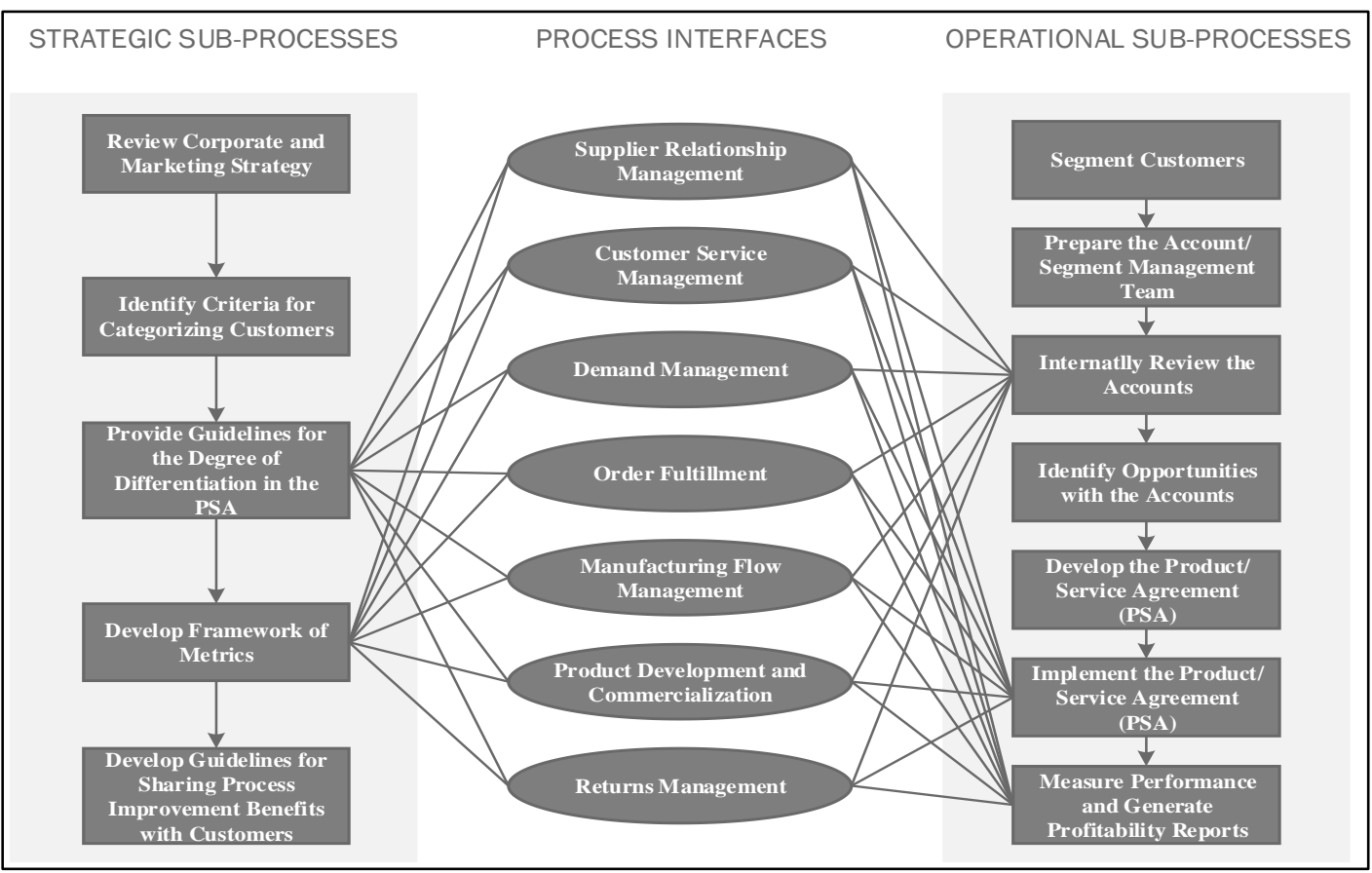

Source: Adapted from Lambert (2009)

\section{STRATEGIC LEVEL OF CRM PROCESS}

First, the process team reviews the corporate and marketing strategy in order to identify customers segments that are key to the organization's success now and in the future (Croxton et al., 2001).

Next, the team must identify criteria for categorizing customers within the markets and target segments identified in the first sub-process. This second level of segmentation provides guidelines for determining which customers are qualified for tailored PSAs and which customers will be grouped into segments and offered a standard PSA that is developed to provide value to the segment and meet the firm's profit goals for that segment (LAMBERT, 2009).

Lambert (2009) provides some potential segmentation criteria, including: profitability, growth potential, volume, competitive positioning issues, access to market knowledge, market share, goals, margin levels, level of technology, resources and capabilities, compatibility of strategies, channel of distribution and buying behavior.

Other activity of this sub-process is the development of the firm strategy for dealing with segments of customers who do not qualify for individually tailored PSAs (LAMBERT, 2009). According to the author, PSAs come in many forms, both formal and informal, and may 
be referred to by different names from company to company. However, for best results, they should be formalized as written documents.

In the third strategic sub-process, the team develop guidelines for the degree of differentiation in the PSA. This involves developing the differentiation alternatives and considering the revenue and cost implications of each. The goal is to offer PSAs that enhance the profitability of the firm and the customers, in order to do this, this sub-process will interface with all of the other processes (CROXTON et al., 2001). According to Lambert (2009) the output of this sub-process is the degree of customization that can be offered to customers based on the potential of the customer(s).

Developing the framework of metrics involves outlining the metrics of interest and relating them to the customer's impact on the firm's profitability as well as the firm's impact on the customer's profitability (Croxton et al., 2001; Lambert, 2009). Lambert, Cooper and Pagh (1998) states that management needs to insure that all internal and external measures are driving consistent and appropriate behavior.

The last sub-process consist of develop guidelines for sharing process improvement benefits with customers. The goal is to make process improvements win-win solutions for both the firm and the customers. If all of the parties involved do not gain from process improvement efforts, it will be difficult obtain their full and sustained commitment (Croxton et al., 2001; Lambert, 2009).

As Croxton et al. (2001) and Lambert (2009) summarized, the objective of customer relationship management at the strategic level is to identify customer segments, provide criteria for categorizing customers, provide customers' teams with guidelines for customizing the product and service offering, develop a framework for metrics, and provide guidelines for the sharing of process improvement benefits with customers. Figure 41 summarizes the activities of each strategic sub-process and also the interfaces that each sub-process has with other process in the SCM processes framework. 
Figure 41 - Activities and interfaces of CRM strategic sub-processes

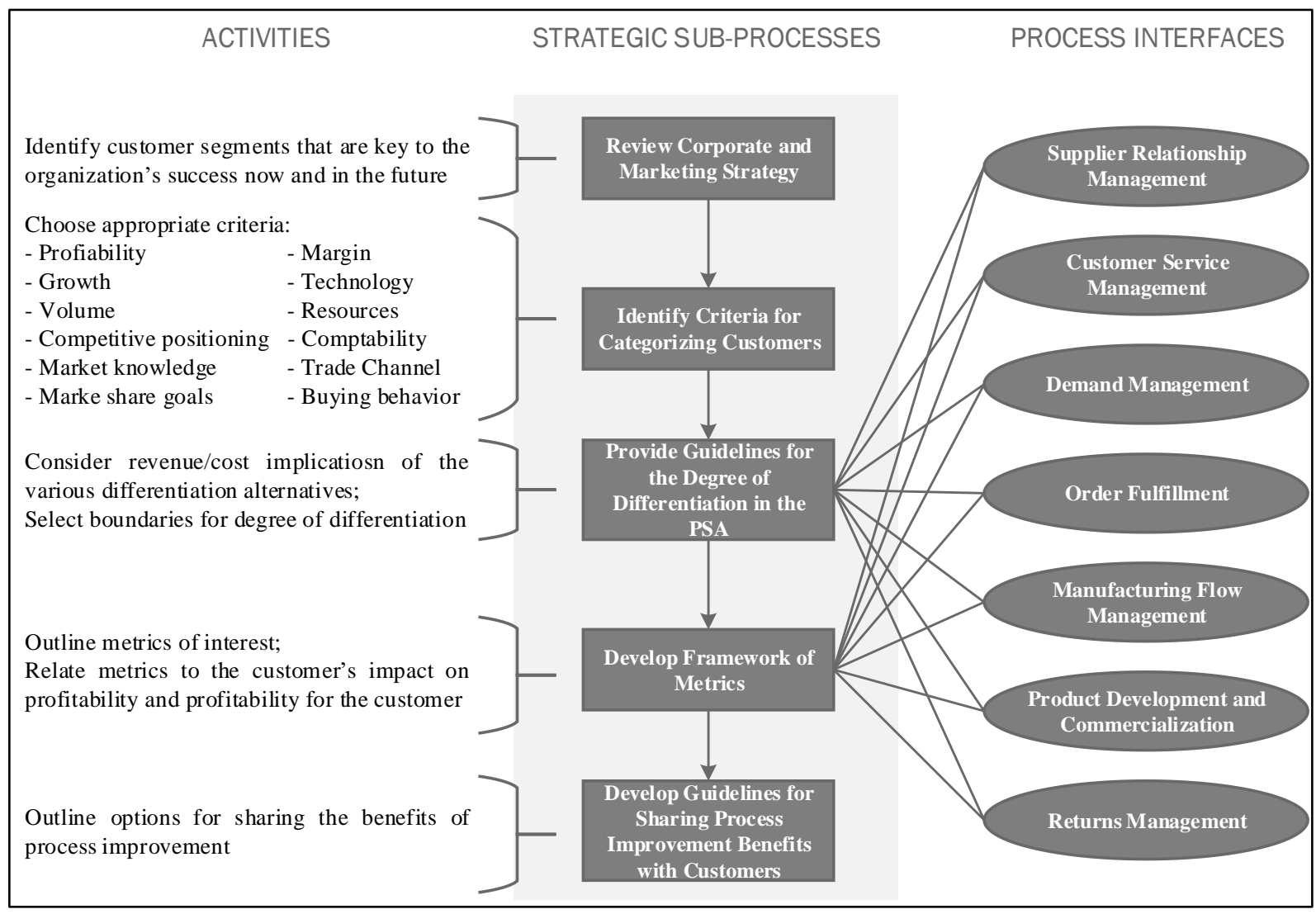

Source: Adapted from Lambert (2009)

\section{OPERATIONAL LEVEL OF CRM PROCESS}

At the operational level, the CRM process deals with segmenting customers as well as writing and implementing the PSAs (LAMBERT, 2009). As shown in Figure 40, it is comprised of seven sub-processes.

The first of its operational sub-processes is segment customers based on the criteria that were established in the strategic process. According to Lambert (2009) the goal is to identify those customers who desire and deserve special treatment so that offerings can be tailored to meet their needs while achieving the firm's profit goals for the customer. A key measure is the current profitability of each customer combined with growth potential (TURNBULL et al., 1996).

Next, follows the preparation of the account/segment management teams, were the account or segment management teams are formed, including the salesperson who will be the account or segment manager (CROXTON et al., 2001). The teams should be cross-functional with representation from each of the functional areas of the company, including marketing, 
sales, research and development, logistics, production, information systems, purchasing and finance (LAMBERT, 2009).

The third operational CRM sub-process consists in internally review the accounts, as Lambert (2009) states, at this moment each team reviews their account or segment to determine the products purchased, sales growth and their position in the industry. The CRM team must have the ability to understand and meet the customers' priorities as well as identify opportunities to co-create value.

The following step is to identify opportunities with the accounts. Lambert (2009) summarizes this sub-process in identifying customer priorities that are being ignored and find a way to profitably respond to them. Once the team has an understanding of the customers, they work with each account or segment of accounts to develop improvement opportunities in sales, costs and service.

The fifth sub-process consist of develop the Product/Service Agreement (PSA) for their account or segment of accounts. Croxton et al. (2001) suggests that the team must first outlines and drafts the PSA, and thein gain commitment from the internal functions. For key accounts, they present the PSA for acceptance, and work with the customer until reach an agreement. For other accounts, the PSA is presented to the customer.

Next, the team implements the PSAs, which includes holding regular planning sessions with each key customer. The CRM teams must work with other process teams to make sure that each PSA is being implemented as planned, and schedule regular meetings with customers to review progress and performance. In addition, the team must provide input to each of the other seven macro-business processes that are affected by the customizations that have been made in the PSAs (LAMBERT, 2009).

The last operational sub-process, the team should measure performance and generate profitability reports by capturing and reporting it. Metrics from each of the other processes also are captures in order to generate the customer profitability reports. These reports provide information for measuring and selling the value of the relationship to each customer and internally to upper management (CROXTON et al., 2001).

Figure 42 summarizes the activities of each operational sub-process and also the interfaces that each sub-process has with other process in the SCM processes framework. 
Figure 42 - Activities and interfaces of CRM operational sub-processes

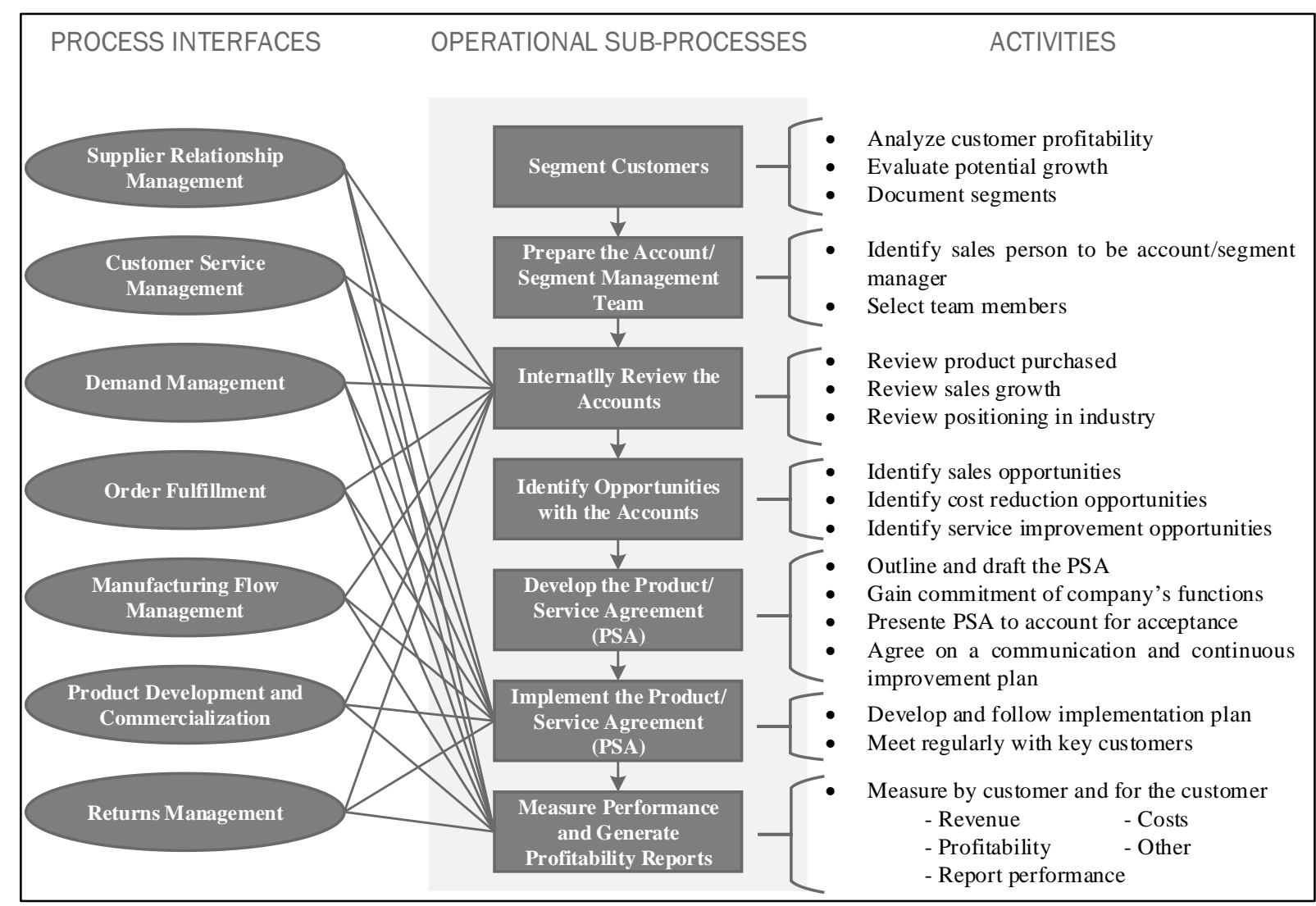

Source: Adapted from Lambert (2009)

\section{THE SUPPLIER RELATIONSHIP MANAGEMENT (SRM) PROCESS}

Supplier relationship management is the business process that provides the structure to develop and maintain relationships with suppliers (LAMBERT; SCHWIETERMAN, 2012). As the names suggests, it mirrors the customer relationship management. According to Croxton et al. (2001) just as it is important to a company to develop relationships with its customers, it needs to foster relationships with its suppliers.

According to Lambert and Schwieterman (2012) it has become a critical business process as a result of a few factors. Among them, competitive pressures; the need to consider sustainability and risk; the need to achieve cost efficiency in order to be cost competitive; and the need to develop closer relationships with key suppliers who can provide the expertise necessary to develop innovative products and bring them to market.

Supplier relationship management teams work with key suppliers to tailor product and service agreements (PSAs) to meet the organization's needs, as well as those of the selected 
suppliers. The goal is to develop PSAs that address the major business drivers of both the organization and the supplier (LAMBERT; SCHWIETERMAN, 2012).

According to Lambert (2009) and Lambert and Schwieterman (2012) supplier relationship management and customer relationship management provide the critical linkages throughout the supply chain (see Figure 39) and each of the other six processes are coordinated through this linkage.

The supplier relationship management process, as the other processes of SCM, is comprised of the strategic, in which management establishes and strategically manages the process, and the operational part, in which implementation takes place (LAMBERT; SCHWIETERMAN, 2012).

The Figure 43 demonstrate the existent relations between the strategic and operational sub-processes of supplier relationship management and the other processes of the supply chain management.

Figure 43 - Sub-processes and interfaces of SRM process

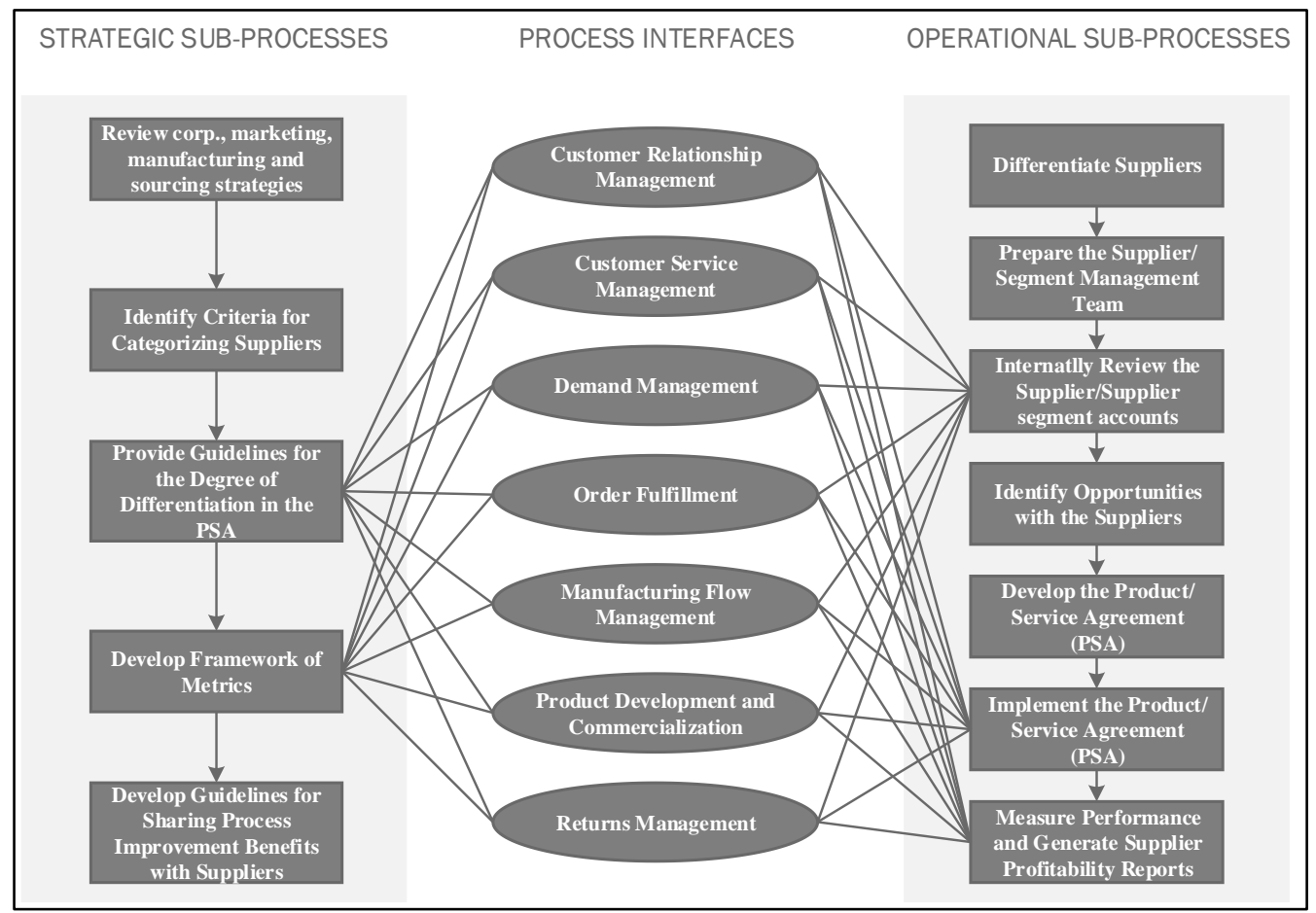

Source: Adapted from Lambert and Schwieterman (2012) 


\section{STRATEGIC SUPPLIER RELATIONSHIP MANAGEMENT PROCESS}

At the strategic level, the output of the process is an understanding of the levels of relationships the firm will maintain, and the process for segmenting the suppliers and working with them to develop appropriate PSAs (CROXTON et al., 2001).

Lambert and Schwieterman (2012) describe the first step as to review corporate, marketing, manufacturing and sourcing strategies, in order to identify supplier segments that are critical to the organization's success now and in the future. The supplier network is a key part of profitable business development, so management can identify strategic issues and opportunities for value co-creation, sustainability problems and supply risks, incorporating them into a strategy for managing supplier relationship.

The second sub-process is to identify criteria to further segment suppliers. Croxton et al. (2001) lists some of the criteria used to segment, among them: supplier's profitability; growth and stability; criticality of the components purchased; supplier's technological capabilities; the volume purchased from the supplier; the quality level.

Lambert and Schwieterman (2012) affirm that the appropriate criteria must meet the specific needs and goals of the firm and the team must determines which criteria to use and how supplier will be evaluated on each criteria. A segmentation scheme is developed to guide the operational team on determining the firm's key suppliers, and grouping other suppliers into segments.

In the third sub-process, the team develops guidelines for the degree of differentiation in the PSA. Croxton et al. (2001) when describe this sub-process affirm that key suppliers work with customized PSAs; other supplier work with standard PSAs with little to no customization. In order to provide the guidelines the team consider the quality and cost implications of various differentiation alternatives, and select the boundaries for the degree of customization that might be required or desired.

The fourth sub-process is to develop the framework of metrics. According to Lambert and Schwieterman (2012) it involves outlining metrics of interest and relating them to the supplier's impact on the firm's profitability as well as the firm's impact on the supplier's profitability.

The final sub-process is to develop guidelines for sharing process improvement benefits with suppliers. It is important for the supplier relationships to be win-win. If both parties do not 
gain from the relationship, the incentive to be in the relationship is diminished and it will likely dissolve (CROXTON et al., 2001).

The Figure 44 shows a summary of some of the activities related to each strategic subprocess of the Supplier Relationship Management as it was previous discussed.

Figure 44 - Activities and interfaces of SRM strategic sub-processes

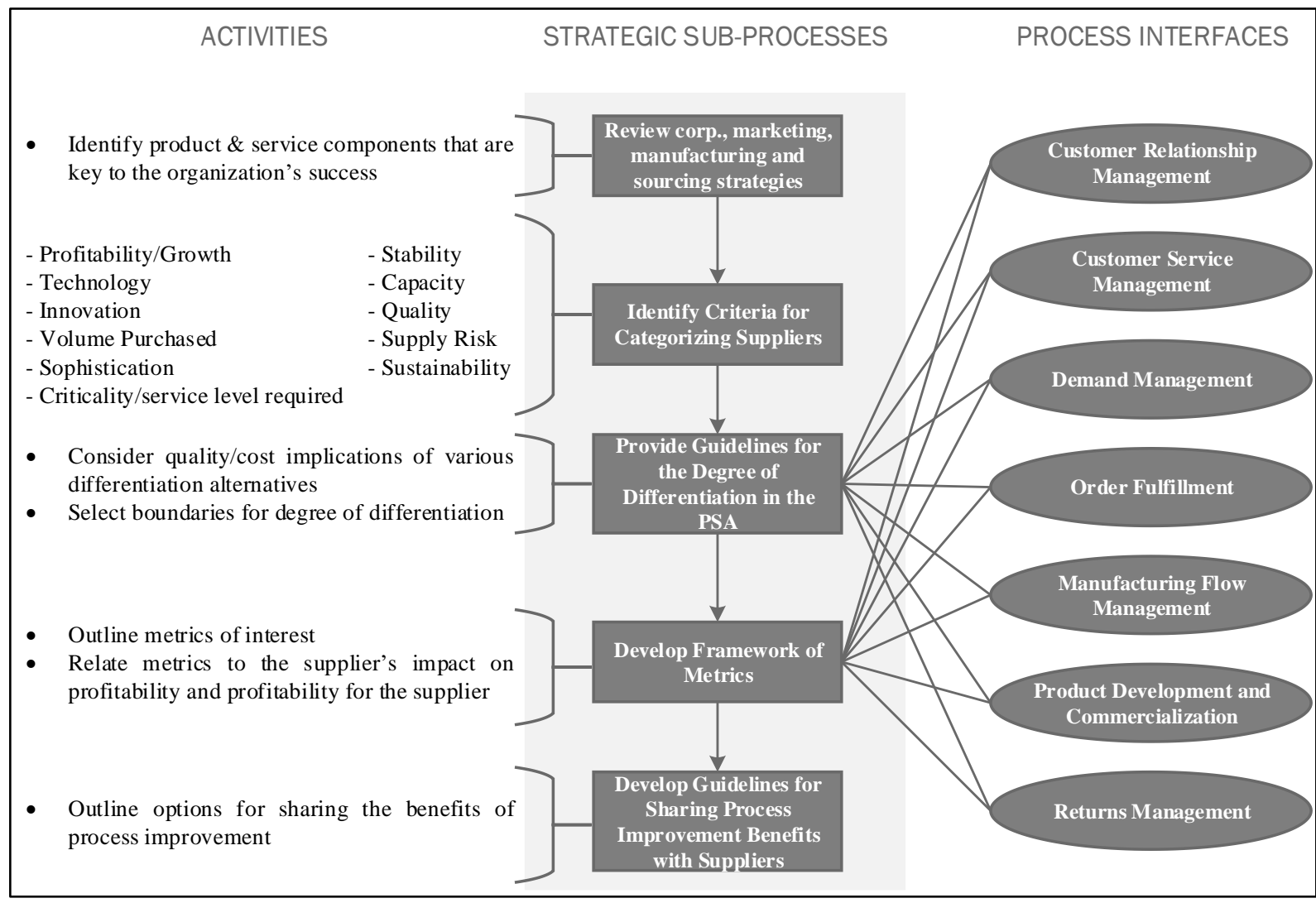

Source: Adapted from Lambert and Schwieterman (2012)

\section{OPERATIONAL SUPPLIER RELATIONSHIP MANAGEMENT PROCESS}

At the operational level, the supplier relationship management process deals with developing and implementing the PSAs (LAMBERT; SCHWIETERMAN, 2012). First, the team must segment suppliers based on the criteria that were established in the strategic process. The output of this sub-process is the identification of which suppliers are key to the firm and which suppliers should be grouped into segments (CROXTON et al., 2001).

The second step is to prepare the supplier/segment management teams. According to Lambert and Schwieterman (2012) in this sub-process the teams are formed, including the buyer who will be the supplier or supplier segment relationship manager. A team manager and a crossfunctional group of members will comprise the team. 
The third step is to internally review the supplier/supplier segment. Each team, according to Croxton et al. (2001), assures that the suppliers understand its role on the supply chain. In the fourth step, the team also works with each key supplier in order to identify improvement opportunities within the account, such as opportunities to increase sales, reduce costs and improve service.

Lambert and Schwieterman (2012) wrote about the fifth sub-process which is develop the product and service agreement (PSA) and the communication plan. According to them, each team develops the PSA for their supplier or segment of suppliers. It is important that each PSA for key suppliers include a communication and continuous improvement plan. For non-key suppliers, a standard PSA must be developed stating the minimum requirements to be a supplier, and they must not be negotiable.

The sixth sub-process, the team implements the PSA, which includes holding regular planning session with key suppliers. The supplier relationship management teams provide inputs for each of the other SCM process teams that are affected by the customization that have been made in the PSAs (LAMBERT; SCHWIETERMAN, 2012).

The last sub-process, according to Croxton et al. (2001) is to measure performance and it is a critical part of the supplier relationship management process because management needs to assess the success of the firm's relationships. Those metrics are tied to the profits of both the firm and the supplier, and the results are reported internally and to the supplier.

The Figure 45 shows the activities related to each of the operational sub-processes of supplier relationship management. 
Figure 45 - Activities and interfaces of SRM operational sub-processes

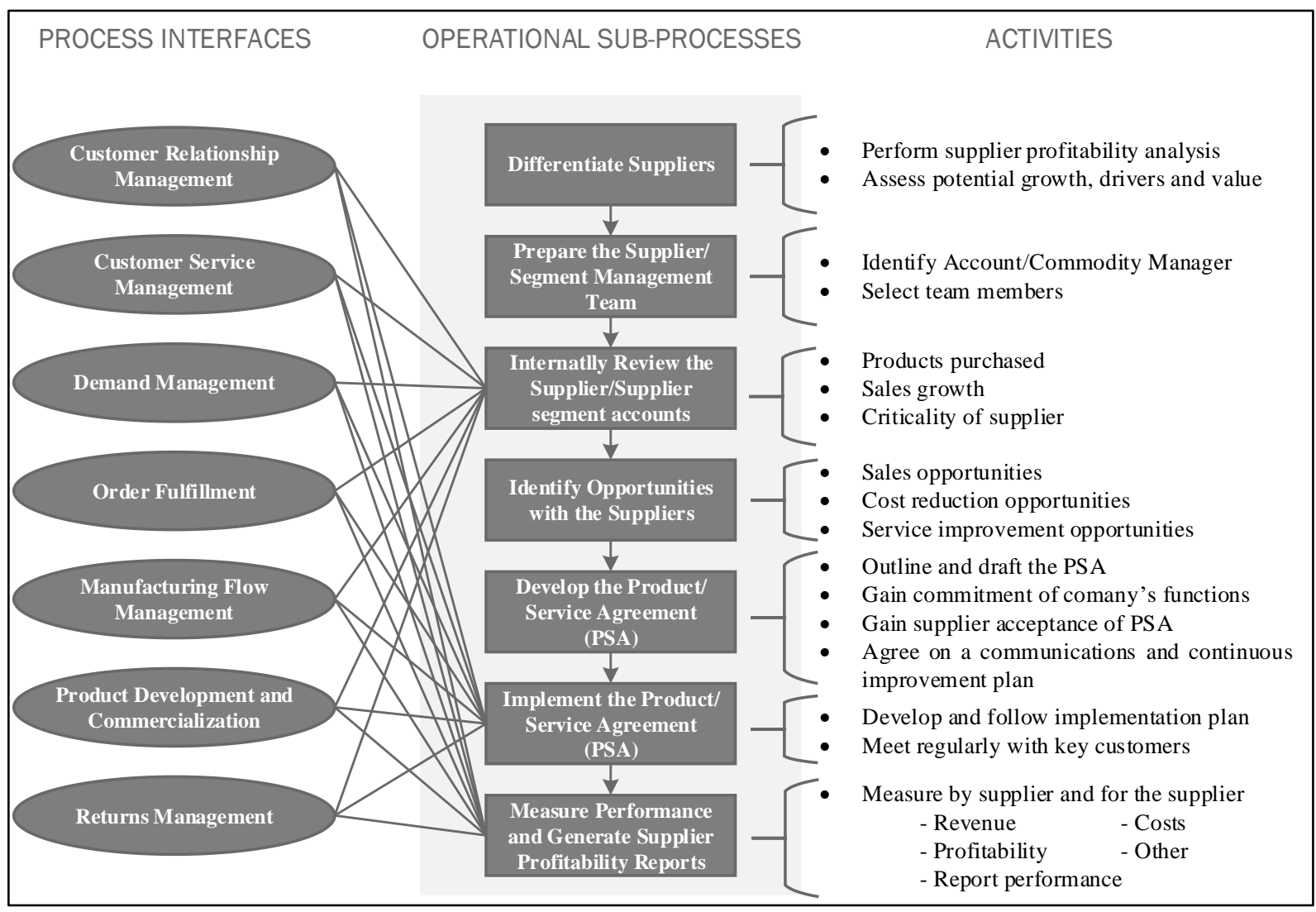

Source: Adapted from Lambert and Schwieterman (2012)

\section{THE CUSTOMER SERVICE MANAGEMENT (CSM) PROCESS}

Driven by an increasing expectation for timely and accurate information before, during and after transactions, customers expect and ease of doing business that entails adoption of a process approach towards customer service (BOLUMOLE, et al. 2003).

According to Croxton et al. (2001) the customer service management process is the firm's face to the customer. It provides the single source of customer information, such as product availability, shipping dates and order status.

Real-time information is provided to the customer through interfaces with the firm's functions, such as manufacturing and logistics. It is also responsible for administering the PSA (CROXTON et al., 2001).

Bolumole et al. (2003) states that in a competitive business environment, it is necessary that firms actively manage their customer service management process in order to provide a focused point of contact for all customer inquiries. The well-managed customer service 
management allows a company to be more proactive to service requests and more responsive to service problems.

As Bolumole et al. (2003) affirms, the Customer Service Management Process provides the firm's face to its customers. At the strategic level, the process provides what is needed to deal with the necessary framework and infrastructural basis for implementing PSAs, and it is comprised of four sub processes.

The Figure 46 shows the relation between the strategic sub-processes, the operational sub-processes and the interfaces between them and each of the other seven SCM processes.

Figure 46 - Sub-processes and interfaces of CSM processes

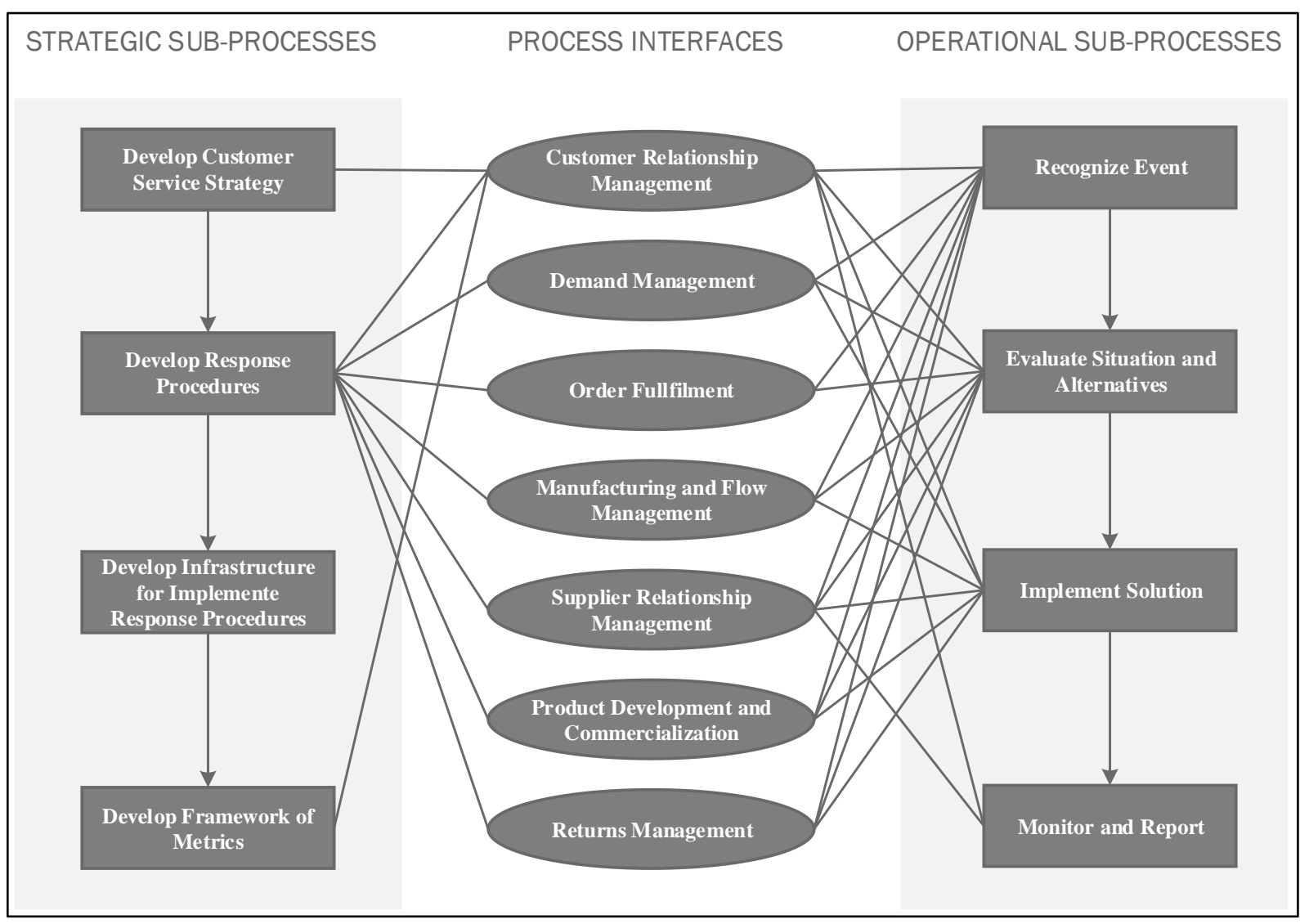

Source: Adapted from Bolumole et al. (2003)

\section{STRATEGIC CUSTOMER SERVICE MANAGEMENT PROCESS}

The first sub-process of the Customer Service Management Process is to develop customer service strategy for the set of PSA features identified in the CRM process. The team identify the deliverables of the customer service process, operationalizes the triggers for initiating action, and defines the staffing needs. The deliverables of the process are standardized 
responses to standardized events that occur while administering the PSA (CROXTON, et al., 2001).

According to Bolumole et al. (2003), when implementing the first strategic sub-process, the customer service management team interfaces with the CRM team. The driving force is the recognition that you cannot be everything to everyone. In addition, according to the authors, prior to the implementation of the next sub-process, organizations must define a customer service structure that identifies what staffing; administrative; and technological resources are needed and available, matching resource availability with the organization's strategic alignment.

In the second sub-process, the team determines the types of events that require responses and then develops response procedures for each of these events. This includes developing the internal and external coordination required to respond and distinguish between customer and internal responses. This sub-process requires organizations to have clearly segmented their customers (BOLUMOLE et al., 2003).

Once the team decides on appropriate response procedures to the relevant events, the team identifies the structure to implementing response procedures. The sources of the information needed to handle each event and determining the appropriate communication protocols for internal and external coordination must be identified. The team must also identify the information technology and communication needs for managing the PSAs efficiently and effectively. If there are technical constraints restricting the establishment of this infrastructure, the components of the PSA must be re-evaluated and modified to make them feasible (BOLUMOLE et al., 2003).

Croxton et al. (2001) states that, as in the other processes, the last sub-process of customer service management at the strategic level is to develop the framework of metrics. The metrics should provide management with the information necessary to identify problems and improvement opportunities in the administration of the PSA.

The Figure 47 shows a summary of the activities related to each strategic sub-process of the Customer Service Management as it was discussed behind. 
Figure 47 - Activities and interfaces of CSM strategic sub-processes

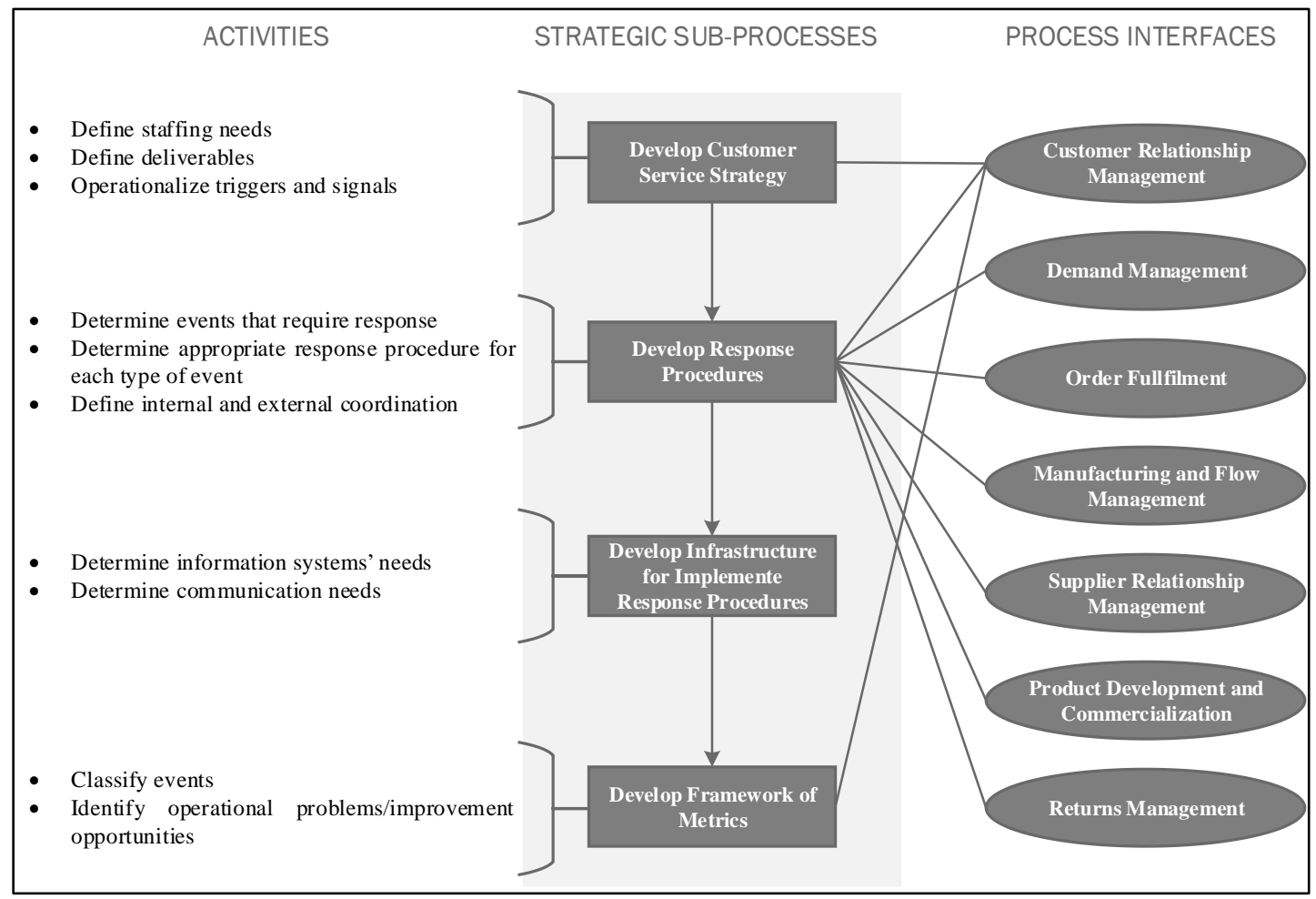

Source: Adapted from Bolumole et al. (2003)

\section{OPERATIONAL CUSTOMER SERVICE MANAGEMENT PROCESS}

At the operational level, customer service management process teams (CSMs) are responsible for the execution of the process as it was designed within the framework set up by the strategic process team and respond to both internal and external events (BOLUMOLE et al., 2003; CROXTON et al., 2001).

The first step is recognize the event. According to Croxton et al. (2001) this might seem trivial but the goal of being proactive makes this a challenging part of administering the PSA. The teams needs to have a thorough understanding of the firm's operations, and try to foresee the effects of a given event on the customer and on the internal operations of the firms. Events that require action might originate in any one of the other processes, so coordination is essential.

Bolumole et al. (2003) adds that it is necessary to classify events and responses accordingly, based on internally set triggers, and also the importance of internal communication in order to identify potential obstacles to fulfill the customers' unique requirements.

After the event recognition, the CSM evaluates situation and alternatives to manage the event with the least disruption possible to the customer and internal operations. The CSM, 
working with the specialists in each of the functions affected by the event or that who can contribute implementing the solution. This requires interfacing with other processes that might be affected by the alternative responses (BOLUMOLE et al., 2003)

The third step is to implement solution. Croxton et al. (2001) highlight the importance of coordination of actions, as other business process owners or functions managers often need to participate in the implementation. At this point, the actual response to the event is executed.

The last sub-process is to monitor and report the process performance. According to Bolumole et al. (2003) it includes identifying possible process improvements and feedback to the strategic level sub-process to develop response procedures. It also includes recording the event and monitoring the evolution of the event in order to know to what extent the response has been implemented.

The Figure 48 summarizes the activities related to each operational sub-process of the Customer Service Management process.

Figure 48 - Activities and interfaces of CSM operational sub-processes

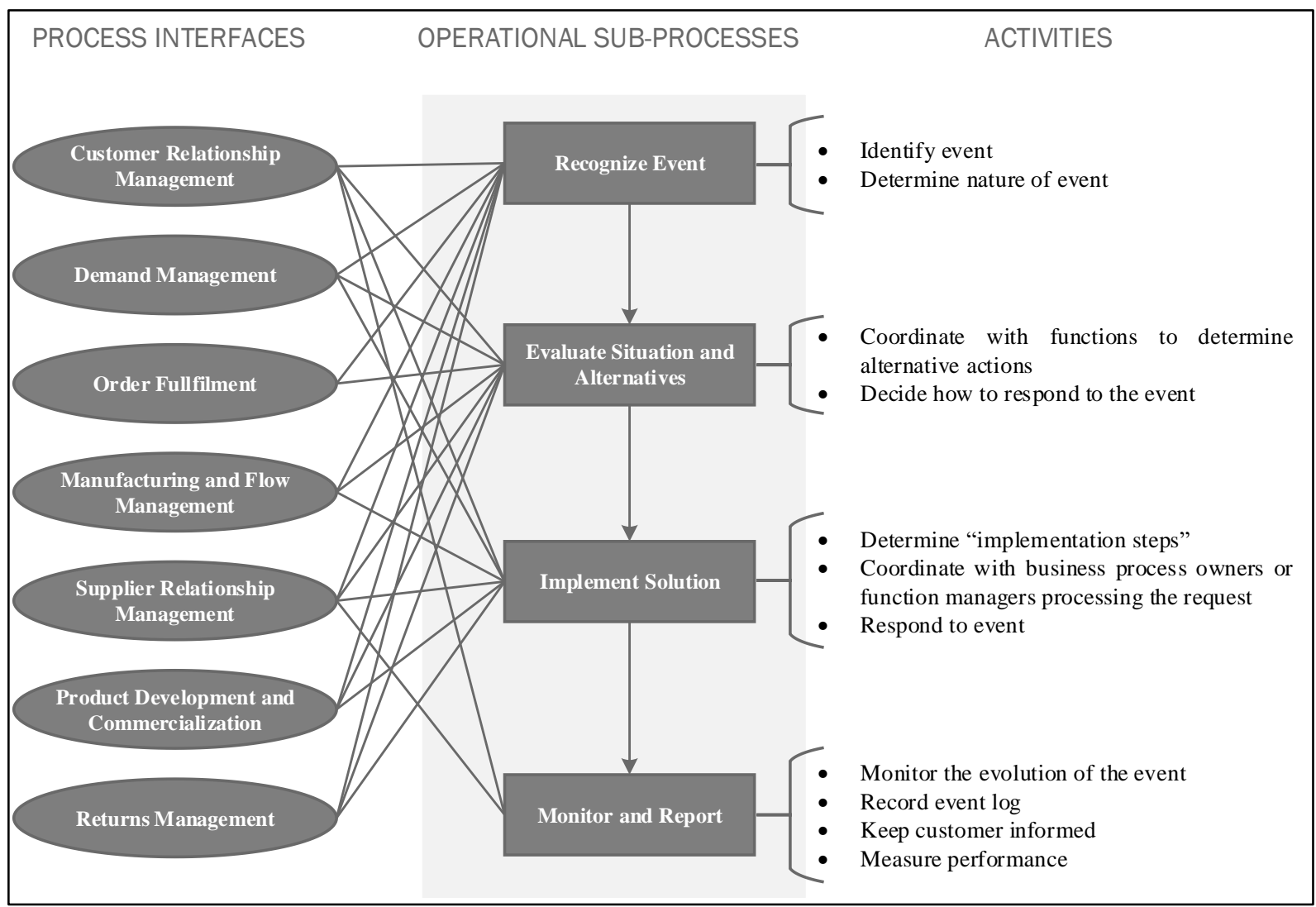

Source: Adapted from Bolumole et al. (2003) 


\section{THE DEMAND MANAGEMENT (DM) PROCESS}

The demand management process can have a significant impact on the profitability of a firm, its customers and suppliers. Its main concern is to balance the customers' requirements with the capabilities of the supply chain. This includes forecasting demand and synchronizing it with production, procurement, and distribution capabilities. A good demand management process can enable a company to be more proactive to anticipated demand, and more reactive to unanticipated demand (CROXTON et al., 2002).

According to Croxton et al. (2001) the process is also concerned with developing and executing contingency plans when operations are interrupted and has, like the other processes, both strategic and operational elements.

Later when writing about the Demand Management Process, Croxton et al. (2002) affirm that in the strategic process, the team establishes the structure for managing the process. The operational process is the actualization of demand management. The process team is comprised of managers from several functions in both strategic and operational and might also include members from outside the firm as a key supplier or a third-party provider.

The Figure 49 shows the relation between the strategic sub-processes, the operational sub-processes and the interfaces between them and each of the other seven SCM processes. 
Figure 49 - Sub-processes and interfaces of DM process

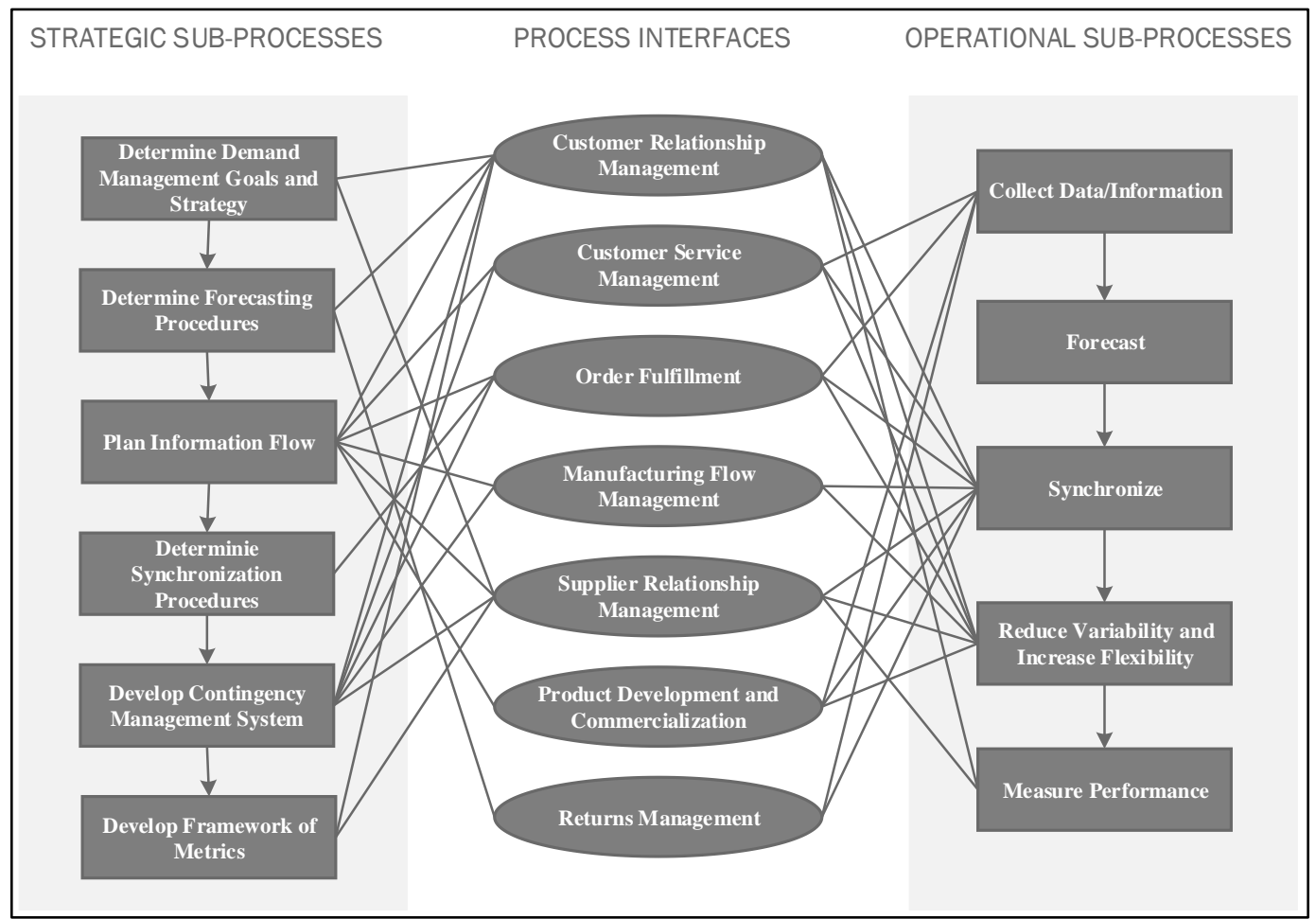

Source: Adapted from Croxton et al. (2002)

\section{STRATEGIC DEMAND MANAGEMENT PROCESS}

According to Croxton et al. (2002) Demand Management is about forecasting and synchronizing. As shown in Figure 49 the strategic process is comprised of six sub-processes that are aimed at designing an efficient operational system for matching supply and demand.

Although there are several technologies on the market to help managers with components of the demand management process, the team needs to determine how the firm will use technology within demand management process. It is important that the technology solution is consistent with the expected benefits (CROXTON et al., 2002).

The first step of the demand management process is to determine demand management goals and strategy. This step was not present in Croxton et al. (2001) work but was added later in a study about the Demand Management Process. According to Croxton et al. (2002) the process team must have a deep understanding of the firm's strategy, the customer and their needs, the capabilities and the supply chain network in order to have a high-level discussion about the goals and the focus of the process, which may vary across different firms and industries. Sometimes, increase flexibility has better results than improve forecast accuracy, for example. This first discussion will set the tone for how demand management will be structured. 
The second sub-process is about determining the forecasting procedures and is a critical piece of demand management (CROXTON et al., 2002). According to Croxton et al. (2001), this step includes determining the levels and timeframes of the forecasts needed and the sources of data required to generate forecasts. This includes historical data, sales projections, promotion plans, corporate objectives, market share data, trade inventory, market research and new categories of growth. On this point the team also decides about using Collaborative Planning, Forecasting and Replenishment (CPFR) or Vendor Managed Inventory (VMI), on which cases the customer becomes a direct source of data.

Once the team determines what type of forecast is needed, and what data are available, it is necessary to select the forecasting method and define a process to follow for each required forecast, including how often the forecasting procedures will be reevaluated (CROXTON et al., 2002).

The third step is plan the information flow, Croxton et al. (2002) talk about the action needed in order to accomplish this step, such as determine the sources of data, how this input data will be transferred and what output needs to be communicated to whom. In addition, the team must decide what data will be shared with other members of the supply chain. The process team should look for ways to share insight that is gained as part of executing the demand management process with other key decision makers in the firm.

The next and fourth step is to determine synchronization procedures required to match the demand forecast to the supply chain's manufacturing, supply and logistics capabilities. Frequently, this is referred to as sales and operations planning (S\&OP) (CROXTON et al., 2002).

In order to do this, the team must understand the capacity and flexibility available at all points along the supply chain. They also need to determine the long-term planning requirements, particularly in the case of demand with high seasonality or long-term changes, such as sustained growth. At this point the team might recognize future capacity issues and make recommendations to address them before they cause problems (CROXTON et al., 2001).

Croxton et al., (2002) later talk about the necessity of policies about stockpiling and allocating: that is, where to stock inventory when supply is greater than demand and how to reposition inventory when demand is greater than supply. They also states how different product-lines might use different synchronization procedures and how the team must be aware to these aspects. 
Another important component in developing contingency management system for the events of either internal or external causes that disrupt the balance of supply and demand. The team must develop guidelines or rules to deal with unexpected events in accordance with the expectations of the customers outlined in the CRM process (CROXTON et al., 2001). According to Croxton et al. (2002) determining reaction procedures prior to the possible events allow management to respond quickly in case of occurrence of any of these events.

The final step is to develop framework of metrics who shall be used to measure and monitor the performance of the process and sets the goals for performance improvement (CROXTON et al., 2002).

The Figure 50 shows a summary of the activities related to each strategic sub-process of Demand Management as prior discussed.

Figure 50 - Activities and interfaces of DM strategic sub-processes

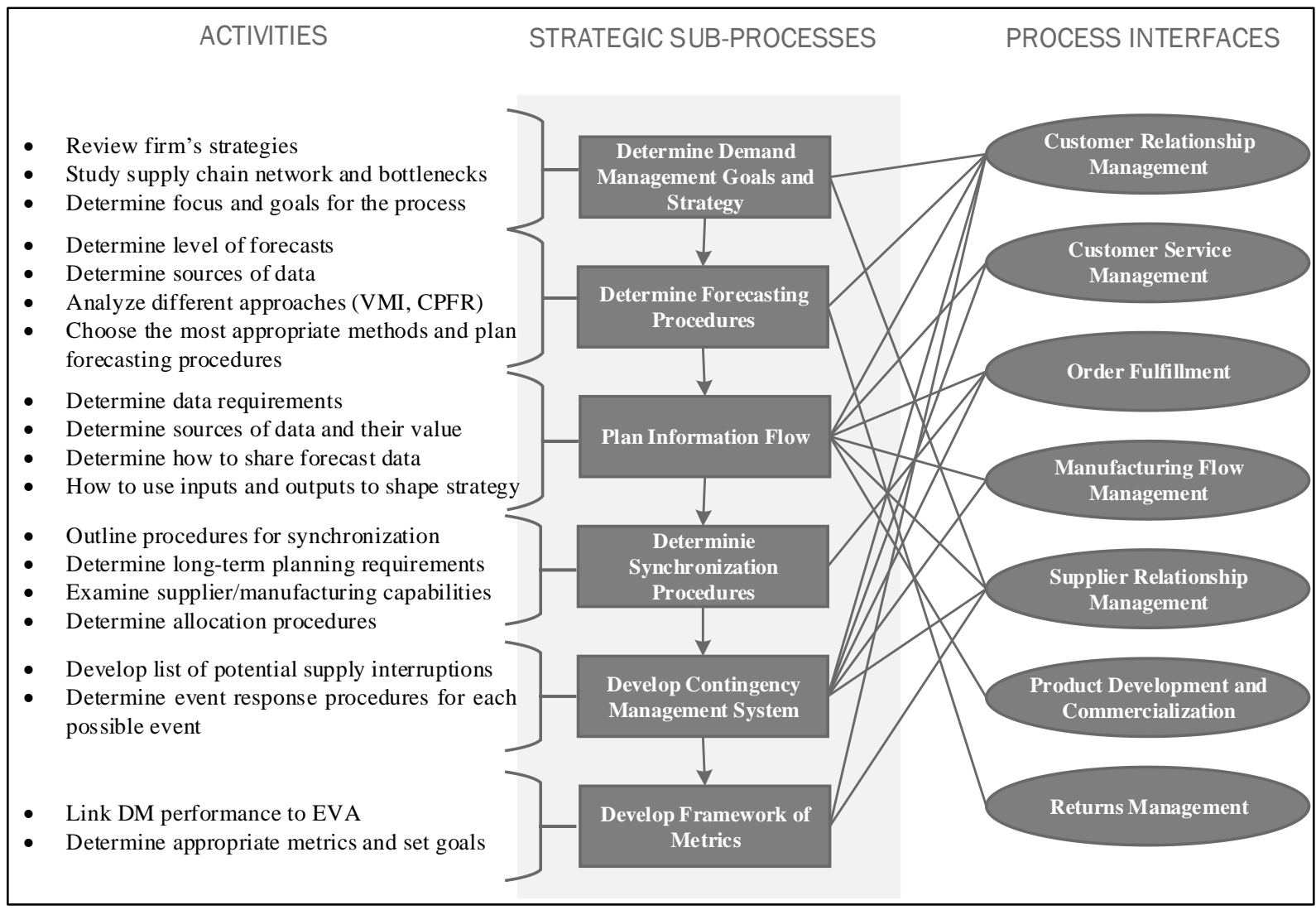

Source: Adapted from Croxton et al. (2002)

\section{OPERATIONAL DEMAND MANAGEMENT PROCESS}

At the operational level, the process team must execute the forecasting and synchronization as it was designed at the strategic level (CROXTON et al., 2001; 2002) 
The first step is to collect data/information that were determined at the strategic level. This is made through interface with the marketing function, order fulfillment, customer service management, product development and commercialization, and returns management process (CROXTON et al., 2002).

With all the data in hand, the team is ready to the second step, which is develop forecast. Croxton et al. $(2001 ; 2002)$ emphasize the importance of keeping track and analyze the forecast error. According to them, incorporate this feedback to fine-tune the forecasting methods is an important component of the learning process associated with good forecasting.

The forecast provides the input needed for the third step, which is synchronize or matching demand with supply. This synchronization follows the procedures determined at the strategic level. At this point, forecast turns into a demand execution plan (CROXTON et al., 2002).

The output of the synchronization sub-process is a demand execution plan that includes aggregate production plans and inventory-positioning plans. Some firms refer to this as aggregate planning. (CROXTON et al., 2001; 2002). It is also a responsibility of the team to communicate these plans within the other processes (CROXTON et al., 2002).

Another key component according to Croxton et al. $(2001,2002)$ is increasing flexibility and reducing variability (in demand, lead-times, capacity, etc). The former helps management respond quickly to both internal and external events, and the later aids in consistent planning and minimizing surprises.

The last step is to measure performance, such as every other SCM processes. The process team is responsible for measuring the performance of the process with the metrics developed at the strategic level. These metrics are used to improve the process and are conveyed to the customer relationship management and supplier relationship management teams (CROXTON et al., 2001).

The Figure 51 summarizes the activities related to each operational sub-process of the Demand Management process. 
Figure 51 - Activities and interfaces of DM operational sub-processes

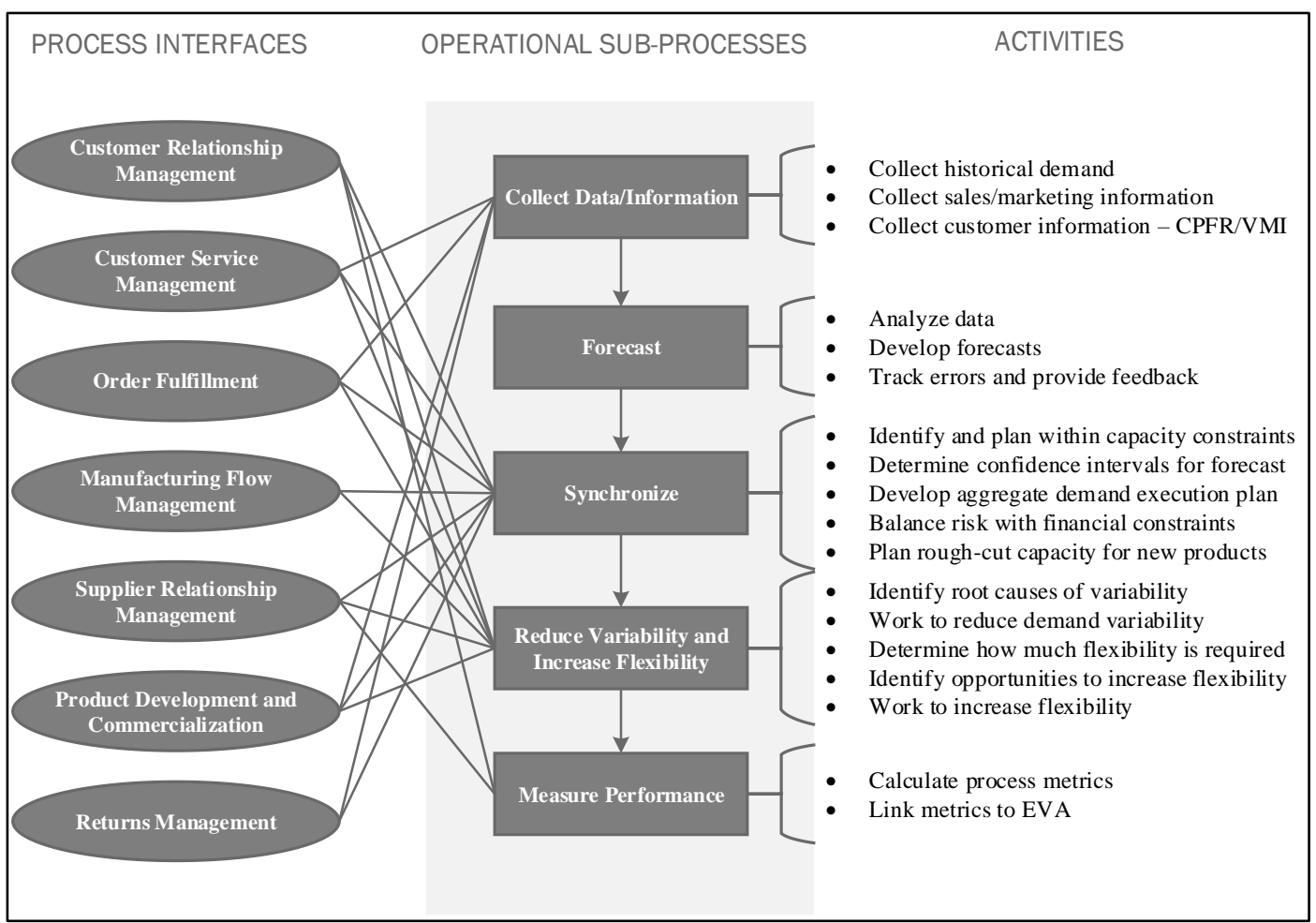

Source: Adapted from Croxton et al. (2002)

\section{THE ORDER FULFILLMENT (OF) PROCESS}

According to Croxton (2003) the order fulfillment involves generating, filling, delivering and servicing customer orders. In some cases, it is only through this process that the customer interacts with the firm, and therefore, the order fulfillment process can determine the customer's experience.

More than two decades ago, Kumar and Sharman (1992) talked about how the key to an effective supply chain management is to meet customer requirements in terms of order fulfillment. According to Croxton et al. (2001), effective order fulfillment requires integration of the firm's manufacturing, logistics and marketing plans in order to meet customer requirements and reduce total delivered cost to customers.

Croxton (2003) affirms that, despite some managers consider order fulfillment to fall within the role of the logistics function, the integration with other functions in the firm and across the supply chain that becomes key to define order fulfillment as a supply chain process.

At the operational level, the order fulfillment process focuses on transactions, while at the strategic level, management can focus on making critical improvements to the process that influence the financial performance of the firm, its customers and its suppliers. Order 
fulfillment directly affects product availability, which influences total sales volume (CROXTON, 2003).

The Figure 52 shows the relations between the strategic sub-processes, the operational sub-processes and the interfaces between them and each of the other seven SCM processes.

Figure 52 - Sub-processes and interfaces of OF process

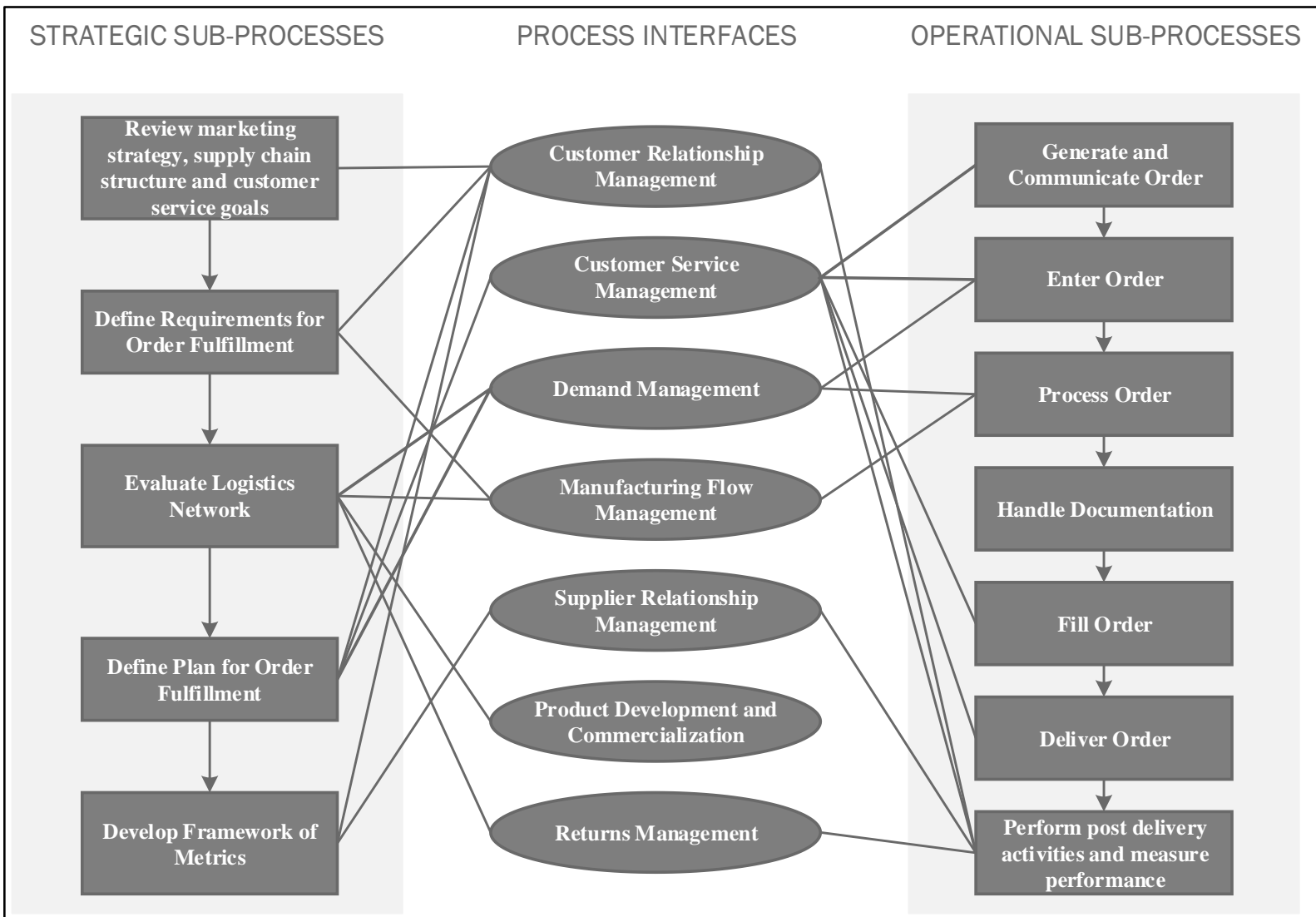

Source: Adapted from Croxton (2003)

\section{STRATEGIC ORDER FULFILLMENT PROCESS}

At the strategic level, the process team should design the operational order fulfillment process, including design the network, establish policies and procedures, and determining the role of technology in the process (CROXTON, 2003).

The first sub-process at the strategic level is the reviewing of marketing strategy, supply chain structure and customer service goals. According to Croxton (2003) the focus of this subprocess is to understand the requirements of the customer and the role that customer service plays in the overall strategy of the firm to determine which services are necessary to achieve and maintain supply chain goals. 
The second step is define the requirements for Order Fulfillment. According to Croxton et al. (2001) the team must evaluate the core competencies within order fulfillment and determines which aspects of the process are potentially service differentiating. The team should determine what value-added services will be provided and to whom it will be provided, as well as their impact on the profitability of the firm and the supply chain.

After the first two sub-processes, the team should have a clear view of the capabilities of the supply chain and the requirements of the customers. If the capabilities cannot support the requirements, the next step is to evaluate the logistics network (CROXTON, 2003).

According to Croxton (2003), the design and operation of the logistics network has a significant influence on the cost and performance of the system. It can affect customer service levels, lead times and part component costs. Croxton et al. (2001) affirm that is necessary to evaluate the network, including which plants produce which products, where warehouses, plants and suppliers are located; and, which transportation modes should be used.

The fourth step is the definition of the plan for Order Fulfillment. This sub-process consist in determining how orders from various customers or segments of customers will be taken and filled. The team must also determines which portions of the process will be outsourced to a third party. In addition, it is important to determine what will be done when an order cannot be filled. (CROXTON, 2003).

Another point that requires attention, according to Croxton (2003) is the demand variability. The effectiveness of the order fulfillment process can be strained by demand that is highly variable. During this step, the team should work with the demand management process team, to find ways to reduce demand variability.

The final sub-process is to develop framework of metrics. Croxton (2003) affirms that a streamlined order fulfillment process can reduce expenses such as handling, freight and overhead. However, the execution has less obvious implications, such as improved product availability which results in sales and market share increase. After understanding the implications of order fulfillment to the financial performance of the firm, metrics need to be developed for the activities performed.

The Figure 53 shows a summary of the activities related to each strategic sub-process of Order Fulfillment as prior discussed. 
Figure 53 - Activities and interfaces of OF strategic sub-processes

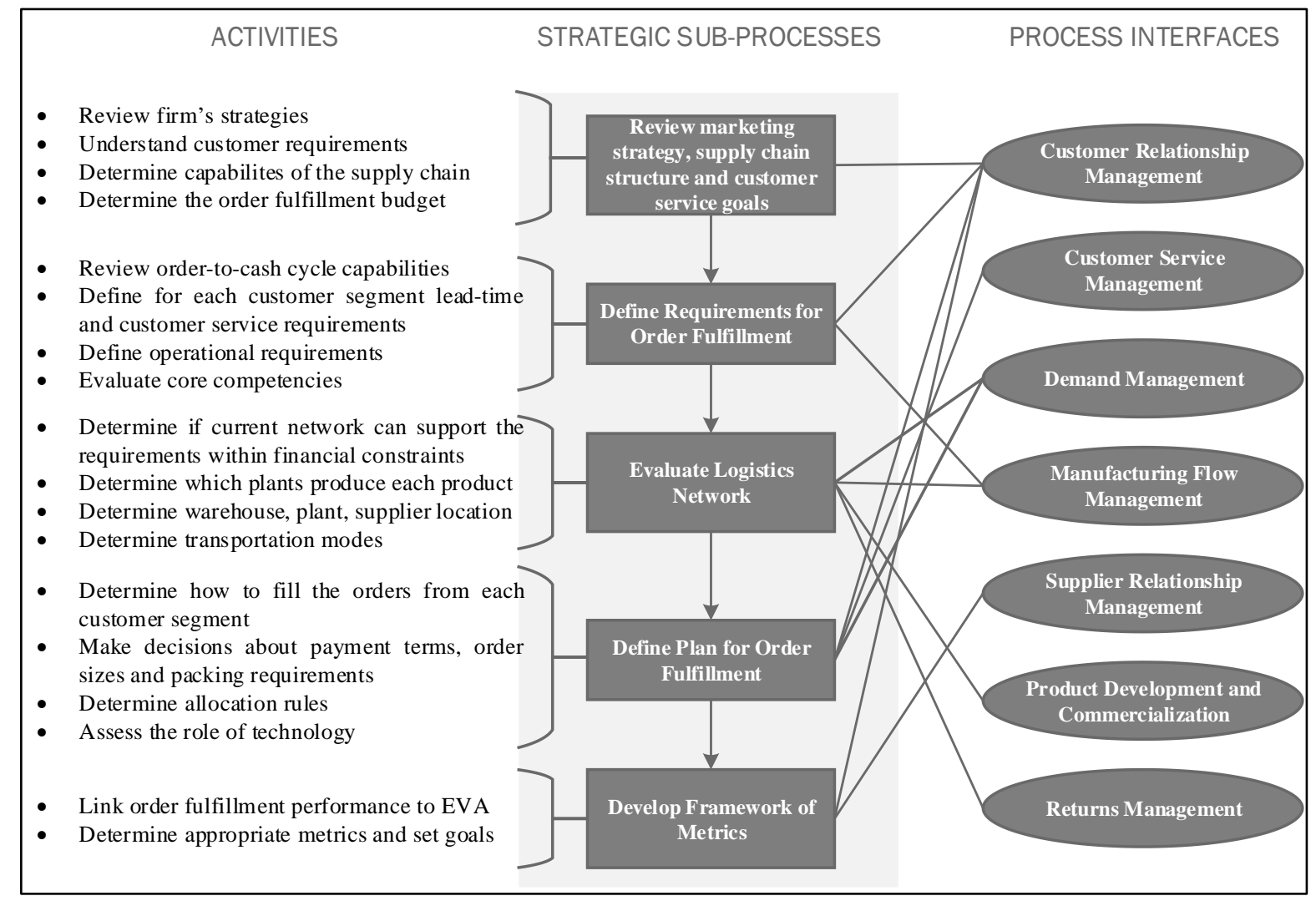

Source: Adapted from Croxton (2003)

\section{OPERATIONAL ORDER FULFILLMENT PROCESS}

At the operational level, order fulfillment is very transactional. It is focused on managing the customer order cycle and the specific activities are executed primarily within the logistics function (CROXTON, 2003).

According to Croxton et al. (2001) the operational process defines how customer orders are: generated and communicated, entered, processed, documented, picked, delivered and handled post-delivery. There are three steps to accepting and processing an order. First, orders are generated and communicated. Generally, these orders come from customer service management, but it can also be automatically placed (CROXTON, 2003).

The second step of the operational process is to enter the order, which consists of receive, enter, edit, and transmit the data to the customer service management and demand management processes. After that, the third step consists of processing the order, in this point the inventory and customers' credit are checked and the information is provided to the manufacturing process (CROXTON et al., 2001). 
The next sub-process the team handles all documentation. According to Croxton et al. (2001) the team acknowledge the order and prepare the bill of lading, picking instructions, packing slips and generate the invoice.

At the next stage, order filling, the merchandise is picked, packed and staged for loading. The loading confirmation is prepared and feedback is provided to customer service management. The final step in the order-to-delivery process is to arrange delivery of order. This is where all the shipping documents are prepared, the transportation plan is executed, delivery is confirmed and the freight bill is audited and paid (CROXTON, 2003).

The final step of the operational order fulfillment process is to perform post-delivery activities and measure performance. According to Croxton (2003) this should include the receive and post payment, record bad debt expense and measure the process performance as a whole.

The Figure 54 summarizes the activities related to each operational sub-process of the Order Fulfillment process.

Figure 54 - Activities and interfaces of OF operational sub-processes

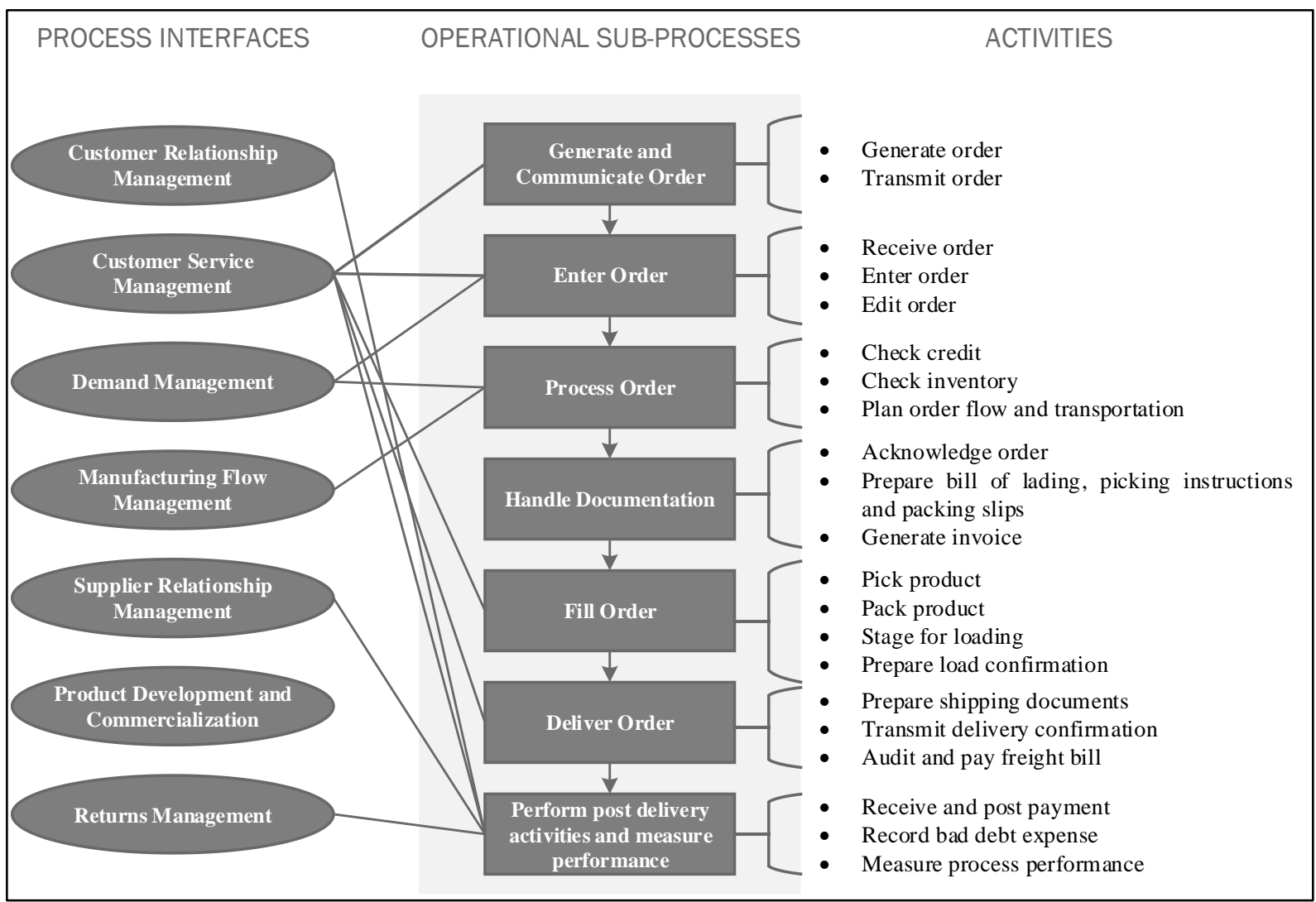

Source: Adapted from Croxton (2003) 


\section{THE MANUFACTURING FLOW MANAGEMENT (MFM) PROCESS}

Goldsby and García-Dastugue (2003) and Croxton et al. (2001) state that determining the right degree of flexibility is at the center of the manufacturing flow management process. This process includes all activities necessary for managing the product flow through the manufacturing facilities.

Manufacturing flow management should be implemented across the members of the supply chain that participate in the flow of products, as well as across those that have an effect on, or are affected by, the degree of manufacturing flexibility achieved by the supply chain as a whole (GOLDSBY; GARCIA-DASTUGUE, 2003).

Goldsby and García-Dastugue (2003) also affirms that while it might initially appear relevant only to the finished goods manufacturer (or assembler), manufacturing flow management is significantly influenced by the up and downstream members of the supply chain. Downstream members demonstrate influence through the demand for products. Upstream members affect the manufacture's ability to fulfill the customers' expectations. The potential of the manufacturing flow management process is only as good as the capabilities of upstream suppliers.

Manufacturing flow planning and execution must extend beyond the four walls of the manufacturer to other members of the supply chain. The most convenient decoupling points in the supply chain are determined considering the impact on customer service levels and total supply chain costs. Depending on the requirements, the implementation of more than one supply chain configuration might be necessary (LAMBERT; ENZ, 2017).

The manufacturing flow management, like the other supply chain management processes, relies on external connectivity to accomplish its objectives. The Figure 55 demonstrate the existent relations between manufacturing flow management sub-processes and the other SCM processes. 
Figure 55 - Sub-processes and interfaces of MFM process

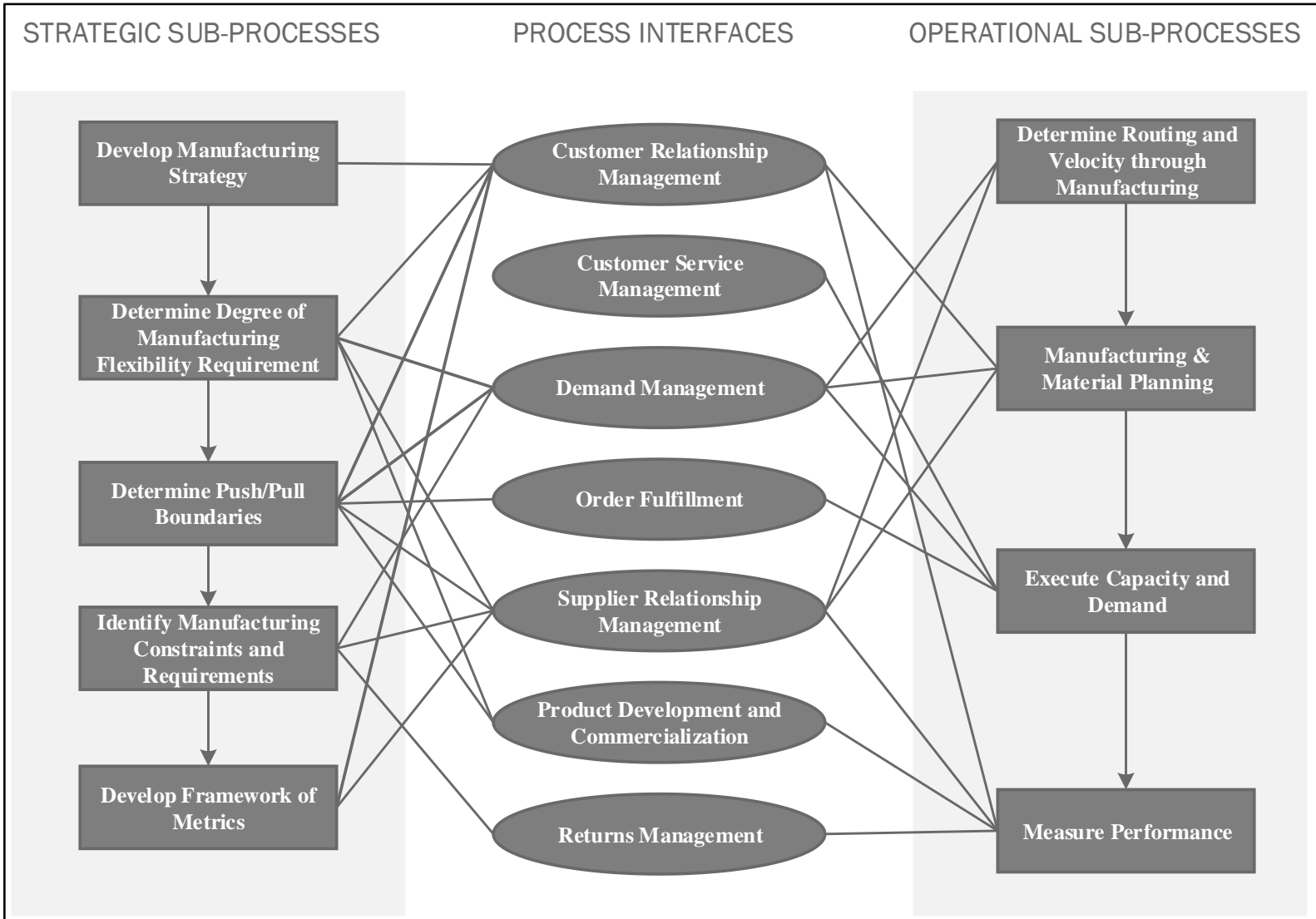

Source: Adapted from Goldsby and Garcia-Dastugue (2003)

\section{STRATEGIC MANUFACTURING FLOW MANAGEMENT PROCESS}

According to Goldsby and Garcia-Dastugue (2003) and Croxton et al. (2001) the strategic portion of manufacturing flow management consists of five sub-processes that represents the decision-making infrastructure for the process. The infrastructure embodies the development of the manufacturing plan, the means of execution, limits to execution and the appropriate measures of performance.

The first strategic sub-process is to develop the manufacturing strategy. According to Demeter (2003), the manufacturing strategy dictates the priorities of the production function and the roles of its suppliers and supporting service providers.

About the manufacturing strategy, Goldsby and Garcia-Dastugue (2003) state that it is not determined by the production function in isolation. Typically, the team will review corporate and marketing strategies to determine the manufacturing strategy that best accommodates customer demand. This important distinction leads to an assortment of products that satisfy the needs of distinct market segments. 
Naylor et al. (1999) describes five generic manufacturing strategies which varies from most rigid to most flexible. (1) Ship to Stock (STS): products are standardized and prepositioned in the market for immediate availability supported by the maintenance of speculative safety stock at all distribution points. (2) Make to Stock (MTS): products are standardized but not allocated to specific locations and demand is anticipated to be stable relying in forecasts. (3) Assemble to Order (ATO): products can be customized within a range of possibilities based upon a standard platform, final form of the product is postponed until demand is known. (4) Make to Order (MTO): Uses the same raw materials and components but can be configured in a wide array of products. (5) Buy to Order (BTO): Products demanded can be unique down to the raw material level with virtually limitless product variety. The Figure 56 illustrate the relationship between demand volatility and product variety for each generic strategy.

Figure 56 - Five generic manufacturing strategies

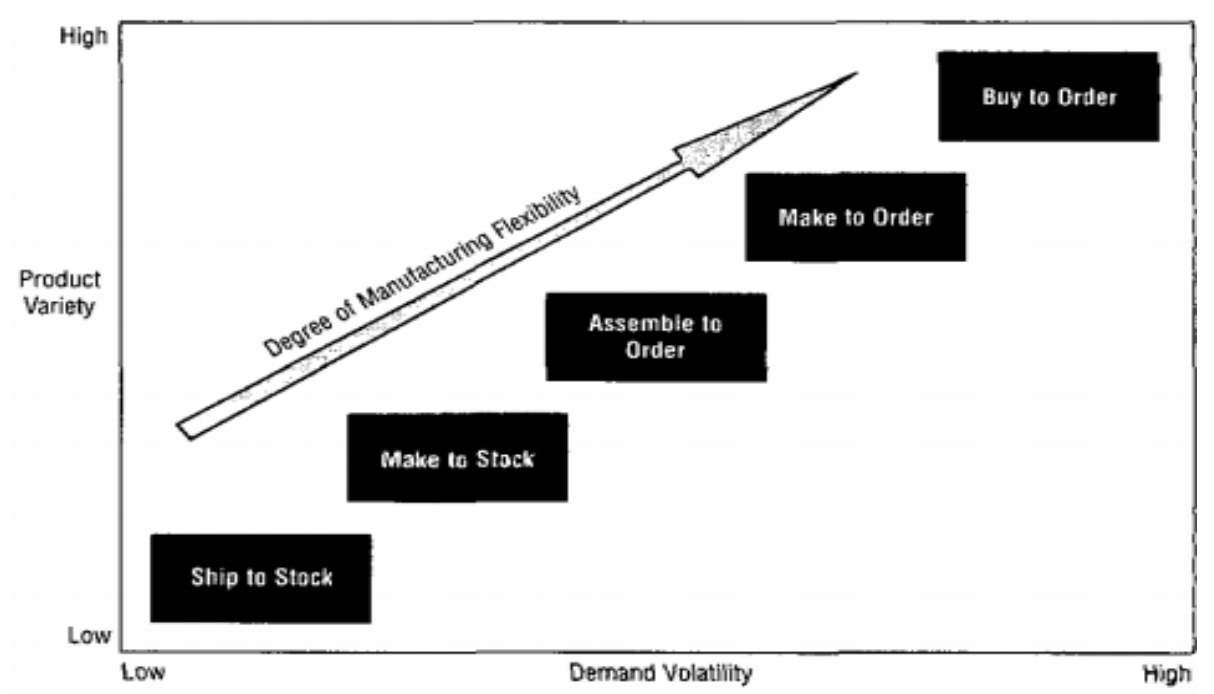

Source: Naylor et al. (1999)

Hill (2000, p.30) affirms that, when developing a manufacturing strategy, companies require a strategy not based solely on marketing, manufacturing or any other function, but one that embraces the interface between markets and functions. Thus, what should and must be the link between functional strategies is the markets the business serves or intends to serve. Marketing and manufacturing must have a common understanding and agreement about company markets. Only then can the degree of fit between the proposed marketing strategy and manufacturing's ability to support it be known at the business level and objectively resolved within corporate perspectives and constraints.

When writing about strategy determination, Golsby and Garcia-Dastugue (2003) affirm that it may be driven, in part, by the manufacturing philosophy of the firm, such as lean 
manufacturing or agility, for example. However, more than philosophies, it is important that the manufacturing strategy fits with the corporate strategy and remains consistent with the strategies of key supply chain members.

The objective of the second sub-process is to determine the degree of manufacturing flexibility the firm and the supply chain requires. It provides the manufacturing capabilities and constraints, such as the minimum batch size and cycle time, the labor expertise needed for manufacturing and the quality policy and controls (CROXTON, et al., 2001).

According to Goldsby and Garcia-Dastugue (2003) flexibility can have different meaning in different contexts. Manufacturing flexibility ensures the company's ability to manage resources and uncertainty to meet various customer requests. Generally, more flexibility is preferred over less. However, there is a cost associated with developing manufacturing flexibility and management may pursue high degrees of flexibility for key customers.

The degree of flexibility determined in the previous step lead to the determination of the push-pull boundaries. The push pull boundaries described by Naylor et al. (1999), Goldsby and Garcia-Dastugue (2003) and Simchi-Levi et al. (2005) is complementary to the concept of Customer Order Decoupling Point (CODP), introduced by Wortmann (1992). Goldsby and Garcia-Dastugue (2003) defines the push-pull boundaries as the positioning of decoupling points in the supply chain - up to which supply is pushed forward as make-to-stock but beyond which demand drives make-to-order execution.

The key to determining a push/pull boundary is recognizing the stage of value-added processing in which differentiation from a standard configuration takes place. In a BTO arrangement, manufacturing flexibility is at a premium and the primary decoupling point is upstream from the manufacturer. At the other extreme, STO strategies generate a standardized product, allowing the decoupling point inventories to reside in the manufacturer's distribution channel (NAYLOR et al., 1999).

Once the primary decoupling point is determined, as approached by Goldsby and Garcia-Dastugue (2003), the order fulfillment process must act in support of the push-pull decision to ensure that customers' expectations are fulfilled with minimal delay. In fact, the postponement of manufacturing activities might shift processing responsibilities typically performed by production to the logistics function of the business.

After determine where the push/pull boundaries are going to be located, the third step in the strategic manufacturing flow management is to identify manufacturing constraints and requirements. According to Goldsby and Garcia-Dastugue (2003) recognizing bottlenecks in 
the manufacturing is critical in achieving this objective. The ability to forecast peaks and valleys in demand patterns accurately is essential to providing adequate supply at the lowest possible cost. Therefore, the demand management team not only must be aware of potential bottlenecks or problems in manufacturing flow but also must communicate demand forecasts well in advance.

The identification of manufacturing constraints and requirements will lead to the development of the inventory policy for each facility in the supply chain network structure. The inventory policy will include how much inventory is to be held in the form of raw materials, subcomponents, work-in-process, and finished goods, and how often inventory will be replenished (GOLDSBY; GARCIA-DASTUGUE, 2003).

The final strategic sub-process is to develop the framework of metrics where the team develops the metrics framework and communicates it to the customer relationship management team. These metrics measure the effectiveness of the manufacturing flow process and might include cycle time, inventory levels, and product quality (CROXTON et al., 2001).

The Figure 57 shows some activities related to the strategic manufacturing flow management process.

Figure 57 - Activities and interfaces of MFM strategic sub-processes

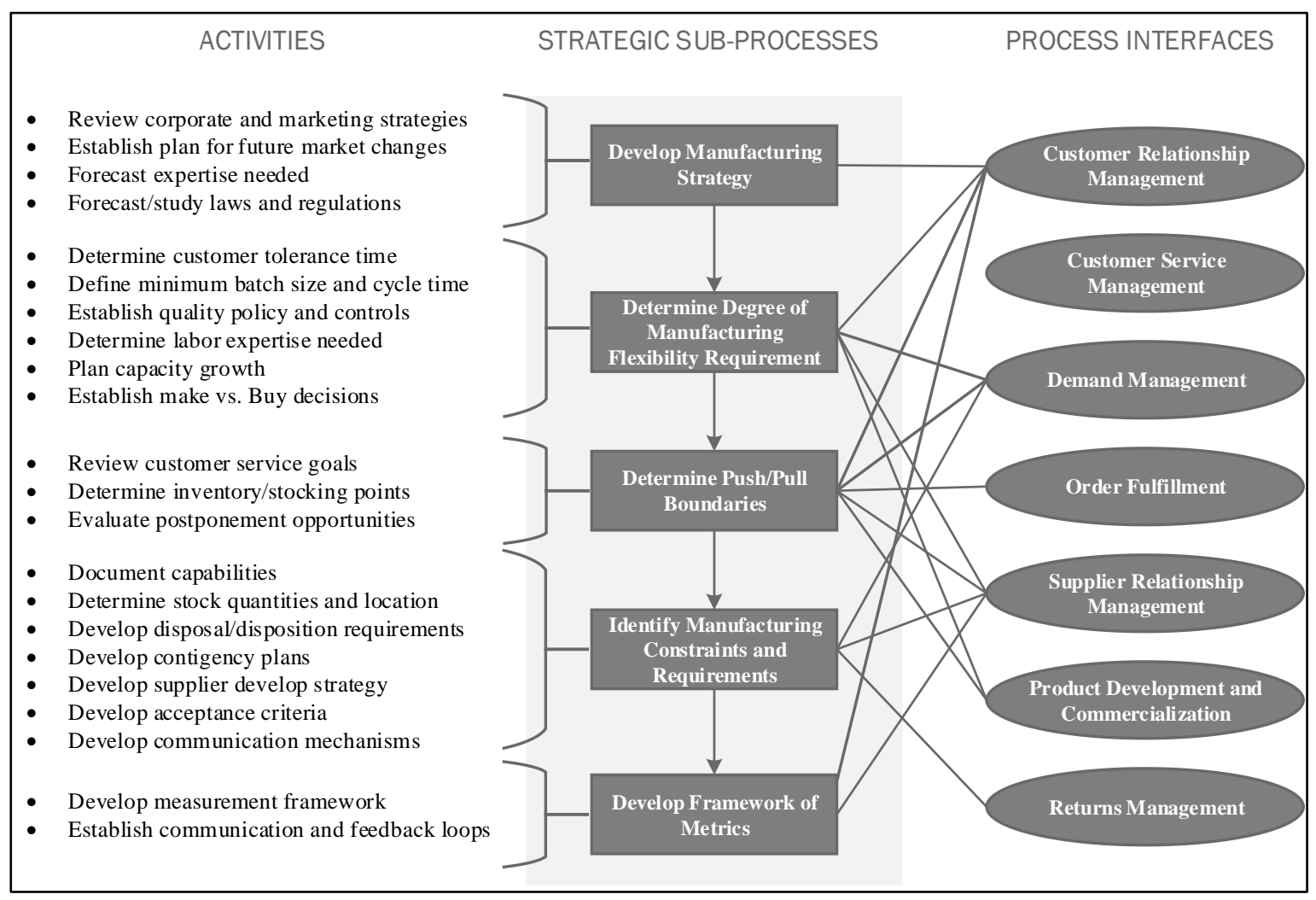

Source: Adapted from Goldsby and Garcia-Dastugue (2003) 


\section{OPERATIONAL MANUFACTURING FLOW MANAGEMENT PROCESS}

The operational part of manufacturing flow management process deal with the realization of what was developed in the strategic level. Goldsby and Garcia-Dastugue (2003) highlights that there are similarities between the operation sub-processes and the production function, but key differences exist. These differences include the guidance provided by the infrastructure developed at the strategic level and the structured links with the other seven supply chain management processes.

In the first sub-process the team determine the routing and velocity through manufacturing. This step includes developing a master production schedule (MPS) by translating the output of demand management into resource and production planning. The team integrates the capacity of the manufacturing facilities into these decisions to assure no disruption in the product flow (CROXTON et al., 2001).

Once MPS is developed in the previous step, the team should develop the manufacturing and material planning. According to Goldsby and Garcia-Dastugue (2003) the first move inside this sub-process is to develop the material requirements plan (MRP) to identify the quantities and timing of all subassemblies, components and raw materials needed to support production of the "parent" items.

Next, production management develops the capacity resource plan, which represents a time-phased plan of the capacity needed from each resource. Should a capacity or materials shortage be identified, the team will interact with the demand management team to find possible solutions to the bottleneck (CROXTON et al., 2001).

The third step is to execute capacity and demand. This is achieved, according to Goldsby and Garcia-Dastugue (2003), by maintenance of the optimal flow of material, work-in-process and finished goods. Daily checks may be employed to ensure that schedule attainment is achieved - providing adjustments as necessary. In order to do this, frequent interface between the demand management team and the order fulfillment process is needed.

The final operational sub-process is measure performance and includes more than just tracking process measures, and reporting them. It includes analyzing product quality and examining the root causes of quality problems. The team is responsible for finding solutions to quality issues, which might involve working with supplier relationship management, product development and commercialization or returns management (CROXTON et al., 2001).

The Figure 58 summarizes some of the activities performed by the manufacturing flow management team during the operational sub-processes. 
Figure 58 - Activities and interfaces of MFM operational sub-processes

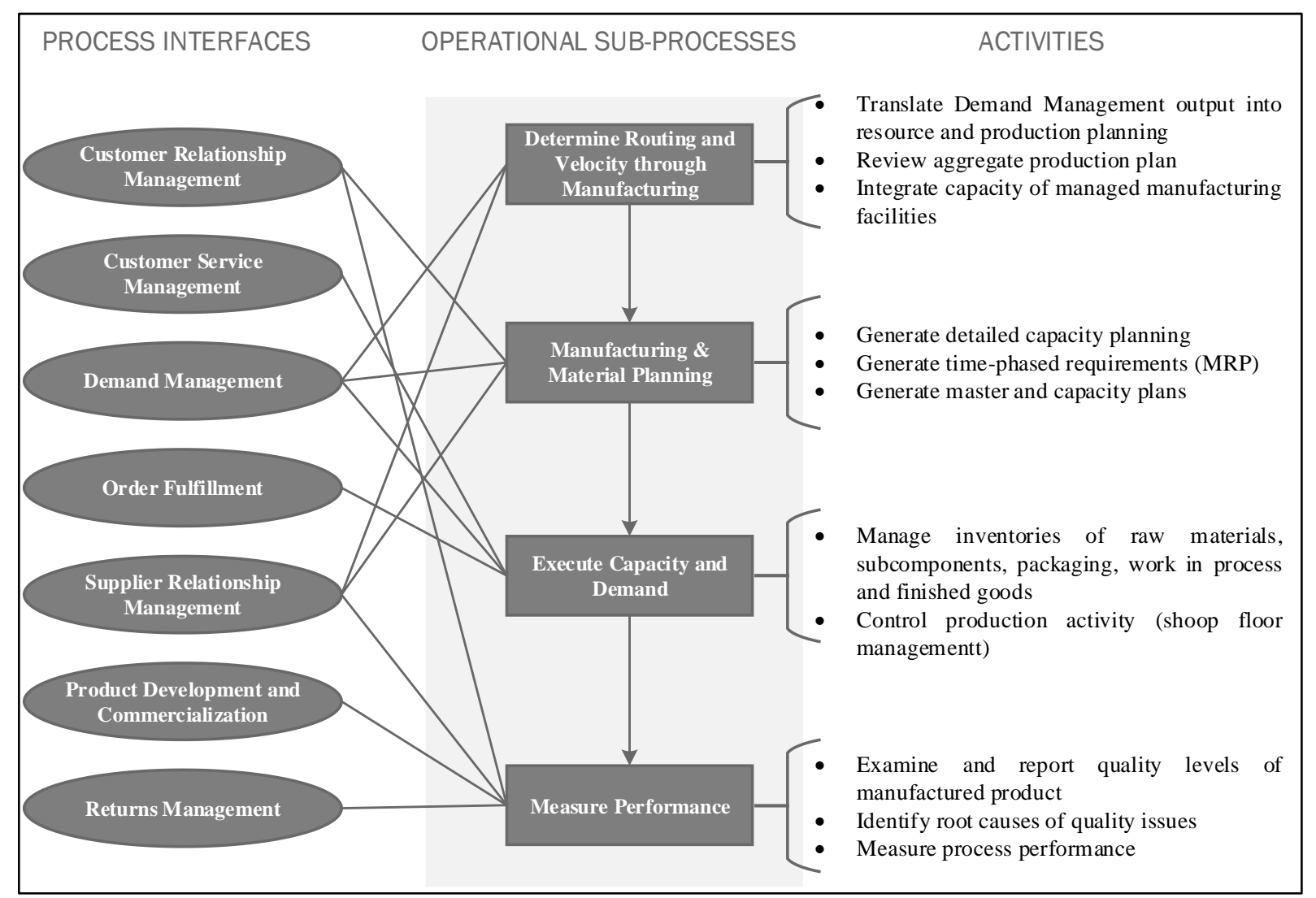

Source: Adapted from Goldsby and Garcia-Dastugue (2003)

\section{THE PRODUCT DEVELOPMENT AND COMMERCIALIZATION (PDC) PROCESS}

The product development and commercialization process is the SCM process that provides the structure for developing and bringing to market products jointly with customer and suppliers and requires effective planning and execution throughout the supply chain, and if managed correctly can provide a sustainable competitive advantage (ROGERS et al., 2004).

According to Schilling and Hill (1998), developing new products quickly and getting them to the marketplace in an efficient manner is a major component of corporate success. Time to market is a critical objective of this process.

Effective implementation of this process not only enables management to coordinate the efficient flow of new products across the supply chain, but assists other members of the supply chain with the ramp-up of manufacturing logistics, marketing and other activities necessary to support the commercialization of the product (OSTENDORF; MOUZAS; CHAKRABARTI, 2014). 
As previous discussed, each of the eight supply chain management processes contains strategic and operational elements, and the process of product development and commercialization is no different.

Rogers et al. (2004) state that the strategic portion of the process establishes a structure for developing a product and moving it to the market, providing a template for implementation within the firm. The operational portion is the realization of the process that has been established at the strategic level.

Figure 59 shows the sequence of sub-processes that comprise the strategic and operational product development and commercialization processes. The lines connecting the diagrams depict the interfaces between each sub-process and the other processes.

Figure 59 - Sub-processes and interfaces of PDC process

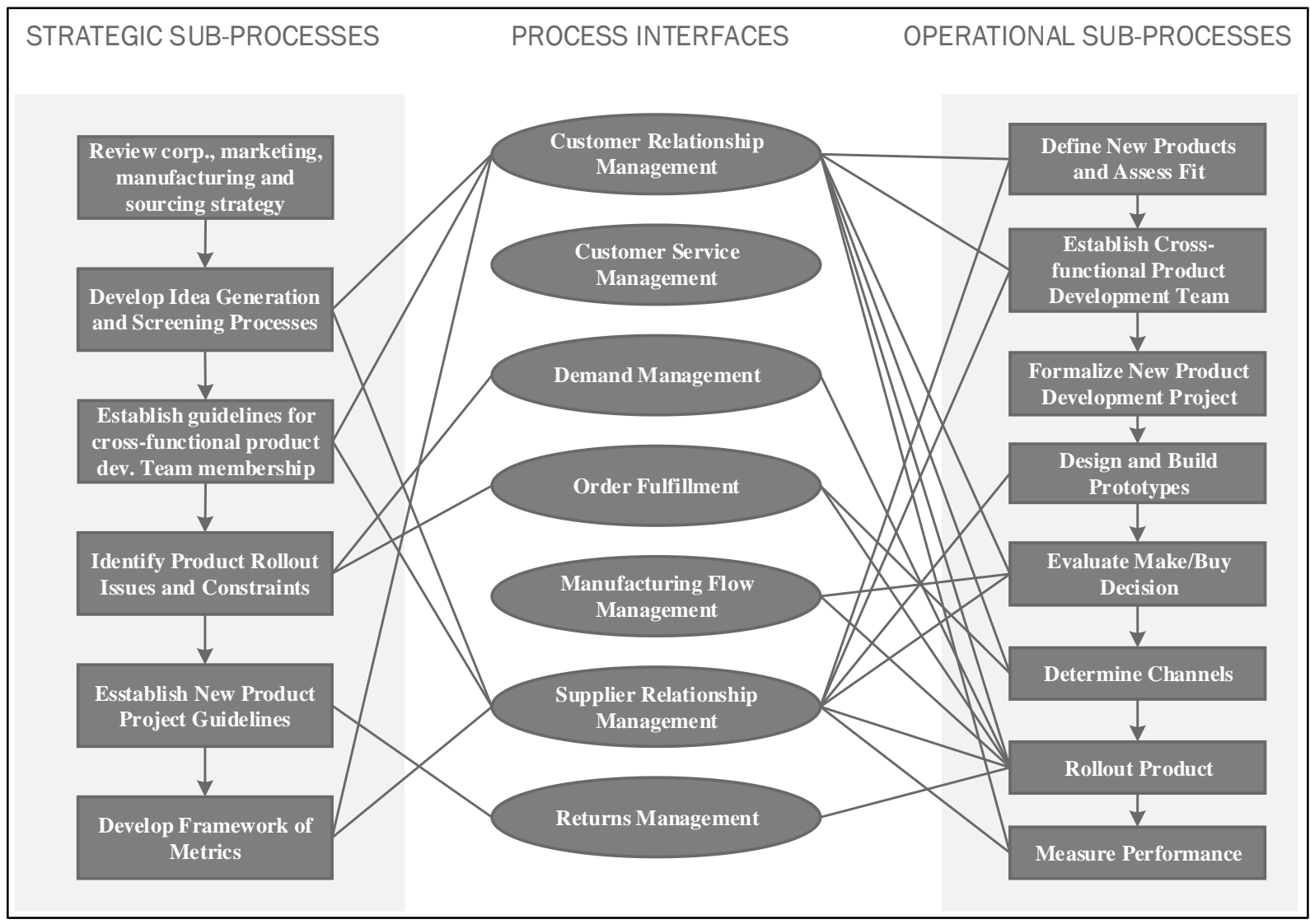

Source: Adapted from Rogers et al. (2004) 


\section{STRATEGIC PRODUCT DEVELOPMENT AND COMMERCIALIZATION PROCESS}

The objective of the strategic portion of the product development and commercialization management process is to construct a formalized structure through which the operational process is executed (ROGERS et al., 2004). According to Croxton et al. (2001) the first step in the strategic process is to review the corporate, marketing, manufacturing and sourcing strategies to determine how they will impact product to be developed and sold.

This review of these strategies, according to Rogers et al. (2004), is particularly relevant as management establishes the objectives for the process and examines how resources and competencies support achievement of these objectives. In addition to review the overall product strategy, the team reviews the sourcing, manufacturing and marketing strategies in order to assess the fit of the product development objectives with current capabilities of the supply chain.

The next step is to develop the idea generation and screening procedures. As stated by Croxton et al. (2001) this stage can include determining sources for ideas, considering incentives for developing new products for the local firm and their suppliers and customers, beginning to develop formalized customer feedback programs and establishing guidelines for strategic fit. At this point, the team provides the framework that will be used to determine how new products will affect customers and the level of acceptance of those products.

The third step is the establishment of guidelines for cross-functional product development team membership. The involvement of the process teams from customer relationship management and supplier relationship management is central to managing the relationships across the supply chain (ROGERS et al., 2004).

According to Croxton et al. (2001) this step also includes determining the extent of involvement from both key customers and suppliers. The team should assess relative strengths, weaknesses and roles of personnel to determine who should be involved in the process.

The fourth sub-process is the identification of product rollout issues and constraints. In this step, as mentioned by Rogers et al. (2004) pinch points that will hamper the process are determined, including considerations of market and promotion planning, sales force training, inventory deployment planning, transportation planning and capacity planning. Each of the internal business functions need to be involved to avoid poor product rollouts. 
The fifth sub-process is to establish new product project guidelines. At that moment, just as Rogers et al. (2004) mentioned, the expectations for time to market are developed, as well as product profitability scenarios, the implications for human resources resulting from new product projects and guidelines for examining the strategic fit of potential new products.

The last step is to develop the framework of metrics. As stated by Croxton et al. (2001) typical process metrics might include time to market, time to profitability and first year sales. The metrics are communicated to the CRM team to assure they do not conflict with other metrics or the firm's objectives.

The Figure 60 shows some activities related to the strategic product development and commercialization process.

Figure 60 - Activities and interfaces of PDC strategic sub-processes

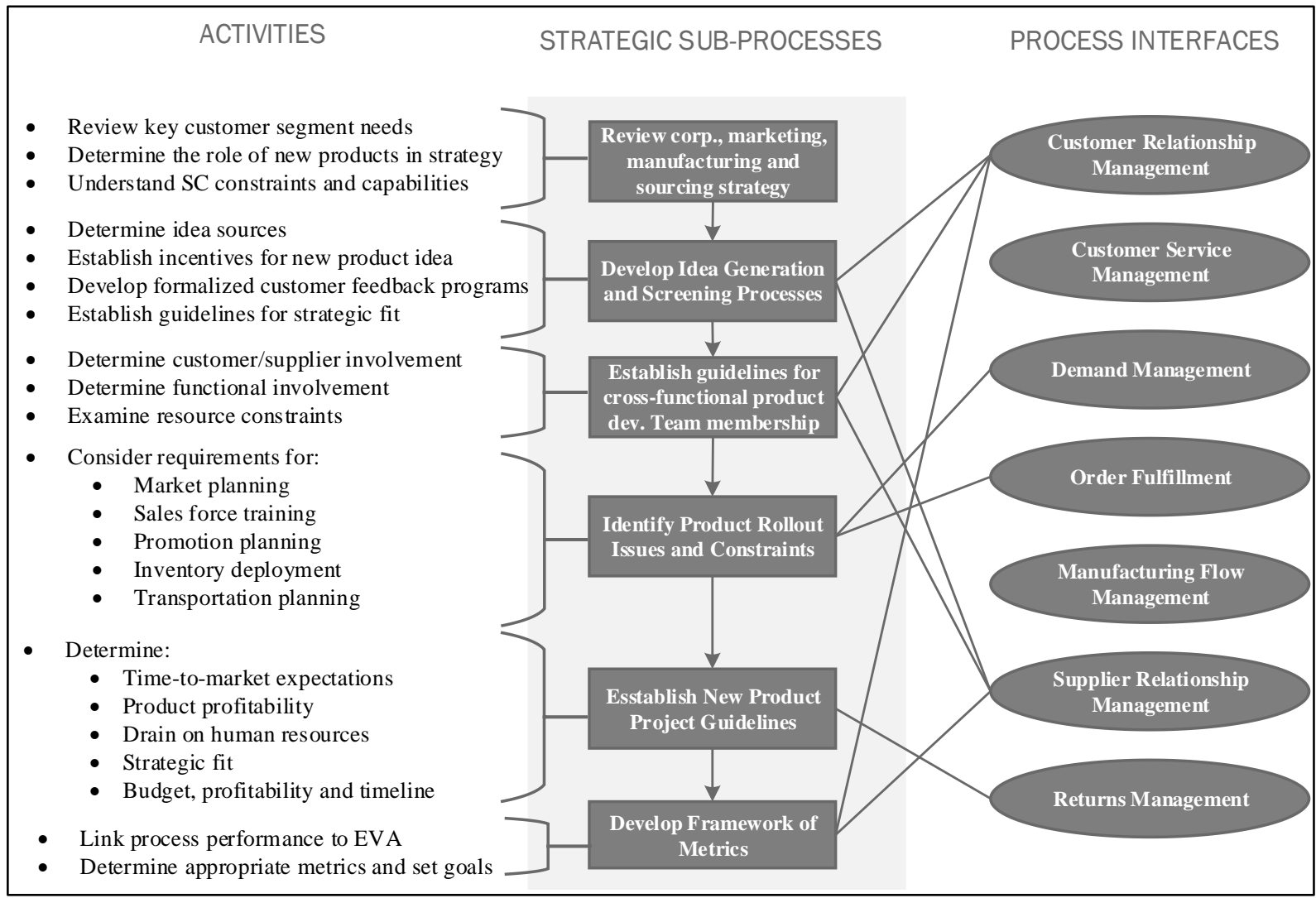

Source: Adapted from Rogers et al. (2004)

\section{OPERATIONAL PRODUCT DEVELOPMENT AND COMMERCIALIZATION PROCESS}

The operational portion of the product development and commercialization process is the implementation of the structure developed at the strategic level. It is a template for the 
synchronization of product development and commercialization activities and consists of eight sub-processes (ROGERS et al., 2004).

The first step is to define new products and assess fit. As stated by Croxton et al. (2001) using the means defined at the strategic level, new product ideas are generated and screened. In this initial screening the team determines the fit with existing channels, manufacturing and logistics environments.

Using the guidelines developed at the strategic level, the team must establish a crossfunctional product development team for each product idea (CROXTON et al., 2001). According to Rogers et al. (2004) internal and external parties such as suppliers or customers whose input is necessary for the success of the new product need to be included on the team as early as possible. These teams formalize the new product development project.

The third step is to formalize the new product development project. The product development team examine the strategic fit of the new product within the organization's current portfolio. The team works with key suppliers to formalize time to market expectations, product profitability goals and budget requirements (ROGERS et al., 2004).

The fourth step is to design, build and test prototypes. In this phase, according to Rogers et al. (2004) teams work with suppliers and perform a value analysis to determine what portions of the product design and rollout process truly add value. Then, they source prototype materials and manufacture product samples. The final step of this sub-process is to test the product.

Once the team evaluates the prototypes, they should evaluate make/buy decision. In other words, according to Rogers et al. (2004) the team needs to determine whether the product should be manufactured in-house or purchased from suppliers. Croxton et al. (2001) states that many firms adopt a short-term perspective for making the make/buy decision. However, these decisions may have strategic implications for the firm. Once the make/buy decision is made, the team assesses supply capabilities and manages request for quotations.

The sixth sub-process, the marketing and distribution channels are determined. Rogers et al. (2004) highlights the importance of the channel decision and how, in some cases, this is the primary factor in determining a product's success. Strengths and weaknesses of various channels need to be analyzed.

These channels are defined with input from CRM and Order Fulfillment. Then, the team develops the market plan for the product and does initial inventory planning (CROXTON et al., 2001). 
The next step is the actual product rollout. Rogers et al. (2004) state that many products are unsuccessful because of poor product rollout. There is a great need for synchronicity and all other processes should be involved in planning and executing the product rollout. On the other hand, a successful rollout can enhance the impact that a new product has in the marketplace. No matter how much potential a new product has, if it is not moved to market efficiently, it is likely that the product will not be successful.

The final step, the team measure process performance using the metrics developed at the strategic level and communicates results to the CRM and SRM teams (CROXTON et al., 2001).

The Figure 61 summarizes some of the activities performed by the product development and commercialization team during the operational sub-processes.

Figure 61 - Activities and interfaces of PDC operational sub-processes

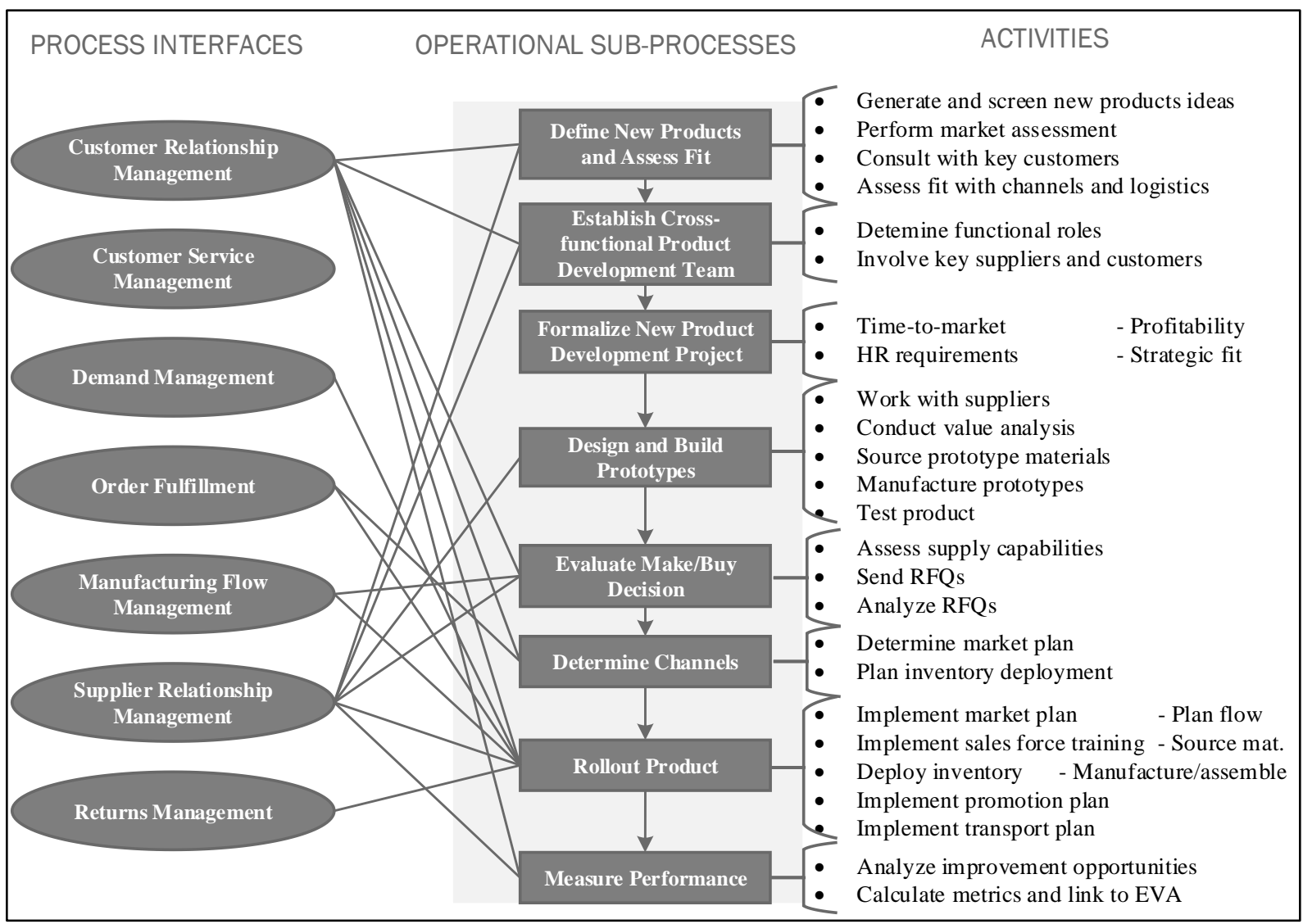

Source: Adapted from Rogers et al. (2004)

THE RETURNS MANAGEMENT (RM) PROCESS

Returns management is a critical supply chain management process that requires planning and effective execution throughout the supply chain. Effective implementation of 
returns management enables executives to identify productivity improvement opportunities (ROGERS et al., 2002).

Mollenkopf et al. (2007) calls returns management the long the forgotten stepchild of logistics/supply chain managers, and according to them, the strategic importance of effectively managing returns is becoming increasingly evident as firms seek to maximize the value they create for themselves and for customers. When firms view returns as just a cost center or a regulatory compliance issue, they miss potential value that can be created for themselves and their customers.

Rogers et al. (2002) highlights the importance of adequately describe the returns management. As stated by the authors, several definitions of other terms, such as, reverse logistics, closed-loop supply chain management, returns (as described by the SCOR model), does not translate what actually is the returns management. In order to provide a better understanding, the authors provided the following definition for the term: "Returns management is that part of supply chain management that includes returns, reverse logistics, gatekeeping and avoidance”.

This definition includes critical activities to supply chain management, such as avoidance, which is finding ways to minimize the number of returns request, and gatekeeping, which is making decisions to limit the number of items that are allowed into reverse flow (ROGERS et al., 2002).

Like the other processes, it is comprised of strategical and operational processes that are led by a cross-functional management team. The Figure 62 show the existent interface between returns management sub processes and the other supply chain management processes. 
Figure 62 - Sub-processes and interfaces of RM process

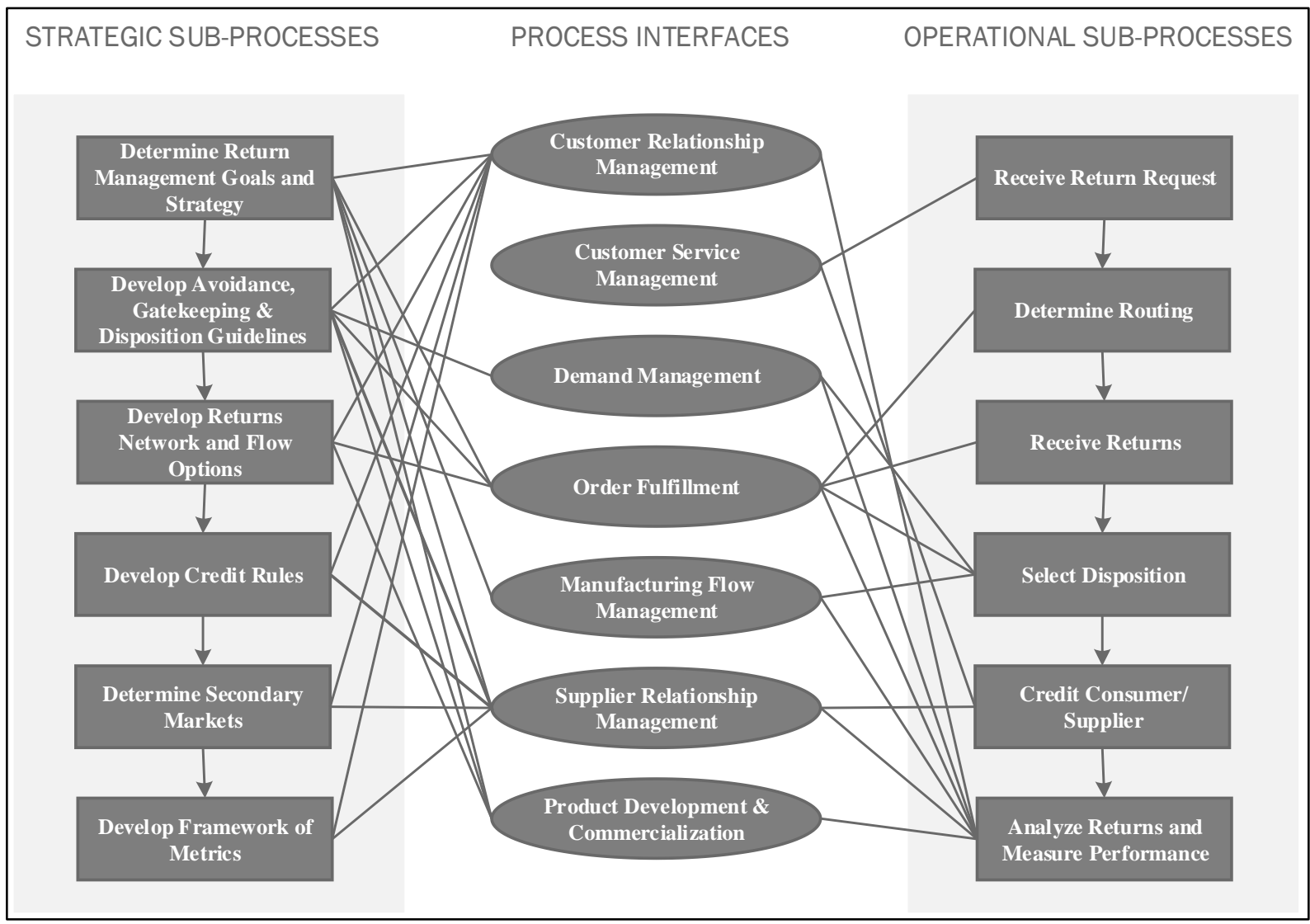

Source: Adapted from Rogers et al. (2002)

\section{STRATEGIC RETURNS MANAGEMENT PROCESS}

The objective of the strategic portion of the returns management process is to construct a formalized structure through which the operational process is executed and it is composed of six sub-processes (ROGERS et al., 2002).

In the first step of the strategic returns process, the team determine returns management goals and strategy. According to Rogers et al. (2002) returns policies can be used to improve customer loyalty, improve profits and enhance the brand or firm's public image and its returns management capabilities should be used strategically to enhance the overall performance of the company.

Another key consideration in this sub-process is to understand the environmental and legal compliance issues that impact the firm and the supply chain. Each member of the supply chain needs to understand and minimize the environmental impact of returned materials (ROGERS et al. 2002). 
According to Genovese et al. (2017) new supply chain paradigms, such as sustainable supply chain management and circular economy seeks to integrate environmental concerts into organizations by minimizing materials' flow unintended negative consequences of production and consumption processes.

The second step in the strategic returns management process is to develop return avoidance, gatekeeping and disposition guidelines. As stated by Rogers et al. (2002) this step includes determining the types of returns the firm might face and developing policies and screening mechanisms to handle those anticipated returns.

The use of effective avoidance, gatekeeping and disposition procedures minimizes the cost of moving returned items back through the supply chain. Avoidance aims to reducing the number of return requests. Gatekeeping identifies as early as possible what products should be accepted as a return. The disposition procedures will enable quick routing of a return to the most appropriate destination (ROGERS et al., 2002).

The third step is to develop returns network and flow options. According to Croxton et al. (2001), during this stage, the team develops plans for transporting and holding returned products until they reach their final disposition and evaluates if it is appropriate to outsource any of the returns management activities to logistics providers.

The fourth sub-process is to develop credit rules. In this stage of the process, just as Rogers et al. (2002) mentioned, general guidelines are established with input from suppliers and customers that will determine how returned merchandise will be valued. Credit authorization guidelines will be developed and credit policies established.

The fifth sub-process is to determine secondary markets. According to Rogers et al. (2002) these secondary markets can include internet-based auctions, specialized retailers or outlet malls. Firms that choose to obtain additional value from items that have been returned must consider sales cannibalization of first quality items and the impact of secondary markets on brand image.

The last sub-process consists in the development of framework of metrics. Rogers et al. (2002) affirms that metrics that might be used include return rates and financial impact of returns. As part of this sub-process, the team should analyze return rates and trace them back to the root causes.

The Figure 63 depicts some of the activities related to the strategic returns management process. 
Figure 63 - Activities and interfaces of RM strategic sub-processes

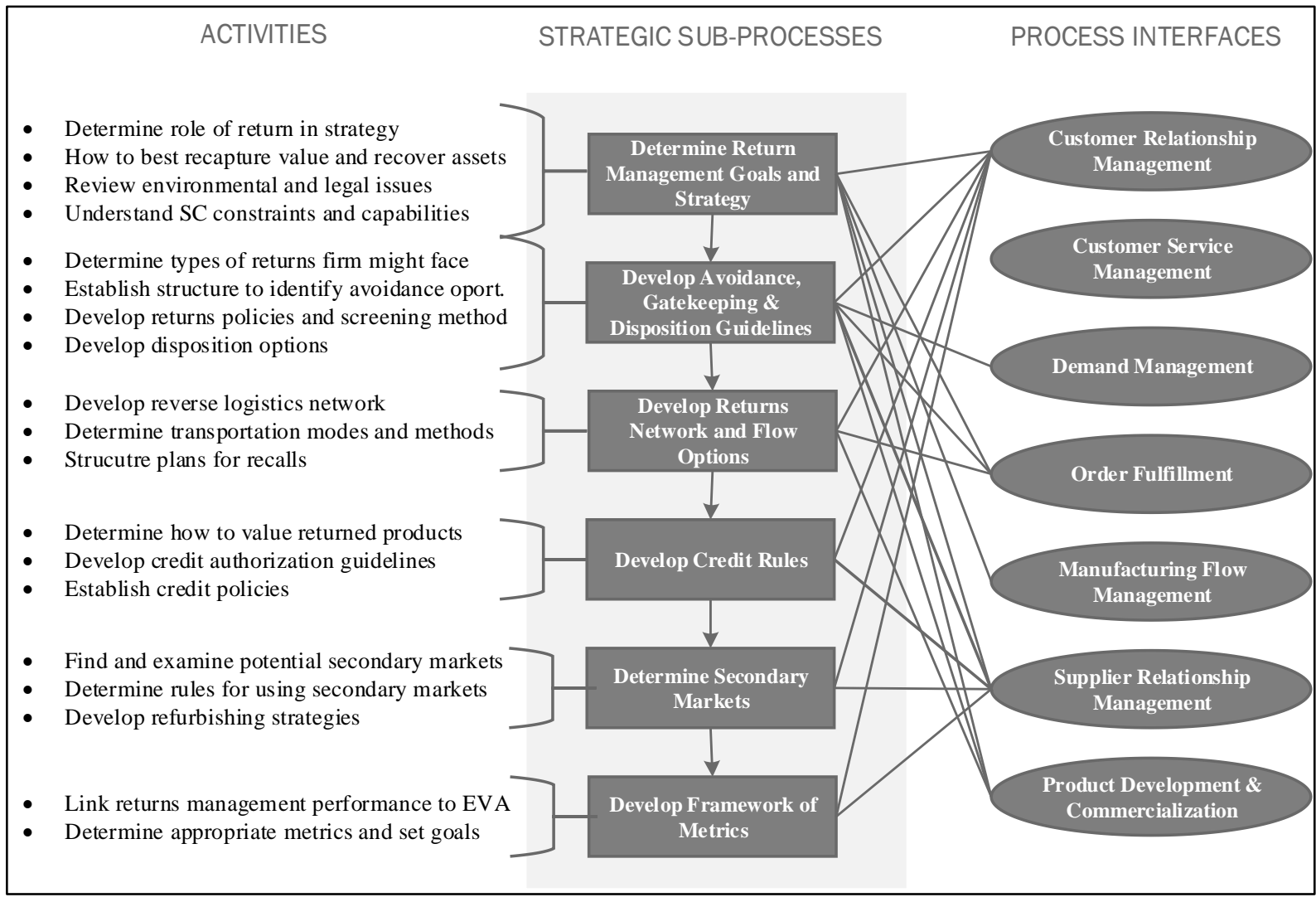

Source: Adapted from Rogers et al. (2002)

\section{OPERATIONAL RETURNS MANAGEMENT PROCESS}

For returns management, the operational portion is a template for managing returns transactions and consists of six sub-processes (CROXTON et al., 2001). The first step of the process is to receive a return request from the customer. Returns may originate from consumers bringing the item back, or marketing returns from retailers or distributors due to slow sales, clearing credit lines or stock rotation (ROGERS et al., 2002).

Once the return request is received, as stated by Rogers et al. (2002) the next step is to determine routing based on the guidelines and policies established in the strategic portion of the process. During this process, return material authorizations (RMA) derived from a return request are generated to signal that a material is returning to the firm.

The third step is receive returns. When a product is received, it is needs to be verified, inspected and processed. Generally this is a manual process that should be completed as quickly as possible to improve cash flow. The process team should also determines the reason for the returns (ROGERS et al., 2002). 
The fourth step is to select disposition. According to Croxton et al. (2001) after analyzing the returns, the disposition of the product can include return to the supplier, refurbishment, remanufacture, recycling, reselling as is, reselling through secondary markets or sending the product to a landfill.

Once the returns have been processed, the next step is to credit the customer/supplier. This process can be difficult and requires negotiation between members of the supply chain. The clearer the rules are in the PSAs, the easier it will be to determine the appropriate credit (ROGERS et al., 2002).

The final step in the operational process is to analyze the returns and measure performance. Croxton et al. (2001) argue that the data on returns should be used to make improvements to the product and the processes. This analysis should be used in the ongoing strategic returns process to help develop avoidance guidelines.

The Figure 64 summarizes some of the activities performed by the returns management team during the operational sub-processes.

Figure 64 - Activities and interfaces of RM operational sub-processes

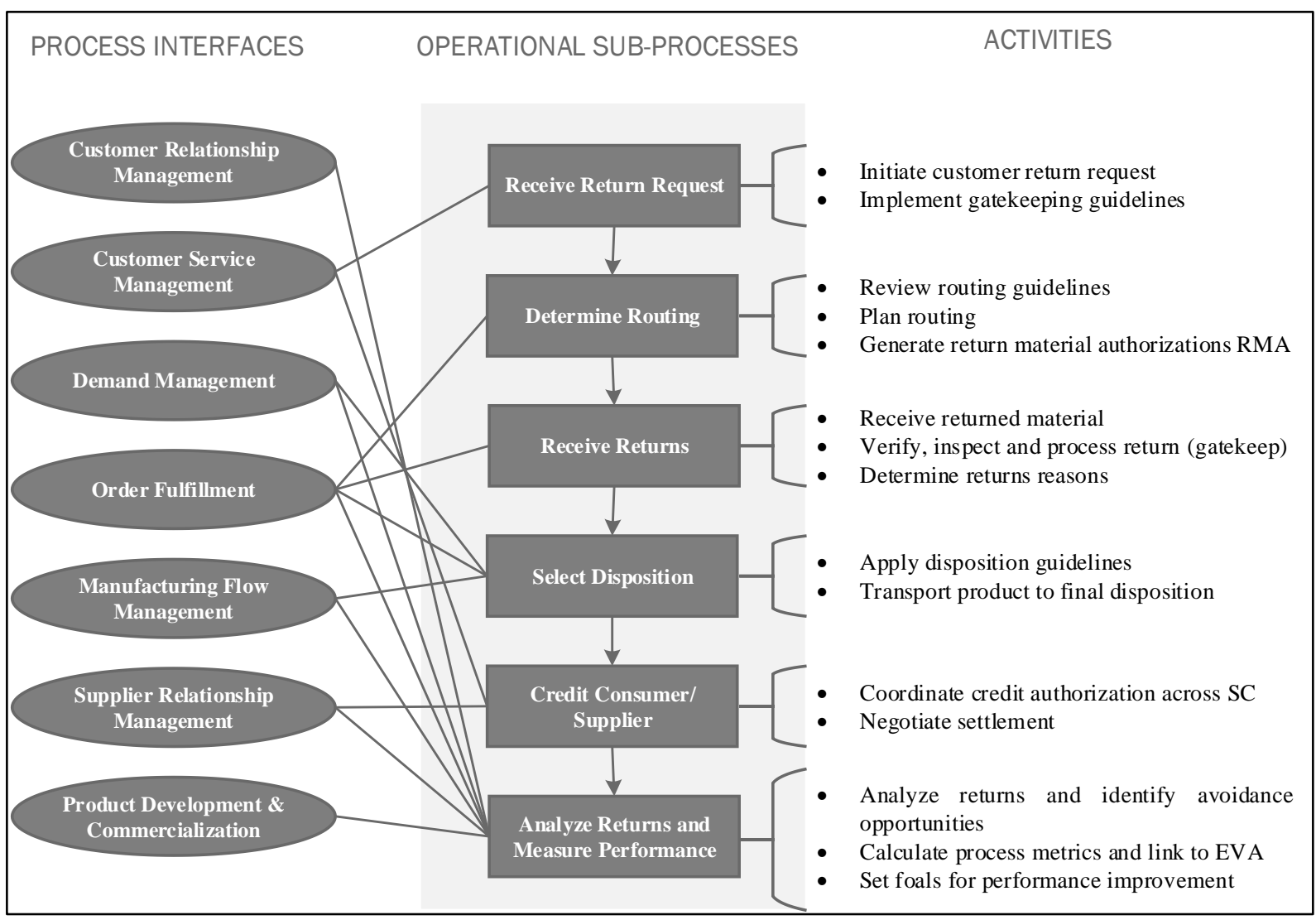

Source: Adapted from Rogers et al. (2002) 